MARIA DE LOURDES RODRIGUES

"CONHECIMENTO DO TEMPO MÉDIO EXISTENTE DESDE O PRIMEIRO COMPARECIMENTO DAS GESTANTES PARA INSCRICĀO NOS CENTROS DE SAUUDE ATÉ A PRIMEIRA CONSULTA MÉDICA"

Tese apresentada ao Departamen to de Prática de Saúde Pública da Faculdade de Saúde Pública da USP, para obtenção do título de Doutor em Saúde Pública.

Orientadora: Dra. Ernestine Maurer Bastian

\title{
SĀO PAULO
}

1979

\section{BIBLIOTECA}


o valor qualquer, minimo seja, deste trabalho, dedico-o a:

- minha mãe,

- minha irma Ruth e sua familia,

- meu irmão Rodrigues,

pelo amor e pelo apoio incondicional que me testemunharam nas horas dificeis e pela ajuda inestimāuel que me deram. 
Ao Dr. Reinaldo Ramos, meu reconhecimento pelos longos anos de amizade, apoio e com preensão. 
AGRADECIMENTOS 
A Ernestine Maurer Bastian, Professor Assistente Dou tor do Departamento de Prātica de Saúde Pública da Fa culdade de Saủde Pública da USP pela dignidade e res peito com que nos orientou neste trabalho e pelo estí mulo que sempre nos transmitiu.

A Nilce Piva Adami, Professor Assistente Doutor do De partamento de Prâtica de Saủde Pública da Faculdade de Saūde Püblica da USP, de quem, alēm da amizade, recebe mos sempre orientação e apoio, incentivo e ajuda, sem reservas.

A Judith Costa, Professor Assistente Doutor da Escola de Enfermagem de Ribeirão Preto, da USP, pela amizade, compreensão e carinho que nos demonstrou em todas as portunidades.

Ao Professor José Gabriel Borba, Professor Adjunto do Departamento de Prática de Saúde Pública da Faculdade de Saủde Püblica da USP, por sua compreensão e bondade e pelo encorajamento com que nos transmitiu a seguran ça imprescindível para a elaboração deste trabalho.

Ao Professor Pedro Augusto Marcondes de Almeida, do De partamento de Saūde Materno-Infantil da Faculdade de Saūde Pública da USP, pela orientação prestimosa, pela amizade e pela compreensão extrema que sempre nos ma nifestou.

Ao Professor Evaristo Manoel Pereira, pela competên cia, dedicação e amizade que demonstrou na orientação do aspecto estatistico deste estudo.

Ao Doutor José Souza de Morais, Diretor do Departamento Regional de Saūde da Grande São Paulo,da Coorjenado ria de Saúde da Comunidade da Secretaria de Estado da 
Saūde de São Paulo, pela boa vontade com que nos fran queou o campo de trabalho e pela valiosissima ajuda em superar as dificuldades administrativas.

Às Enfermeiras do Serviço de Enfermagem da Coordenado ria de Saúde da Comunidade - SES-SP, pela preciosa a juda que nos prestaram.

Aos funcionários do Centro de Informações para a Saú de, da Secretaria de Estado da Saūde de São Paulo; do Departamento de Estatística da Secretaria de Economia e Planejamento do Estado de São Paulo; e do Instituto Brasileiro de Geografia e Estatistica, pelas facilidades proporcionadas na coleta de dados.

A Maria Zuleide Cavalcante, por sua amizade e sua ex trema boa vontade, compreensão e esmero nos trabalhos de datilografia.

A Gentila Malta Mendonça Batista, amiga incansävel, cu jo auxilio desmedido não poderemos reconhecer bastante.

E mais: a todos aqueles cujos nomes aqui não figuram, mas cuja colaboração fez este trabalho possível. 
pảg .

INDICE DE FIGURAS, QUADROS E TABELAS

SIGLAS MENCIONADAS

RESUMO

SUMMARY

I $\quad$ - INTRONUÇAO $\ldots \ldots \ldots \ldots \ldots \ldots \ldots \ldots \ldots \ldots \ldots \ldots \ldots \ldots \ldots \ldots$

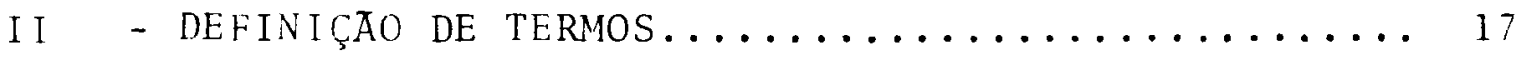

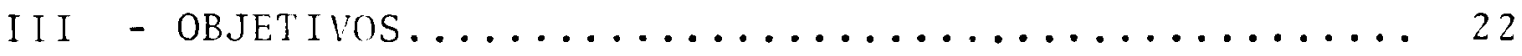

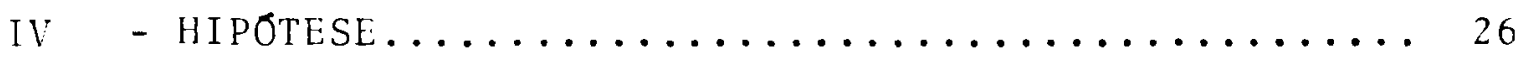

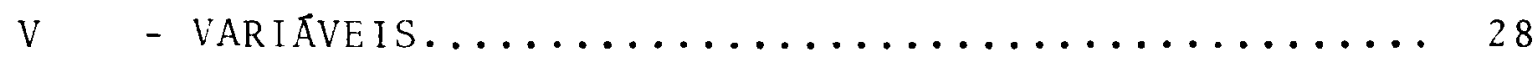

1. Variâveis: seleção e definição operacional... 29

VI - MATERIAL E METODO..................... 34

1. População......................... 35

2. Amostra.......................... 42

3. Procedimento...................... 60

Vil - Resultados e discussao.................. 77

1. Variāve 1 dependente.................. 77

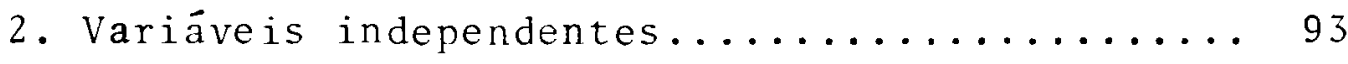

3 . Teste de associacão das variáveis.......... 95

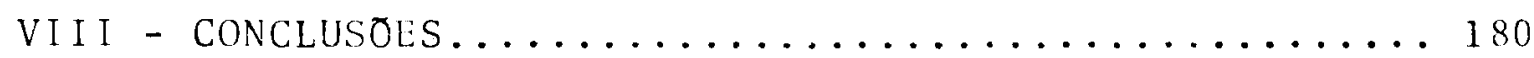

IX $\quad$ RECOMENDAÇOES........................... 183

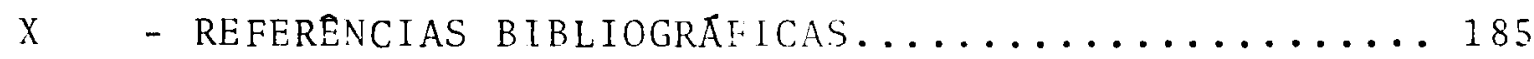
ANEXOS 


\section{INDICE DE FIGURAS, QUADROS E TABELAS}

päg.

\section{FIGURAS :}

1 - Resultados da gestação segundo Grau de Risco Gra vídico - Avaliado pelos índices MCHC............ 1

2 - Gráfico de associação do tempo de espera com algu mas variāveos independentes, segundo as Regionais... 151

3 - Gráfico de associação do tempo de espera de ges tantes inscritas...e algumas variāveis independen tes, segundo o tipo de centro de saüde.......... 152

\section{QUADROS :}

1 - Relação dos centros de saúde sorteados para const $\underline{i}$ tuírem a amostra, segundo o tipo: Tipo I.......... 55

2 - $\operatorname{Re} 1$ ação...

Tipo II......... 56

3 - Relação...

Tipo III....... 57

4 - Relação...

Tipo IV......... 58

5 - Relação...

Tipo $V \ldots \ldots \ldots+59$

6 - Configuração do tempo de espera para a primeira

e consulta médica de algumas gestantes da amostra,se

6 a gundo a Regional, o número de centro de saúde e o intervalo paramétrico................... 86-88 
7 - Dados bāsicos para cálculo da cobertura da assis-

a tência pré-natal alcançada nos meses de janelro a

10 setembro,nas unidades sanitärias, segundo a Regio na1................................

11 - Percentual de cobertura da assistência prë-natal 125

a alcançada nos meses de janeiro a setembro,nas $\underline{u}$

14 nidades sanitärias, segundo a Regional.........

15 - Disponibilidade do I.N. responsável pela C.M. e

a A.E. realizados nos centros de saũde, segundo a

18 classifticação do CS e a numeração do mesmo na pesquisa..........................

19 - Comparação do tempo de espera com os percentuais

a alcançados de cobertura da consulta médica,o ren

27 dimento instrumenta1, o grau de utilizaçäo do instrumento e a média da idade gestacional ao tempo da inserição....................

28 - Número de consultas médicas e de atendimento de

a fermagem realizados nos meses de janeiro a setem

31 bro, nas unidades sanitärias, segundo a Regional - o t1po de centro de saúde.................

32 - Dados bäsicos para cälculo do R.I. de hora/médi166

a co, segundo o tipo de centro de saüde núme ro do

35 mesmo na pesquisa.....................

36 - Média da idade gestacional das gestantes inscritas nos centros de saude, no perído de janelro a setembro, segundo a Regional, o tipo de centro de $s$ aúde a numeração deste ne pesquisa.......

37. Grau de alcance das metas programadas para consulta médica das gestantes nos centros de saúde,

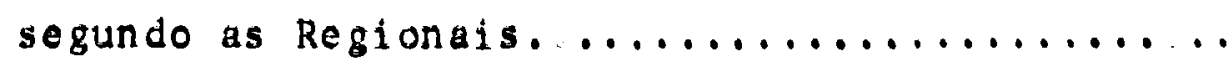




\section{TABELAS :}

1 - Relação entre atendimento pré-natal e mortali

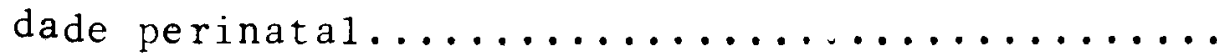

2 - Distribuição dos centros de saũde, segundo os tipos, por Regionais e por Distritos Sanitários.

3 - Gestantes matriculadas, segundo o tipo de cen tro de saủde e a Regional................

4 - Centros de Saúde e gestantes que participaram $\mathrm{d}_{\mathrm{a}}$ amostra, segundo o tipo e a Regiona1........

5 - Tempo de espera para a primeira consulta médi

a ca,segundo o trimestre da gestação, a Regional

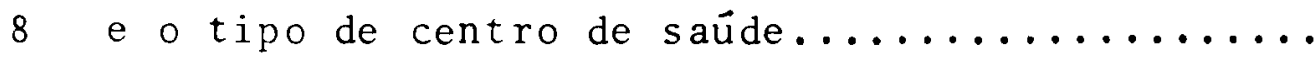

9 - Número de gestantes inscritas por idade de ges

a tação, nos meses de janeiro a setembro, nas $\underline{u}$

12 nidades sanitárias, segundo a Regional e o tipo de centro de saúde...................

13 - Processo de inscrição das gestantes nos centros

a de saúde, segundo a classificação do CS e nume

16 ração do mesmo na pesquisa...............

17 - Gestantes segundo o tempo de espera da consulta e as regiões dos centros de saủde............

18 - Gestantes segundo a mediana do tempo de espera da consulta e as regiões dos centros de saūde...

19 - Gestantes segundo o tempo de espera da consulta e o tipo de centro de saúde................

20 - Gestantes segundo a mediana do tempo de espera da consulta e o tipo de centro de saúde........ 
pág.

21 - Gestantes segundo o tempo de espera da consulta

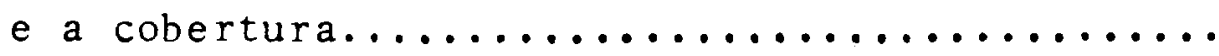

22 - Gestante segundo a mediana do tempo de espera e

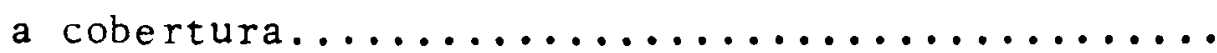

23 - Gestantes segundo o tempo de espera da consulta e a presença do instrumento nuclear........... 138

24 - Gestantes segundo a mediana do tempo de espera e a presença do instrumento nuclear..............

25 - Gestantes segundo o tempo de espera da consulta

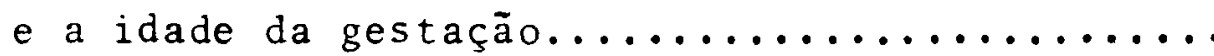

26 - Gestante segundo a mediana do tempo de espera da

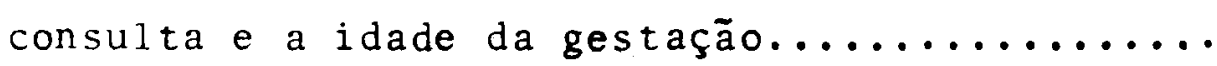




\section{SI GLAS MENCIONADAS}

CIAM - Centro de Integração de Atividades Mëdicas

CIs - Contro de Informações da Saüde

CM - Consulta Médica

CS - Centro de Saüde

CSC - Coordenadoria de Saüde da Comunidade

DRS, 1- Departamento Regional de Saúde da Grande São Paulo

IN - Instumento Nuclear

MCHC - Maternal Child Health Care

MS - Ministério de Saúde

OMS - Organização Mundial da Saúde

OPAS - Organização Panamericana da Saüde

SEADE- Sistema Estadual de Anälise de Dados(Fundação)

SEPLAN-Secretaria de Economia e Planejamento

SES - Secretaria de Estado da Saúde

WHO - World Health Organization 
RESUMO 
0 autor se propõe a medir o tempo que decorre entre a inscrição e a primeira consulta médica de gestantes que pro curam os centros de saúde para assistência pré-natal. o propó sito do estudo é dar subsídios para a identificaçāo de instru mentos de medida da qualidade da assistência prestada a gestan tes por instituições de saüde püblica. Para tanto, foram desen volvidas algumas ações bãsicas.

Considerando a medida desse tempo, um evento sem significação quando estudado isoladamente, o autor se propôs tes tar a hipötese de haver alguma correlação entre aquele tempo e outros eventos administrativos.

0 autor fez as seguintes verificações:

- o tempo de espera apresenta algumas variaçōes, segun do a região onde se localizam os centros de saúde, sendo maior em duas das focalizadas;

- segundo a classificação dos centros de saúde: a va riação é significativamente maior nos centros de saú de de tipo mais complexo, isto é, no tipo I, onde o atendimento é igualmente intensificado;

- segundo a cobertura: foi verificado que o tempo de espera tende a crescer nas äreas onde a cobertura é maior.

Quanto à idade da gestação não houve variação sob es sa rubrica.

0 autor concluiu que a medida de tempo de espera para a primeira consulta médica de gestantes em centros de saúde po de indicar um problema de atendimento quando sua grandeza, u 1 trapassando o período considerado parâmetro de normalidade - 0 à 7 dias - estaria ligado a: cobertura aquém da meta esperada, demanda excessiva, deficiência quantitativa e/ou qua litativa da hora/instrumento responsāvel pela consulta e, espe cialmente, quando a demora se relacionasse também com inscri ções feitas a partir do segundo trimestre da gestação. 
$S U M M A R Y$ 
The author's purpose is to measure the time lagbetween the registration on the clinic and the prenatal first visit by the pregnant woman.

The study's purpose is to provide subsidies for the identification of quality standars in relation to the care provided to the future mothers by the publichealt institutions.

For this purpose some basic steps were developed.

Considering this time lag as non significant by itself, the author's purpose is to show the correlation between it and other administrative events, as well.

The author made the folowing verifications:

- the vaiting time according to the region on where the centers are located is greater, as it happened in two of the observed Regions;

- in relation to the classification of the health center, the variation is significant:the lag is larger in the more complex type of health centers where the assistance is intensified;

- according to the coverage it was verified that the waiting time increases in the areas where the coverage is larger;

- as related to the age of pregnancy, there was no variation on waiting time.

Considering the time lag by itself the conclusion is that the too small intervals observed are not significant because of its correlation with a too small coverage score observed all over the health centers.

The author concludes that the waiting time for the pregnant woman first visit to prenatal clinic can indicate a problem at assistance when it is longer than the standard time lag - 0 to 7 days; when it is conected to a coverage too much behind or too much beyond objective expectations; an excessive demand; a quantitative or qualitative deficiency in instrument productivity and, specialy, when the delay was related also to the registrations starting at the second trimester of pregnancy. 
1 - INTRODUÇĀA 
Segundo o Comité de Peritos da WHO 67 "mais da meta de das mulheres grāuidas do mundo não recebem supervisão espe cializada no perīodo pré-natal nem assistência igualmente especializada durante o parto" mesmo em se considerando, quanto a isto, as circunstancias diferenciadas dos países desenvolvidos onde os indicadores de saúde evidenciam uma situação privile giada com índices baixos de morbidade e mortalidade materna e infantil.

No entanto, apesar da diversidade desses níveis, há um interesse gera1, demonstrado por todas as naçōes, no sentido de se melhorarem, cada vez mais, as condiçōes de vida dos indi víduos desse grupo, pois, até nos países adiantados, apesar da riqueza, ainda existem bolsões de pobreza e de subdesenvolvi mento. A propósito, a pergunta lançada por Lesser no seu arti go Progress in maternal and child Health 38 "Porque existem 12 paises em que a taxa de mortalidade infantil $\bar{e}$ mais baixa que nos EEUU?", é uma evidência desse interesse.

O autor, no entanto, ressalta a importância secundária da pergunta e salienta o peso maior do fator disparidade pon derāvel nas taxas de mortalidade infantil em diferentes níveis da comunidade, dentro do pröprio território americano. Segundo aponta Lesser ${ }^{38}$ a taxa de mortalidade infantil é um meio de identificar certas iniquidades numa sociedade democrātica e pe lo que nos interessa, evidencia, pelo menos, a iniquidade da agressão ao direito de todo ser humano à vida, à saúde e, por tanto, aos mesmos meios de preservā-la. Quanclo o direito de cada gestante e seu filho a um bom cuidado à saúde, proclamado e aceito pelas nações do mundo, se tornar uma realidade, certạ mente cairão as taxas de morbi-letalidade indicadoras do desní vel.

Entretanto, diante da problemática relacionada ao gru po materno-infanti1, considerando-se não somente os agravos a que está sujeito mas, tambēm, aqueles que, por isso, agridem cada nação como um todo, tem havido um interesse especial na 
adoção de medidas que possam diminuir os riscos de adoecerem e de morrerem as mães e as crianças.

Essas medidas estão sintetizadas em programas de ação preconizadas a partir do nível internacional. A OMS, pois, re definindo as prioridades de um dos seus objetos, determinou co mo objetivos especificos da Saúde Materno Infantil 69

- redução da mortalidade e morbidade maternas, perinatais, infantis e da criança;

- promoção da saūde da reprodução e do desenvolvimen to físico e psicossocial da criança e do adolescente, no ambiente familiar;

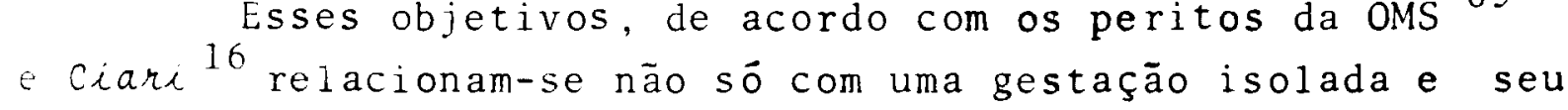
produto imediato, mas abrangem todo o período de vida dos indi víduos e referen-se também à saúde da comunidade.

As novas tendências que apresentam os serviços de saú de. no enfoque da assistência materno-infantil, são de conhe cimento obrigatório de todos os que, de alguma forma,se re lacionam com essa assistência.

Com este enfoque a OMS detalha os aspectos da as sistência sanitária prestada ao grupo numa sequência que acom panha a ordem dos eventos vitais: gestação, idade neo-natal,pe ríodo infantil e préescolar, a escolar e adolescência, regula ção da fertilidade e criação de filhos.

No plano americano o Informe final da III Reunião E. pecial de Ministros de Saúde das Américas 57 faz referéncias sobre a precariedade da assistência materno infantil,qualifica da de "limitada, descontinua e, comumente, de eficiência res trita: a cobertura das gestantes é geralmente inferior a $30 \%$, a assistência institucional ao parto, em quase metade dos paí ses, $\bar{e}$ inferior a $50 \%$ e a assistência ao puerpério, geralmente, não chega a 5\%".

Essa assistência diz respeito a $63^{\circ}$ da população to 
tal da América Latina representada pelas mulheres em idade fertil - por sua vez, 20 a $22 \%$ desta cifra - e às crianças me nores de 15 anos. Este volume tende a crescer com a explosão demográfica, esperando-se para 1980, uma duplicação da quantidade de mulheres grávidas ${ }^{43}$.

A toxemia, a hemorragia e as infecções - todas passí veis de correção com uma boa assistência à saúde são apontạ das, na América Latina, como as principais causas de mortalida de materna, cum taxas que atingem ainda altas cifras, como a de 33,7 em Cali (Colombia) e de 40,9 em Santiago (Chile), por 100.000 habitantes 3 .

Nos óbitos perinatais e neonatais são de destaque os nascidos com baixo peso, não só pela proporção que representam nas causas de öbitos mas, principalmente, por serem fenômenos reversíveis pela assistência correta no pré-natal. Esses óbi tos são uma porcentagem significativa da mortalidade infantil considerada ainda alta, na ordem de $108,68 \%$, em comparação com países mais adiantados; diz-se que na Amërica Latina há um "ex cesso" de $2 / 3$ de mortes na infancia se se considerar que, das 948.000 crianças que morrem anualmente, não morreriam 828.000 se as taxas de mortalidade infantil fossem iguais àquelas ho je existentes em países altamente desenvolvidos, como a Finlan dia e a Suëcia ${ }^{3}$.

Para atender a esta problemática a prestação de assis tência médica na América Latina está geralmente mal caracteri zada, com deficiente visão global da problemática de saúde,com a múltiplicidade e descoordenação inter e intra setoriais nas instituiçōes públicas e privadas, com a duplicidade de servi ços, coberturas desiguais, desperdício e encarecimento dos be nefícios. Isso é agravado e, até condicionado pela descrença na racionalidade das medidas de planejamento e pela inadequa ção do enfoque político. Acrescenta-se a isso a desarticula f̧ão e a inadequação na formação de recursos humanos para a saú de em relação ao mercado de trabalho, o conhecimento insuficí ente da tecnologia apropriada e a deficiência dos procedimen 
tos administrativos.

Essa problemātica, cuja explicação se atribui aos fa tores sócio económicos adversos, à qualidade e quantidade de atenção prestada ao grupo, considerada usualmente tardia, des contínua, parcial e limitada, leva à conclusão de que os siste mas de saúde são ineficientes, de baixa qualidade e pouco efe tivos 69

A nível nacional todo um programa com referência às mães e crianças foi descortinado na $V$ Conferência Nacional de Saúde, realizada em Brasília, em 1977, "o Programa de Saúde Mạ terno Infantil" 69

Como justificativas básicas para a elaboração do mes mo, foram apresentados, além do grande volume de indivíduos que integram o grupo materno infanti1, - nada menos de $70,98^{\circ}$ da população brasileira - a grande vulnerabilidade a que está ex posta esta parcela de individuos, sujeita aos agravos cujas ca racteristicas são praticamente as mesmas consideradas para a mérica Latina, a saber:

- "elevadas taxas de morbidade e mortalidades;

- elevada proporção de ōbitos de menores de 1 ano em relaçäo ao total de óbitos em crianças de 1 a 4 a nos;

- predomināncia de óbitos por causas evitāveis;

- precāria assisténcia hospitalar, para-hospitalar e médico-sanitäria;

- recursos humanos insuficientes, deficientemente for mados, desproporcionalmente distribuidos" 69 .

Estas características advêm da mesma espécie de fato res condicionantes que se poderiam invocar para as áreas Centro e Sul Americanas, nomeando-se os de natureza político-económica, cultural e aqueles ligados às organizaçōes prestadoras de ser viços, entre outras:

- pluralidade de instituições; 
- desarticulação das instituições entre si e com os órgãos formadores de recursos;

- ausência de programas de serviço e baixa produtivi dade.

A maior atenção voltada para a assistência materno-in fantil compensa, a curto, médio e longo prazo, se se levar em conta que, alguns dos problemas existentes no setor poden ser imediatamente evitados por uma atenção adequada em pontos no dais, deixando, portanto, de onerar a nação com uma assistên cia mais cara em outro nível ou mesmo com a morte. Evitar-se-ä o que acontece às vezes, segundo Osuna*, que a medida visan do a saúde chega demasiadamente tarde, representando um fracas so das pessoas em conservá-1a.

No âmbito do Estado embora as possibilidades de cana 1ização de recursos para a assistência materno-infantil sejam teoricamente maiores e, embora haja evidente atenção prestada ao reajustamento do setor saúde, pode-se dizer que a situação băsica em relação à prestação de assistência materno-infantil não é muito melhor. A reorganização dos serviços e a atualiza ção da tecnologia ainda estão em tempo de implantação, sujẹi tas, portanto, aos problemas característicos dessa fase.

A problemática de saúde no Estado de São Paulo quanto ao grupo materno-infantil, é bem a mesma referida para a Nação. O contingente de indivíduos, no grupo, mantém-se em torno de 60 a $65 \%$ da população do Estado ${ }^{42}$. Os fatores sócio-econômicos responsāveis pelos agravos a estes indivíduos, embora não exis tam, sobre eles, estimativas precisas, no Estado, estão indubi tavelmente presentes, haja vista a notåvel identidade da natu reza dos problemas identificados por diversos pesquisadores. Yu nes 68 cita uma mortalidade infantil em 1970 no Município de São Paulo da ordem de 74,8 óbitos para mil nascidos vivos, sen

* Osuna, L。J - La Repronducción y el desperdício de recursos humanos. Rev.int.Educ.salud., 13(1):13-9,1975. 
do $46 \%$ destes no período neenatal; a maioria dos nascimentos ( $51,94 \%$ ) ocorre nos domicilios; dos óbitos verificados em são Paulo $46 \%$ são teoricamente evitáveis.

Laurenti et al. 35 no seu levantamento de $68 / 69$ so bre o óbito infantil ocorrido na cidade de São Paulo, verifica que da taxa de mortalidade infantil 69.0 por 1.000 nascidos vi vos 34,8 eram atribuidos à mortalidade neonatal, corresponden do a 50,4 da mortalidade infantil, sendo considerada pela "In vestigação de mortalidade na infância" alta em relação a outras āreas em que se verificou o estudo; São Paulo, colocou-se em $10^{\circ}$ lugar em relação à mortalidade infantil e em $4^{\circ}$, com refe rência à mortalidade neonatal.

Em 24\% dos casos, as mães não receberam cuidados prénatais e cerca de $40 \%$ receberam 4 ou mais consultas pré-na tais. Outros aspectos esclarecedores do estudo de Laurenti de $\underline{i}$ $x$ am de ser abordados aqui por não se relacionare diretamente com os objetivos deste trabalho.

Também, é de silientar o problema da desnutrição in fantil associada à má nutrição materna 42 o que fala em vor da influência da qualidade da assistência à gestante na saúde do feto.

Segundo Moneti $i^{42}$ apenas $5:$ das Unidades Sanitārias es taduais possuiam 1972 serviços de Higiene Pré-Natal e,nestas, apenas $2 / 3$ dos médicos responsāveis pela atenção pré-natal era capacitado para tal. Alëm disso, salienta a evidente disper são de recursos tendo em conta a multiplicidade de serviços sem a devida coordenação, repetindo-se aqui a situação anteriormen te focalizada em nivel nacional e continental.

Moneti ${ }^{4} \bar{l}$ fala da dificuldade de se localizarem todas as organizaçōes assistenciais existentes em São Paulo na ärea materno-infantil e mais comumente ainda, conhecer seus pro gramas de trabalho e sua produtividade.

Nessa digressão que acabamos de fazer em todos os 
níveis assistenciais relacionados à problemática de saúde ma terna e da infância, nosso intuito foi o de salientar algumas características que nos pareceram comuns a todas as áreas geo gráficas - continente, território nacional, estadual e munici pal - onde as populações podem ser consideradas em desenvolvi mento.

o fator sobre o qual desejamos focalizar maior atenção é a correlação constante, salientada por todos os autores consultados, entre os problemas de saủde materno-infantis, es pecialmente aqueles reversíveis segundo técnicas conhecidas, a tuais e accessiveis e os cuidados prë-natais.

Posto isto, vejamos algumas considerações sobre a pres tação da assistência visando a reduçāo da problemātica discutida.

Os pontos básicos a serem pesados nessa assistência são a nota comum encontrada em värios documentos pertinentes: dos Comités Especializados da $\mathrm{OMS}^{67}$ e da OPAS ${ }^{48}$, da IV Reunião Especial de Ministros da Saúde das Américas ${ }^{57}$, da V Conferência Nacional de Saūde ${ }^{69}$ e de outros $3,24,40$, com ênfase nos se guintes aspectos:

- integração intra e intersetorial dos planos de saú de ;

- adaptação racional dos modelos de assistência;

- uso racional dos recursos;

- extensão de cobertura para que seja: universal, ac cessível e contínua de acordo com a política sócioeconômica e cultural do país;

- atenção primária e participação da comunidade.

A proposição inclui também a adoção de uma estratégia especial para os países subdesenvolvidos, desaconselhando-se o uso indiscriminado de métodos e técnicas relativamente so fisticados, adotados, propriamente, em países desenvolvidos. 
As tendências que apresentam os programas de assistên cia materno-infantil preconizados pelos diversos organismos internacionais e nacionais, envolvem todos os grupos, começan do pela gestante, estendendorse pelo recëm-nascido, infante, escolar, adolescente, até fechar o círculo com a mãe de famí lia e a comunidade.

o conteúdo desses programas prevê um cuidado compreen sivo para atender a todas as necessidades (obedecendo-se à ten dência apontada) a começar pela atenção primāria ao aspecto do crescimento e desenvolvimento da criança, prevenção das in fecções, incremento do estado nutricional, desenvolvimento de atitudes positivas da adolescência frente à gravidez, patern dade responsāvel e sensata, e envolvimento da comunidade no a tendimento de suas próprias necessidades.

As consideraçōes desses programas salientam a impor tância do equilíbrio entre necessidades, demanda e disponibí lidade de serviços para adequar as medidas de ajustamento que se fizerem indicadas, de conformidade com a ärea de desequilí brio identificada:

- reforço de serviços;

- processos educativos especiais;

- ajustamento de oferta.

Hā uma constante, tambēm, na ênfase quanto à necessí dade de se proceder previamente a um levantamento cuidadosoda situação existente, a fim de que se possa fazer uma avaliação judiciosa dos problemas encontrados e estabelecer uma escala de prioridades do atendimento a ser dispensado a cada um de les. O procedimento $\bar{e}$ imprescindível se se quiser compatibili $z$ ar as necessidades volumosas e os recursos, nem sempre paralelamente bem proporcionados, a fim de se evitarem a dispersão dos esforços e a improdutividade.

Esta necessidade é focalizada por um grande número de autores $8,9,14,16,21,22,46,48,51,53,58$, especialistas no assun to, aconselhando a elaboração de escalas de prioridades no a 
tendimento de gestante; falam também da necessidade da expan são de estudos $53,58,65$ com a finalidade de racionalizar a des tinação da assistência e dos recursos ao grupo mais atingido.

De modo geral, o impacto dos insucessos letais e sub letais da gravidez, traduzidos em óbitos maternos e fetais e nas incapacitaçōes, tornou-se tão insustentāvel que jä se pro moveram inúmeros estudos no sentido de descobrirem-se métodos e técnicas que possibilitem ou facilitem a identificação,a de limitação e o tratamento do problema.

Nesbitt 46 estudou os insucessos da gravidez patológ ca e, desse estudo, apresentamos a Figura $n^{\circ} 1$ do nosso traba lho visando ilustrar a idéia da grandeza dos eventos que se podem esperar pela ausência ou mau controle da gravidez.

A escala de prioridades retro referida baseia-se na identificação e seleção da porção de gestantes $(30, \%){ }^{46}$ que é tida como responsável pela percentagem de maus resultados da gravidez $4,14,33,36,58,65,66$ ou porque as vitimas não recebem cuidados, perdendo-se na multidão das gestantes que não são atingidas pela cobertura, ou porque os recebem tardia e/ou $\underline{i}$ nadequadamente. Tokuhata ${ }^{65}$ diz que,o pré-natal, no conceito estereotipado com que é feito não é compreendido pelos profis sionais da saúde e muito menos pelas clientes.

Perkin 51 lembra a limitação que podem trazer as esca las de prioridades e aconselha a reavaliação das gestantes pe riodicamente.

Entretanto, para possibilitar a seleção do grupo mais carente de assistência, muitos autores emitem conceitos de ris co gravídico, de alto risco e de suas classificações $8,13,14,15$, $31,53,58,66$ e propõem estratégias para o seu controle como a do Comitê de Especialistas da OPAS ${ }^{67}$, que recomenda: distri buição mais racional e flexível de recursos de acordo com o nível do risco, de modo a proporcionar-se algum cuidado para todos e cuidados especiais para o alto risco; para isto reco menda o levantamento e gradação do risco, da sua prevalência 
na comunidade, da possibilidade de ser controlado e da sua percepção pela comunidade.

Segundo a $\mathrm{OMS}^{67}$ hā uma universalidade na apresentação dos fatores de risco sobre os quais deve ser fundamentada a estratégia proposta, o que pode facilitar a prática da sua $\underline{i}$ dentificação.

Desde que o alto risco seja identificado,localizandose geograficamente sua maior incidência, (se possível),para de limitá-1o, as gestantes poderão receber a assistência precon zada, obedecendo-se para istoàs tendências atuais, entre ou tras a de se adotarem medidas de caráter local.

$$
\text { Laurenti }{ }^{35,36} \text {, ciari }{ }^{14} \text { e Tokuhata }{ }^{65} \text {, fazem referências }
$$

sobre a porcentagem de óbitos perinatais que podem ser evita dos se as gestantes submeterem-se a um adequado controle prénatal. Tokuhata ${ }^{65}$ recomenda que a qualidade deve ser mais en carecida que a quantidade e numa extensa exposição estatísti ca, relata os resultados do seu estudo sobre a patologia gra vídica relacionada à prematuridade, acidentes do parto, anoma lias congênitas e complicações da gravidez, mostrando como sen do as menos associadas as complicaçöes do parto. Conclui com a notável observação da associação de inscrições de gestantes patológicas no $2^{\circ}$ trimestre da gestação com anomalias congê nitas, especialmente dos órgãos respiratórios e cardiovascula res.

De wallace 66 apresentamos a Tabela que figura como a de $n^{\circ} 1$ neste trabalho, em que esse autor mostra a relação en tre óbitos perinatais e a quantidade de consultas no pré-ná tal.

Em São Paulo e Santa Catarina alguns estudos procuram indicar esse relacionamento $14,17,18,19,29,35,36,60,64,68$ sem contudo chegarem à comprovação estatística de cada relaciona mento, como Tokuhata 65 .

Segundo os estudiosos da saúde materno-infantil sali- 
TABELA l-Relação entre atendimento Pré-natal e Mortalidade perinatal.

\begin{tabular}{|c|c|c|c|c|}
\hline \multirow{2}{*}{$\begin{array}{l}\text { NOMERO DE } \\
\text { CONSULTAS }\end{array}$} & \multicolumn{2}{|c|}{ TOTAL DE PACIENTES } & \multicolumn{2}{|c|}{ MORTAL I DADE PERINATAL } \\
\hline & $N^{9}$ & $\stackrel{o}{o}$ & $N ?$ & $\stackrel{o}{b}$ \\
\hline 0 & 151 & 0,5 & 25 & 16,6 \\
\hline $1-3$ & 1,146 & 4,1 & 93 & 8,1 \\
\hline $4-7$ & 3,886 & 13,9 & 139 & 3,6 \\
\hline 8 ou mais & 9,670 & 34,5 & 126 & 1,3 \\
\hline Em outros locais & 242 & 0,9 & 15 & 6,2 \\
\hline Desconhecido & 12,941 & 46,1 & 416 & 3,2 \\
\hline TOTAIS & 28,036 & 100,0 & 814 & 2,9 \\
\hline
\end{tabular}

FONTE: Referência bibliogräfica $n^{\circ} 66$. 
ent am os problemas dessa ārea sāo multidisciplinares

por natureza ${ }^{65}$ e alguns autores ${ }^{12,26,56}$ recomendam o pleno apro veitamento de profissionais além do médico, nomeadamente a en fermeira, a obstetriz e a educadora na prestação de cuidados pré-natais.

Duarte $^{26}$ chama a atenção para o fato de que devendo ser a atenção da gestante, progressiva e integral, a enferme ra por sua capacitação está habilitada a atuar com pacientes em estado de saúde e de doença. Entretanto, em virtude da gra dação do seu preparo a ela pode ser atribuída a responsabilidade de controle da gestante sadia, dando à gestante de alto risco a oportunidade de receber maior atenção especializada e, com isto, possibilitar o aumento da cobertura. Para isto a au tora ressalta a necessidade de se estudarem o contingente de enfermagem disponíve 1 , suas atividades e sua equipe de traba lho, assim como as possibilidades do seu aperfeiçoamento para satisfazer ao aumento de responsabilidades.

Entretanto, Leite et a $1^{37}$ alertam para o perigo exis tente de ocorrer, na delegação de funções que a enfermeira faz aos membros de sua equipe sem cumprir ou poder cumprir, conco mitantemente com a sua função supervisora, um agravamento do problema constituindo-se essa delegação não supervisionada mais um fator de risco para a comunidade.

Entre as värias referências encontradas sobre estudos das associações de eventos da gravidez com fatores diversos.àlguns ligados às clientes, outros a profissionais e outros $\underline{a}$ inda a condições institucionais - não localizamos nenhuma refe rência a estudos científicos do intervalo de tempo decorrente entre a data de inscriçāo das gestantes e a da sua primeira consulta médica em serviços de pré-natal.

Não sendo possíve1, dada a natureza do levantamento 
que planejamos, chegar até à especificação da influência desse fenômeno na efetividade do serviço de prë-natal, propomo-nos, entāo, chegar atē à configuraçāo de alguns aspectos do evento.

Acreditamos que este trabalho poderā contribuir para a identificação e estudo de mais um instrumento de medida de qualidade da assistência prestada a gestantes em serviços prénatais.

Para efeito de simplificação e com a finalidade de fa cilitar os enunciados, doravante a expressão constante no tema deste trabalho: "tempo existente desde o aparecimento das ge tantes para inscrição nos centros de saủde até a primeira con sulta médica" será substituída pelo seguinte enunciado: "tempo de espera para obtenção da primeira consulta médica" e por seu equivalente "tempo de espera".

A suposiçāo de que, condicionadas, por " $n$ " razões, as

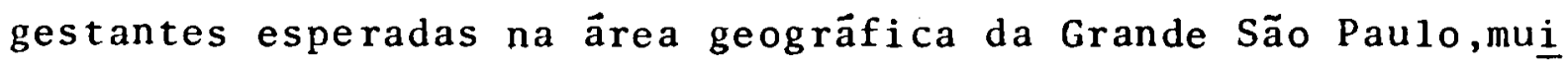
tas vezes chegam tardiamente a receber assistência mëdica, le va-nos também a indagações quanto às causas porque tal fenôme no ocorre.

Diante dessas conjecturas e sob o estímulo que consti tui a problemática incidente sobre o grupo materno-infanti1, to mamos como centro do nosso estudo o provável tempo de espera das gestantes da supra referida área para chegarem à efetiva ção da primeira consulta médica nos serviços de prë-natal.

Antes de mais nada, porém, cabe uma primeira indaga ção bāsica: existe mesmo um tempo de espera para que as gestan tes da Grande São Paulo consigam chegar à primeira consulta mé dica para controle da gestação?

Outras questōes podem, então, ser colocadas:

- se existe esse tempo, qual a sua grandeza?

- o fenômeno se relaciona com quem e com o que? quando? e, 
- como se comporta nesse relacionamento?

Dadas as sērias limitações - financeira, de tempo e de finalidade - de trabalhos a cuja natureza se equipara o nos so, cabe o seguinte reparo: embora desejáve1, não nos seria pos sível realizar um inquérito que atingisse todas as gestantes e xistentes, no momento que escolhemos, na ärea geogräfica de São Paulo. Assim sendo, selecionamos para estudo a porção des sas gestantes que nos pareceu passível de ser alcançada.

Frente às maiores facilidades operacionais com que po deríamos provavelmente contar, em virtude das características que vinculam as duas instituições, Faculdade de Saúde Pública da USP e Secretaria da Saúde, decidimo-nos relacionar nosso estudo tão somente com as gestantes atendidas nos serviços de pré-natal das unidades sanitārias do Departamento Regional de Saúde da Grande São Paulo, da Coordenadoria da Saúde da Comuni dade, da Secretaria de Estado da Saúde de São Paulo.

Com esta ressalva, consideramos suficientemente delimitado o nosso estudo. Para realizá-1o delineamos uma pesqui sa do tipo "Ex Post Facto"(50) com a qual tentaremos obter res postas das indagações retro-formuladas, tendo em vista o dire cionamento deste inquērito definimos os objetivos geral e espe cíficos, que expomos no Capítulo III. 
II - DEFINIÇĀO DE TERMOS 
AGENDAMENTO - consiste no ato de marcar dia e hora no cartão de identificação e agendamento pertencente a cada cliente do Centro de Saúde, a fim de que o mesmo receba, nessa data e ho rário, uma ação de saúde planejada previamente. (61)(FERREIRA, A.B. de H. Novo Dicionārio da Língua Portuguesa).

ALTO RISCO - é o risco gravídico em gradação mais elevada que traz para as mães e os conceptos maiores probabilidades de mor bidade e de mortalidade. (baseada na definição de PERKIN)(51).

ATENDIMENTO DE ENFERMAGEM - consiste no atendimento da gestan te e criança sadias e ainda da criança, gestante e adulto em controle da tuberculose e hanseníase, em períodos previstos pe la programação, nos quais são delegadas determinadas ações previamente estudadas e normalizadas(61).

ATIVIDADE - conjunto de ações que se realizam em sucessão cro nológica para atingir os objetivos(61).

ATRIBUTO DE ATIVIDADES - caracteristica qualitativa ou quanti tativa que indica a atividade. (FERREIRA, A.B. de H. Novo Dí cionārio da Língua Portuguesa).

CENTRO DE SAÚDE - unidade dinâmica responsāvel, sob uma chefia, pela execução de atividades de saúde püblica, que podem ser descentralizadas em um órgão local e que atua em determinada ärea. Os Centros de Saúde da Secretaria de Estado da Saúde de São Paulo foram classificados em cinco tipos I, II, III, IV e $V$, de acordo com o grau de complexidade decrescente que apre sentam, respectivamente (1).

COBERTURA - é expressa em termos de uma relação percentual en tre o número de pessoas atendidas por uma determinada atividade e a população da ārea programática, podendo ser a população total, a acessivel ou a suscetível (7). 
COBERTURA PROGRAMADA - porcentagem de pessoas a serem alcança das pelas ações do Programa (61).

COBERTURA REAL - porcentagem de pessoas que receberam as ações do Programa (61).

CONCENTRAÇĀO - è o nümero de atividades executadas para um indivíduo, porém em função da mesma causa (7).

CONCENTRAÇĀO NORMALIZADA - é o nümero de atividades previamen te determinado como ótimo, para atender uma necessidade de saú de (7) .

CONSULTA MÉDICA A GESTANTE - consiste num conjunto de açōes com binadas qualitativa e quantitativamente, de acordo com crité rios de eficiência, constituindo uma unidade de ação completa realizada pelo médico, em sequência ordenada, durante o proces so de gestação, visando a proteção da saúde e/ou o diagnóstí co e controle de tratamento da gestante( 7 ).

CORRELAÇĀO - dependência entre as funções de distribuição de duas ou mais variáveis aleatórias, em que a ocorrência de um valor de uma das variáveis favorece a ocorrência dum conjunto de valores das outras variāveis (FERREIRA, A.B. de H. Novo Di cionārio da Língua Portuguesa).

CUIDADO PRÉ-NATAL - é a assistência prestada precocemente, de forma contínua e periódica, durante a gestação, o parto e o pu erpério, com o objetivo de prevenir os riscos que atingem tan to a melher quanto o concepto, assim como diagnosticar e tra tar as possiveis intercorrências patológicas (69).

FICHA DE CONTROLE - é um impresso no qual são registradas, pạ ra cada cliente do Centro de Saúde, as atividades principais por ocasião do seu agendamento e respectivo comparecimento(61). 
IDADE GESTACIONAL - é o tempo total, atual de gravidez; a contagem desse tempo começa a partir da concepção e vai até a da ta focalizada. Para fins de determinação da duração completa da gestação, a contagem termina com a expulsão do concepto. Essa contagem pode ser feita em dias, semanas ou meses, e é realiza da mediante vários processos:

- a OMS preconiza a contagem desde o $1^{\circ}$ dia da últí ma menstruação;

- hả obstetras, entre eles Almeida, P.A.M.* de, que adotam o processo da adição de alguns dias -7 ou 10 - ao $1^{9}$ dia da última menstruação e, por conta gem regressiva de 3 meses, determinam a data pró vảvel do parto.

INSCRIÇĀO - consiste no início do atendimento de rotina a ser prestado ao cliente, jä matriculado no Centro de Saúde e que im plica em controle das atividades que para ele forem necessạ rias (61).

INSTRUMENTO - conjunto de recursos - pessoal e material - com binados, qualitativa e quantitativamente, segundo critérios de funcionalidade e eficiência, utilizados na execução de uma at vidade básica de saúde ( 7 e 61).

INSTRUMENTO NUCLEAR - indica o recurso mais significativo que entra na composição do instrumento e determina a sua denomina ção como por exemplo hora/mëdico, hora/enfermeira, hora/obste triz etc. (7).

PROBLEMAS DE SAÚDE - consiste no conjunto de fatores que condi cionam as doenças e sua distribuição em cada sociedade. Estes fatores são de ordem biológica, econômica, histórica e cultu ral (48).

PROGRAMAÇĀO - conjunto de decisões tomadas a respeito de: obje tivos e metas a serem alcançados pelo sistema de saúde, atividades a serem desenvolvidas para o alcance desses objetivos e

* Do Departamento de Saúde Materno-Infantil da FSP/USP. 
estimativa dos recursos (pessoal, material, financeiro) neces sários à execução das atividades. A programação deve apresen tar o suficiente detalhe relativo aos seus objetivos, ativida des e recursos, em termos de período do plano de saúde estabelecido - a longo, médio ou curto prazo(7).

PRONTUARIO - consiste num envelope modelo padrão, no qual es tão contidas as fichas de cliente matriculado no Centro de Saúde (61).

RENDIMENTO INSTRUMENTAL - é o nümero de atividades produzidas pelo instrumento, dentro do limite da unidade de tempo refer $\underline{\underline{i}}$ do na sua denominação (7).

RENDIMENTO INSTRUMENTAL NORMALI ZADO - número de atividades que se considera desejável produzir por unidade de instrumento(69)

RISCO GRAVIDICO - é a portunidade de agravos físicos, psíqui $\cos$ e sociais a que estão expostos a gestante e o feto (4).

SAUdDE MATERNA - 0 Comitê Especial da OMS $^{67}$ define Saüide Mater na como: "conceito amplo e aceito de cuidados de promoção, pre venção, recuperação e reabilitação da saúde das mãe e filhos, considerando as seguintes äreas:

- saúde materna;

- planejamento familiar;

- saúde infantil:

- saúde escolar:

- cuidado de saúde da criança defeituosa;

- saúde do adolescente;

- aspectos do cuidado de crianças em situações es peciais, como as creches.

VOLUME DE ATIVIDADE - número total de atividades executadas em função de cada dano ou demanda, durante um período de termpo determinado. o volume de atividades produzidas, permite veri ficar se a concentração de atividades para cada dano ou demanda é ou não a esperada(7). 
II I - OBJETIVOS 


\section{OBJETIVO GERAL}

Contribuir para a ampliação do conhecimento de causas da ocorrência de determinados problemas, reversíveis, de saú de da gestante e do concepto, estabelecendo a correlação, por ventura existente, entre a variação do tempo de espera para a primeira consulta médica de gestantes em centros de saúde e a guns fatores, possivelmente influentes, na ärea de saúde mater na.

Para o alcance deste objetivo geral, estabelecemos os seguintes objetivos específicos:

\section{OBJETIVOS ESPECIFICOS}

2.1 Identificar e medir segundo a idade da gestação,o tem po decorrente entre a data da inscrição e a da prime ra consulta médica das gestantes inscritas no período de janeiro a setembro de 1979 nos cinco tipos de centros de saúde das quatro Regionais do DRS-1, SP, in cluídos na amostra.

2.2 Identificar, na ocorrência de intervalos maiores que aquele considerado parâmetro de normalidade, se deter minadas características dos seguintes fatores institu cionais apresentam correlação com a anormalidade verí ficada:

2.2.1 1ocalização do Centro de Saúde;

2.2.2 tipo de Centro de Saüde;

2.2.3 cobertura alcançada, segundo o tipo de Centro de Saúde e a Regiona1;

2.2.4 disponibilidade do instrumento nuclear para a consulta médica e o atendimento de enfermagem 
(enfermeira e obstetriz);

2.2.5 idade gestacional ao tempo da inscrição.

Observação: a fim de completar a caracterização dos fato res selecionados, embora sem submetê-los a téc nicas acuradas de medidas de correlação, obje tivamos ainda:

a) identificar, em relação ao grau de cobertu ra alcançado, qual das modalidades de aten dimento, abaixo relacionadas, é a utilizada visando o encaminhamento das gestantes para a primeira consulta médica no pré-natal dos centros de saúde estudados:

- agendamento;

- atendimento ilimitado da demanda;

- atendimento limitado da demanda;

b) identificar sinais da associação entre as variações da concentração das consultas mé dicas oferecidas às gestantes inscritas nos referidos centros de saúde com a cobertura alcançada e com o rendimento instrumental da hora/médico efetivado;

c) identificar eventual evidência de associa ção da variação do tempo de espera com a rea lização ou não realização,pelos instrumen tos nucleares da consulta médica e do aten dimento de enfermagem, de atividades no se tor de saúde materna dos centros de saúde focalizados, segundo o seguinte elenco:

- triagem de gestantes;

- consulta de gestantes;

- atendimento de enfermagem a gestantes; 
- supervisão do setor;

- outras atividades no setor;

- outras atividades fora do setor.

2.3 Testar as correlações identificadas entre os fatores es pecificados nos itens $2.2 .1,2.2 .2,2.2 .3,2.2 .4$, 2.2 .5 e o tempo de espera mensurado.

A definição destes objetivos possibilita-nos a formu lação de uma hipótese que terá a finalidade de dirigir nos sa busca de respostas que esclareçam, ou contribuam para esclarecer, aspectos das associaçōes que procuramos carac terizar, identificar e testar. 


\section{IV - HIPÓTESE}


O tempo de espera de gestantes para obtençāo da prí meira consulta médica no pré-natal de Centros de Saúde pode estar correlacionado a determinados fatores ligados às institui ções, à clientela e aos instrumentos nucleares responsáveis pe la consulta médica e pelo atendimento de enfermagem. 
$V$ - VARIÁVEIS 


\section{VARIAVEIS: SELEÇĀO E DEFINIÇĀO OPERACIONAL}

Das variáveis contidas dentro da hipótese formulada, selecionamos, como significativas para este estudo, as seguin tes :

1.1 Variável dependente:

Tempo de espera para obtenção da primeira consulta medica.

Para isolar a variável dependente responderemos a três quesitos:

- o que é tempo de espera?

- com quem se relaciona?

- como pode ser identificado?

De conformidade com os interesses deste trabalho esta remos, assim, definindo o tempo de espera, caracteri $z$ ando-o e tornando-o mensuráve 1 .

\subsubsection{Definição:}

Tempo de espera, neste estudo, será considera do aquele que se escoa desde a data da inscri ção da gestante, no centro de saúde, para con trole pré-natal, até a data da primeira consul ta médica efetivada.

\subsubsection{Caracterização:}

1.1.2.1 O tempo de espera pode existir ou não existir:

- a "não existência" é expressa pelo zero (0) absoluto, significando a ocorrência da inscrição e a da pri meira consulta médica no mesmo dia, portanto, sem espera; 
- a "existência" é expressa em número de dias inteiros, podendo apresen tar variação de um (1) a " $n$ " dias, contados a partir da data da inscri ção até a da primeira consulta médí ca.

1.1.2.2 0 tempo de espera pode ser considerado aceitável ou não aceitável:

- tempo de espera aceitável é aquele que se mantém dentro do intervalo paramétrico de normalidade*, isto é, não ultrapassa o período de 0 a 7 dias; a expressão "aceitável" se rá, aqui, considerada sinônima de "normal";

- tempo de espera não aceitável é o que ultrapassa 0 intervalo paramé trico de normalidade. A expressão "não aceitável", será neste traba 1ho, equivalente a "anormal".

1.1.2.3 O tempo de espera, neste estudo,é uma expressão ligada especificamente às seguintes gestantes:

- gestantes matriculadas nos cinco ti pos de centros de saúde, (classificados de conformidade com a S.E.S.),

* Segundo ALMEIDA, P.A.M de** o parâmetro de normalidade de tempo de espera é o período de 0 a 7 dias, definido em fun ção da necessidade de se diagnosticar, tão precocemente quañ to possível, a gradação do risco gravídico apresentada pela gestante. $\bar{A}$ medida que a espera se prolonga além do $7^{\circ}$ dia, aumentam as possibilidades de exposiçäo do risco vigente e e rebaixa-se a qualidade da assistência.

**Do Departamento de Saúde Materno-Infantil da FSP/USP. 
das quatro Regionais do Departamento Regional de Saúde da Grande São Pau 1o, C.S.C. da S.E.S. - SP, inscritas para controle pré-natal, no período de janeiro a setembro de 1979;

- gestantes identificadas por meio de levantamento de informações registra das em cada centro de saúde, coletan do-se diretamente das fichas de con trole e dos prontuārios das gestan tes por meio de uma ficha roteiro os seguintes dados:

- tipo e denominação do Centro de Saú de e classificação da Regional;

- nümero da matrícula das gestantes;

- idade da gestação ou data da últi ma menstrução;

- data da inscrição;

- data da primeira consulta.

- gestantes classificadas e quantifica das por trimestre da gestação ao tem po da inscrição.

1.1.3 Mensuração:

Para medir o tempo de espera contou-se para cada gestante o tempo dccorrido desde a data da inscrição ate a primei ra consulta mëdica.

$\mathrm{Na}$ mensuração inicial do tempo de espe ra não se usou nenhum processo elaborado, computando-se os dados em bruto, ex ceção feita para o trimestre da gestação que foi considerado na computação. 
A computação dos dados foi feita manua mente, utilizando-se as informações con tidas na ficha roteiro (Anexo I)

O Resultado foi lançado no Quadro de Computação (Anexo IV).

\subsubsection{Associação:}

0 tempo de espera "aceitāvel" ou não a ceitável pode ser considerado um indica dor da qualidade - boa ou má - da as sistência prestada à gestante no pré-na tal, porém, sua validez está condiciona da a determinadas características de ou tros indicadores imprescindíveis para a avali ação.

1.2 Variảveis independentes significativas, selecio nadas para estudo, por apresentarem sinais evi dentes de influência condicionante sobre a va riāvel dependente:

- condições de accessibilidade apresentadas pe los centros de saúde segundo sua localjzaçäo e classificaça na S.E.S.;

- metas de cobertura normalizadas;

- alcance das metas de cobertura em relação às metas propostas;

- disponibilidade do instrumento nuclear responsável pela consulta médica e pelo atendi mento de enfermagem;

- trimestre da gestação ao tempo da inscrição; 
- modalidade de atendimento das gestantes vi sando seu encaminhamento para a primeira con sulta médica no prë-natal.

- grau de alcance das metas de concentração da consu1 ta médica;

- atuação do instrumento nuclear no setor de Saúde Materna;

- rendimento instrumental hora/médico;

- média de idade gestacional na inscrição.

Com o devido tratamento estatístico procuramos com provar a correlação existente do tempo de espera das gestantes para a primeira consulta médica com as variảveis indepen dentes mencionadas acima, do $1^{\circ}$ ao $5^{\circ}$ itens.

Quanto aos cinco ültimos da relação, pretendemos ape nas subsidiar a identificação de possibilidades de associação provāvel com a variável dependente. 
VI - MATERIAL E MÉTODO 


\section{POPULAÇĀO}

o objeto central da pesquisa foi o "tempo de espera", retro definido.

A população na qual identificamos este tempo de espe ra para torná-10 mensurävel e no qual procuramos conhecer, tam bể, a existência e as características de determinados fatores, interligados a este objeto na prestação de assistência prê-na tal à gestante, foi dividida em duas classes:

- população de material relacionado à variável depen dente ou tempo de espera;

- população de material relacionado às variáveis inde pendentes e que serão individualizadas ao relacio narmos o material sobre o qual se apoiou 0 estudo.

Nota: os instrumentos utilizados para a coleta dos dados neces särios para este estudo, constituem os anexos I, II elif.

1.1 Na população de material relacionado à variâuel depen dente, selecionamos como significativo o seguinte:

1.1.1 dados secundários existentes e registrados, le vantados dos boletins de produção do DRS-1, SP, relativos ao volume de gestantes inscritas e ao das existentes nos centros de saúde da rede deste bepartamento, nos meses de janeiro a se tembro de 1979 ;

1.1.2 dados secundários, existentes e registrados, fornecidos pela C.S.C. - S.E.S. SP - Nivel Cen tral, contendo: relação completa dos Centros de Saúde da rede, localizados na Grande SãoPau 
10, discriminados segundo o tipo de Centro de Saúde, sua distribuição por Distritos Sanitâa rios e Regionais e os respectivos endereços.

Estas informações foram utilizadas como base para a tomada de decisão quanto à abrangência do universo, isto é, se optaríamos pelo censo ou não. Segundo Candeias (12) in Oppenheim*"Não sendo possivel contar o todo, conta-se uma $a$ mostra representativa para, a seguir, inferirse sobre a população global".

Considerando o elevado número de unidades da população, conforme se vê na Tabela 2, opta mos por uma porção da mesma, constituída por uma classe geral, os centros de saúde, dentro dos quais selecionamos novamente outra porção de unidades, representadas pelas fichas das gestantes inscritas nesses centros de saúde.

No primeiro caso foi utilizado um processo de amostragem que será relatado no sub-capítulo se guinte.

No segundo caso o processo de seleção é parte do mētodo de trabalho utilizado e será igua 1 mente descrito adiante.

1.2 População de material relacionado às variāveis in dependentes.

O material utilizado para identificação, caracterí $z$ ação e mensuração das variāveis independentes sig nificativas serā relacionado sob a rubrica de cada

* Oppenheim, A.N. Questionaire disign and attitude measurement. New York, Basic Books Pub1., 1966. 
uma dessas variảveis e consta de dados secundários e primários.

1.2.1 Material relacionado às "condições de acces sibilidade apresentadas pelos centros de saú de segundo sua localização e classificação no centro de saúde":

- constitui-se de dados secundārios colhidos do quadro fornecido pela C.S.C. - S.E.S. SP, Nível Central, jā citado no item 1.1.2.

Deste quadro retiramos as informações pa ra:

- identificação e endereços dos centros de saúde da rede do Estado, localizados na Grande São Paulo, segundo sua distribui ção por tipo, distritos sanitärios e por regionais e selecionados para integrarem a amostra.

1.2.2 Material relacionado às "metas de cobertura normalizadas":

- programação da C.S.C. - S.E.S. - SP,para o ano de 1979, referente à assistência a saú de materna, da qual foram foram isolados os seguintes dados secundários:

- metas de cobertura para inscrição de ges tantes esperadas;

- concentração normalizada de consulta mé dica e atendimento de enfermagem;

- rendimento instrumental normalizado;

- dados básicos secundários para prograna ção, fornecidos pela Seção de Planejamen to da Divisão de Estudos e Programas do DRS-1, SP, a saber: 
- número de gestantes esperadas para o ano de 1979 para 17 (dezessete)centros de saúde daqueles incluídos na amostra; quanto aos demais não havia informa ções disponíveis com referência a ges tantes esperadas.

- dados básicos secundários referentes aos centros de saúde da amostra, fornecidos por:

- SEADE - SEPLAN, SP: população estimada para 1978 na ărea geogrä́fica dos centros de saúde; número de nascimentos e natimortos na mesma área, no mesmo período;

- CIS - SES - SP: população estimada para 1978, na área específica de cada distri to civil correspondente à área programá tica do centro de saúde, ou àquela onde o mesmo se localiza.

Observação: estes dados relativos à popula ção estimada foram utilizados pa ra o cálculo das gestantes espe radas para inscrição nos 34 cen tros de saúde da amostra, cujos nomes não constavam da relação fornecida pelo DRS-1, SP.

1.2.3 Material relacionado ao"alcance das metas de cobertura em relação às metas propostas" pa ra o atendimento das gestantes inscritas pa ra controle pré-natal nos centros de saüde da amostra, no período em foco:

- dados secundários levantados na Seção de Planejamento da D.E.P.-DRS-1, SP, dos bole tins de produção dos centros de saúde da $\underline{a}$ 
mostra e dados primários levantados nos próprios centros de saúde, diretamente dos prontuärios das gestantes inscritas para atendimento pré-natal, no período citado; estes dados nos deram as seguintes informa ções :

- nümero de gestantes inscritas e existen tes, segundo o trimestre da gestação, no período do estudo;

1.2.4 Material relacionado à "disponibilidade dos IN (instrumentos nucleares) responsáveis pe la consulta médica e pelo atendimento de en fermagem das gestantes inscritas nos centros de saúde da amostra, no período indicado:

- dados secundários existentes sobre pessoal para os centros de saúde da rede da S.E.S. SP: coletados da Portaria do Coordenador da C.S.C. - S.S. - CG ${ }^{8} 8$ (54) que dispõe, como vemos, sobre o nümero de médicos para atendimento de gestantes inscritas no pré-natal dos centros de saúde da rede, de acordo com a complexidade desses centros, a saber:

- CS I - 2 médicos em tempo parcial -4 ho ras diarias;

- CS II - 1 médico em tempo parcial - 4 họ ras diārias;

- CS III- 1 médico em metade do tempo par cial - 10 horas semanais;

- CS IV - 1 mëdico, em $1 / 5$ do tempo par cial - 4 horas semanais;

- CS V - 1 médico em $1 / 5$ do tempo par cial - 4 horas semanais. 
- dados primários sobre o número de médicos, enfermeiras e obstetriz, em exercício nos centros de saúde da amostra, no período focalizado, fornecidos pelas regionais do DRS-1 -SP: R.1.1, R. 1.2, R.1.3 e R.1.4.

1.2.5 Material relacionado ao "trimestre da gestação, ao tempo da inscrição":

- dados secundários existentes levantados nos boletins de produção arquivados na Seção de Planejamento da Divisão de Estudos e Pro gramas do DRS-1, sobre o nümero de gestan tes inscritas segundo o trimestre da gesta ção;

1.2.6 Material relacionado à "modalidade de aten dimento" das gestantes, visando seu encami nhamento para a primeira consulta médica no pré-natal dos centros de saúde estudados:

- agendamento;

- atendimento ilimitado da demanda espontânea;

- atendimento limitado da demanda espontânea;

Esta informação foi obtida por meio do levan tamento de dados primários realizado junto do médico responsảvel pelo centro de saúde ou do encarregado administrativo, na falta do primeiro.

1.2.7 Material relacionado à "atuação dos instrü mentos nucleares responsáveis pela consulta médica e pelo atendimento de enfermagem no setor de saúde materna", nos centros de saú de da amostra, no período compreendido no es tudo: 
- os dados necessários para o conhecimento dessa atuação foram dados primários colh $\underline{i}$ dos por meio de ficha roteiro* contendo in formações pertinentes a serem obtidas jun to de cada profissional responsável pela consulta médica e atendimento de enfermagem, e referiram-se às seguintes ativida des:

- triagem;

- consulta médica;

- atendimento de enfermagem;

- supervisão no setor de SM (saūde mater na) ;

- outras atividades no setor de saúde ma terna;

- outras atividades fora do setor de saú de materna;

1.2.8 Material relacionado à verificação do "rendi mento instrumental da hora/médico alcança do":

- os dados secundários necessários para essa verificação foram referentes ao volume de consulta médica realizada, obtidos dos bo letins de produção dos centros de saúde da amostra, arquivados no DRS-1 - SP;

- os dados primários, referentes à hora/médico trabalhadas no dia, més e ano, foram obtidos por meio de levantamento específico realizado junto das Regionais em que se localizam os centros de saúde focalizados.

* Anexo II: Ficha 1. 


\section{AMOSTRA}

Este estudo baseou-se numa pesquisa que se desenvolveu na ārea programática do Departamento Regional de Saúde da Grande São Paulo, abrangendo o período de janeiro a setembro de 1979 .

Tendo em vista a necessária autorização para realizarmos este inquérito,promovemos os devidos entendimentos pes soais e os formais por correspondencia com a Coordenadoria de Saúde da Comunidade e com o Departamento Regional de Saúde da Grande São Paulo.

Feito isto, iniciamos o levantamento, em junho do cor rente ano, com a coleta de informações referentes ao número, tí pos e endereços dos centros de saúde da Secretaria de Estado da Saúde - SP, localizados na Grande São Paulo, obtendo estes dados da Coordenadoria de Saúde - Nível Central.

Com base no material que nos foi fornecido, elaboramos a Tabela 2 .

Outro passo preliminar que se fez necessārio foi o le vantamento do número de gestantes inscritas nos meses de $j$ ane $i$ ro a setembro, em todos os centros de saúde da rede do DRS-1. Para tal fim utilizamos os dados secundários extraídos dos bo letins de produção desses centros de saúde, arquivados na Se ção de Planejamento da Divisāo de Estudos e Programas do DRS-1 e os registramos num mapa estruturado para isto, conforme o Anexo 1 ; tabulando manualmente os dados, construimos a Tabela 3 , apresentada no sub capítulo 1 do Capitulo VI(Amostra).

A finalidade deste levantamento foi a de conhecermos - tamanho da população de gestantes a que pertenciam os indiví duos da pesquisa, uma vez que, segundo parecer exarado pelo especialista consultado, da Disciplina de Estatística do Depar 
tamento de Epidemiologia da Faculdade de Saúde Pública de centru de saúde, com as quais se relaciona inerentemente o tempo de espera, condicionaria a escolha da tẻcnica da coleta de dados, isto $\bar{e}$, deveria ser feito o levantamento censitário se a população fosse muito pequena em cada centro de saúde ou se poderia aplicar a técnica de amostragem, se o volume de gestantes inscritas fosse suficiente para isto. 
TABElA 2 - Distribuição dos Centros de Saūde do DRS-1 da C.S.C., da S. E. S. de São Paulo, segundo os tipos, por Regionais e por Distritos Sanitärios. SP, 1979.

\begin{tabular}{|c|c|c|c|c|c|c|c|c|c|c|c|c|c|c|c|c|c|c|c|c|c|c|}
\hline \multirow[b]{2}{*}{$\begin{array}{l}\text { CENTROS DE SAODE } \\
\text { SEGUNDO OS TIPOS }\end{array}$} & \multicolumn{3}{|c|}{$\left[\begin{array}{c}\mathrm{R} .1 .1 \\
\text { Sede:Capital }\end{array}\right.$} & \multicolumn{5}{|c|}{$\begin{array}{ll} & \text { R. } 1.2 \\
\text { Sede: Guarulhos }\end{array}$} & \multicolumn{5}{|c|}{$\begin{array}{c}\text { R.1. } 3 \\
\text { Sede: Santo André }\end{array}$} & \multicolumn{8}{|c|}{$\begin{array}{c}\text { R.1. } 4 \\
\text { Sede: Osasco }\end{array}$} & \multirow[b]{2}{*}{$\begin{array}{l}-1 \\
4 \\
H \\
0 \\
6\end{array}$} \\
\hline & $\begin{array}{l}\mathscr{0} \\
\text { 预 } \\
\text { 蛋 } \\
\text { 它 }\end{array}$ & $\begin{array}{l}\text { 움 } \\
\text { 点 } \\
\text { 夏 } \\
\text { 嵹 }\end{array}$ & 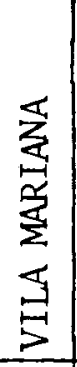 & 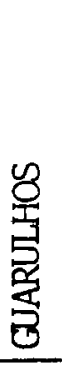 & 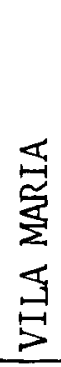 & 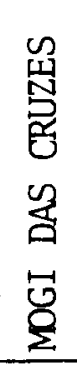 & 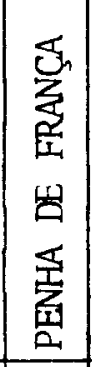 & 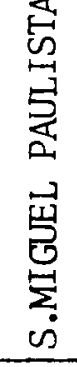 & 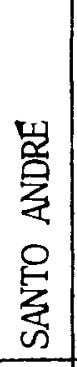 & 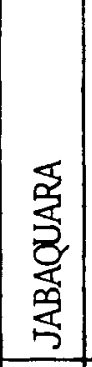 & 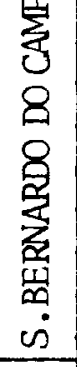 & 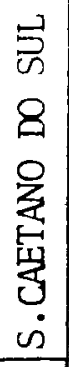 & 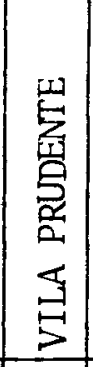 & 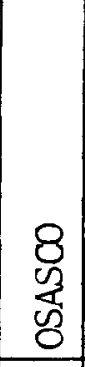 & $\begin{array}{l}\text { 旨 } \\
\text { 怘 } \\
\text { 皇 } \\
\end{array}$ & 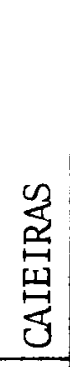 & 离 & 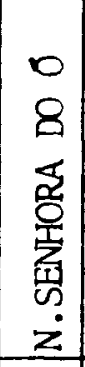 & 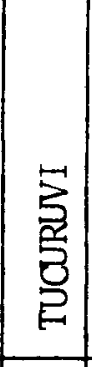 & 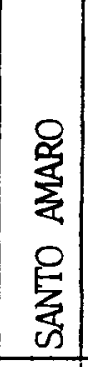 & 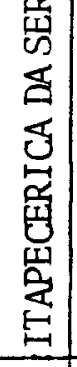 & \\
\hline C.S. I & 1 & 1 & 1 & 1 & 1 & 1 & 1 & 1 & 2 & 1 & 1 & 1 & 2 & 1 & 1 & - & 1 & 1 & 1 & 1 & - & 21 \\
\hline C.S. II & $\mathrm{I}^{\star *}$ & 1 & - & - & - & 1 & - & 2 & 1 & - & 1 & - & - & 1 & 1 & 1 & 1 & - & 1 & $* *$ & - & 12 \\
\hline C.S. III & - & 2 & - & - & 1 & 2 & 3 & - & 1 & $1^{* *}$ & - & - & - & - & - & 1 & - & 1 & 1 & - & 1 & 14 \\
\hline C.S. IV & - & - & - & 2 & - & 3 & 3 & 1 & - & - & - & - & 1 & 3 & 1 & 2 & 4 & 2 & 1 & 1 & 1 & 25 \\
\hline C.S. V & 2 & 3 & 4 & $2^{*}$ & 4 & 4 & $16^{*}$ & $9^{*}$ & 4 & 8 & - & - & 11 & 8 & 7 & 1 & 9 & $9^{*}$ & 9 & $9 *$ & 3 & 122 \\
\hline TOTAL & 4 & 7 & 5 & 5 & 6 & 11 & 23 & 13 & 8 & 10 & 2 & 1 & 14 & 13 & 10 & 5 & 15 & 13 & 13 & 11 & 5 & 194 \\
\hline
\end{tabular}

* Excluídos os não instalados

**Excluídos os C.S. Escola

FONTE: C.S.S. - S.F.S. - SP. 
TABELA 3 - Gestantes matriculadas, segundo o tipo de Centro de Saúde e a regional, janeiro - junho de 1979. São Paulo, 1979 .

\begin{tabular}{|c|c|c|c|c|c|c|}
\hline & \multirow{2}{*}{ TIPO } & \multicolumn{4}{|c|}{ RE $G$ I O N A L } & \multirow{2}{*}{ TOTAL } \\
\hline & & $\mathrm{R} 1-1$ & $\mathrm{R} 1-2$ & $\mathrm{R} 1-3$ & $R 1-4$ & \\
\hline CS & I & 656 & 1.193 & 1.214 & 1.282 & 4.345 \\
\hline $\mathrm{CS}$ & I I & 501 & 487 & 109 & 699 & 1.796 \\
\hline CS & I I I & 168 & 813 & 243 & 207 & 1.431 \\
\hline $\mathrm{CS}$ & IV & - & 531 & 75 & 1.200 & 1.806 \\
\hline $\mathrm{CS}$ & V & 417 & 1.259 & 409 & 1.865 & 3.950 \\
\hline TOT & $\mathrm{AL}$ & 1.742 & 4.283 & 2.050 & 5.253 & 13.328 \\
\hline
\end{tabular}

Fonte: DRS-1 - S.S.C.-S.E.S.- SP. 
2.1 Tamanho da Amostra (Tabe 1a 3)

2.2 Förmula empregada

Adotou-se como expressão do número mínimo de elementos da amostra:

$$
\mathrm{n}=\frac{\left(\frac{\alpha}{2}+\mathrm{K}_{\beta}\right)^{2}}{\mathrm{~d}^{2}}
$$

em que:

$\alpha$ - é a probabilidade de ocorrência do erro tipo I, is to é: a probabilidade de rejeição de uma hipótese verdadeira;

$\beta$ - é a probabilidade de ocorrência do erro tipo II, is to é: a probabilidade de aceitação de uma hipótese falsa;

$\underline{\alpha}$ - é o valor da abscissa da distribuição normal padro nizada que deixa $\frac{\alpha}{2}^{\circ}$ à sua direita;

$\beta^{-}$é o valor da abscissa da distribuição normal padro nizada que deixa $\beta \%$ à sua esquerda;

d - é o valor da diferença entre a verdadeira média e a média amostral medida em unidades de desvio pa drão. 
TABELA 4-Centros de Saúde e gestantes que participaram da amostra, segundo o tipo de Cen tro de Saúde e as Regionais. SP, 1979.

\begin{tabular}{|c|c|c|c|c|c|c|c|c|c|c|}
\hline \multirow{3}{*}{ TIPO } & \multicolumn{8}{|c|}{$\mathrm{R} E \mathrm{E} \quad \mathrm{I} O \mathrm{O}$ A L } & \multicolumn{2}{|c|}{ TOTAL } \\
\hline & \multicolumn{2}{|c|}{ R.1.1 } & \multicolumn{2}{|c|}{$\mathrm{R} .1 .2$} & \multicolumn{2}{|c|}{ R. 1.3} & \multicolumn{2}{|c|}{$\mathrm{R} .1 .4$} & \multirow[b]{2}{*}{ CS } & \multirow[b]{2}{*}{ GEST. } \\
\hline & $\mathrm{CS}$ & GEST & $\mathrm{CS}$ & GEST. & $\mathrm{CS}$ & GEST . & $\mathrm{CS}$ & GEST . & & \\
\hline CS I & 1 & 40 & 2 & 74 & 2 & 75 & 2 & 79 & 7 & 268 \\
\hline CS I I & ] & 75 & 1 & 73 & 1 & 16 & 2 & 104 & 5 & 268 \\
\hline CS III & 1 & 31 & 2 & 152 & 1 & 46 & 1 & 39 & 5 & 268 \\
\hline CS IV & - & - & 3 & 79 & 1 & 11 & 5 & 178 & 9 & 268 \\
\hline $\mathrm{CS} \mathrm{V}$ & 2 & 28 & 7 & 85 & 5 & 28 & 11 & 127 & 25 & 268 \\
\hline TOTAL & 5 & 174 & 15 & 463 & 10 & 176 & 21 & 527 & 51 & 1.340 \\
\hline
\end{tabular}


2.3 Nümero mínimo de elementos de cada amostra

O agrupamento bảsico analisado é o tipo de Centro de Saủde.

Admite-se que as probabilidades de ocorrência dos e ros tipos I e II são iguais a $5 \%$ e que o erro máximo na deter minação da média populacional é $25 \%$ do desvio padrão.

Tem-se, então:

$$
\begin{aligned}
& n=\frac{(1,96+1,64)^{2}}{(0,25)^{2}} \\
& n \equiv 208
\end{aligned}
$$

Serão levantados, assim, um mínimo de 208 dados para cada um dos tipos de centro de saúde, implicando no exame de, no mínimo, 1.040 gestantes dos cinco tipos de centro de saủde existentes nas Regionais do DRS-1, SP. 


\subsection{Estratificação Proporcional}

Considerando que cada tipo de centro de saúde está distribuído por quatro regionais, foi estabelecida a participa ção de cada regional proporcionalmente à quantidade de gestan tes matriculadas no período pesquisado.

Tem-se portanto:

$$
\mathrm{n}_{\mathrm{h}}=\mathrm{n} \cdot \frac{\mathrm{N}_{\mathrm{n}}}{\mathrm{N}}
$$

em que:

$$
\begin{aligned}
& \mathrm{n}_{\mathrm{h}} \text { - } \mathrm{e} \text { o número de elementos da amostra da regional } \mathrm{h} \text {; } \\
& \text { n - } \vec{e} \text { o número de elementos da amostra para o tipo de }
\end{aligned}
$$

Frente à necessidade de se iniciar e prosseguir imedi atamente com o levantamento, decidíramos em julho próximo passado, considerar para estudo o período contido entre os me ses de janeiro a junho de 1979 , porque eram relativos a este tempo os dados elementares encontrados no DRS-1.

Todavia, no desenvolvimento do trabalho foi possível, incluir as informações, referentes aos meses de julho a setembro, tornando o inquérito mais completo e mais atualizado. 
A Tabela 3 apresenta o número de matrículas de gestan tes. no período de janeiro-junho de 1979, segundo o tipo de centro de saúde e a regional.

Aplicando-se a förmula do item anterior, vem:

2.5.1 Número de elementós das amostras dos CS I

a) para $\mathrm{R} 1-1$

$$
\begin{aligned}
& n_{1}=208 \times \frac{656}{4.345} \\
& n_{1} \cong 31
\end{aligned}
$$

b) para R1-2

$$
\begin{aligned}
& \mathrm{n}_{2}=208 \times \frac{1.196}{4.345} \\
& \mathrm{n}_{2} \approx 57
\end{aligned}
$$

c) para R1-3

$$
\begin{aligned}
& n_{3}=208 \times \frac{1.214}{4.345} \\
& n_{3} \equiv 58
\end{aligned}
$$

d) para R1-4

$$
\begin{aligned}
& n_{4}=208 \times \frac{1.282}{4.345} \\
& n_{4} \cong 62
\end{aligned}
$$


2.5.2 Nümero de elementos das amostras dos CS II

a) para R1-1

$$
\begin{aligned}
& n_{1}=208 \times \frac{501}{1.796} \\
& n_{1} \equiv 58
\end{aligned}
$$

b) para $\mathrm{R} 1-2$

$$
\begin{aligned}
& \mathrm{n}_{2}=208 \times \frac{487}{1.796} \\
& \mathrm{n}_{2} \equiv 56
\end{aligned}
$$

c) para $\mathrm{R} 1-3$

$$
\begin{aligned}
& \mathrm{n}_{3}=208 \times \frac{109}{1.796} \\
& \mathrm{n}_{3} \equiv 13
\end{aligned}
$$

d) para R1-4

$$
\begin{aligned}
& \mathrm{n}_{4}=208 \times \frac{699}{1.796} \\
& \mathrm{n}_{4} \equiv 81
\end{aligned}
$$

2.5.3 Nümero de elementos das amostras dos CS III

a) para $\mathrm{R} 1-1$

$$
n_{1}=208 \times \frac{168}{1.431}
$$


$\mathrm{n}_{1} \cong 24$

b) para $\mathrm{R} 1-2$

$$
\begin{aligned}
& \mathrm{n}_{2}=208 \times \frac{813}{1.431} \\
& \mathrm{n}_{2} \equiv 119
\end{aligned}
$$

c) para $\mathrm{R} 1-3$

$$
\begin{aligned}
& \mathrm{n}_{3}=208 \times \frac{243}{1.431} \\
& \mathrm{n}_{3} \cong 35
\end{aligned}
$$

d) para R1-4

$$
\begin{aligned}
& \mathrm{n}_{4}=208 \times \frac{207}{1.431} \\
& \mathrm{n}_{4} \equiv 30
\end{aligned}
$$

2.5.4 Nûmero de Elementos das Amostras dos CS IV

a) para $\mathrm{R} 1-1$

$$
\begin{aligned}
& \mathrm{n}_{1}=208 \times \frac{0}{1.806} \\
& \mathrm{n}_{1} \cong 0
\end{aligned}
$$

b) para $\mathrm{R} 1-2$

$$
\begin{aligned}
& \mathrm{n}_{2}=208 \times \frac{531}{1.806} \\
& \mathrm{n}_{2} \cong 61
\end{aligned}
$$


c) para R1-3

$$
\begin{aligned}
& \mathrm{n}_{3}=208 \times \frac{75}{1.806} \\
& \mathrm{n}_{3} \cong 9
\end{aligned}
$$

d) para R1-4

$$
\begin{aligned}
& \mathrm{n}_{4}=208 \times \frac{1.200}{1.806} \\
& \mathrm{n}_{4} \cong 138
\end{aligned}
$$

2.5.5 Número de Elementos das Amostras do CS V

a) para R1-1

$$
\begin{aligned}
& n_{1}=208 \times \frac{417}{3.950} \\
& n_{1} \equiv 22
\end{aligned}
$$

b) para $\mathrm{R} 1-2$

$$
\begin{aligned}
& \mathrm{n}_{2}=208 \times \frac{1.259}{3.950} \\
& \mathrm{n}_{2} \cong 66
\end{aligned}
$$

c) para $\mathrm{R} 1-3$

$$
\begin{aligned}
& \mathrm{n}_{3}=208 \times \frac{409}{3.950} \\
& \mathrm{n}_{3} \cong 22
\end{aligned}
$$


d) para R1-4

$$
\begin{aligned}
& \mathrm{n}_{4}=208 \times \frac{1.865}{3.950} \\
& \mathrm{n}_{4} \equiv 98
\end{aligned}
$$

2.6 Nümero de Centros de Saüde da Amostra

Os centros de saüde comparecem tambëm na amostra em nümero proporcional à sua participação em cada tipo e região. Adotou-se, no caso, o fator de proporcionalidade(aproximandose os resultados para o inteiro seguinte) 0,2 para o CS $V$, e o fator 0,3 para os demais centros.

A Tabela 4 mostra o nümero de centros de saúde e ge $\underline{s}$ tantes que participaram da amostra distribuídos segundo os ti pos de centros de saúde e as regionais com o tamanho da amo $\underline{s}$ tra jā modificado. 
QUADRO 1 - Re laçāo dos Centros de Saủde sorteados para constituirem a amostra, segundo o tipo de CS. SP, 1979 .

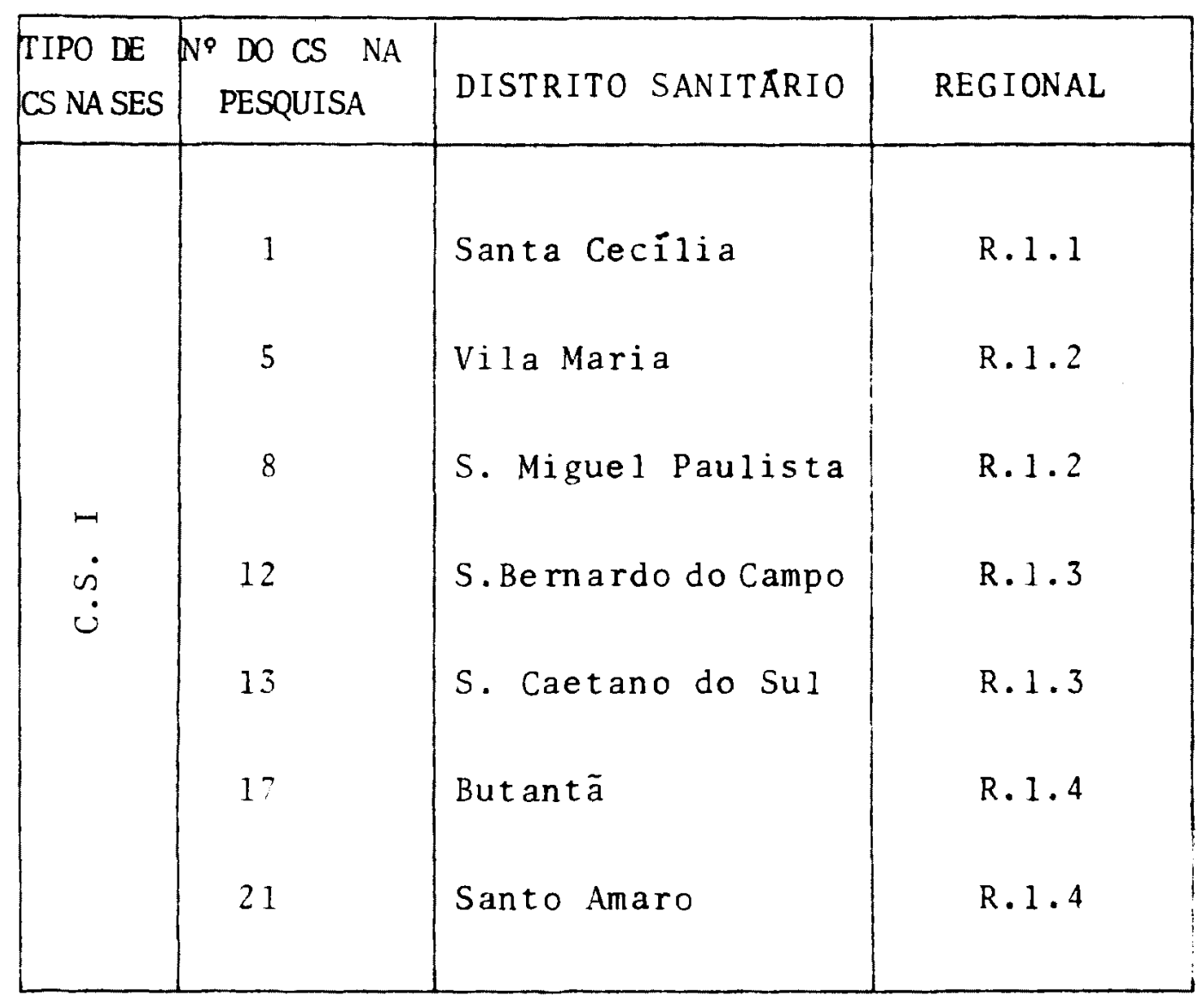


QUADRO 2 - Re 1ação dos Centros de Saúde sorteados para constituirem a amostra, segundo o tipo de CS. SP, 1979.

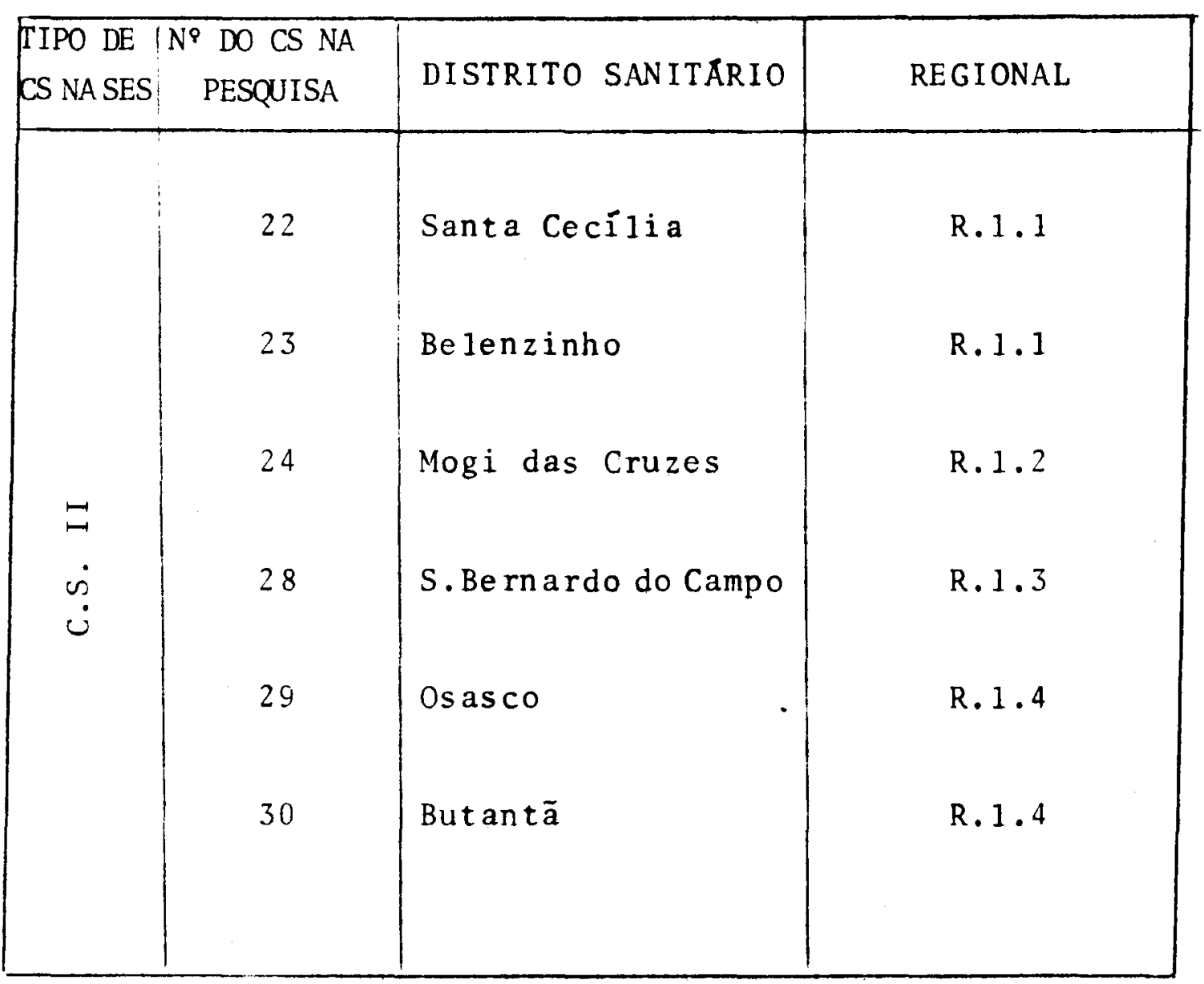


QUADRO 3 - Relação dos Centros de Saúde sorteados para constituirem a amostra, segundo o tipo de CS. SP, 1979 .

\begin{tabular}{|c|c|c|c|}
\hline $\begin{array}{l}\text { TIPO DE } \\
\text { CS NA SES } \\
\end{array}$ & $\begin{array}{c}N^{\circ} \text { DO } C S \text { NA } \\
\text { PESQUISA }\end{array}$ & DISTRITO SANITARIO & REGIONAL \\
\hline \multirow{8}{*}{$\begin{array}{l}= \\
\dot{\varpi} \\
\dot{v}\end{array}$} & 34 & Belenzinho & R. 1.1 \\
\hline & 35 & Belenzinho & R.1.1 \\
\hline & 36 & Vila Maria & R. 1.2 \\
\hline & 40 & Penha de França & $\mathrm{R} .1 .2$ \\
\hline & 41 & Penha de França & R. 1.2 \\
\hline & 43 & Jabaquara & $\mathrm{R} .1 .3$ \\
\hline & 45 & N. Senhora do 0 & $\mathrm{R} .1 .4$ \\
\hline & 46 & Tucuruvi & $\mathrm{R} .1 .4$ \\
\hline
\end{tabular}


QUADRO 4 -Relação dos Centros de Saũde sorteados para constituirem a amostra, segundo o tipo de CS. SP, 1979.

\begin{tabular}{|c|c|c|c|}
\hline$\left[\begin{array}{l}\text { IIPO DE } \\
\text { CS NA SES }\end{array}\right.$ & $\begin{array}{l}\text { P DO CS NA } \\
\text { PESQUISA }\end{array}$ & DISTRITO SANITARIO & REGIONAL \\
\hline \multirow{5}{*}{$\geq$} & 48 & Guarulhos & R. 1.2 \\
\hline & 50 & Mogi das Cruzes & R. 1.2 \\
\hline & 53 & Penha de França & R. 1.2 \\
\hline & 57 & Vi la Prudente & R.1.3 \\
\hline & 58 & Os as co & R.1.4 \\
\hline$\dot{0}$ & 59 & Os asco & R. 1.4 \\
\hline & 67 & Lapa & R. 1.4 \\
\hline & 69 & N.Senhora do 0 & R. 1.4 \\
\hline & 70 & Tucuruvi & R. 1.4 \\
\hline & 72 & It apecerica da Serra & R. 1.4 \\
\hline
\end{tabular}


QUADRO 5 - Relação dos Centros de Saúde sorteados para constituirem a amostra, segundo o tipo de CS. SP, 1979.

\begin{tabular}{|c|c|c|c|}
\hline $\begin{array}{l}\text { TIPO } \quad \text { DE } \\
\text { CS NA SES }\end{array}$ & $\begin{array}{c}N^{\circ} \text { DO CS NA } \\
\text { PESQUISA }\end{array}$ & DISTRITO SANITARIO & REGIONAL \\
\hline $\begin{array}{l}= \\
\dot{v}\end{array}$ & $\begin{array}{r}75 \\
81 \\
84 \\
85 \\
87 \\
102 \\
107 \\
112 \\
115 \\
118 \\
119 \\
120 \\
132 \\
135 \\
142 \\
148 \\
149 \\
150 \\
158 \\
159 \\
163 \\
186 \\
187 \\
193 \\
194\end{array}$ & $\begin{array}{l}\text { Belenzinho } \\
\text { Vila Mariana } \\
\text { Vila Maria } \\
\text { Vila Mariá } \\
\text { Vila Maria } \\
\text { Penha de França } \\
\text { Penha de França } \\
\text { S.Miguel Paulista } \\
\text { S.Miguel Paulista } \\
\text { Santo André } \\
\text { Santo André } \\
\text { Santo Andrë } \\
\text { Vila Prudente } \\
\text { Vila Prudente } \\
\text { Osasco } \\
\text { Butantã } \\
\text { Butantä } \\
\text { Butantä } \\
\text { Lapa } \\
\text { Lapa } \\
\text { Lapa } \\
\text { Santo Amaro } \\
\text { Santo Amaro } \\
\text { Itapecerica da Serra } \\
\text { Itapecerica da Serra }\end{array}$ & 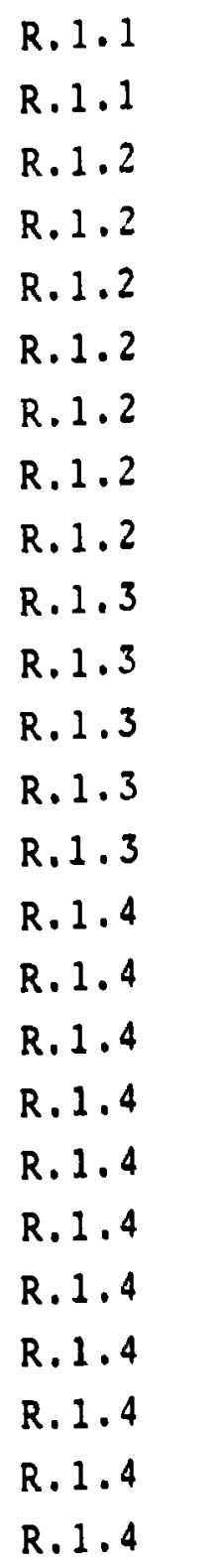 \\
\hline
\end{tabular}




\section{PROCEDIMENTO}

Antes do início da coleta de dados visitamos três cen tros de saúde, tipos I, II e III, com a finalidade de verifí car os processos de inscrição das gestantes. Pudemos observar que nesses centros as gestantes são recebidas, por ocasião de sua primeira visita, por um atendente que as encaminha ao 'fi chário onde são inscritas, seguindo imediatamente para a consulta mëdica ou para o atendimento de enfermagem - que, neste ca so, é o que já se denomina, fora da Secretaria de Estado da Saúde de São Paulo, de consulta de enfermagem -. Não foi possí vel identificar, nesse momento, se as gestantes são atendi das, conforme a demanda, sem limites de quantidade ou se hả um determinado número de vagas para atendimento diário além do qual as excedentes são encaminhadas para inscrição em outro dia.

No momento da inscrição as gestantes recebem um núme ro, mas surgiu aí uma dúvida que se intensificou posteriormen te: não conseguimos perceber se, na prātica, é feita a diferen ça entre os termos "matrícula" e "inscrição", sendo provāvel que, normalmente, sejam considerados equivalentes. Com certa frequência, ao computarmos os dados levantados nos centros de saúde, tivemos que eliminar da amostra algumas inscriçōes com data de 1977 ou princípio de 1978 que, pela lógica, indicavam uma gestação hã muito terminada; como a essas inscrições se guia-se uma data recente de consulta, concluimos que se trata va da data da matrícula que, para cada cliente, é sempre a mes ma, não importando o tempo em que retorna ou a clínica que pró cure.

No ato da consulta (do médico ou da obstetriz), são registradas em fichas especializadas, as datas da ủitima menstruação ou idade da gestação e da primeira consulta.

Por meio das Normas e Instruções 61 da Secretaria de Estado da Saūde, verificamos que o processo de inscrição e os registros observados devem ser idênticos para todas as unida des sanitärias da rede. 
3.1 Instrumento para coleta de dados

Feito isto, elaboramos nossos instrumentos para a co leta de dados, nos centros de saúde, constando de dois mo delos que denominamos Ficha 1 e Ficha 2, conforme os Ane xos II e III.

A Ficha 1 foi estruturada com os seguintes objetivos:

a) informar sobre a existência ou não existência,nos centros de saúde dos instrumentos hora/médico, ho ra/enfermeira e hora/obstetriz, assim como sobre o número dos mesmos em exercício efetivo;

b) indicar qual a atuação desses instrumentos nuclea res, especificamente em relação às seguintes ativi dades:

- triagem

- consulta médica

- atendimento de enfermagem

- supervisão

- outras atividades no Setor de Saúde Materna e ou tras atividades fora do Setor de Saúde Materna.

Justificamos a inclusão destes itens na Ficha 1 pelas razões expostas a seguir:

TRIAGEM: o objetivo da coleta deste dado é a identificação do instrumento que executa esta atividade. Evidentemente no caso de gestantes, a triagem é uma das primeiras oportuni dades para a identificação de fatores que participam na classificação do alto risco gravídico. Se o instrumento responsävel pela triagem for suficientemente treinado as possibilidades de se detectar tais fatores de risco mais cedo e encaminhar mais oportunamente as gestantes para con trole, são maiores. Se o instrumento pertence a uma catego ria funcional que não conte com as mesmas possibilidades de treinamento suficiente, a execução dessa atividade deve ser examinada à luz dos resultados relativos à atividade "su 
pervisão", relacionada igualmente para levantamento.

CONSULTA MÉDICA: Foi colocada por uma questão de coerência pois seria supérflua, considerando que só o médico a execu ta; consequentemente, se não houver médico na unidade, não haverá consulta médica, podendo contar-se, às vezes, só com o atendimento da obstetriz. Essa ocorrência, por si somen te, já seria um indicador de qualidade deficiente da assis tência prestada, uma vez que o serviço de enfermagem só de ve atender, normalmente, às gestantes sadias.

ATENDIMENTO DE ENFERMAGEM: A realização ou não realização desta atividade num centro de saúde para o qual é prevista, é um elemento para a avaliação da cobertura esperada desde que, conforme consta nas normas, devem ser oferecidos a ca da gestante que se inscreve no primeiro trimestre, pelo me nos quatro atendimentos de enfermagem. Entretanto pode-se encontrar situações em que haja desvio de função quando a obstetriz executa atividades que poderiam ser delegadas a pessoal auxiliar e a enfermeira não realiza o atendimento de enfermagem. No caso em que tais irregularidades sejam verificadas, medidas de ajustamento se impõem, pois esses dois instrumentos são suficientemente dispendiosos para não se admitir o desperdício.

SUPERVISĀO: A importância do levantamento de informações sobre este item advém da necessidade da sua realização. 0 exercício da função supervisora, adequadamente realizada pe la enfermeira encarregada do Setor de Enfermagem, é um in dício da existência de um fator de ajustamento da qualida de da atenção prestada.

OUTRAS ATIVIDADES NO SETOR DE SAÚDE MATERNA: Sempre hä uma possibilidade de que a enfermeira ou a obstetriz, embora não realizando a prestação de assistência de enfermagem nem exercendo a função supervisora, realizem ou participem da realização de outras atividades no Setor de Saúde Ma terna, especificamente as de caráter administrativo, tais 
como: planejamento, organização, coordenação e direção das atividades de enfermagem.

E de grande importância o conhecimento pelo menos de indí cios elementares da atuação da enfermeira na área de saúde materna, dada a grande importância que a sua participação aí vem merecendo. Frente à escassez de recursos existente para tratar a problemática do setor, a enfermeira é um ele mento valioso porque além da sua contribuição direta na as sistência a ser prestada, participa como agente multiplica dor por excelência em relação ao pessoal auxiliar, ao qual se preconiza, atualmente, com grande ênfase, a delegação de atribuições junto ao grupo de gestantes.

O levantamento desses dados servirā, quando menos, para $\underline{u}$ ma primeira penetração no conhecimento de problemas jā ma nifestados, porém, não comprovados,empiricamente, quanto à não atuação ou atuação insuficiente da enfermeira no Setor de Saúde Materna.

OUTRAS ATIVIDADES FORA DO SETOR DE SAÚdE MATERNA: Const i tuem um item cuja informação é um reforço do esclarecimen to obtido nos anteriores; teoricamente, há casos em que a enfermeira e/ou obstetriz prestam assistência de enfermagem na ärea de saúde da criança, ou por algum desvio de função, realizam atividades não previstas nas normas até em áreas não ligadas à saúde materno-infantil.

A simples confirmação dessa informação indica um problema de múltiplas faces que demanda solução urgente, mas que $\underline{e}$ xige um melhor conhecimento em profundidade. Como não é ob jetivo deste trabalho identificar e caracterizar tais pro blemas, principalmente quando fora do Setor, o levantamento deste dado foi conduzido apenas para obtenção da infor mação genérica sobre a realização de atividades fora do Se tor.

A Ficha 2 foi utilizada para o levantamento das informa ções relacionadas ao tempo de espera. Expomos em seguida, 
as razōes porque selecionamos os itens constantes deste mode 10:

- o registro do número de ordem visou o controle do número de gestantes cuja inscrição foi levantada, uma vez que a quantidade era prevista;

- o número da matrícula permitiria o controle posterior do dado, se ou quando necessário;

- a data da ūltima menstruação ou idade da gestação, foi considerada um dado bāsico porque o conhecimento da ida de gestacional ao tempo da inscrição é um indicador da qualidade da assistência;

- as datas da inscrição e da primeira consulta médica, fo ram consideradas dados essenciais para a identificação do tempo de espera, registrado em dias para possibilitar sua mensuração.

\subsection{Escolha da amostra}

Em seguida sorteamos as unidades sanitārias que deve riam constituir a amostra. Para isto fizemos uma relação dos centros de saúde da rede do DRS-1-SP, conforme os da dos procedentes da C.S.C. já referidos. Numeramos esses centros de 1 a 194; do total que eram 209,foram excluídas: as unidades tipo PAS por oferecerem atendimento elementar, os centros de saúde não instalados, embora constantes da lista e os centros de saúde escola, devido ao atendimento diferenciado por sua finalidade.

o sorteio, que obedeceu ao disposto no sub-capítulo "Amos tra", selecionou, de início, 51 unidades sanitārias; Toda via, acrescentamos mais uma do tipo II, porque um dos cen tros de saúde desse tipo, sorteado, apresentava um número de inscrições menor que a parcela da amostra para ele pre 
sumida, acontecendo o mesmo com o segundo centro deste $E \underline{i}$ po, da Regional, que só possuia os dois. Assim, sendo, opta mos pelo acréscimo em vez da substituição.

No decorrer do levantamento outras substituiçōes e acréscimos se fizeram necessäries:

- acréscimo de 1 unidade tipo III para complementar o tama nho da amostra nesta classe;

- substituiçāo de 3 unidades, tipo IV, por nāo apresentarem, na seleção, nenhum atendimento de gestantes;

- substituição de 28 unidades tipo V: 3 foram substituídas após a visita da auxiliar de levantamento, pois esses centros também não atendiam gestantes e não possuiam tele fone para confirmar, previamente, a existência desse aten dimento;

- 25 unidades foram eliminadas em virtude das ocorréncias a cima relatadas, não apresentando um número de inserições. pe 10 menos no limite de segurança para a amostragem, núme ro que consideramos indicado a partir de 24. Nümero menor poderia ocasionar perda do tempo disponível e encarecimen to do processo.

Relacionamos nos Quadros, , e todas as unidades sanitárias sorteadas, inclusive as que comparecem como com plementares, com os nümeros recebidos no sorteio, e a dis criminação dos Distritos Sanitários e Regionais a que per tencem.

3.3 Seleção e treinamento das auxiliares do levantamento:

Passamos, então, à seleção das auxiliares do levantamento. Embora houvesse bastante desigualdade na sua forma ção básica - 5 eram alunas do $4^{\circ}$ ano do Curso de Enfermagem, Departamento de Enfermagem-Escola Paulista de Medicina e 3 a 
sumida, acontecendo o mesmo com o segundo centro deste tí po, da Regional, que só possuia os dois. Assim sendo, opta mos pelo acréscimo em vez da substituição.

No decorrer do levantamento outras substituições e acréscí mos se fizeram necessärias:

- acréscimo de 1 unidade tipo III para complementar o tama nho da amostra nesta classe;

- substituição de 3 unidades, tipo IV, por não apresentạ rem, na seleção, nenhum atendimento de gestantes;

- substituição de 28 unidades tipo v: 3 foram após a visita da auxiliar de levantamento, pois esses centros também não atendiam gestantes e não possuiam te lefone para confirmar,previamente, a existência desse a tendimento;

25 unidades foram eliminadas em virtude das ocorrências acima relatadas, não apresentando um número de inscri ções, pelo menos no limite de segurança para a amostra gem, número que consideramos indicado a partir de 24 . Nú mero menor poderia ocasionar perda do tempo disponíve 1 e encarecimento do processo.

Relacionamos nos Quadros 2,3,4,5 e 6 todas as unidades sanitárias sorteadas, inclusive as que comparecem como com plementares, com os números recebidos no sorteio, e a dis criminação dos Distritos Sanitários e Regionais a que per tencem.

3.3 Seleção e treinamento das auxiliares do levantamento:

Passamos, então, à seleção das auxiliares do levantą mento. Embora houvesse bastante desigualdade na sua formação básica - cinco eram alunas do quarto ano do Curso de Enfermagem da Escola Paulista de Enfermagem e três eram a 
lunas da oitava série do $1^{8}$ grau, no Colégio Portugal - de cidimos pelo aproveitamento de todas, considerando que os dados a serem coletados eram secundärios na sua maioria e sua ação seria de natureza bastante mecânica; por outro lado, os dados primärios a serem levantados nos centros de saüde eram simples, não demandando especialização alguma para se obtê-los.

A equipe de auxiliares recebeu 2 horas de orientação inicial, quando foram discutidas as informaçöes escritas (Anexo $V$ ) que lhes eram entregues juntamento com o mate rial necessário para o levantamento; essa orientação cons tituiu-se dos esclarecimentos sobre a finalidade da pesqui sa, a técnica de abordagem nos centros de saúde e o preen chimento dos modelos. Como era de esperar-se as alunas do Curso de Enfermagem demandaram menos tempo de treinamento que as colegiais, em virtude de jä estarem mais familiari $z$ adas com o assunto e com os termos do levantamento.

A cada auxiliar foram atribuídas 7 (sete)unidades sa nitárias para a coleta de dados e o levantamento nos cen tros de saúde teve início no dia 30 de outubro. Ao chega rem à unidade, as auxiliares apresentaram-se ao médico di retor ou ao seu substituto, explicaram o motivo da visita, comprovando a autorização para o levantamento mediante a entrega da carta do Diretor do DRS-1, cuja cópia consta no Anexo VI e solicitarama sua colaboração para o preenchimen to da Ficha 1.

3.4 Técnica de seleção das fichas:

A seguir procederam ao preenchimento da Ficha 2 de a cordo com a técnica recomendada.

Considerando que o número total das inscrições nos centros de saúde, de janeiro a junho de 1979 , de acordo com os boletins de produção desses centros arquivados no 
DRS-1, era de 13.328 gestantes, foi necessärio optarmos não só pela amostragem em relação ao número de tipo de centros de saúde, corno já foi referido antes, mas também com refe rência ao número de fichas existentes nos centros de saúde sorteados, pois não poderíamos devido às limitaçōes exís tentes, levantar todos os dados de todas elas.

A técnica que decidimos utilizar para a seleção des sas fichas, relatamos a seguir.

Como ponto de partida adotamos o processo descrito em "Comunicação sobre Estudos de Morbidade"*, aconselhävel, no presente trabalho, por ser de fácil utilização por pessoal não especializado. Contamos, como era indicado no modelo adotado, com as fichas de registro de dados relacionados às consultas, agrupadas no "Prontuário" das clientes, estes no Fichārio Geral em ordem numérica e com a Ficha de Con trole de cada gestante, arquivada em fichărio à parte obe decendo ordem alfabética.

A sequência dos procedimentos para a seleção das $f \underline{i}$ chas foi do seguinte modo:

3.4.1. localização das fichas de controle no fichärio e separação daquelas utilizadas em 1979, mesmo que a inscrição tivesse sido feita em 1978;

3.4.2. contagem de todas as fichas de gestantes atendi das em 1979 para a primeira consulta médica, a co meçar da primeira, atendida no dia $1^{\circ}$ de janeiro até a última atendida no dia 30 de setembro. Não adotamos o expediente de contar somente $1 / 4$ apro ximado das fichas contidas na la. gaveta porque verificamos ser necessário fazer o levantamento

* Fundação Serviços de Saúde Pública - MS Comunicação so bre Estudos de Morbidade, 1970 (mimeografado). 
de todas as gestantes inscritas, com toda a pre cisão possíve1, examinando todos os possíveis 1으 cais de acondicionamento de fichas, para não de $\underline{i}$ xarmos de registrar nenhuma das porventura exis tentes. A razão motivante foi a verificação de que os dados disponíveis com referência às ges tantes inscritas nos centros de saúde ate junho certamente seriam submetidos a revisão pelo ní vel departamental, sendo, portanto, sujeitos a correção, até mesmo aqueles registrados em livros onde a contagem poderia apresentar alguma discre pância. A verificação a que nos referimos ocor reu quando se evidenciou o problema retro citado da não concordância dos dados encontrados nos centros de saüde com os dados registrados nos bo letins de produção.

Alguns dos centros de saủde sorteados não mais a presentavan atendimento de gestantes; outros só atendiam gestantes à tarde, pelo CIAM (que não podiam ser incluídos no levantamento, restrito es te às unidades da rede do DRS-1) e outros,enfim, apresentavam um atendimento tão diminuto que não chegava nem ao tamanho da amostra - a qual varia va de 6 a 75 na dependência do tipo de centro de saúde, da frequência de cada tipo na amostra e da Regional em que se localizavam os centros de s aúde.

Além destes, outro problema foi verificado; algu mas auxiliares do levantamento registraram somen te as inscrições de janeiro a junho e outras, as de junho a outubro, contrariando a instrução es pecifica que lhes havia sido transmitida para re gistrarem todas as inscrições de $1^{\circ}$ de janeiro a 30 de outubro.

Diante destes problemas decidimos, ao terceirc dia de trabalho, recomeçar o levantamento com as 
seguintes modificações:

- contar todas as fichas existentes, como dito acima;

- se o número de fichas contado permitisse a con sideração de um intervalo, este seria calcula do e observado; se isto não fosse possível, far-se-ia um censo de todas as gestantes ins critas.

Para aplicar estas medidas, a toda a amostra uni ficando o processo, determinamos voltar às unida des onde os problemas haviam ocorrido e, por is to, registramos 14 retornos a 9 centros de saúde.

3.4.3. Contadas todas as fichas de controle existentes, dividimos o número total pelo número equivalente ao tamanho da amostra, para o centro de saúde em apreço, obtendo, assim, o intervalo a ser obser vado, de uma ficha para outra.

3.4.4. Sorteamos, então, a primeira ficha; se possuísse todos os dados necessários eram eles registrados na Ficha 2, de coleta de dados; passávamos à segunda depois de contado o intervalo a observarse. Quando a primeira ficha sorteada não possuia qualquer dos dados procurados era desprezada e tomávamos a imediata até encontrar uma com os da dos requeridos que eram coletados. Contávamos o intervalo e pegávamos a segunda ficha da amos tra que era considerada quando possuia os dados ou desprezada quando os não possuia. Este proces so foi repetido precisamente até o fim do fichá rio completo, pois a amostra deveria estar dis tribuída igualmente por todo o fichário.

3.4.5. Caso não fosse obtido o número necessário de fi chas ao chegarmos ao fim do fichário, procedía mos de conformidade com a técnica que manda con 
siderar como inicio do intervalo as fichas conti das no fim do fichário e completar esse interva10 com o número indicado de fichas, no início do fichário, ao qual se volta e continua-se a conta gem até completar-se a amostra prevista.

Cada ficha sorteada que continha os dados procu rados foi utilizada, colhendo e lançando no mode 10 próprio - a Ficha 2 - os seguintes dados:

- número de inscrição;

- data da última menstruação ou idade da gesta ção;

- data da inscrição;

- data da primeira consulta médica.

No dia 23 de novembro terminamos a coleta de dados nos centros de saúde. Em alguns deles, devido à pequena quanti dade de inscrições, o tempo gasto entre a localização das fichas e prontuários e o registro dos dados de interesse pa ra estudo, foi de aproximadamente 2 horas. Nas unidades maiores, tipo I e II, foi necessārio dispender um tempoque variou de 6 a 8 horas; entretanto, apezar da baixa classi ficação, num dos centros de saúde tipo IV, só conseguimos organizar o fichário e terminar o levantamento após três retornos e, no último destes, com um trabalho contínuo de 9 horas.

Houve poucas dificuldades de ordem técnica em campo, superadas por meio de entendimentos telefonicos. Os ajus camentos das auxiliares de levantamento foram feitos dia riamente com as colegiais, pessoalmente, em virtude da pro cimidade das suas residencias. Quanto às alunas do Curso de Enfermagem mantivemos com elas, no inicio, uma comunica ção por telefone, diária, e pessoal, a cada três dias,para controle das possíveis dificuldades. Deu-se uma exceção no $3^{\circ}$ dia, quando foi necessário trasmitir-lhes a modifica ção do processo de coleta dos dados. Não houve problemas 
com o grupo.

Algumas dificuldades de natureza administrativa foram registradas no decorrer do inquérito de campo:

- em algumas unidades a visita das auxiliares do le vantamento coincidiu com a realização de campanha de vacinação e nestes casos, tivemos de suspender a visita e voltar no dia seguinte; esta volta, porém, não foi computada como retorno, mas tida em conta de imprevistos não significativos;

- houve dificuldades de comunicação apenas em 6 cen tros de saüde, sendo que em um destes o trabalho foi um tanto bloqueado; todavia, contamos sempre com ex trema compreensão e boa vontade, especialmente da Diretoria do DRS-1, assim como das Regionais e Distritos Sanitários, o que contribuiu para a solu ção satisfatória e imediata de todos os problemas surgidos e para a rapidez com que foi realizado o levantamento.

3.5 Processamento dos dados:

Imediatamente após a coleta dos dados, foi iniciada a sua computação.

$\mathrm{Na}$ primeira fase, calculamos as idades gestacionais a partir da data da última menstruação registrada, unifor mizando os dados e transformando todos em meses de gesta çāo.

Em seguida, quantificamos as inscriçōes havidas em ca da centro de saúde, segundo os meses do ano, de janeiro a setembroe efetuando a somatória de todos os meses.

Fizemos, a seguir, a contagem, em dias, do tempo de es pera de cada gestante incluída na amostra do centro de saú 
de, considerando o tempo decorrido entre a data da sua inscrição e a da sua primeira consulta médica.

Como dados bäsicos, colhidos nos centros de saủde com putamos para utilização posterior:

a) o tempo de espera, que foi lançado num quadro es truturado para este fim, com o objetivo de permi tir a identificação e a comprovação da correlação entre ele e algumas variảveis independentes, confor me se vê no Anexo IV.

b) o número de gestantes inscritas, incluídas na amos tra, computado segundo o trimestre da gestação, a presentado nas Tabelas $9,10,11$ e 12 .

c) a idade gestacional das gestantes da amostra da qual calculamos a média e apresentamos no Quadro 36 segundo os centros de saúde da amostra e as Re gionais em que se localizam;

d) o volume de gestantes inscritas, de janeiroasetem bro, apresentado nas Tabelas de 9 a 12 por cen tro de saúde selecionado, segundo as Regionais.

e) a disponibilidade dos instrumentos nucleares:hora/ médico, hora/enfermeira e hora/obstetriz, com a dis criminação da sua atuação no setor de Saúde Mater na, conforme os Quadros 15, 16, 17 e 18 .

f) a modalidade de atendimento das gestantes visando seu encaminhamento para a primeira consulta médica no pré-natal dos centros de saúde, conforme as $\mathrm{T} \underline{a}$ belas $13,14,15$ e 16 .

Concomitantemente ao levantamento de dados nas unida des sanitärias, buscamos em outras fontes, outras informa çōes necessārias para a identificação e caracterização de algumas variáveis independentes, como o volume de gestan- 
tes esperadas para a ärea programātica dos centros de saú de da amostra, uma vez que, somente para 17 deles, estavam disponiveis estes dados.

Considerando, porém, a necessidade de uniformização dos dados básicos imprescindiveis para investigar-se a cor relação das variáveis, decidimos não utilizar aqueles refe rentes aos 17 centros acima referidos, mas levantar as in formações requeridas sobre as gestantes esperadas para to das as unidades sanitärias focalizadas no levantamento.

Do SEADE - SEPLAN obtivemos a população geral estimada para 1978, para a Grande São Paulo e o município de São Pau 10 .

Numa tentativa de quantificarmos a população feminina em idade fértil estimada para 1978, em São ${ }_{n \rightarrow 0}$ aulo, colhemos informaçōes também no CIS e na FIBGE. Comordispünhamos dos índices de natalidade e natimortalidade do Estado de São Paulo para 1978, conseguimos do SEADE, uma relação dos nas cidos vivos e dos natimortos no ano de $1978 \mathrm{em}$ todas as á reas geográficas dos centros de saúde da amostra.

Em vista disto, para o cálculo da população de gestan tes esperadas para as áreas geográficas dos centros de saúde de interesse deste estudo, de conformidade com a or $\underline{i}$ entação recebida da Disciplina de Saúde Materna, da Facu 1 dade de Saúde Pública da USP, consideramos:

- o número de nascidos vivos, mais

- o número de natimortos, menos

- o percentual ( $1 \%$ ) correspondente aos partos gemel res esperados.

Aos totais obtidos não acrescentamos a taxa de crescí mento vegetativo por julgarmos que ela jā se encontra in clusa no volume dos nascidos vivos e mortos. Esses totais foram utilizados para o cálculo das gestantes esperadas pa 
ra as āreas programáticas dos centros de saúde da amostra.

Para distribuição nessas áreas programāticas, das ges tantes quantificadas nas āreas geogräficas desses centros de saūde, adotamos o seguinte processo:

- Aos centros de saúde atribuímos pesos invertidos em relação à sua classificação, is to é:

- ao tipo I demos peso 5;

- ao tipo II, peso 4 ;

- ao tipo III, peso 3 ;

- ao tipo IV, peso 2 ;

- ao tipo $\mathrm{V}$, peso 1 .

- A seguir, verificamos se na ārea geogräfica estuda da havia outra(s) unidades(s) da rede do DRS-1 e $\underline{\text { a }}$ ceitamos as seguintes possibilidades:

$1^{\circ}$ - não existiam outras unidades; neste caso o pe so do centro de saúde era 1, não importando sua classificação e o número de gestantes espera das para a sua ārea programātica* era idêntico ao da sua ārea geogrāfica**;

$2^{\circ}$ - existiam outras unidades sanitārias da rede do DRS-1, na ārea geogrāfica do centro de saúde. Neste caso, identificávamos todas essas unida des, segundo sua classificação na SES e lhes a tribuímos os pesos arbitrados para o tipo de centro de saúde respectivo. A seguir, somäva

* Area programáti ca é aque la considerada para a cobertura da assistência de saude a ser prestada, delimitada pe los poderes sanitários competentes e indicada nas prō gramações existentes.

* * Area geográfica é aquela definida pelos poderes admi nistrativos do município do Estado, indicada em mapas e documentos oficiais. 
mos todos os pesos das unidades sanitärias identificadas e, por este total, dividíamos o número de gestantes espera das para a área geogrāfica dessas unidades. o resultado des ta operação consideramos como o número de gestantes elemen tar, de peso 1 , o tipo $V$, se houvesse algum; para os cen tros de saúde de outros tipos, multiplicávamos o seu peso pelo número de gestantes atribuído ao tipo $\mathrm{V}$.

Com a finalidade de ilustrar esse processo descrevemos, a seguir, um exemplo:

- numa dada área geográfica, o tipo de centro de saú de, $n^{\circ} \times$ da amostra, era do tipo $I$, portanto com o peso 5 ;

- na mesma ārea geográfica, identificavam-se mais uni dades sanitárias da rede do DRS-1 cujos pesos soma dos, juntamente com o do centro de saúde seleciona do, perfaziam um total de 15 ;

- o nūmero de gestantes esperadas para a ārea geogrā fica dessas unidades era de 20.281;

- este número, dividido por 15, resultava em 1.352 , nú mero equivalente ao das gestantes esperadas para a ārea programática de um centro de saủde mais simpli ficado, o tipo $V$, se aí houvesse algum, devendo a tender, teoricamente, a menor parcela da população;

- como o centro de saúde da amostra tem o peso 5, por ser do tipo I, o número de gestantes para a sua á rea programática será: $1.352 \times 5=6.761$, portanto, a maior parcela das gestantes esperadas, devendo es tar adequadamente equipado para isto.

De acordo com este processo, calculamos as gestantes esperadas para todas as áreas programāticas dos centros de saúde incluídos na amostra.

Em seguida, considerando as metas para a cobertura das 
gestantes esperadas, determinadas pela C.S.C., de acordo com as informaçōes colhidas no Nível Central desta Coorde nadoria, estimamos as gestantes centro dependentes, isto $\vec{e}$, a porcentagem de gestantes esperadas para a ārea que se planejou serem atendidas em 1979 pelos centros de saúde se lecionados. Esta porcentagem, entretanto, foi relativa a 9 meses uma vez que tivemos de delimitar o período do nos so estudo, de $1^{\text {9 de }}$ janeiro a 30 de setembro, em virtude da restrição advinda da não disponibilidade de dados dos me ses de outubro e novembro.

Consideramos o processo descrito acima para cálculo das gestantes esperadas como um dos mais lógicos que foi possível encontrar, tendo em vista que, nas äreas geográfi cas onde só há uma unidade do DRS-1, deve ela atender teo ricamente toda a demanda ou volume de gestantes previstas para cobertura. Por outro 1ado, havendo outras unidades sa nitárias a demanda ou a previsão de cobertura deve ser di $\underline{s}$ tribuída proporcionalmente ao grau de complexidade do cen tro de saúde.

Em se tratando de um estudo personalizado, o critério que adotamos para valorização das unidades, visando a di $\underline{s}$ tribuição da clientela, foi arbitrário, não importando,evi dentemente, na obrigatoriedade da sua aceitação pelos ser viços focalizados nem em crítica ao processo adotado por esses serviços cujo procedimento não nos foi possível co nhecer. 
VII - RESULTADOS E DISCUSSĀO 


\section{VARIAVEL DEPENDENTE}

Para efeito do estudo das associaçōes possíveis da va riável dependente "tempo de espera para consulta" decidimos a presentä-la sempre expressa em dias, mas em dois tempos, sendo em cada um deles sob forma diversa: no primeiro tempo utiliza mos para a análise e discussão do fenōmeno tempo de espera em si, a forma tabular em que o tempo de espera foi dicotomizado em menor que 7 dias ( $<7$ dias) e maior que 7 dias ( 7 dias).

No segundo tempo a apresentação da variāvel dependen te foi feita em gráficos e tabelas e para efeito de estudo das associaçōes foi expressa em dias distribuídos em classes em de corrência da sua apresentação variāvel e irregular.

Passemos aos resultados e às discussōes em primeiro tempo.

Reportando-se a ciari $i^{16,18}$ vemos que se pode medir in diretamente a qualidade de um Serviço de Saúde Materna por meio do conhecimento e anālise da produção de algumas de suas atividades básicas visando a apreciação do equilíbrio entre o seu nü me ro e a sua qualidade.

Segundo expõe Ramos 55 é importante saber-se o grau em que se levou a cabo uma atividade programada, porém esta ativi dade só alcançará o objetivo desejado se a qualidade prevista for conseguida.

Assim $\vec{E}$ que o tempo de espera para a realizaçāo dà primeira consulta médica das gestantes inscritas nos centros de saúde amostrados do DRS-1 para controle pré-natal, pode ser co nhecido quanto à sua existência ou não existência e, sendo um evento quantificável, pode ser medido. Este conhecimento em si teria um valor bastante restrito e provavelmente pouco elucida tipo quanto à situação do serviço, em termos de seus problemas programáticos quantitativos e qualitativos. Entretanto, o estu do desse evento pode ser utilizado como uma medida da qualida- 
de da assistência prestada a essas gestantes, se for analisado tendo em vista suas possíveis associações com alguns atributos da consulta médica que escolhemos como foco por ser, conforme Ciari ${ }^{16}$, a ação por excelência entre o elenco de atividades de senvolvidas para o controle da saúde da gestante.

Diante da importância da complementação da quantidade pela qualidade, decidimos expor nossos achados sobre o fenómeno "tempo de espera de gestantes para a primeira consulta médica no pré-natal" e suas características, em comparação com outros a ele interligados, considerando a possibilidade de se descorti nar o aspecto elucidativo destas comparações em relação à quali dade dos serviços em apreço.

De acordo com esta ordem de idéias relatamos os resul tados obtidos quanto ao tempo de espera salientando os seguintes aspectos :

- estado existencial do tempo de espera nos Centros de Saúde da população amostral;

- caracterização desse tempo de espera quanto a:

- grandeza

- distribuição

- correlação

1.1 Estado existencial do tempo de espera

O tempo de espera de gestantes para a primeira consul ta médica no pré-natal, foi estudado em 56 das 194 Unidades Sanitárias do DRS-1 relacionadas para a amostragem e agrupa das após o sorteio, conforme os Cuadros $1,2,3,4$ e 5 apresen dos no Capítulo VI.

Nessas 56 Unidades Sanitárias, dentre as 8.756 gestan tes inscritas no pré-natal, de janeiro a setembro de 1979 isolamos para estudo, também pelo processo de amostragem, cu jo procedimento foi descrito no capítulo retro citado, 1.795 gestantes que representaram, portanto, aproximadamente $20 \%$ 
da população amostral. A razão porque aumentamos esta amos tra acha-se exposta quando falamos especificamente sobre o assunto, à página 65 .

O tempo de espera identificado em relação à primeira consulta médica destas 1.795 gestantes, foi medido e apre sentado, segundo o trimestre em que foram feitas as inscri ções, os tipos dos centros de saúde sorteados e as Regionais em que se localizavam estes centros nas Tabelas $5,6,7$ e 8

Respondendo às questões colocadas ao difinirmos a va riável dependente neste estudo, temos a seguinte situação:

- o tempo de espera "aceitável", isto é, aquele que se mantém dentro do parâmetro de normalidade - 0 a 7 dias de intervalo entre a inscrição e a primeira con sulta médica - apresenta uma grandeza bastante signi ficativa, nunca inferior a $79 \%$ indo até a $96,51 \%$ do total de inscrições conforme se vê nas Tabelas 5. 6,7 e 8 .

- foi sempre maior que o não aceitáve1, isto é, aquele que ultrapassou de 7 dias o intervalo paramétrico da normalidade, nas 4 Regionais do DRS-1, e nestas Re gionais, também assim se comportou na maioria dos 56 centros de saúde da amostra.

1.2 Grandeza e distribuição do tempo de espera.

Para uma apreciação melhor do comportamento do fenôme no, vejamos sua quantificação e distribuição pelos centros de saúde amostrais, segundo as Regionais.

Por estes resultados (Tabela 5 ) podemos constatar que o tempo de espera aceitável na R.1.1 foi relativo a 194 ges tantes que representam $81,85^{\circ}$ das 237 incluidas nas amostra, com 0 (zero) dias, isto é, sem espera para a pri meira consulta.

o tempo de espera não aceitäve1, nesta Regiona1,1igou- 
se a 43 gestantes, apenas $18,14 \%$ do total, com uma média de 35 dias de intervalo para a primeira consulta médica. Esta ocorrência verificou-se em 3 das 7 unidades da amostra e a sim se distribuiu:

\begin{tabular}{|l|l|l|}
\hline 19 trimestre & $2 \div$ trimestre & $3 \div$ trimestre \\
\hline $\begin{array}{l}23 \text { gestantes } \\
53,490 \text { com 41 dias } \\
\text { de espera }\end{array}$ & $\begin{array}{l}15 \text { gestantes } \\
34,880 \text { com 25 dias } \\
\text { de espera }\end{array}$ & $\begin{array}{l}5 \text { gestantes } \\
11,63 \% \text { com } 35 \text { dias } \\
\text { espera }\end{array}$ \\
\hline
\end{tabular}

$\mathrm{Na}$ R.1.2 (Tabela 6 ) o total de gestantes incluidas na amostra foi de 621 .

Destas, 492 gestantes, $79,23 \%$ do total, não sofreram um tempo de espera anormal, sendo que 274 ou sejam 44,12\% não tiveram espera alguma e 218 , is to é, $35,10^{\circ}$ tiveram uma espera de 2 dias em média, apenas.

Em contraposição, foi nesta Regional onde se verificou - maior número de gestantes com tempo de espera não eceitá ve 1: $20,77 \%$ que em números absolutos corresponde a 129 ges tantes com a média de 25 dias de espera assim distribuidos:

\begin{tabular}{|c|c|c|}
\hline $1^{8}$ trimestre & $2^{\circ}$ trimestre & $3^{\circ}$ trimestre \\
\hline $\begin{array}{l}48 \text { gestantes } \\
7,730 \text { com } 29 \text { dias } \\
\text { de espera }\end{array}$ & $\begin{array}{l}68 \text { gestantes } \\
10,95 \% \text { com } 21 \text { dias } \\
\text { de espera }\end{array}$ & $\begin{array}{l}13 \text { gestantes } \\
2,09 \% \text { com } 30 \text { dias } \\
\text { de espera }\end{array}$ \\
\hline
\end{tabular}

Esta anormalidade ocorreu em 15 das 16 unidades da Re gional sendo que em uma delas atingiu,79,60\% das gestantes inscritas, numa outra, 55,56\% e numa terceira, 25,0\%. Nas de mais o número de gestantes envolvidas decresceu, mas o tem po de espera foi bastante grande, chegando até a 70 dias num dos centros estudados, conforme se vê na Tabela 6 apresen 
TABELA 6 - Tempo de espera para a primeira consulta médica da população mostrada inscrita no prë-natal dos centros de saüde do DRS-1, SP segundo o trimestre da gestação, a Regional e o tipo do centro de saude. SP, 1979.

\begin{tabular}{|c|c|c|c|c|c|c|c|c|c|c|c|c|c|c|c|c|c|c|c|c|c|c|c|}
\hline \multirow{2}{*}{$\begin{array}{l}\text { CF:TRO DE } \\
\text { SivE }\end{array}$} & \multicolumn{6}{|c|}{$1^{\circ}$ TRIMESTRE } & \multicolumn{6}{|c|}{ 20 TRINESTRE } & \multicolumn{6}{|c|}{ 3० TRIMESTRE } & \multicolumn{5}{|c|}{ ToTAL } \\
\hline & \multicolumn{3}{|c|}{$<7$ dias } & \multicolumn{3}{|c|}{$>7$ di as } & \multicolumn{3}{|c|}{$<7$ dias } & \multicolumn{3}{|c|}{$>7$ dias } & \multicolumn{3}{|c|}{$<7$ dias } & \multicolumn{3}{|c|}{$>7$ dias } & \multicolumn{3}{|c|}{$<7$ dias } & \multicolumn{2}{|c|}{$>7$ dias } \\
\hline$C L 255 I \mid y^{\circ} \mathrm{M}$ & CEST & TES & TDIA & CEST & NTES & FEDIA & CES & TES & IEDIA & G:S & NTES & MTEDIA & GRST & TES & MroIA & CEST & TES & MEDIA & CES & AITES & SIDERA & GESTANTES & IENIA \\
\hline SES QUISA & $N^{*}$ & 1 & $\begin{array}{l}\text { ESP. } \\
\text { DIAS }\end{array}$ & $\mathbf{N}^{\circ}$ & 1 & ESP. & $\mathbf{N}^{\mathbf{P}}$ & 1 & $\begin{array}{l}\text { ESP. } \\
\text { DIAS }\end{array}$ & $\mathbf{N}^{0}$ & 1 & $\begin{array}{l}1 \text { ESP. } \\
\text { RIAS } \\
\end{array}$ & Ne & 1 & $\begin{array}{l}\text { ESP. } \\
\text { DIAS }\end{array}$ & $\mathrm{N}^{*}$ & 1 & $\begin{array}{l}\text { ESP. } \\
\text { DIAS }\end{array}$ & $\mathrm{N}^{*}$ & 1 & ESP. & $\begin{array}{lll}\boldsymbol{N} & \mathbf{l}\end{array}$ & $\begin{array}{l}\text { ESP. } \\
\text { DI.iS }\end{array}$ \\
\hline
\end{tabular}

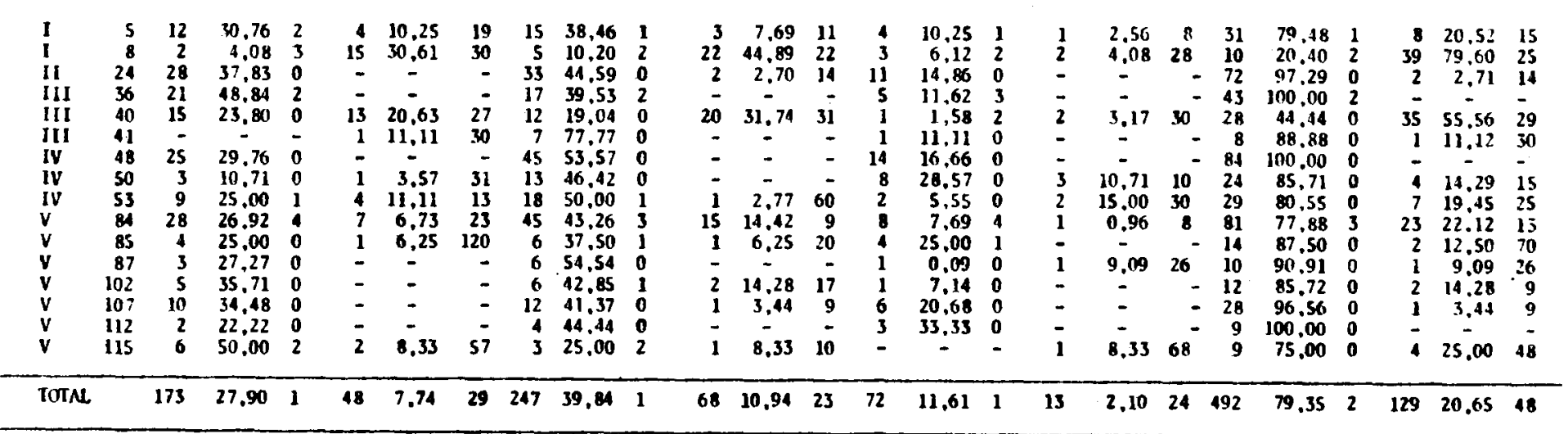


tada.

Outras características interligadas a este fenômeno se rão expostas e discutidas em separado por apresentarem as pecto que assumem importāncia, dada a gravidade de sua influ ência.

Das 201 gestantes estudadas, (Tabela 7) a quase totali dade, 194, equivalendo portanto a $96,51 \%$, não teve tempo de espera, conseguindo a consulta médica no mesmo dia em que se inscreveu, na R.1.3.

Somente 7 gestantes, 3,48\% do total, apresentaram 42 dias de espera em média, sendo que esta espera concentrou se no $1^{8}$ trimestre em que 2 gestantes tiveram um intervalo bastante grande, 27 dias em média e 5 , no $2^{\circ}$ trimestre, com 48 dias em média.

Esse tempo de espera diluiu-se por 7 centros de saúde, atingindo 2 gestantes em 2 deles e 1 gestante nos demais; contudo a espera foi de 11 dias a 69 , em média, o que é um intervalo absurdo, nestas circunstâncias.

A R.1.3 foi a Regional em que o tempo de espera aceitá vel relacionou-se ao maior número de gestantes, $96,51 \%$, sen do, portanto, em média o menor tempo de espera, (Tabela 7).

R.1.4, (Tabela 8 ) Em virtude da sua grande abrangên cia física e do número de unidades que a compōem,esta Regio nal teve o maior número de gestantes inscritas: 736 .

A não espera aqui, foi a segunda em grandeza, relacio nando-se a 702 gestantes, $95,38 \%$ do total. Embora num dos centros de saúde tivesse havido 63 gestantes com um tempo médio de 3 dias de espera e, num outro, 12 gestantes apre sentassem 6 dias de intervalo até à primeira consulta médi ca, esse tempo diluiu-se entre as 23 unidades da Regional e resultou em 0 (zero) dias.

4,62\% das gestantes da Regional, 34 ao todo tiveram um 
TABELA 7 - Tempo de espera para a primeira consulta médica da população amos trada inscrita no pré-natal dos centros de saúde do DRS-1, SP, se gundo o trimestre da gestação, a Regional e o tipo do centro de. saūde. SP, 1979 .

R. 1.3

\begin{tabular}{|c|c|c|c|c|c|c|c|c|c|c|c|c|c|c|c|c|c|c|c|c|c|c|c|c|c|}
\hline \multirow{2}{*}{\multicolumn{2}{|c|}{$\begin{array}{l}\text { G.Tim n: } \\
\text { sidote }\end{array}$}} & \multicolumn{6}{|c|}{10 TRIMESTRE: } & \multicolumn{6}{|c|}{ 20 TRIMESTRE } & \multicolumn{6}{|c|}{ 30 TRIMESTRE } & \multicolumn{6}{|c|}{ TOTAL } \\
\hline & & \multicolumn{3}{|c|}{$<7$ dias } & \multirow{2}{*}{\multicolumn{3}{|c|}{$\begin{array}{l}>7 \text { di as } \\
\text { CESTMTES hEDIA }\end{array}$}} & \multicolumn{3}{|c|}{$\langle 7$ dias } & \multicolumn{3}{|c|}{$>7$ dins } & \multicolumn{3}{|c|}{$<7 \mathrm{djas}$} & \multicolumn{3}{|c|}{$>7$ dias } & \multicolumn{3}{|c|}{$<7$ dias } & \multicolumn{3}{|c|}{$\Rightarrow$ dias } \\
\hline \multirow{2}{*}{$\begin{array}{c}\text { CLASSI } \\
\text { CACAO } \\
\text { SES }\end{array}$} & \multirow{2}{*}{\begin{tabular}{|l|} 
NeMA \\
PES- \\
Quisus \\
\end{tabular}} & \multicolumn{2}{|c|}{ QSTANTES } & \multirow{2}{*}{ 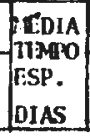 } & CESTMNTES & & \multirow{2}{*}{$\begin{array}{l}\text { EDIA } \\
\text { Trupo } \\
\text { ESP. } \\
\text { DIAS }\end{array}$} & \multicolumn{2}{|c|}{ CESTANTIS } & \multirow{2}{*}{ 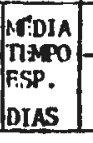 } & \multicolumn{2}{|c|}{ CESTANTEC } & \multirow{2}{*}{$\begin{array}{l}\text { MEDIA } \\
\text { TiNPR } \\
\text { ESP. } \\
\text { DIAS }\end{array}$} & \multicolumn{2}{|c|}{ GESTANTES } & \multirow{2}{*}{$\begin{array}{l}\text { AEDIA } \\
\text { TEMPO } \\
\text { ESP. } \\
\text { DIAS }\end{array}$} & \multicolumn{2}{|c|}{ GESTANTES } & \multirow{2}{*}{\begin{tabular}{|l} 
EEDTA \\
Thav? \\
ESP. \\
DIAS
\end{tabular}} & \multirow{2}{*}{\multicolumn{3}{|c|}{\begin{tabular}{|c|c|c|} 
ESTANTES & EnIA \\
$N^{\circ}$ & 1 & ESTP. \\
\end{tabular}}} & \multicolumn{2}{|c|}{ CESTANTES } & \multirow{2}{*}{ 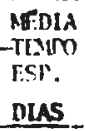 } \\
\hline & & $N^{\bullet}$ & 1 & & L & 1 & & No & 1 & & $\mathrm{~N}^{\circ}$ & 8 & & 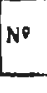 & 1 & & No & 1 & & & & & No & & \\
\hline $\begin{array}{l}1 \\
1 \\
\text { II } \\
\text { II } \\
\text { v } \\
v \\
v \\
v \\
v \\
v\end{array}$ & $\begin{array}{r}12 \\
13 \\
28 \\
43 \\
57 \\
118 \\
119 \\
120 \\
132 \\
135\end{array}$ & $\begin{array}{c}13 \\
15 \\
2 \\
13 \\
4 \\
3 \\
3 \\
1 \\
1\end{array}$ & $\begin{array}{l}34,21 \\
39,97 \\
12.50 \\
20,63 \\
36, .36 \\
50.00 \\
60.00 \\
16.60 \\
50.00\end{array}$ & $\begin{array}{l}\mathbf{0} \\
0 \\
0 \\
0 \\
0 \\
\mathbf{0} \\
\mathbf{0} \\
\mathbf{0} \\
\mathbf{0}\end{array}$ & $?$ & $\begin{array}{l}\vdots \\
\vdots \\
3,27 \\
\vdots \\
\vdots\end{array}$ & $\begin{array}{l}\bar{z} \\
\overline{27} \\
\bar{z}\end{array}$ & $\begin{array}{c}22 \\
14 \\
11 \\
39 \\
5 \\
2 \\
2\end{array}$ & $\begin{array}{l}57,89 \\
36,84 \\
68,75 \\
61,90 \\
45,45 \\
60.00 \\
403,03 \\
550,00 \\
83,33\end{array}$ & $\begin{array}{l}0 \\
0 \\
0 \\
0 \\
0 \\
-0 \\
0 \\
0 \\
0 \\
0\end{array}$ & 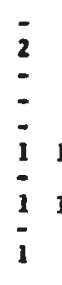 & $\begin{array}{c}5,26 \\
\vdots \\
- \\
16,66 \\
16,66 \\
8,33\end{array}$ & $\begin{array}{l}69 \\
- \\
\text { il } \\
31 \\
58\end{array}$ & $\begin{array}{l}3 \\
7 \\
3 \\
9 \\
2 \\
2\end{array}$ & $\begin{array}{r}7.80 \\
18.42 \\
18.75 \\
14.28 \\
18.18 \\
-0 \\
33.33 \\
.3,33 \\
8,33\end{array}$ & $\begin{array}{l}0 \\
0 \\
0 \\
1 \\
0 \\
1 \\
\vdots \\
1 \\
0\end{array}$ & $\begin{array}{l}5 \\
\vdots \\
\vdots \\
\vdots\end{array}$ & $\vdots$ & $\bar{z}$ & & 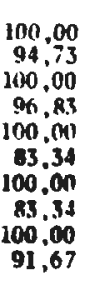 & $\begin{array}{l}0 \\
0 \\
0 \\
0 \\
0 \\
0 \\
0 \\
0\end{array}$ & $\begin{array}{l}2 \\
2 \\
i \\
1 \\
1 \\
i\end{array}$ & $\begin{array}{c}5,26 \\
3.17 \\
16,06 \\
- \\
16,66 \\
8.33\end{array}$ & $\begin{array}{l}69 \\
5 \\
27 \\
11 \\
5 \\
31 \\
58\end{array}$ \\
\hline NOA & 201 & 57 & 28.36 & 0 & 2 & 1,00 & 27 & 108 & 53.73 & 0 & 52 & 12 & 48 & 29 & 1.43 & 0 & - & & & & 6.51 & & & .48 & 12 \\
\hline
\end{tabular}


TABElA 8 - Tempo de espera para a primeira consulta médica da população amos trada inscrita no pré-natal dos centros de saủde do DRS-1, SP, sé gundo o trimestre da gestação. a Regional e o tipo do centro de s aüde. SP, 1979.

\begin{tabular}{|c|c|c|c|c|c|c|c|c|c|c|c|c|c|c|c|c|c|c|c|c|c|c|c|c|c|}
\hline \multirow{2}{*}{\multicolumn{2}{|c|}{$\begin{array}{l}\text { CEITAO IE } \\
\text { Sitie }\end{array}$}} & \multicolumn{6}{|c|}{$1^{\circ}$ TRIMESTRE } & \multicolumn{6}{|c|}{ 20 TRIMESTRE } & \multicolumn{6}{|c|}{$3^{\circ}$ TR IMESTRE } & \multicolumn{6}{|c|}{ TOTAL } \\
\hline & & \multicolumn{3}{|c|}{$<7$ dias } & \multicolumn{3}{|c|}{$>7$ dias } & \multicolumn{3}{|c|}{$<7$ dias } & \multicolumn{3}{|c|}{ I 7 di as } & \multicolumn{3}{|c|}{$<7$ dias } & \multicolumn{3}{|c|}{$>7$ dias } & \multicolumn{3}{|c|}{$<7$ días } & \multicolumn{3}{|c|}{$>7$ dias } \\
\hline \multirow{2}{*}{$\begin{array}{l}\text { CLASSI } \\
\text { CACAO } \\
\text { SES }\end{array}$} & \multirow{2}{*}{$\begin{array}{l}X e N A \\
\text { PeS- } \\
\text { cuISA }\end{array}$} & \multicolumn{2}{|c|}{ GESTANTES } & \multirow{2}{*}{$\begin{array}{l}\text { TIDIA } \\
\text { TEMPO } \\
\text { ESP. } \\
\text { OIAS } \\
\end{array}$} & \multicolumn{2}{|c|}{ GESTANTES } & \multirow{2}{*}{$\begin{array}{l}\text { hEDIA } \\
\text { TTEPO } \\
\text { ESP. } \\
\text { DIAS }\end{array}$} & \multicolumn{2}{|c|}{ GESTANTES } & \multirow{2}{*}{$\begin{array}{l}\text { MTIIA } \\
\text { TEIOO } \\
\text { ESP. } \\
\text { DIAS } \\
\end{array}$} & \multicolumn{2}{|c|}{ GESTNTES } & \multirow{2}{*}{ 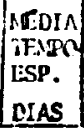 } & GEST & TANIES & MEDIA & GEST & MTES & Firom & GES & TANTES & IIDIA & GESTA & IVTES ! & MEDIA \\
\hline & & No & 1 & & $N$ & 3 & & $N^{*}$ & 1 & & $\mathbf{N}^{*}$ & 1 & & No & 1 & $\begin{array}{l}\text { ESP. } \\
\text { DLAS }\end{array}$ & No & 11 & $\begin{array}{l}\text { ESP. } \\
\text { Dus }\end{array}$ & No & 11 & $\begin{array}{l}\text { ESP. } \\
\text { DIAS }\end{array}$ & No & 1 & $\begin{array}{l}\text { ESP. } \\
\text { DLAS }\end{array}$ \\
\hline I & 17 & 18 & 16.15 & 0 & - & - & - & 27 & 8 & 3 & - & - & - & 4 & & 0 & - & - & - & 39 & & J & & & \\
\hline I & 21 & 8 & 20,00 & 0 & - & & - & 23 & 57,50 & 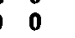 & - & - & - & 9 & & 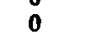 & 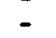 & - & - & 40 & & 0 & $=$ & $=$ & - \\
\hline it & 29 & 16 & 20,77 & 1 & 5 & 6.49 & 25 & 38 & 49.35 & 1 & 6 & 7.79 & 20 & 9 & 11.68 & 1 & 3 & $3 . m$ & 23 & 63 & 81.81 & 3 & 14 & 18.18 & 68 \\
\hline III & $\begin{array}{l}30 \\
45\end{array}$ & $\begin{array}{l}29 \\
15\end{array}$ & $\begin{array}{l}56,86 \\
32,60\end{array}$ & $\begin{array}{l}0 \\
0\end{array}$ & - & : & $\overline{-}$ & $\begin{array}{l}21 \\
22\end{array}$ & $\begin{array}{l}41,17 \\
47,8\end{array}$ & $\begin{array}{l}0 \\
0\end{array}$ & $\overline{5}$ & $1 A^{-}, 86$ & $\overline{9}$ & 1 & $\begin{array}{l}1.96 \\
8.69\end{array}$ & $\begin{array}{l}0 \\
0\end{array}$ & $=$ & $=$ & - & $\begin{array}{l}51 \\
41\end{array}$ & $\begin{array}{r}100.00 \\
89.13\end{array}$ & $\begin{array}{l}0 \\
0\end{array}$ & $\overline{5}$ & 10.86 & $\overline{9}$ \\
\hline III & 46 & 10 & 28.57 & 0 & - & - & - & 24 & 68,37 & 0 & $?$ & 10,80 & - & $i$ & $\begin{array}{l}8.09 \\
2.85\end{array}$ & $\begin{array}{l}0 \\
0\end{array}$ & 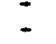 & - & : & $\begin{array}{l}41 \\
35\end{array}$ & $\begin{array}{r}89.15 \\
100.00\end{array}$ & 0 & $\begin{array}{l}5 \\
-\end{array}$ & 10.80 & $\stackrel{9}{-}$ \\
\hline Iv & 59 & 11 & 26,82 & 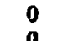 & - & $=$ & $=$ & 23 & 56,09 & 0 & - & - & - & 7 & 17.07 & 0 & - & - & - & 41 & 100.00 & $\mathbf{0}$ & - & - & - \\
\hline IV & 59 & 6 & 25 & 0 & & & & 16 & 66.66 & 0 & - & & & 2 & 8,33 & 0 & - & - & - & 24 & 100 & 0 & - & - & - \\
\hline IV & 67 & 3 & 25,00 & 0 & 2 & 16.66 & 62 & 5 & 41,66 & 0 & - & - & - & 1 & 8.33 & $\mathbf{0}$ & 1 & 8.33 & 30 & 9 & 75.00 & 0 & 3 & 25.00 & 92 \\
\hline IV & 69 & 1 & 11.11 & 0 & - & - & - & 7 & 77.77 & 0 & 1 & 11,11 & 102 & - & - & - & $=$ & $=$ & - & 8 & 88.88 & 0 & $i$ & 11.11 & 102 \\
\hline IV & to & 7 & 20,00 & 0 & - & - & - & 24 & 68,57 & 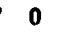 & 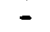 & 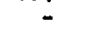 & - & 4 & 11,42 & 0 & - & - & - & 35 & 100.00 & 0 & - & $\because$ & \\
\hline IV & 72 & 13 & 21 & n & - & - & 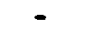 & 34 & 58,33 & 3 & - & - & - & 12 & 20,00 & 0 & - & - & - & 60 & 100 & 0 & - & - & - \\
\hline v & 142 & 24 & 38,09 & 0 & - & - & - & 29 & 46,03 & 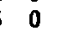 & 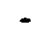 & - & - & 10 & 15.87 & 0 & 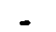 & $\rightarrow$ & - & 3 & & 0 & - & - & - \\
\hline $\mathbf{v}$ & 148 & 17 & 32.07 & o & $\begin{array}{lll}- & \end{array}$ & 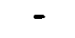 & 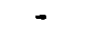 & 24 & 1528 & 0 & & 1.88 & 18 & 30 & & & 1 & $I_{2}$ & 39 & si & 96.22 & 0 & 2 & 3,77 & 57 \\
\hline$v$ & 149 & 3 & & 0 & 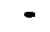 & - & - & 0 & & & & - & - & 3 & 20,00 & $n$ & - & $=$ & - & 15 & & 0 & - & - & - \\
\hline$v$ & 150 & 4 & 30,76 & 0 & 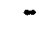 & - & - & 7 & 53.84 & 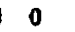 & - & - & - & 2 & 15,38 & 0 & - & - & - & 13 & & 0 & - & - & - \\
\hline$v$ & 158 & 5 & 11,66 & 0 & 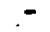 & - & - & 7 & 58.33 & 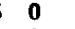 & - & - & - & - & - & - & - & - & - & 12 & 100 & 0 & - & - & - \\
\hline$v$ & 159 & 9 & 50,00 & 0 & - & - & - & 7 & 38. & 3 & - & - & - & 2 & 11.11 & o & - & - & - & 18 & 100.00 & 0 & - & - & - \\
\hline$v$ & 163 & 2 & 33,33 & 0 & 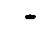 & 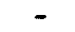 & - & 1 & 16.66 & 0 & 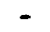 & - & - & 2 & 33,33 & o & 1 & 16.66 & 21 & & 83,33 & 0 & 1 & 16.66 & 21 \\
\hline$v$ & 186 & 14 & 40,00 & 0 & ( & 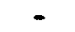 & 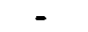 & 16 & 45.71 & 0 & - & - & - & 5 & 14.28 & 1 & 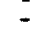 & - & - & 35 & 100,00 & 1 & - & 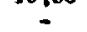 & - \\
\hline$y$ & 187 & II & 30.55 & 1 & $\cdot$ & - & - & 9 & 25.00 & 0 & 5 & 13,88 & 39 & 10 & 27.27 & 0 & 1 & 2.77 & 37 & 30 & 83.33 & 31 & 6 & 16.66 & 76 \\
\hline $\begin{array}{l}y \\
v\end{array}$ & $\begin{array}{l}193 \\
194\end{array}$ & 3 & 23,07 & 1 & $\cdot$ & - & - & 7 & $\begin{array}{l}53.84 \\
33.33\end{array}$ & $\begin{array}{l}2 \\
0\end{array}$ & $\overline{1}$ & 33.33 & 27 & 2 & $\begin{array}{l}15.38 \\
33.33\end{array}$ & $\begin{array}{l}3 \\
0\end{array}$ & $i$ & 7.69 & 23 & $\begin{array}{r}12 \\
2\end{array}$ & $\begin{array}{l}92.30 \\
66.66\end{array}$ & $\begin{array}{l}6 \\
0\end{array}$ & 1 & $\begin{array}{r}7.70 \\
33.33\end{array}$ & $\begin{array}{l}23 \\
27\end{array}$ \\
\hline TOTA & & 229 & 31.11 & 0 & 7 & 0.96 & 36 & 408 & 55.43 & 0 & 19 & 21.00 & 405 & 101 & 13.72 & 0 & 8 & 1.09 & 277 & 702 & 95,38 & 80 & 34 & 4.62 & 59 \\
\hline
\end{tabular}


tempo de espera não aceitável de 59 dias em média com a se guinte distribuição:

\begin{tabular}{|l|l|l|}
\hline 19 trimestre & 29 trimestre & \multicolumn{1}{|c|}{$3^{\circ}$ trimestre } \\
\hline $\begin{array}{l}7 \text { gestantes } \\
20,59 \% \text { com } 36 \text { dias } \\
\text { de espera }\end{array}$ & $\begin{array}{l}19 \text { gestantes } \\
558 \% \text { com } 26 \text { dias } \\
\text { de espera }\end{array}$ & $\begin{array}{l}83,533^{\circ} \text { com } 27 \text { dias } \\
\text { de espera }\end{array}$ \\
\hline
\end{tabular}

o comportamento da variável dependente quanto à distri buição de suas grandezas apresenta alguns aspectos estra nhos.

Não discutiremos ainda as possíveis conclusões a que se poderia chegar em relação à qualidade de um serviço con dicionado por existência ou não existência do tempo de espe ra, e por seu tamanho. Vamos nos ater, por ora, somente ao aspecto da sua distribuição. Numa Regional essa distribui ção toma, por vezes, configuração bastante estranhāvel, có mo ilustra o Quadro seguinte:

QUADRO 6 - Configuração do tempo de espera para a primeira consulta médica de algumas gestantes da amostra segundo a Regional, o nümero do centro de saúde na pesquisa e o intervalo paramétrico. SP, 1979.

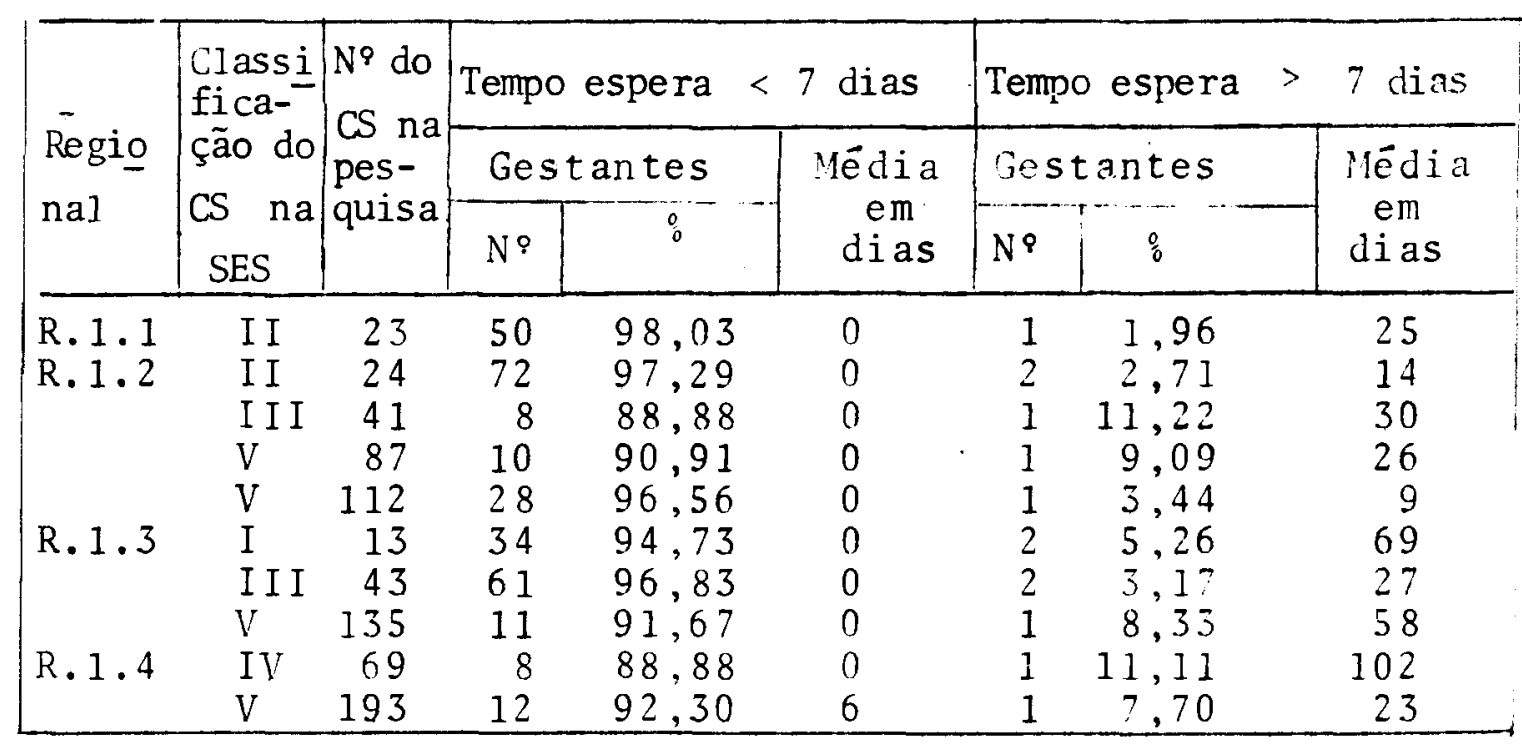


O que causa estranheza é que a constante da Regional sendo a apresentação de um tempo de espera aceitável, muitas vezes sem intervalo, aparecerem a quebrar essa tendência em algumas unidades com uma porção infíma - 1 ou 2 - gestantes com um tempo de espera desrazoável até de 102 dias, como é o caso do CS $n^{9} 69$, tipo IV, na R.1.1.4 incluído no quadro anterior.

Dadas as circunstâncias em que esses fenômeno se apre senta e se repete nas 4 regionais, somos levadas a conject rar sobre a possibilidade de que essa espera, nos casos em apreço, seja condicionada tão somente a fatores ligados às clientes a eles relacionadas, uma ve $z$ que o intervalo para métrico foi o observado na grande maioria das inscriçōes dos centros de saūde onde se registraram essas ocorrências. Po der-se-ia questionar: por que, para a maioria absoluta das gestanteshaveria condições para uma consulta médica sem de mora e deixaria de haver essas mesmas condiçōes só para um número reduzidíssimo que teria de esperar até 102 dias? Se a causa do evento se prende, como parece, a condições da própria gestante, o fato, por sua vez indica problemas bas tante graves, que, entre outros, poderiam ser:

- baixa valorização do controle precoce da gestação pela clientela envolvida;

- insuficiência e/ou deficiência da educação sanitä ria;

- condições de atendimento questionáveis, incluindo se aqui a dificuldade ou auséncia de coordenação cum outros setores assistenciais para encaminhamento à assistência ao parto;

- dificuldades da accessibilidade geogräfica e/ou eco nômica.

Em algumas unidades sanitárias da amostra, entretanto, - comportamento da variável dependente foi bastante diferen te do exposto até aqui, como podemos ver pelo quadro que a seguir, apresentamos. 
QUADRO 6 a - Configuração do tempo de espera para a primeira consulta médica de algumas gestantes da amostra segundo a Regional, o número do centro de saúde na pesquisa e o intervalo paramétrico. SP, 1979.

\begin{tabular}{|c|c|c|c|c|c|c|c|c|}
\hline \multirow{3}{*}{ Regio } & \multirow{3}{*}{$\begin{array}{l}\text { Classi } \\
\text { fi ca- } \\
\text { ção do } \\
\text { CS na } \\
\text { SES }\end{array}$} & \multirow{3}{*}{$\mid \begin{array}{l}N^{\circ} \text { do } \\
\text { CS na } \\
\text { pes- } \\
\text { quisa }\end{array}$} & \multicolumn{3}{|c|}{ Tempo de espera< 7 dias } & \multicolumn{3}{|c|}{ Tempo de espera $>7$ dias } \\
\hline & & & \multicolumn{2}{|c|}{ Gestantes } & \multirow{2}{*}{$\begin{array}{c}\text { Média } \\
\text { em } \\
\text { dias }\end{array}$} & \multicolumn{2}{|c|}{ Gestantes } & \multirow{2}{*}{$\begin{array}{c}\text { Média } \\
\text { em } \\
\text { dias }\end{array}$} \\
\hline & & & $\mathrm{N}$ ? & $\stackrel{0}{0}$ & & $N^{\circ}$ & $\stackrel{0}{0}$ & \\
\hline \multirow[t]{2}{*}{ R. 1.1} & $\mathrm{I}$ & 1 & 16 & 38,09 & 2 & 26 & 61,90 & 34 \\
\hline & V & 81 & 6 & 42,85 & 0 & 8 & 57,14 & 47 \\
\hline \multirow[t]{4}{*}{ R. 1.2} & I & 8 & 10 & 20,40 & 2 & 39 & 79,60 & 25 \\
\hline & I I I & 40 & 28 & 44,44 & 0 & 35 & 55,56 & 29 \\
\hline & V & 84 & 81 & 77,88 & 3 & 23 & 22,50 & 13 \\
\hline & V & 115 & 9 & 75,00 & 0 & 4 & 25,00 & 48 \\
\hline \multirow[t]{3}{*}{ R. 1.4} & I I & 29 & 63 & 81,81 & 3 & 14 & 18,18 & 68 \\
\hline & V & 187 & 30 & 83,33 & 1 & 6 & 16,66 & 76 \\
\hline & V & 194 & 2 & 66,66 & 0 & 1 & 33,33 & 27 \\
\hline
\end{tabular}

Nestes centros de saủde estä evidenciada uma mudança de tendência em que aumenta consideravelmente a grandeza do tempo de espera não aceitável(Quadro 6a) .

Pode provocar dúvidas a inclusão, no quadro acima ex posto, das unidades em que a porcentagem de tempo de espera dentro do parâmetro aceitável foi maior, porém consideramos justificável o procedimento, tendo em vista que houve um nú mero razoāvel de gestantes com tempo de espera bem alëm do normal, mesmo em se tratando do último, o centro de saúde $n^{\text {: }}$ 194, da R. 1.4; nesta unidade, as condições de registro foram tão precárias que, das 43 gestantes cujas fichas de controle foram separadas, só pudemos selecionar as 3 em questão, em virtude das irregularidades encontradas nos prontuários das demais, nos quais, entretanto, a razão do tempo de espera $>7$ dias foi aproximadamente a que se vê no quadro acima, is to é, $1: 2$. 
Com referência a estes centros de saúde o tempo de es pera não aceitável parece prender-se a outros aspectos além daqueles jà referidos, aparentemente ligados só às clientes. Podemos conjecturar sobre os fatores que condicionariam esta problemática; de acordo com Ciari ${ }^{7}$ os sete ejementos consi derados no processo de acreditação de uma unidace sanitária merecem atençāo justamente por influirem fortemerite nas con dições da assistência prestada por elas. No caso desses cen tros de saúde a influência sobre a existência e tamanho do tempo de espera, poderia estar advindo de todos ou de alguns dos elementos, adiante citados, nos quais estariam situadas as insuficiências ou deficiências:

- Planta física \} insuficientes ou inadequados pa

- Recursos materiais\} ra a demanda, sendo portanto, ne cessärio dimensionar o atendimen to diārio de acordo com a capaci dade instalada;

- Recursos humanos: por um lado o volume da demanda po de estar a lém da capacidade dos ins trumentos nucleares; por outro, en tretanto, pode estar havendo sub utilização desses instrumentos; es te fato é ilustrado conforme se po de ver em Adami ${ }^{1}$ em que uma das di ficuldades apontadas para a execuçāo do serviço, a de $n^{\circ} 20$, referese ao pequeno tempo de permanência do médico-chefe no centro de saúde;

- liuncionamento: o horärio de atendimento poderá não estar de acordo com as possibilidades de acesso da clientela;

- Programação: a previsāo das metas com a consequente previsão de recursos pode apresen tar problemas 1 igados ao desconheci mento real da situação da comunidade servidis: 
- Preparo do pessoal: as dificuldades quanto a este item poderiam estar ligadas à deficiência na percepção ou no conhecimento da necessidade do controle precoce da gestação.

Quanto ao sétimo item "atividades profiláticas de âm bito interno", não se aplica diretamente para o estudo do tempo de espera, por isto não o comentamos.

Que problemas poderiam advir, por sua vez, do próprio tempo de espera prolongado? De conformidade com a literatu ra comentada, é indiscutíve 1 a necessidade de se identifi car, o mais perto possível do início da gestação, o grau de risco que as gestantes apresentam. Segundo Ciari Jr. C. et al ${ }^{15}$, Aubry, R.H. \& Pennington,J.C. ${ }^{9}$ e muitos outros auto res, as inscrições das gestantes para o controle pré-natal, quando feitas do segundo trimestre em diante, possibilitam - atendimento apenas de processos evidentes pela sua gravi dade, às vezes jă irreversivelmente instalados, tal é o ca so das anomalias congênitas que podem ser atribuidas a pro b lemas como a sifilis congennita cuja ocorrência Laurenti ${ }^{36}$ a ponta como ainda bastante elevada.

Os especialistas na ārea da saúde materna, tanto os obstetras quanto os sanitaristas, dão a maior ênfase à ne cessidade de se identificar precocemente as gestantes porta doras de alto risco gravídico porque, embora constituam, co mo já citado, um grupo relativamente pequeno dentro do volu me de todas as gestantes, são as responsáveis por uma pro porção muito significativa dos resultados negativos da gra vide $z$, tais como os apresentados na Figura 1 :abortos, fe tos prematuros, complicaçōes da gravidez, mortalidade peri nata1 e outros, segundo Nesbitt ${ }^{46}$.

Numa visão em superfície poderíamos ser levados a con siderar a questão do tempo de espera nas 4 Regionais do DRS1 como um assunto não problemático, portanto, não estaria influindo diretamente na incidência dos eventos negativos 
da gravidez, nem indiretamente no seu agravamento, pois das 1.795 gestantes cujo tempo de espera foi medido nessas 4 Regionais, 1.582 ou sejam $88,18^{\circ}$ tiveram uma espera aceitâa ve 1 , dentro do parâmetro de normalidade e somente 212 ou $11,82 \%$ apresentaram uma espera maior que o intervalo paramé trico.

Este resultado indicaria, se analisado isoladamente, $\underline{u}$ ma situaçàc excelente, porque estes 11,82 : das gestantes sub metidas à espera inaceitâuel para a primeira consulta médi ca são una quantidade pouco significativa, aparentemente, e estão distribuídas em poucis unidades a saber: 4 centros de saủde nos quais a proporção do tempo de espera anormal foi maior que a do normal; em 15 unidades em que a proporção de gestantes atingidas variou de 25 a $7^{\circ}$ e em 11 unidades que apresentaram uma espera referente a grupos de 5 a 1 gestan tes.

As demais unidades, quase a metade dos centros de saú de estudados, ou sejam 25 em 56, apresentaram um tempo de espera norma1.

Não seria difícil, portanto, aplicar de imediato medi das corretivas para ajustar o tempo de espera nas unidades mais atingidas desde que indicadas e exequíveis, como seria - caso das dificuldades que estariam ligadas à instituiçāo, pois que, aquelas referentes ao comportamento das clientes já demandariam mais tempo e ações mais complexas.

Contudo, a questão não nos parece tão simples como po de se apresentar a um primeiro exame.

Antes de mais nada, não sabemos realmente a que se de ve a existência do tempo de espera nos centros de saúde em que foi identificado; essa existência deve ser considerada grave, mesmo se levarmos em conta a pequena significância da sua grandeza em relação à quantidade global de gestantes não submetidas a espera, pois a este aspecto prende-se ou tro ainda mais ponderável: tambẻm ignoramos quantas das ge 
tantes que apresentaram um tempo de espera inaceitável, e tariam incluídas no grupo de alto risco, podendo, portanto, ser altamente prejudicadas. E quantas destas gestantes -que são 11,828 do tota1 - estariam perfazendo os $30 \%$ esperados de alto risco, responsāvel pela estatística indesejāvel de resultados negativos da gravidez? Estas consideraçōes nos levam a conjecturar que, na verdade não deve haver tempo de éspera inaceitável para gestante alguma e que, mesmo uma quantidade pequena, como a identificada nas unidades da mostra, assume proporções de grande significância relativa, devido à gravidade que o fenômeno pode apresentar.

Além destas ponderações relacionadas a aspectos do pro blema que exigiriam um estudo estrutural, em profundidade, há outras ligadas a questōes cujo conhecimento foi viável, podendo alterar bastante, senão completamente, a primeira visão dos resultados expostos. Referimo-nos a alguns aspec tos do contexto em que está inserida a problemática do tem po de espera - normal ou anormal - das gestantes inscritas para o pré-natal nos centros de saúde amostrados.

Embora não fosse o objeto fundamental deste trabalho o conhecimento exaustivo de outros aspectos da assistência materna nesses centros de saúde, considerando o impasse que resultaria do conhecimento isolado da existência e da gran deza do tempo de espera, mereceu-nos reparo a possibilidade de identificarmos associaçōes que elucidariam a dicotó mia com que o fenômeno se apresentava segundo a nossa obser vação, prévia ao levantamento.

Objetivamos, por isto, a coleta concomitante de dados sobre alguns fatores que constituiram as variáveis indepen dentes e que poderiam estar provocando, condicionando, agra vando ou apenas explicando as variaçōes do tempo de espera. 


\section{VARIAVEIS INDEPENDENTES}

Consideramos que o tempo de espera aceitável, normente quando identificado nas proporções encontradas neste estudo, poderia ser uma medida da boa qualidade da assistência prestada, desde que outros indicadores dessa qualidade, considerados de grande valor na sua avaliação segundo Ramos 55 , Ciari et al 16,19 Giron $^{29}$ eschor ${ }^{60}$, apresentassem igualmente o mesmo comportamento, isto é, manifestassem indícios de ligarem-se a um atendimento satisfatório das necessidades de saúde da população alvo, apre sent ando:

- um alcance desejāvel das metas de cobertura e con centração;

- um grau de utilização razoāvel dos instrumentos dis poníveis.

Seria uma discrepância manter um tempo de espera ace $\underline{i}$ távelàs custas de uma baixa cobertura e da utilização inadequada dos instrumentos.

Em outras palavras, como se comportaram nos centros de saúde da amostra: a cobertura alcançada frente à programada, a concentração obtida em face da normalizada, a utilização real dos recursos disponíveis versus a utilização esperada? Qual foi a idade média em que as gestantes visadas pelas atividades pro gramadas e cujo tempo de espera para receberem essa assistência foi medido, inscreveram-se nos serviços?

Interessou-nos também pesquisar, por razões que ex poremos oportunamente, certas circunstâncias da accessibilidade que cercaram os centros de saúde envolvidos no estudo.

Desta forma foi possivel determinar as variáveis inde pendentes com as quais presumimos associações significativas da variävel "tempo de espera" e as relacionamos na seguinte ordem em que foram analisadas e discutidas:

- condições de acessibilidade apresentadas pelos cen- 
tros de saúde da amostra, segundo sua localização geogräfica e sua classificação na S.E.S.;

- grau de alcance das metas de cobertura previstas pa ra as gestantes, segundo os tipos dos centros de saúde estudados e as Regionais em que se localizam;

- disponibilidade dos instrumentos nucleares responsá veis pelas consultas médicas e pelos atendimentos de enfermagem, segundo os centros de saúde da amos tra e as respectivas Regionais;

- trimestre da gestação ao tempo da inscrição das ges tantes amostradas, segundo os centros de saúde foca lizados e as Regionais de origem;

- modalidade de atendimento das gestantes nos centros de saúde da amostra visando seu encaminhamento para a primeira consulta médica no pré-natal;

- grau de alcance da meta normalizada para a concentração das consultas médicas e dos atendimentos de en fermagem;

- atuação do instrumento nuclear responsável pela consulta médica e pelo atendimento de enfermagem;

- grau de utilização do instrumento hora/médico;

- média da idade gestacional na inscrição. 


\section{TESTE DE ASSOCIAÇĀO DAS VARIÁveIS}

Por ser a variảvel de interesse quantitativa e expres sa numa escala de razão, a saber:

$$
\begin{aligned}
& -0-\text { dias } \\
& -1-10 \text { dias } \\
& -11-20 \text { dias } \\
& -21-40 \text { dias } \\
& -41-80 \text { dias } \\
& -81-120 \text { dias }
\end{aligned}
$$

a prova mais poderosa para verificação das hipóteses de traba Iho-relação entre o tempo de espera da consulta e outras variá veis, seria a anälise de variância, que permite comprovar ${ }^{47}$ :

a) a existência de diferença significativa entre as médias de dois ou mais grupos; e

b) a influência de fatores e suas interrelações sobre uma variável de interesse.

A par de sua versatilidade e sensibilidade, porém, a

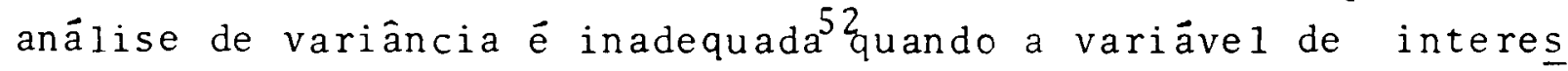
se não se comporta como uma distribuição normal dentro de cada agrupamento determinado pelas variáveis independentes. E esse é o caso da variável tempo de espera da consulta que, sob todos os fatores selecionados, tem distribuição marcadamente assimé trica, como se pode ver nas Tabelas, 17,19,21,23 e 25.

A solução foi, portanto, voltar-se para uma tẻcnica não-paramétrica, cujas conclusões independem da forma de distri buição apresentada pela população que se estuda na amostra.

0 teste escolhido, dada a clara dicotomização das a mostras (tempo de espera excedente e não excedente de zero dias), foi uma extensão da prova da mediana para k grupos inde pendentes: 
Esta prova consiste em dicotomizar a variāvel dependen te em valores que não excedem a mediana e valores que a excedem. Constroem-se, a seguir, tabelas de contingencia da forma $k x 2$ em que $o k$ é $o$ nümero de classificaçāo da variāvel independente sob anālise.

A hipótese de nulidade - as amostras provêm da mesma população, em relação à mediana - é testada mediante o emprego do $x^{2}$, definido por:

$$
x^{2}=\sum_{i=1}^{2} \sum_{j=1}^{k} \frac{\left(0_{i j}-E_{i j}\right)^{2}}{E_{i j}}
$$

com grau de liberdade igual a:

$$
g=(2-1)(k-1)
$$

sendo:

$0_{i j}=$ a frequência observada e inscrita na casa corres pondente à linha $i$ e à coluna $j$ da tabela de con tingência;

$E_{i j}=\frac{N_{n} \cdot n_{j}}{N} e_{\text {è a frequência esperada, sob a hipótese nu }}$ lativa à frequência observada ${ }_{i j}$, onde :

$\mathrm{N}_{\mathrm{i}} \overline{\mathrm{e}}$ a frequência marginal da coluna $i$,

$\mathrm{N}_{\mathrm{j}} \overline{\mathrm{e}}$ a frequência marginal da coluna $\mathrm{j}$; e

$\mathrm{N}$ è o número total de observaçōes

$k \vec{e}$ o número de coluna da tabela de contingência.

O nivel de confiança da decisão estatística é, em to dos os casos de 958, o que corresponde a um erro tipo I (nivel de significância) de $58(x=0,05)$. 
3.1 Condições de accessibilidade apresentadas pelos cen tros de saúde da amostra, segundo sua localização geo gráfica e sua classificação na S.E.S.

Segundo destaca o Documento Oficial $\mathrm{n}^{9} 155$ da OPAS ${ }^{57}$, uma das primeiras condições exigidas dos serviços de saúde para que possam satisfazer as necessidades de saúde da pop lação a que servem é que sejam accessíveis, Não se trata,pó rém, da accessibilidade em sentido restrito e sim nasuasig nificação mais ampla, englobando três elementos principais de que trataremos parceladamente; o primeiro, apropriado à discussão desta variáve1, refere-se à "existência de una ferta contínua e sistemática de serviços proporcionados por um conjunto de recursos combinados e destinados geográfica, economica, cultural e funcionalmente ao alcance das comuni dades" 57 . Aos dois outros elementos que integram o con ceito de accessibilidade faremos referências nos próximos itens.

O significado da accessibilidade nos diversos aspe tos citados pode ser entendido como segue:

- geográfica: inclui os aspectos da distância a que se encontra o serviço,do tempo necessạ rio para atingi-10 e dos meios de trans porte existentes até o local;

- econômica: designa a ausência de barreiras derivadas do sistema de aquisição dos serviços: pagamentos e contribuições;

- cultura 1: refere-se à ausência de barreiras entre as normas técnicas e administrativas dos serviços e os padröes culturais, os hä bitos e costumes da população usuária;

- funcional: diz respeito à provisão de servicos o portunos, permanentes, com horārios adequados às necessidades, anropriados na ra satisfação da demanda real e com mecanismos de referências adequados. 
Como podemos ver, este é um conceito complexo que se prestaria sozinho a um inquérito de grandes dimensões em am plitude e profundidade. Por serem de interesse imediato pa ra a caracterização de algumas variáveis, destacamos somen te dois dos aspectos citados: o geográfico e o funcional re lacionado à propriedade para satisfação da demanda.

Quanto aos aspectos geográficos os centros de saúde da amostra apresentam,todos, condições satifatórias de access $\underline{i}$ bilidade, segundo os critérios enunciados pelo Documento re tro citado 57 :

- todos foram facilmente atingidos por ocasião do in quérito de campo; em relação à população alvo da área programática desses centros de saúde essas con dições de accessibilidade estão bem configuradas:as unidades sanitärias foram implantadas em äreas es tratégicas para satisfazer o critério de fácil aces so.

As 4 Regionais da DRS-1 dão cobertura a toda a gran de São Paulo distribuindo-se por todos os pontos cardeais:

- a R.1.1 abrange a área do município da Capital,por tanto situa-se no centro da Grande São Paulo;

- a R.1.2 cobre uma pequena parte da zona nordeste e a zona leste;

- a R.1.3 atende a população da zona sudeste e uma porção dos residentes da zona sul;

- a R.1.4 tem sua rede de unidades distribuída por uma parte da zona norte, pela zona oeste e pela sul doeste.

Essas áreas são servidas por inúmeras emprezas de ria a ção coletiva e às vezes por ferrovias e pelo metrô. Como as unidades são situadas em pontos estratégicos o tempo de a cesso para a população alvo é razoáve j.

Apesar dos indícios de normalidade da accessibilidade 
geográfica apontados pelos critérios discutidos anteriormen te, decidimos ampliar o estudo dessa accessibilidade levan tando dados relacionados a outras de suas facetas.

Com estes dados que nos permitiram estimar a população alvo das unidades sanitárias amostrais e identificar a clas sificação destas unidades, conforme apresentamos no capítú lo VI, subcapitulo 2 "Amostra", estruturamos as bases para - conhecimento do tempo de espera apresentado nas Tabelas $5,6,7$ e 8 . Os resultados finais foram utilizados pa ra o estudo do relacionamento das variações desse tempo de espera com a localização geográfica e a classificação das unidades sanitärias, conforme apresentaremos e discutire mos a seguir.

3.2 Relação com a localização dos centros de saúde

A Tabela 17 apresenta as gestantes segundo o tempo de espera da consulta e as regiões em que estão localizados os centros de saūde.

Para aplicação do teste da mediana - considerando que o tempo de espera mediano é 0 dias - os dados foram reelabo rados como mostra a Tabela 18 .

o valor calculado de $x^{2}$ é de 329,762 , superando, por tanto, o valor tabulado 27 para 3 graus de liberdade e níve 1 de significância de $5 \%$, que é 7,815 . Pode-se, assim, reje tar a hipótese nula.

Conclui-se, então, que o tempo de espera está associa do à localização do centro de saúde. Os elementos da Tabela 18 permitem afirmar que, nos centros de saúde da região R.1.2,aproporção das gestantes com tempo de espera superior à mediana é significantemente maior que a esperada.

A importância do estudo desta associação está nas se guintes razões: 
- necessidade de se localizar e delimitar problema o peracional qual é:o tempo de espera;

- disponibilidade para que no futuro, se/ou quando for de interesse, se usem essa localização e essa delinitação como subsídios com o fim de esclarecer problemas considerados prioritärios, principalmente nos aspectos que se interligarem com o alto risco gravídico.

Segundo Anderson, U.M. et al ${ }^{6}$, è de suma importância a identificação dos segmentos da comunidade que são porta dores do alto risco e que, por isto, carecem mais dos servi ços de saúde materna. Localizando-se geograficamente esta população serä possível racionalizar o dimensionamento e a distribuição dos recursos necessários para o seu tratamento e controle. 
TABELA 17 - Gestantes segundo o tempo de espera da consulta e as regiões dos Centros de Saúde. SP, 1979.

\begin{tabular}{|c|c|c|c|c|c|}
\hline \multirow{2}{*}{\multicolumn{2}{|c|}{$\begin{array}{l}\text { IEMPO DE } \\
\operatorname{ESPER}(\mathrm{d} \text { ias })\end{array}$}} & \multicolumn{4}{|c|}{$R \quad E \quad G \quad I \quad O \quad E S$} \\
\hline & & $\mathrm{R} 1-1$ & $R 1-2$ & $R 1-3$ & $R 1-4$ \\
\hline \multicolumn{2}{|l|}{0} & 180 & \multicolumn{2}{|l|}{303} & 643 \\
\hline 1 & -10 & 17 & 185 & 16 & 21 \\
\hline 11 & -20 & 4 & 29 & 1 & 4 \\
\hline 21 & -40 & 28 & 51 & - & 8 \\
\hline 41 & -80 & 6 & 12 & 2 & 6 \\
\hline 81 & -120 & 2 & 3 & 1 & 1 \\
\hline \multicolumn{2}{|c|}{ TOTAL } & 237 & 583 & 185 & 683 \\
\hline
\end{tabular}


TABELA 18-Gestantes segundo a mediana do tempo de espera da consulta e as regiōes do Centro de Saúde (teste da mediana). SP, 1979.

\begin{tabular}{|c|c|c|c|c|c|}
\hline \multirow{2}{*}{$\begin{array}{l}\text { POS IÇAO RE- } \\
\text { LAT IVAMENTE } \\
\text { A MEDIANA } \\
\text { COMUM }\end{array}$} & \multicolumn{4}{|c|}{$R E G I O E S$} & \multirow{2}{*}{ TOTAI } \\
\hline & $\mathrm{R} 1-1$ & $\mathrm{R} 1-2$ & $R 1-3$ & $R 1-4$ & \\
\hline Não excedem & $\begin{array}{c}180 \\
(181,26)\end{array}$ & $\begin{array}{c}303 \\
(445,88)\end{array}$ & $\begin{array}{r}165 \\
(141,49)\end{array}$ & $\begin{array}{c}643 \\
(522,37)\end{array}$ & 1.291 \\
\hline Exce dem & $\begin{array}{c}57 \\
(55,74)\end{array}$ & $\begin{array}{c}280 \\
(137,12)\end{array}$ & $\begin{array}{r}20 \\
(43,51)\end{array}$ & $\begin{array}{c}40 \\
(160,63)\end{array}$ & 397 \\
\hline TOTAL & 237 & 583 & 185 & 683 & 1.688 \\
\hline
\end{tabular}

Nota: os números entre parênteses são as frequências esperadas sob a hipótese nula.

$$
x^{2} \text { calc. }=329,762
$$


3.3 Variável independente - Tipo de Centro de Saúde

Os dados relacionados à variável "Tipos de Centros de Saúde" estão apresentados em Quadros e Tabelas.

Nesses quadros se identificam todos as unidades sanitärias incluídas no estudo, distribuídas segundo sua classi ficação na S.E.S., isto é, os tipos, segundo os distritos sanitários a que pertecem e as Regionais em que se locali$z$ am. A apresentação tomou a seguinte modalidade:

$$
\begin{aligned}
& \text { Quadron: } 1 \text { - relaciona os Centros de Saúde Tipo I } \\
& \text { Quadron: } 2 \text { - relaciona os Centros de Saúde Tipo II } \\
& \text { Quadron: } 3 \text { - relaciona os Centros de Saúde Tipo III } \\
& \text { Quadron: } 4 \text { - relaciona os Centros de Saúde Tipo IV } \\
& \text { Quadron: } 5 \text { - relaciona os Centros de Saúde Tipo V }
\end{aligned}
$$

Para caracterizar a variável também utilizamos os da dos referentes à quantificação do tempo de espera nesses cen tros de saúde, tal como está apresentada nas tabelas do nú mero 5 ao número 8 .

Todos estes dados foram processados manualmente e lan çados num quadro, conforme se vê no Anexo IV para que se ti vesse o computo do tempo de espera das gestantes inscritas nesses centros, no período escolhido, dentro das situações escolhidas para estudo, entre elas a sua localização confor me o tipo de unidade sanitária.

A partir dos resultados obtidos foi feito o teste da relação do tipo de centro de saúde com a variável dependen te, o tempo de espera. 
3.3.1 Teste da relação com o tipo de Centro de Saúde

As gestantes classificam-se, segundo o tempo de espera da consulta e o tipo de centro de saúde, conforme mostrado na Tabe1a 19.

O teste da mediana foi aplicado sobre os dados reela borados da Tabe 1a 20 .

O valor calculado de $x^{2}$ é de 124,351 , que é maior que o valor tabulado $(9,488)$ para 4 graus de liberdade e níve de confiança de $95 \%$. Pode-se, entāo, rejeitar a hipótese nula.

Conclui-se, assim, pela existência de associação en tre as duas variāveis. Verifica-se, da Tabela 20 que a propor ção das gestantes dos CS-I e dos CS-V com tempo de espera maior que o mediano é significativamente superior à esperada.

TABELA 19 -Gestantes segundo o tempo de espera da consulta e o tipo de Centro de Saüde. SP, 1979.

\begin{tabular}{|c|c|c|c|c|c|}
\hline \multirow{2}{*}{$\begin{array}{l}\text { TEMPO DE } \\
\text { ESPERA } \\
\text { (dias) }\end{array}$} & \multicolumn{5}{|c|}{ TIPO DE CENTRO DE SAODE } \\
\hline & $\mathrm{CS}-1$ & CS. -2 & $\mathrm{CS}-3$ & $C S-4$ & $C S-5$ \\
\hline 0 & 155 & 263 & 208 & 293 & 372 \\
\hline $1-10$ & 44 & 26 & 40 & 11 & 118 \\
\hline $11-20$ & 17 & 7 & 4 & 4 & 6 \\
\hline $21-40$ & 42 & 5 & 27 & 3 & 10 \\
\hline $41-80$ & 7 & 3 & 4 & 3 & 9 \\
\hline $81-120$ & 3 & - & - & 1 & 3 \\
\hline TOTAL & 268 & 304 & 283 & 315 & 518 \\
\hline
\end{tabular}


TABELA 20-Gestantes segundo a mediana do tempo de espera da consulta e o tipo de Centro de Saúde (teste da mediana). Sl, 1979.

\begin{tabular}{|c|c|c|c|c|c|c|}
\hline \multirow{2}{*}{$\begin{array}{l}\text { POSIÇAO RELATI } \\
\text { VAMENTE A ME- } \\
\text { DIANA COMUM }\end{array}$} & \multicolumn{5}{|c|}{ TIPO DE CENTRO DE SAODE } & \multirow{2}{*}{ TOTAL } \\
\hline & $C S-1$ & $\mathrm{CS}-2$ & $C S-3$ & $\operatorname{CS}-4$ & $C S-5$ & \\
\hline Não excedell & $\begin{array}{r}155 \\
(204,97)\end{array}$ & $\begin{array}{c}263 \\
(232,50)\end{array}$ & $\begin{array}{c}208 \\
(216,44)\end{array}$ & $\begin{array}{c}293 \\
(240,92)\end{array}$ & $\begin{array}{c}372 \\
(396,17)\end{array}$ & 1.291 \\
\hline Excedem & $\begin{array}{r}113 \\
(63,03)\end{array}$ & $\begin{array}{c}41 \\
(71,50)\end{array}$ & $\begin{array}{c}75 \\
(66,56)\end{array}$ & $\begin{array}{c}22 \\
(74,08)\end{array}$ & $\begin{array}{c}146 \\
(121,83)\end{array}$ & 397 \\
\hline TOTAL. & 268 & 304 & 283 & 315 & 518 & 1.688 \\
\hline
\end{tabular}

Nota: os nümeros entre parênteses são as frequências esperadas sob a hipótese nula. $x^{2}$ calc. $=124,351$ 
A relaçāo da variável tempo de espera com o tino de centro de saūde por um lado pode ser facilmente explicada, mas por outro é aparentemente destituída de lógica.

Como jả foi visto no item 3 (Procedimentos) do Capítú lo VI(Material e Método) os centros de saúde apresentam pro gramas de trabalho variáveis em decorrência de sua complexi dade e, esta, por sua vez, cresce em razão inversa do número de classificação do centro de saúde, sendo tanto maior quanto menor for este número. Esse aumento de complexidade pode se traduzir em aumento de demanda e esta, em aumento de espera para consulta.

Outro fator que certamente atua como condicionante na associação positiva, como foi vista, é o fato de que a popu laçāo alvo dos centros de saúde é esperadamente maior à me dida que cresce a complexidade prevista para atendimeento se gundo o tipo da unidade.

Assim sendo, um centro de saúde deve atender ur deter minado número de gestantes de acordo com a estimativa basea da no índice de nascimentos adotado para a ärea relacionada à população desta área; se a população é crescentemente ma ior conforme os tipos, explica-se logicamente que nos cen tros de saúde tipo I que mais se aproximem das metas norma lizadas de cobertura e concentração, o volume de atendimento possa fazer variar para mais o tempo de espera, como se vê no centro de saúde $n^{\ominus} 1$ da R.1.1.

Para visualizar bem esta situação assim como outras que se evidenciaram no decorrer deste trabalho estruturamos quadros de comparação do tempo de espera identificado com os percentuais alcançados de cobertura, concentraçāo, RI e grau de utilização dos instrumentos, como também a mé dia da idade gestacional ao tempo da inscrição.

Os dados desses quadros foram mostrados segundo as Regionais e os tipos de centro de saúde e receberam numera ção de 19 a 27 , sendo apresentados neste subcapítulo. 
QUADRO 19 - Comparação do "tempo de espera" com os percentuais alcançados de cober tura da consulta médica, rendimento instrumental, grau de utilização do instrumento e média da idade gestacional ao tempo de inscrição e a con centração alcançada. SP, 1979.

\begin{tabular}{|c|c|c|c|c|c|c|c|c|c|}
\hline \multirow{2}{*}{\multicolumn{2}{|c|}{ 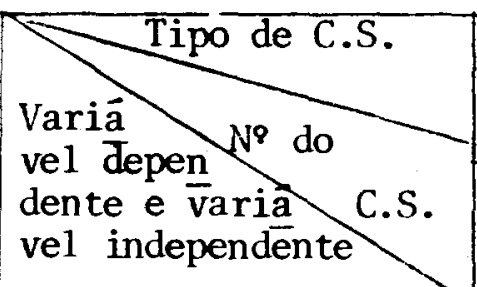 }} & I & I I & I I & I I I & I I I & V & V & Regional \\
\hline & & 1 & 22 & 23 & 34 & 35 & 75 & 81 & Global \\
\hline \multirow{2}{*}{$\begin{array}{l}\text { Tenpo de } \\
\text { espera }\end{array}$} & de 7 dias & 38,9 & 78,94 & 98,03 & 100,0 & 100,0 & 100,0 & 42,85 & 81,85 \\
\hline & de 7 dias & 61,90 & 21,08 & 1.96 & - & - & - & 57,14 & 18,14 \\
\hline \multirow[t]{2}{*}{ Cobertura } & $\begin{array}{l}\text { gobre vo } \\
\text { lume gest } \\
\text { ärea prog }\end{array}$ & 40,33 & 22,22 & 13,37 & 4,95 & 3,49 & 8,16 & 15,15 & 15,38 \\
\hline & $\begin{array}{l}\text { sobre vo } \\
\text { lume ges } t \\
\text { centro dep }\end{array}$ & 89,58 & 49,12 & 29,70 & 11,01 & 7,75 & 18,14 & 33,16 & 34,06 \\
\hline \multirow[t]{2}{*}{$\begin{array}{l}\text { Instrumen- } \\
\text { to nuclear }\end{array}$} & $\begin{array}{l}\text { Rendimen } \\
\text { to }\end{array}$ & 1,45 & 0,17 & 0,17 & 1,65 & 0,95 & 1,25 & 4,70 & 1,48 \\
\hline & $\left\{\begin{array}{l}\text { Grau de } \\
\text { utiliza- } \\
\text { ção }\end{array}\right.$ & 0,24 & 0,03 & 0.03 & 0,28 & 0,16 & 0,21 & 0,78 & 0,25 \\
\hline \multicolumn{2}{|c|}{$\begin{array}{l}\text { Media de idade gest. } \\
\text { ao tempo da inscricão }\end{array}$} & $3 \mathrm{~m} \mathrm{IId}$ & $4 \mathrm{~m} \quad 6 \mathrm{~d}$ & $4 \mathrm{~m} \quad 5 \mathrm{~d}$ & $4 \mathrm{~m} 13 \mathrm{~d}$ & $3 \mathrm{~m} \mathrm{22d}$ & $3 \mathrm{~m} \quad 9 \mathrm{~d}$ & $3 \mathrm{~m} 28 \mathrm{~d}$ & $3 \mathrm{~m} 26 \mathrm{~d}$ \\
\hline \multicolumn{2}{|c|}{$\begin{array}{c}\text { CPncentryação } \\
\text { alcance } \\
\text { alcau de }\end{array}$} & & & & & & & & $\begin{array}{r}2 \\
0.7\end{array}$ \\
\hline
\end{tabular}


QUADRO 20 - Comparação do "tempo de espera" com os percentuais alcançados de có bertura da consulta médica, rendimento instrumental, grau de utilí $z$ ação do instrumento e média da idade gestacional ao tempo de ins crição e a concentração alcançada. SP, 1979.

R.1.2

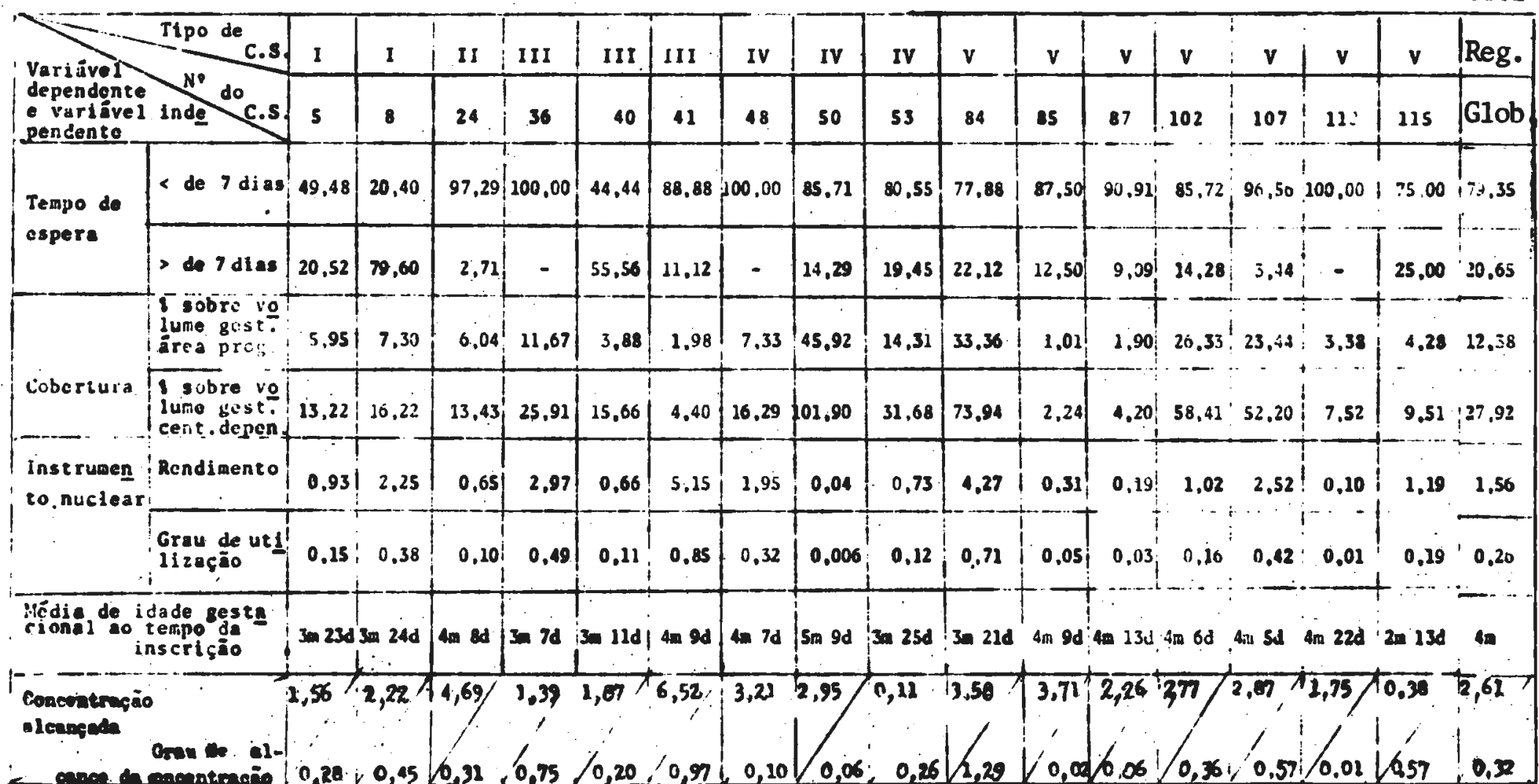


QUADRO 21 - Comparação do "tempo de espera" com os percentuais alcan çados de cobertura da consulta médica, rendimento instrumental, grau de utilização do instrumento e média da ida de gestacional ao tempo da inscrição e a concentração al

\begin{tabular}{|c|c|c|c|c|c|c|c|c|c|c|c|c|}
\hline \multirow{2}{*}{\multicolumn{2}{|c|}{ 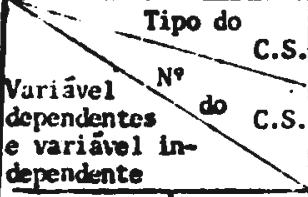 }} & I & I & II & III & IV & $\mathbf{v}$ & $\mathbf{v}$ & v & $\mathbf{v}$ & $v$ & Reg. \\
\hline & & 12 & 13 & 28 & 43 & 57 & 118 & 119 & 120 & 132 & 135 & Glob. \\
\hline \multirow{2}{*}{$\begin{array}{l}\text { Tempo } \\
\text { de } \\
\text { espere }\end{array}$} & de 7 dias & 100,00 & 94.73 & 200.00 & 96.83 & 100.00 & 83.84 & 100,00 & 83,34 & 100,00 & 91.67 & $96.51^{\circ}$ \\
\hline & pde 7 dias & - & 5,27 & - & 3.17 & - & 16.66 & - & 16.66 & - & 8.33 & 3.49 \\
\hline \multirow{2}{*}{ Cobertura } & $\begin{array}{l}\text { B suhre vo } \\
\text { lime gest. } \\
\text { Erea prog. }\end{array}$ & 0.51 & 1,40 & 1.40 & 9.24 & 7.51 & 3,85 & 10,52 & 30.78 & 4,23 & 1.27 & 7.07 \\
\hline & $\begin{array}{l}\text { pisobre vo } \\
\text { pilune gest. } \\
\text { fent.dep. }\end{array}$ & 1,14 & 8,17 & 3,11 & 20.52 & 16.92 & 8.55 & 23.33 & 68,20 & 9.43 & 2.83 & 16.21 \\
\hline \multirow[t]{2}{*}{$\begin{array}{l}\text { Inst rumento } \\
\text { nuclear }\end{array}$} & $\begin{array}{l}\text { Rendinen } \\
\text { to }\end{array}$ & 0,12 & 0.58 & 0.26 & 3.31 & 0.29 & 0.40 & 0.76 & 1.77 & 0.09 & 0.06 & 0.76 \\
\hline & $\left|\begin{array}{c}\text { Grau de } \\
\text { rilizaçä }\end{array}\right|$ & $0 ; 02$ & 0,09 & 0.04 & 0.55 & 0.04 & 0.06 & 0.12 & 0.29 & 0.015 & 0.01 & 0.12 \\
\hline \multicolumn{2}{|c|}{ 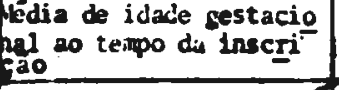 } & $4 m 6 d$ & 3in $29 d$ & 4m 23d & $4 \pi 9 d$ & $4 \pi 2 d$ & $42 \mathrm{~d}$ & 3a 22d & 5m 3d & 3m 29d & 4230 & \\
\hline & & & & & & & & $\gamma$ & & & & \\
\hline
\end{tabular}


QUADRO 22 -Comparação do "tempo de espera" com os percentuais alcançados de cobertura da consulta médica, rendimento instrumental, grau de utilização do instrumento e média da idade gestacional ao tempo da inscrição e a concentração alcançada. SP, 1979 .

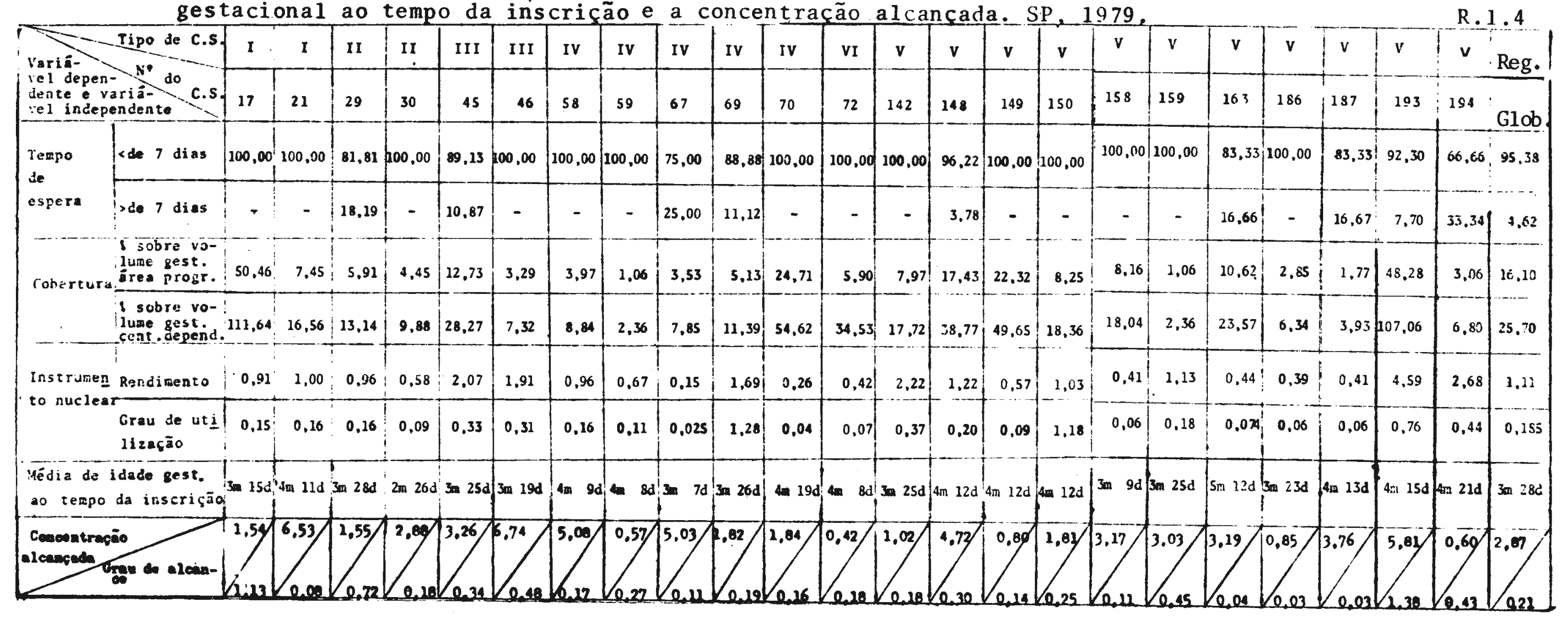


QUADRO 23 - Comparação do "tempo de espera" com os percentuais alcançados de cober tura da consulta médica, rendimento instrumental, grau de utilização do instrumento e média da idade gestacional ao tempo de inscrição e concen tração alcançada. SP, 1979.

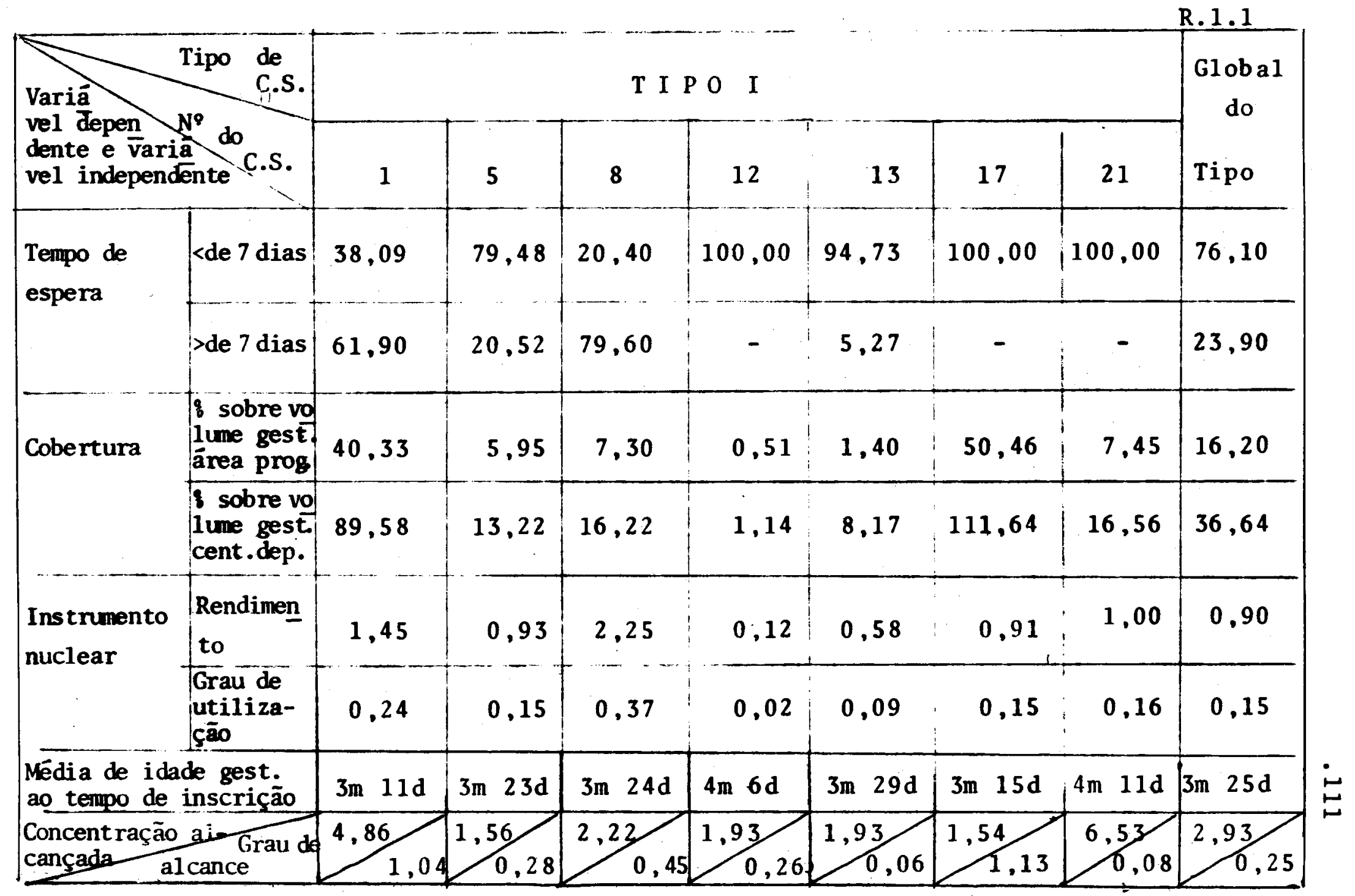


QUADRO - 24 - Comparação do "tempo de espera" com os percentuais alcançados de cober de cobertura da consulta médica, rendimento instrumental, grau de ut $\underline{i}$ lização do instrumento e média da idade gestacional ao tempo da inscrí ção e a concentração alcançada. SP, 1979.

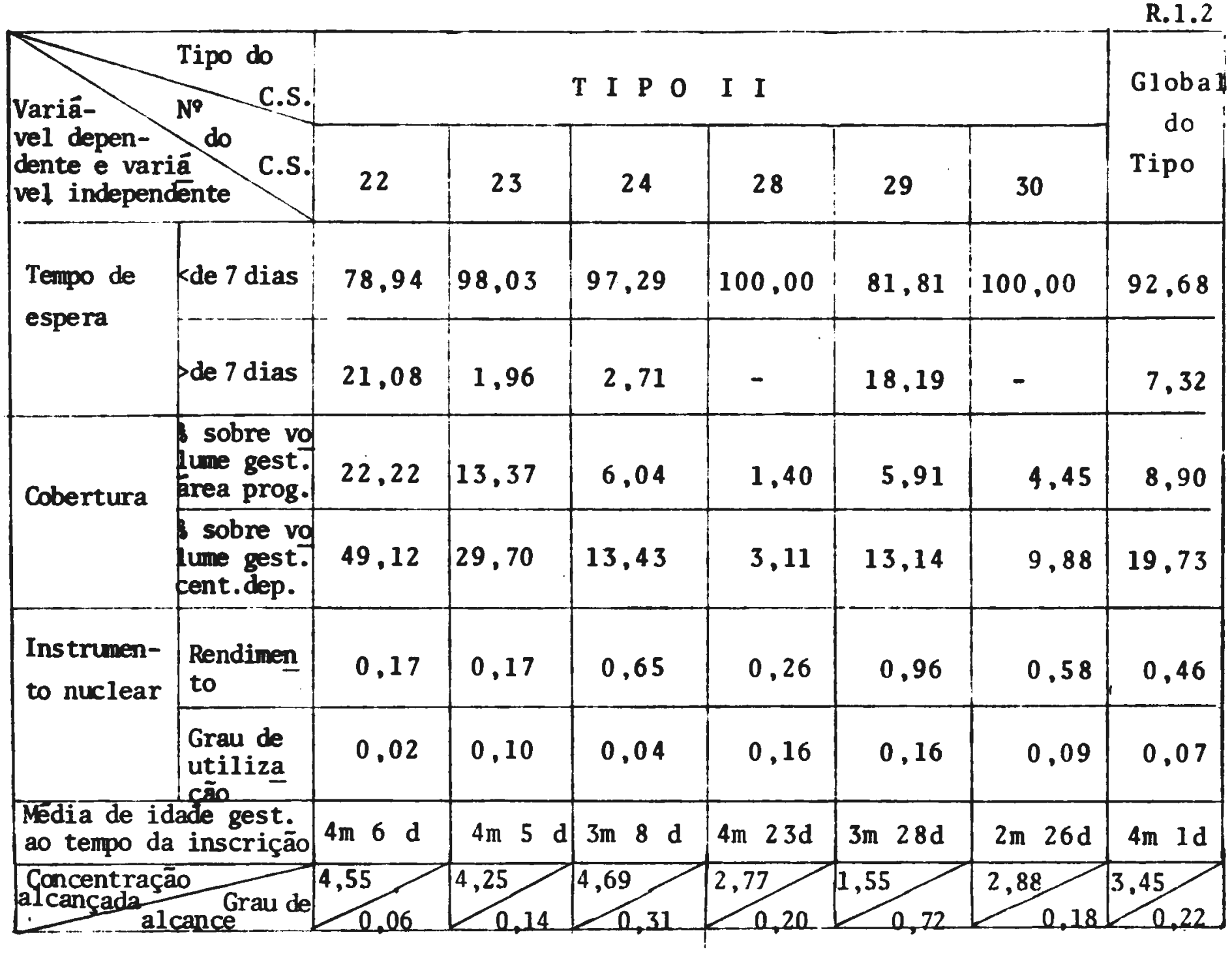


QUADRO 25 - Comparação do "tempo de espera" com os percentuais alcançados de cobertura e concentração da consulta médica, rendimento instrumental, grau de utilização do instrumento e média da idade gestacional ao tempo da inscriçāo e a concentração alcançada. SP, 1979.

\begin{tabular}{|c|c|c|c|c|c|c|c|c|c|c|}
\hline \multirow{2}{*}{\multicolumn{2}{|c|}{$\begin{array}{l}\text { Taria } \\
\text { vel de- } \text { No do }^{2} \text { C.S. } \\
\text { pendente o C.S. } \\
\text { variavel inde } \\
\text { pendente }\end{array}$}} & \multicolumn{8}{|c|}{$\begin{array}{lllllll}T & I & P & 0 & I & I & I\end{array}$} & \multirow{2}{*}{$\begin{array}{c}\text { Global } \\
\text { do } \\
\text { Tipo }\end{array}$} \\
\hline & & 34 & 35 & 36 & 40 & 41 & 43 & 45 & 46 & \\
\hline \multirow{2}{*}{$\begin{array}{l}\text { Tempo de } \\
\text { espera }\end{array}$} & <de 7 dias & 100,00 & 100,00 & 100,00 & 44.44 & 88,88 & 96,83 & 89,13 & 100,00 & 89,91 \\
\hline & i> de 7 días & - & - & - & 55,56 & 11,12 & 3,17 & 10.87 & - & 10,09 \\
\hline \multirow{2}{*}{ Cobertura } & $\begin{array}{l}\text { sobre vó } \\
\text { lume gest. } \\
\text { ărea prog. }\end{array}$ & 4,95 & 3,49 & 11,67 & 3,88 & 1,98 & 9,24 & 12,73 & 3,29 & 6,40 \\
\hline & $\begin{array}{l}\text { sobre vo } \\
\text { lume gest } \\
\text { cent.dep. }\end{array}$ & 11,01 & 7,75 & 25,91 & 15,66 & 4,40 & 20,52 & 28,27 & 7,32 & 15,10 \\
\hline \multirow[t]{2}{*}{$\begin{array}{l}\text { Instrumen } \\
\text { to nuclear }\end{array}$} & $\begin{array}{l}\text { Rendimen- } \\
\text { to }\end{array}$ & 1,65 & 0,95 & 2,97 & 0,66 & 5,15 & 3,31 & 2,07 & 1,91 & 2,33 \\
\hline & Grau de $u$ & 0.27 & 0,15 & 0,49 & 0,11 & 0,85 & 0,55 & 0,34 & 0.31 & 0,38 \\
\hline$\left\{\begin{array}{l}\text { dia de } \\
\text { ao tempo da }\end{array}\right.$ & $\begin{array}{l}\text { dade gest } \\
\text { a inscr. }\end{array}$ & $4 \mathrm{~m} \mathrm{13d}$ & $3 m 22 d$ & $3 m 7 d$ & 3n 11d & $4 m 9 d$ & 4m 9d & $3 \mathrm{~m} \mathrm{25d}$ & $3 \mathrm{~m} 19 \mathrm{~d}$ & $3 m 25 d$ \\
\hline $\begin{array}{l}\text { Concentraça } \\
\text { alcanç de al }\end{array}$ & Icance & $\frac{3,50}{1,23}$ & $\begin{array}{l}3,31 \\
-6,24\end{array}$ & $\begin{array}{r}1,39 \\
0\end{array}$ & & & $\begin{array}{r}3,62, \\
0,20\end{array}$ & 3,26 & 6,74 & $\frac{77}{6,42}=$ \\
\hline
\end{tabular}


QAUDRO 26 - Comparação do "tempo de espera" com os percentuais alcançados de cobertura da consulta médica, rendimento instrumental, grall de $\underline{u}$

- tilização do instrumento e média da idade gestacional ao tempo da inscrição. São Paulo, 1979.

\begin{tabular}{|c|c|c|c|c|c|c|c|c|c|c|c|c|}
\hline \multirow{2}{*}{\multicolumn{2}{|c|}{$\begin{array}{l}\text { Tipo de } \\
\text { Variävel } \\
\text { dependentes } \\
\text { e variável indo c.s. } \\
\text { pendente }\end{array}$}} & \multicolumn{11}{|c|}{$\begin{array}{lllllllllll}I & P & 0 & I V\end{array}$} \\
\hline & & 48 & 50 & 53 & 57 & 58 & 59 & 67 & 69 & 70 & 72 & Global \\
\hline \multirow{2}{*}{$\begin{array}{l}\text { Terpo de } \\
\text { espera }\end{array}$} & jede 7 dias & 100,00 & 85.71 & 80.55 & 100,00 & 100,00 & 100,00 & 75.00 & 88.88 & 100,00 & 160,00 & 93,01 \\
\hline & Pde 7 dias & - & 14,29 & 19,45 & - & - & - & 25,00 & 11,12 & - & - & 6,98 \\
\hline \multirow[t]{2}{*}{ Cobertura } & $\begin{array}{l}\text { \& sobre vo } \\
\text { lume gest } \\
\text { ânea proeg }\end{array}$ & 7.33 & 45,92 & 14,31 & 7.31 & 3,97 & 1,06 & 3.53 & 5,13 & 24,71 & 15.90 & 12,93 \\
\hline & pume gest. & 16.29 & 101,90 & 31,68 & 16.92 & 8.84 & 2,36 & 7,85 & 11.39 & 54,62 & 34,53 & 28.63 \\
\hline \multirow{2}{*}{$\begin{array}{l}\text { Instrunento } \\
\text { nuclear }\end{array}$} & $\begin{array}{l}\text { Rendimen } \\
\text { to }\end{array}$ & 1.95 & 0,04 & 0,73 & 0.29 & 0,96 & 0,67 & 0,15 & 0.69 & 0.26 & 0,42 & 0.71 \\
\hline & Grau de u & 0.32 & 0.06 & 0,12 & 0,04 & 0.16 & 0.11 & 0,02 & 0.28 & 0.04 & 0,07 & 0.11 \\
\hline \multicolumn{2}{|c|}{$\begin{array}{l}\text { Nédia do idade gest. } \\
\text { ao tempo da inscriçäo }\end{array}$} & in $7 d$ & $\sin 9 d$ & $3 m 25 d$ & $m 2 d$ & 408 & 48 & $\sin 7 d$ & 3n 26d & in $19 d$ & $4 \ln 8 d$ & 4a $6 d$ \\
\hline \multicolumn{2}{|l|}{ C.A. ${ }^{*}$} & & & & 0,60 & & & & & & & \\
\hline
\end{tabular}

${ }^{*}$ C.A. = Cobertura Alcançada. 
QUADRO 27 - Comparação do "tempo de espera" com os percentuais alcançados de cobertura da consulta médica, rendimento instrumental, grau de utilização do instrumento e média gestacional ao tempo de inscrição. São Paulo, 1979.

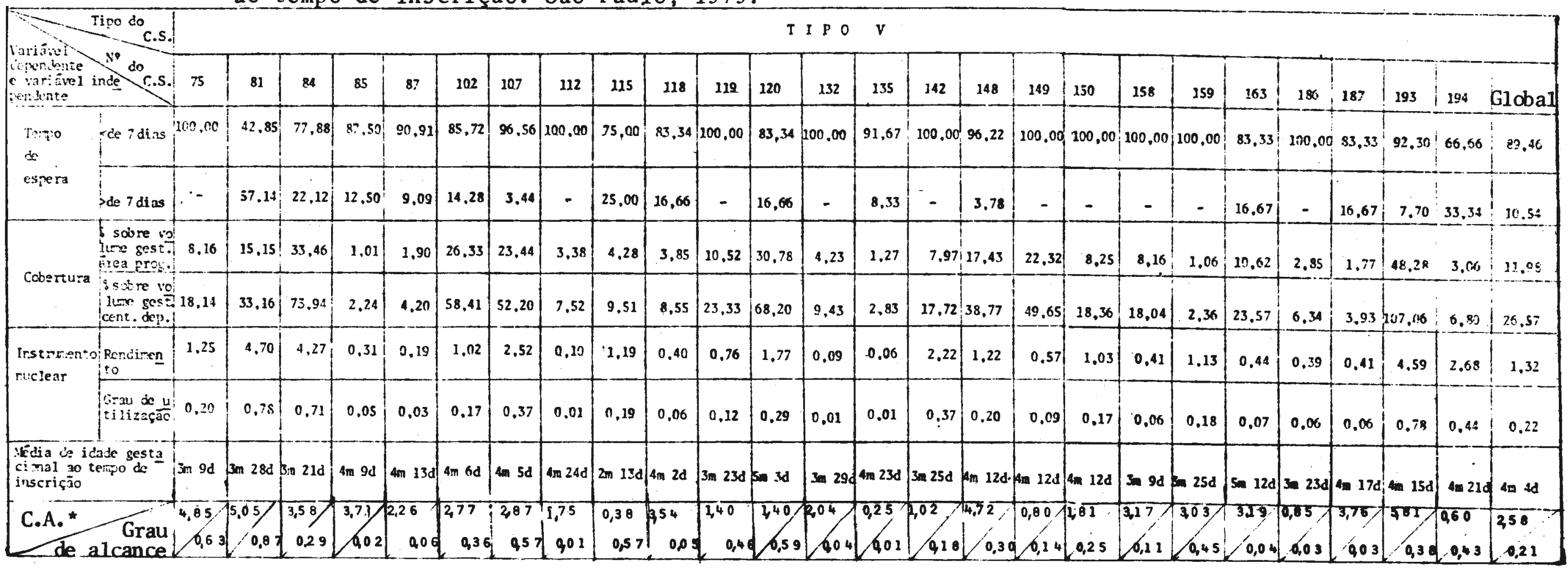

${ }^{\star}$ C.A. = Concentração alcançada، 
Nos centros de saúde tipo I em que o percentual do tem po de espera não aceitável for maior que o aceitảvel (exclu indo-se é claro, o $n^{\circ} 1$ da $R .1 .1$, retro citado) a explicação para esta ocorrência deve-se a outros fatores que não a al ta cobertura alcançada.

Ilustremos com alguns destaques: No centro de saúde $\mathrm{n}^{\circ} 5$, conforme exposto no Quadro 20 , em que o intervalo de espera maior que 7 dias atingiu $20,52 \%$ das gestantes, $O$ RI foi de 0,93 com um grau de utilização instrumental de 0,15 (a razão considerada ótima é de 1 , que significa objetivo alcançado plenamente). Estes fatos por si só explicam o au mento do tempo de espera nesta unidade, pois à cobertura de $13,22 \%$ da meta programada certamente não se deveu. 0 meca nismo hipotético é a sub utilização do instrumento nuclear da consulta médica que condicionou a espera observada diante de uma demanda maior que a capacidade real de trabalho ve rificada.

No centro de saúde número 8 da R.1.2 o tempo de espe ra não aceitável atingiu $79,60 \%$ das gestantes inscritas e a situação foi semelhante à que se deu no centro de saúde n? 5 ; embora a cobertura, a concentração e o RI tenham sido aí, um pouco maiores:16,22 - 0,22 - 0,25 respectivamente,o grau de utilização foi tão baixo que não justificaria nenhuma espera. Esta só encontra explicação, outra vez, na sub utí lização do instrumento.

Seria exaustivo e monótono discutir a situação encon trada nas demais unidades tipo I da amostra, uma vez que $\bar{e}$ idêntica, conforme se vê no Quadro 23, com agravantes:às ve zes o tempo de espera não existiu ou foi baixo e os atribu tos da atividade estudada comportaram-se da mesma forma.

Quanto à associação positiva do tempo de espera acima de 0 (zero) dias como o centro de saúde tipo $V$ não tem a lógica do condicionamento pelo aumento da cobertura aventa da para o tipo I, uma vez que, neste tipo o atendimento de gestantes deve ser menor e menos complexo. Contudo, 6 desses 
centros: os de $\mathrm{n}^{\circ} 84,102,107,120,149$ e 193 apresen taram um percentual de cobertura acima da meta normalizada $(45,0 \%)^{*}$, conforme é mostrado no Quadro n' 27.

Em 3 das unidades: as de $n^{\circ} 81,84$ e 193, o RI foi quase igual ao normalizado: 4,70-4,20 e 4,59 com um grau de utilização de $0,78-0,70$ e 0,77 respectivamente.

E possível que esses fatos evidenciados possam ser, so mente eles, responsabilizados pela associação positiva com provada, porque, no que importa ao relacionamento com os de mais centros de saúde do tipo $V$ não destacados, a situaçāo foi praticamente a mesma descrita para os centros de saúde tipo I: baixo percentual de cobertura alcançada, pequeno RI, subutilização instrumental e grande porcentagem de tempo de espera aceitâve 1 .

* Percentual fornecido pelo Nível Central da C.S.C. S.E.S - SP. 
3.4 Variāvel "Grau de alcance das metas de cobertura".

Para que pudessemos medir o grau de alcance das metas de cobertura, conforme o processo relatado no Capítulo IV, levantamos dados sobre:

- população total de gestantes esperadas para o ano de 1979 nas áreas programáticas dos centros de saú de da amostra;

- volume das gestantes inscritas, segundo o trimestre da gestação;

- percentual de cobertura alcançada.

Quanto ao volume de gestantes inscritas foi necessário utilizar, quando indicado e possível, somente as inscri ções identificadas pelo levantamento direto nos centros de saūde, uma vez que os dados secundários colhidos tiveram de aguardar correção oportunamente.

Os dados acima citados foram processados e agrupados nos Quadros de $\mathrm{n}^{\circ} 7$ a 10 , como dados bāsicos para cálculo de cobertura. Objetivamos a que deem uma visão sequencial do processo: estimativa das gestantes esperadas para a área to tal dos centros de saūde, de gestantes esperadas para a áa rea programática desses centros, de gestantes na ārea total a inscrever (não necessariamente pelo centro de saūde da $\underline{a}$ mostra, mas por ele e outros não sorteados, se existirem)de gestantes da ārea programātica, volume de gestantes inscritas conforme dados primários.

Utilizando esses dados para o cálculo da cobertura a 1 cançada, aplicamos a förmula*

$$
c b=\frac{N^{8} \text { gestantes inscritas }}{\text { população C.D. }} \times 100
$$

e obtivemos resultados que foram processados e agrupados nos Quadros de $n^{\circ} 11$ a 14 , apresentados neste item.

* Fórmula adotada na Disciplina de Saúde Materna do Departamento de Saúde Materno-Infantil - FSP/USP. 
QUADRO T - Dados básicos para cálculo da cobertura da assistência pré-natal alcan çada nos meses de janeiro a setembro de 1979 nas unidades sanitárias do DRS-1, SP incluídas na pesquisa, segundo a Regional. SP, 1979.

\begin{tabular}{|c|c|c|c|c|c|c|}
\hline \multirow{2}{*}{$\begin{array}{l}\text { TIPO DO } \\
\text { CS NA } \\
\text { SES } \\
\text { R.1.1 }\end{array}$} & \multirow{2}{*}{ 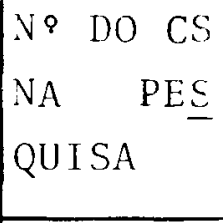 } & \multicolumn{2}{|c|}{ GESTANTES ESPERADAS } & \multicolumn{2}{|c|}{ GESTANTES A INSCREVER } & \multirow{2}{*}{$\begin{array}{l}\text { GESTANTES } \\
\text { INSCRITAS }\end{array}$} \\
\hline & & $\begin{array}{l}\text { DA AREA GEO- } \\
\text { GRAF. DO CS }\end{array}$ & $\begin{array}{l}\text { MA TRLA IRO } \\
\text { GRAM. DO CS } \\
\end{array}$ & $\begin{array}{l}\text { DA } \bar{\Lambda} R L A \text { A (IL:O)- } \\
\text { GRAF. DO CS }\end{array}$ & $\begin{array}{l}\text { UA TRLA A PRO } \\
\text { GRAM. DO C } \bar{S}\end{array}$ & \\
\hline I & 1 & 1.421 & 1.066 & 480 & 480 & 430 \\
\hline II & 22 & 1.451 & 1.088 & 490 & 490 & 38 \\
\hline II & 2.3 & 1.008 & 252 & 341 & 114 & 56 \\
\hline I I I & 34 & 5.341 & 3.005 & 1.803 & 1.353 & 149 \\
\hline I I I & 35 & 708 & 531 & 239 & 239 & 71 \\
\hline V & 75 & 2.500 & 625 & 844 & 281 & 51 \\
\hline V & 81 & 2.324 & 871 & 785 & 398 & 132 \\
\hline
\end{tabular}


QUADRO 8 -Dados básicos para cálculo da cobertura da assistência pré-natal alcan çada nos meses de janeiro a setembro de 1979 nas unidades sanitárias do DRS-1, SP incluídas na pesquisa, segundo a Regional. SP, 1979.

\begin{tabular}{|c|c|c|c|c|c|c|}
\hline \multirow{2}{*}{$\begin{array}{l}\text { T I PO DO DO } \\
\text { CS NA } \\
\text { SES } \\
\text { R. } 1.2\end{array}$} & \multirow{2}{*}{$\begin{array}{lll}\text { NP } & \text { DO } & \text { CS } \\
\text { NA } & \text { PE } \\
\text { OUISA }\end{array}$} & \multicolumn{2}{|c|}{ GESTANTES ESPERADAS } & \multicolumn{2}{|c|}{ GESTANTES A INSCREVER } & \multirow{2}{*}{$\begin{array}{l}\text { GESTANTES } \\
\text { INSCRITAS }\end{array}$} \\
\hline & & $\begin{array}{l}\text { DA AREA GEO- } \\
\text { GRAF. DO CS }\end{array}$ & $\begin{array}{l}\text { DA AREA PRO- } \\
\text { GRAM. DO CS }\end{array}$ & $\begin{array}{l}\text { DA AREA GEO- } \\
\text { GRAF. DO CS }\end{array}$ & $\begin{array}{l}\text { DA ÁREA PRO } \\
\text { GRAM. DO CS }\end{array}$ & \\
\hline I & 5 & 4.614 & 3.461 & 1.558 & 1.558 & 206 \\
\hline I & 8 & 11.722 & 7.327 & 3.956 & 3.297 & 535 \\
\hline I I & 24 & 4.013 & 3.010 & 1.355 & 1.355 & 182 \\
\hline I 1 I & 36 & 9.100 & 788 & 3.072 & 355 & 92 \\
\hline I I I & 40 & 3.867 & 670 & 1.306 & 303 & 166 \\
\hline $\mathrm{I} I \mathrm{I}$ & 41 & 3.295 & 1.059 & 1.113 & 477 & 21 \\
\hline IV & 48 & 15.991 & 2.999 & 5.397 & 1.350 & 220 \\
\hline IV & 50 & 310 & 233 & 105 & 105 & 107 \\
\hline IV & 53 & $3.86 ?$ & 447 & 1.306 & 202 & 64 \\
\hline V & 84 & 9.100 & 263 & 3.072 & 119 & 88 \\
\hline V & 85 & 1.976 & 1.482 & 667 & 667 & 15 \\
\hline V & 87 & 9.100 & 263 & 3.072 & 119 & 5 \\
\hline V & 102 & 3.867 & 224 & 1.306 & 101 & 59 \\
\hline V & 107 & 3.295 & 354 & 1.113 & 159 & 83 \\
\hline V & 112 & 9.363 & 1.004 & 3.161 & 452 & 34 \\
\hline $\mathrm{V}$ & 115 & 9.363 & 1.004 & 3.161 & 452 & 43 \\
\hline
\end{tabular}


QUADRO 9 - Dados básicos para cálculo da cobertura da assistência pré-natal alcan çada nos meses de janeiro a setembro de 1979 nas unidades sanitárias do DRS-1, SP incluídas na pesquisa, segundo a Regional. SP, 1979.

\begin{tabular}{|c|c|c|c|c|c|c|}
\hline \multirow{2}{*}{$\begin{array}{c}\text { TIPO DO } \\
\text { CS NA } \\
\text { SES } \\
\text { R.1.3. }\end{array}$} & \multirow{2}{*}{$\mid \begin{array}{lll}N^{\circ} & \text { DO } & \text { CS } \\
\text { NA } & & \text { PES } \\
\text { QUISA } & \end{array}$} & \multicolumn{2}{|c|}{ GESTANTES ESPERADAS } & \multicolumn{2}{|c|}{ GESTANTES A INSCREVER } & \multirow{2}{*}{$\begin{array}{l}\text { GESTANTES } \\
\text { INSCRITAS }\end{array}$} \\
\hline & & $\begin{array}{l}\text { DA ARI:A GEO- } \\
\text { GRAF.DO CS }\end{array}$ & $\begin{array}{l}\text { DA AREA } \\
\text { CRAMO PRO } \\
\end{array}$ & $\begin{array}{ll}\text { DA AREA } & \text { GEO } \\
\text { GPAF.DO } & \text { CS } \\
\end{array}$ & $\begin{array}{l}\text { DA AREA PRO } \\
\text { GRAM.DO } \text { CS }^{-}\end{array}$ & \\
\hline I & 12 & 12.370 & 9.278 & 4.175 & 4.175 & 48 \\
\hline I & 1.3 & 4.058 & 3.041 & 1.370 & 1.370 & 112 \\
\hline I I & 28 & 6.555 & 4.917 & 2.113 & 2.113 & 69 \\
\hline I I I & 43 & 7.284 & 3.279 & 2.459 & 1.476 & 303 \\
\hline IV & 57 & 12.221 & 1.411 & 4.125 & 636 & 106 \\
\hline $\mathrm{V}$ & 118 & 5.392 & 675 & 1.820 & 304 & 26 \\
\hline $\mathrm{V}$ & 119 & 1.77 & 1.33 & 60 & 60 & 14 \\
\hline $\mathrm{V}$ & 120 & 576 & 432 & 195 & 195 & 133 \\
\hline $\mathrm{V}$ & 32 & 3.295 & 354 & 1.313 & 159 & 15 \\
\hline $\mathrm{V}$ & 135 & 12.221 & 705 & 4.125 & 318 & 9 \\
\hline
\end{tabular}


QUADRO 10-Dados básicos para cảlculo da cobertura da assistência pré-natal alcançada nos meses de janeiro a setembro de 1979 nas unidades sanitärais do DRS-1, SP incluídas na pesquisa, segundo a Regional. SP, 1979.

\begin{tabular}{|c|c|c|c|c|c|c|}
\hline \multirow{2}{*}{$\begin{array}{l}\text { TI PO DO } \\
\text { CS NA } \\
\text { SES } \\
\text { R.1.4 } \\
\end{array}$} & \multirow{2}{*}{ 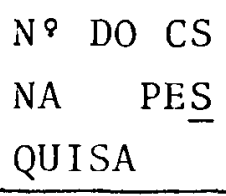 } & \multicolumn{2}{|c|}{ GESTANTES ESPERADAS } & \multicolumn{2}{|c|}{ GESTANTES A INSCREVER } & \multirow{2}{*}{$\begin{array}{l}\text { GEST ANTES } \\
\text { INSCR ITAS }\end{array}$} \\
\hline & & $\begin{array}{l}\text { DA AREA GEO- } \\
\text { GRAF. DO CS }\end{array}$ & $\begin{array}{l}\text { DA AREA PRO } \\
\text { GRAH. DO C } \bar{S}\end{array}$ & $\begin{array}{l}\text { DA AREA GEO- } \\
\text { GRAF. DO CS }\end{array}$ & $\begin{array}{l}\text { DA KRE } \Lambda \text { PRO- } \\
\text { GRAM. IOO CS }\end{array}$ & \\
\hline $\begin{array}{l}1 \\
\text { I } \\
\text { I } 1 \\
\text { I I } \\
\text { I I I } \\
\text { I I I } \\
\text { IV } \\
\text { IV } \\
\text { IV } \\
\text { IV } \\
\text { IV } \\
\text { IV } \\
\text { V } \\
\text { V } \\
\text { V } \\
\text { V } \\
\text { V } \\
\text { V } \\
\text { V } \\
\text { V } \\
\text { V } \\
\text { V } \\
\text { V }\end{array}$ & $\begin{array}{l}17 \\
21 \\
29 \\
30 \\
45 \\
46 \\
58 \\
59 \\
67 \\
69 \\
70 \\
72 \\
142 \\
148 \\
149 \\
150 \\
158 \\
159 \\
163 \\
186 \\
187 \\
193 \\
194\end{array}$ & $\begin{array}{r}516 \\
20.281 \\
4.596 \\
6.081 \\
2.636 \\
9.100 \\
4.621 \\
1.501 \\
5.377 \\
3.894 \\
9.100 \\
3.482 \\
13.029 \\
6.081 \\
6.081 \\
6.081 \\
3.136 \\
5.377 \\
5.377 \\
20.281 \\
20.281 \\
543 \\
1.479\end{array}$ & $\begin{array}{r}323 \\
5.071 \\
3.447 \\
1.303 \\
1.186 \\
788 \\
1.734 \\
1.126 \\
621 \\
1.461 \\
263 \\
2.612 \\
978 \\
327 \\
327 \\
327 \\
294 \\
311 \\
311 \\
1.015 \\
1.015 \\
408 \\
1.110\end{array}$ & $\begin{array}{r}175 \\
6.845 \\
1.552 \\
2.053 \\
890 \\
3.072 \\
1.560 \\
507 \\
1.815 \\
1.315 \\
3.072 \\
1.164 \\
4.398 \\
2.053 \\
2.053 \\
2.053 \\
1.059 \\
1.815 \\
1.815 \\
6.845 \\
6.845 \\
184 \\
500\end{array}$ & $\begin{array}{r}146 \\
2.282 \\
1.552 \\
587 \\
534 \\
355 \\
780 \\
507 \\
280 \\
658 \\
119 \\
1.164 \\
440 \\
147 \\
147 \\
147 \\
133 \\
140 \\
140 \\
457 \\
457 \\
184 \\
500\end{array}$ & $\begin{array}{r}163 \\
378 \\
204 \\
58 \\
151 \\
26 \\
69 \\
12 \\
66 \\
75 \\
65 \\
402 \\
78 \\
57 \\
73 \\
27 \\
24 \\
29 \\
11 \\
29 \\
18 \\
197 \\
34\end{array}$ \\
\hline
\end{tabular}


QUADRO 11 -Percentual de cobertura da assistência pré-natal alcançada nos meses de janeiro a setembro de 1979 , nas unidades sanitárias DRS-1, SP - incluídas na pesquisa, segundo a Regional. SP, 1979.

R.1.1

\begin{tabular}{|c|c|c|c|}
\hline $\begin{array}{l}\text { TIPO DE } \\
\text { CS NA SES }\end{array}$ & $\begin{array}{l}\text { NP DO CS NA } \\
\text { PESQUISA }\end{array}$ & $\begin{array}{l}\text { \% SOBRE AS GESTANTES ES } \\
\text { PERADAS PARA A AREA * }\end{array}$ & $\begin{array}{l}\text { \% SOBRE AS GESTANTES } \\
\text { A SEREM INSCRITAS }\end{array}$ \\
\hline I & 1 & 40,33 & 89,58 \\
\hline I I & 22 & 3,49 & 7,75 \\
\hline I I & 23 & 22,22 & 49,12 \\
\hline I I I & 34 & 4,95 & 11,01 \\
\hline I I I & 35 & 13,37 & 29,70 \\
\hline V & 75 & 8,16 & 18,14 \\
\hline V & 81 & 15,15 & 33,16 \\
\hline
\end{tabular}

* Dados primários 
QUADRO 12 -Percentual de cobertura da assistência pré-natal alcançada nos meses de janeiro a setembro de 1979, nas unidades sanitárias DRS-1, SP - incluídas na pesquisa, segundo a Regional. SP, 1979.

R. 1.2

\begin{tabular}{|c|c|c|c|}
\hline $\begin{array}{l}\text { TIPO DE } \\
\text { CS NA SES }\end{array}$ & $\begin{array}{r}\text { NP DO CS NA } \\
\text { PESQUISA }\end{array}$ & $\begin{array}{l}\text { : SOBRE AS GESTANTES } \\
\text { ESPERADAS PARA A AREA* }\end{array}$ & $\begin{array}{l}\text { SOBRE AS GESTANTES } \\
\text { A SEREM INSCRITAS }\end{array}$ \\
\hline I & 5 & 5,95 & 13,22 \\
\hline I & 8 & 7,30 & 16,22 \\
\hline I I & 24 & 6,04 & 13,43 \\
\hline I I I & 36 & 11,67 & 25,91 \\
\hline I I I & 40 & 3,88 & 15,66 \\
\hline I I I & 41 & 1,98 & 4,40 \\
\hline IV & 48 & 7,33 & 16,29 \\
\hline IV & 50 & 45,92 & 101,90 \\
\hline IV & 53 & 14,31 & 31,68 \\
\hline IV & 84 & 33,46 & 73,94 \\
\hline V & 85 & 1,01 & 2,24 \\
\hline V & 87 & 1,90 & 4,20 \\
\hline V & 102 & 26,33 & 58,41 \\
\hline V & 107 & 23,44 & 52,20 \\
\hline V & 112 & 3,38 & 7,52 \\
\hline V & 115 & 4,28 & 9,51 \\
\hline
\end{tabular}

* Dados primärios 
QUADRO 13-Percentual de cobertura da assistência pré-natal alcançada nos meses de janeiro a setembro de 1979 , nas unidades sanitärias DRS-1, SP - incluídas na pesquisa, segundo a Regional. SP, 1979.

R. 1.3

\begin{tabular}{|c|c|c|c|}
\hline $\begin{array}{l}\text { TIPO DE } \\
\text { CS NA SES } \\
\end{array}$ & $\begin{array}{l}\text { NQ DO CS } \\
\text { PESQUISA }\end{array}$ & $\begin{array}{l}\therefore \text { SOBRE AS GESTANTES } \\
\text { ESPERADAS PARA A AREA }\end{array}$ & $\begin{array}{l}: \text { SOBRE AS GESTANTES } \\
\text { A SEREM INSCRITAS }\end{array}$ \\
\hline I & 12 & 0,51 & 1,14 \\
\hline I & 15 & 1,40 & 8,17 \\
\hline II & 28 & 1,40 & 3,11 \\
\hline I I I & 43 & 9,24 & 20,52 \\
\hline $\mathrm{II}^{\circ}$ & 5 & 7,51 & 16,92 \\
\hline 1 & 118 & 5,85 & 8,55 \\
\hline$V$ & 119 & 10,52 & 23,33 \\
\hline V & 120 & $30,-8$ & 68,20 \\
\hline$V$ & $15:$ & 4,23 & 9,43 \\
\hline$\because$ & 135 & 1,27 & 2,83 \\
\hline
\end{tabular}

Dados primários 
QUADRO 14-Percentual de cobertura da assistência pré-natal alcançada nos meses de janeiro a setembro de 1979 , nas unidades sanitárias DRS-1, SP - incluídas na pesquisa, segundo a Regional. SP, 1979.

R. 1.4

\begin{tabular}{|c|c|c|c|}
\hline $\begin{array}{l}\text { TIPO DE } \\
\text { CS NA SES }\end{array}$ & $\begin{array}{l}N^{\circ} \text { DO CS NA } \\
\text { PESQUISA }\end{array}$ & $\begin{array}{l}\text { ¿ SOBRE AS GESTANTES } \\
\text { ESPERADAS PARA A AREA* }\end{array}$ & $\begin{array}{l}\text { : SOBRE AS GESTANTES } \\
\text { A SEREM INSCRITAS }\end{array}$ \\
\hline I & 17 & 50,46 & 111,64 \\
\hline I & 21 & 7,45 & 16,56 \\
\hline I I & 29 & 5,91 & 13,14 \\
\hline I I & 30 & 4,45 & 9,88 \\
\hline I I I & 45 & 12,73 & 28,27 \\
\hline I I I & 46 & 3,29 & 7.32 \\
\hline IV & 58 & 3,97 & 8,84 \\
\hline I V & 59 & 1,06 & 2,36 \\
\hline IV & 67 & 3,53 & 7,85 \\
\hline IV & 69 & 5,13 & 11,39 \\
\hline IV & 70 & 24,71 & 54,62 \\
\hline II & 72 & 15,90 & 34,53 \\
\hline$V$ & 142 & 7,97 & 17,72 \\
\hline 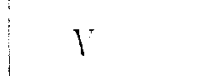 & 148 & 17,43 & 38,77 \\
\hline$V$ & 149 & 22,32 & 49,65 \\
\hline$r$ & 150 & 8,25 & 18,36 \\
\hline$V$ & 158 & 8,16 & 18,04 \\
\hline$V$ & 159 & 9,32 & 20,71 \\
\hline V & 163 & 10,62 & 23,57 \\
\hline V & 186 & 2,85 & 6,34 \\
\hline$V$ & 187 & 1.77 & 3,93 \\
\hline V & 193 & 48,28 & 107,06 \\
\hline V & 194 & 3,06 & 6,80 \\
\hline
\end{tabular}

* Dados primärios 
3.4.1 Teste da relaçāo com a cobertura das metas

Registram-se na Tabela 21 as gestantes conforme 0 tem po de espera da consulta e a cobertura das metas.

Aplicando-se a prova da mediana aos elementos reelabo rados da Tabela 22 encontra-se um $x^{2}$ igual a 97,027. Como es te valor supera o tabulado $(5,991)$ para 2 graus de liberdade e nível de significância de $5 \%$, pode-se rejeitar a hipótese nu $1 a$.

A conclusão é que o tempo de espera é diferenciado nos centros de saúde relativamente à cobertura das metas. Por inspeção da Tabela 22 verifica-se que a proporção das pacientes com tempo de espera superior à mediana é maior que a espe rada nos centros de saúde que cobriram $45 \%$ e mais das metas fí xadas.

TABELA 21-Gestantes segundo o tempo de espera da consulta e a cobertura. SP, 1979 .

\begin{tabular}{|c|c|c|c|c|}
\hline \multirow{2}{*}{\multicolumn{2}{|c|}{$\begin{array}{l}\text { TEMPO DE } \\
\text { ESPERA(dias) }\end{array}$}} & \multicolumn{3}{|c|}{$C O B E R T U R A$} \\
\hline & & menos de $20 \%$ & $20 \%-45$ & $45 \%$ e mais \\
\hline \multicolumn{2}{|l|}{0} & 787 & 310 & 194 \\
\hline-1 & -10 & 75 & 49 & 115 \\
\hline 11 & -20 & 29 & 5 & 4 \\
\hline 21 & -40 & 54 & 9 & 24 \\
\hline 41 & -80 & 17 & 2 & 7 \\
\hline 81 & -120 & 5 & 2 & - \\
\hline \multicolumn{2}{|c|}{ TOTAL } & 967 & 377 & 344 \\
\hline
\end{tabular}


TABELA 22 - Gestantes segundo a mediana do tempo de espera da consulta e a cobertura (teste da mediana). SP, 1979.

\begin{tabular}{|c|c|c|c|c|}
\hline \multirow{2}{*}{$\begin{array}{l}\text { POSIÇÃO RELAT IVA } \\
\text { MENTE } \AA \text { MEDIANA } \\
\text { COMUM }\end{array}$} & \multicolumn{3}{|c|}{ 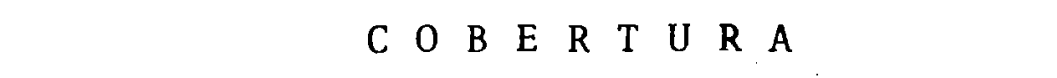 } & \multirow{2}{*}{ TOTAL } \\
\hline & menos de $20 \%$ & $20 \%-45 \%$ & $45 \%$ e mais & \\
\hline Não excedem & $\begin{array}{r}787 \\
(739,57)\end{array}$ & $\begin{array}{c}310 \\
(288,33)\end{array}$ & $\begin{array}{c}194 \\
(263,10)\end{array}$ & 1.291 \\
\hline Excedem & $\begin{array}{r}180 \\
(227,43)\end{array}$ & $\begin{array}{c}67 \\
(88,67)\end{array}$ & $\begin{array}{c}150 \\
(80,90)\end{array}$ & 397 \\
\hline TOTAL & 967 & 377 & 344 & 1.068 \\
\hline
\end{tabular}

iuta:o números entre parênteses são as frequências esperadas sob a hipōtese nula.

$$
x^{2} \text { calc. }=97,027
$$


Esta associação positiva parece-nos a mais evidente à primeira vista, pois vemos nos Quadros 19 a 27 que a tendên cia foi nítida: subindo a cobertura, aumentou o tempo de es pera. Nas unidades em que este fenômeno não ocorreu pode-se notar outras correlaçōes interessantes.

$\mathrm{Na}$ R.1.4 no centro de saúde $\mathrm{n}^{9} 17$ o tempo de espera foi zero, entretanto a cobertura foi de $111,64 \%$, mas a con centração foi de apenas 1,54 e o RI de 0,91; no centro de saúde $n^{\circ} 72$, o tempo de espera foi $100 \%$ normal, e a co bertura de $34,53 \%$, um pouco acima da média, mas a concentra ção foi de 0,42 e o RI 0,42. Todos os destaques de cobertú ra nesta Regional acompanham-se de características negativas dos demais atributos.

Entretanto, passemos a consideraçōes com outra ordem de idéias.

Se a meta normalizada foi de $45 \%$ para a cobertura, se ria razoāvel que os recursos fossem planejados para cumpríla e isto aparentemente não estaria se dando frente às va riações correlacionadas dos aumentos do tempo de espera e da cobertura. Todavia, por comparação com a situação verifi cada quanto aos outros atributos da consulta médica no prénatal, alēm da cobertura, o quadro evidencia um certo dese quilíbrio não indicador de poucos recursos, mas de utilização inadequada dos mesmos. Senão vejamos:

Na R.1.1 com 7 unidades: 2 centros de saúde ( $n^{\circ} \mathrm{s} 1$ e 22) ultrapassaram as metas de cobertura, mas os demais fica ram aquém, chegando o $\mathrm{n}^{\circ} 35$ a apenas 0.17 graus de alcance dessa meta.

0 RI em todas as unidades desta Regional foi reduzido; com excessão do centro de saúde $n^{8} 81$ em que o grau de uti1 ização foi de 0,78 , quase pleno, os demais apresentaram um alcance do rendimento de até 0,25 graus apenas.

Na R.1.2, com excessão do centro de saúde n: 84 com 
um RI de 4,27 e uma cobertura de 73,94, as demais unidades não apresentaram tão boas variações e tão harmônicas,ço mo podemos observar com relação a alguns, a saber:

- $\mathrm{n}^{8} 50$ - cobertura 101,90; tempo de espera anormal de $14,29 \%$, un rendimento de 0,04 , uma con centração de 2,95 e mais uma agravante se ríssima: a média de idade gestacional à inscrição foi de $5 \mathrm{~m} 9$ dias.

Perguntamos neste caso:seriam a demanda $\underline{a}$ cima das possibilidades programáticas e/ ou a sub utilização evidente os pontos nodais da problemática assistencial deste centro de saúde?

- n 840 - em que o tempo de espera anormal atingiu 55,56 das gestantes, a cobertura alcança da foi de 15,66, o RI verificado de $0,66 \mathrm{e}$ a concentração alcançada 1,87 ; poder-seia dizer que a única explicação para a es pera neste centro foi o grau de utilização do instrumento: 0,11 que não foi sü ficiente para atingir em tempo útil nem 0,34 graus da meta de cobertura.

Estes são enfoques de pontos salientes, porque a constante das unidades nesta Regional foi a baixa cobertura, o baixo rendimento instrumental e uma concentração a cançada abaixo da mínima aceitável.

A R.1.3 foi a que apresentou o menor tempo de espe ra. Todavia, os fatores que podemos associar a esta particu laridade também sobressaem-se pela quantidade mínima, como vemos no Quadro 21:

- foi a menor concentração média alcançada:1,69 con sulta/gestante;

- foi o menor RI: 0,76;

- foi a menor cobertura alcançada: 16,21\%. 
$\mathrm{Na} \mathrm{R.1.4} \mathrm{todos} \mathrm{os} \mathrm{destaques} \mathrm{da} \mathrm{cobertura} \mathrm{acima} \mathrm{da}$ meta normalizada acompanharam-se igualmente de característi cas negativas dos demais atributos da consulta médica. Como a situação não apresentou nenhum aspecto diferente dos que foram salientados para as outras Regionais, deixamos de dis cuti-los.

Parece-nos que o problema se apresenta às vezes com dupla face: ora o tempo de espera é baixo, porque os atribu tos da atividade consulta médica para gestantes nos cen tros de saúde são de qualidade questionável; ora o tempo de espera não é aceitável porque aos atributos dessa atividade se poderia atribuir uma qualidade indesejável.

Segundo Ciari Jr, , C. et al ${ }^{16}$ aceita-se como signifi cativa em saúde materna a proteção de 80 a $85^{\circ}$ das gestan tes esperadas, sendo que, para o grupo de gestantes de alto risco não é desejāvel menos que $100 \%$ de cobertura. Além disso é necessário considerar que tem havido grande ênfase, como se verificou no Documento Oficial 118 da OPAS $^{48}$ e na 5 a. Conferência Nacional de Saúde ${ }^{69}$ para que os programas sejam ajustados no sentido de se atingirem metas de $50 \%$ na cobertura do grupo materno.

Ciari ${ }^{19}$ diz também que a concentração de consultas médicas não deve ser inferior a 4 , podendo variar a média entre 4 e 6 , a fim de se prestar uma adequada assistência ao grupo gestante; com uma concentração menor que esta é impos sível dar proteção satisfatória. Porēm, estas metas podem ser alcançadas por etapas, como possivelmente é o caso dos centros de saúde estudados, pois sabe-se que ainda podem ser considerados dentro de uma fase de implantação de programa em que as dificuldades são sobremaneira grandes e, teorica mente, bastante conhecidas. Ciari ${ }^{16}$ salienta porém, que há um mínimo de volume e qualidade da atividade abaixo do qual sua execução é inútil e, acrescentamos, onerosa Este é um aspecto de importância capital, mesmo diante da considera ção acima lembrada, e talvez por esta mesma razão, de tra 
tar-se de uma problemática cheia de relatividades - como a fase de implantação - que ora atenua e explica o problema, ora agrava suas implicações.

3.5 Variável "Disponibilidade do instrumento nuclear res ponsável pela consulta médica e o atendimento de enfer magem".

Os dados referentes a esta variável foram colhidos por meio do levantamento efetuado nos centros de saúde sor teados e nas suas respectivas diretorias distritais. Foram utilizados para a estruturação dos Quadros de $n^{\circ} 15$ a 18 e apresentados neste Capítulo, com a finalidade de fornecerem elementos para análise de determinados aspectos de situação que, segundo presumimos, poderá estar influindo nas condi ções que cercam a prestação de assistência de saúde às ge tantes.

Relacionados a esta variável levantamos dados sobre:

- exercício efetivo do cargo de médico, enfermeira e obstetriz;

- horas/instrumento disponíveis desses profissio nais;

- volume de consultas mëdicas esperadas;

- volume de consultas médicas realizadas.

os dados colhidos foram processados e os resultados lançados nos quadros seguintes:

- do $n^{9} 15$ a 18 - mostram o exercício efetivo dos instrumentos nucleares;

- do $n^{8} 28$ a 31 - volume de consulta médicas e aten dimentos de enfermagem esperados e realizades;

- do $n^{\circ} 32$ a 35 - dados para cálculo do rendimento instrumental da hora/médico.

De acordo com os resultados apresentados nos Qua 
QUADRO 15 - Disponibilidade do I.N. responsável pela C.M. e A.E. realizadas nos CS do DRS-1, SP, segundo a classificação do CS e a numeração do mesmo na pesquisa. SP, 1979.

R. 1.1

\begin{tabular}{|c|c|c|c|c|c|c|c|c|c|c|c|c|c|c|c|c|}
\hline \multicolumn{2}{|r|}{ C.S. } & \multicolumn{5}{|c|}{ M E D I I C 0} & \multicolumn{5}{|c|}{ E N F E R M E I R A } & \multicolumn{5}{|c|}{$O$ B S T E F R I Z } \\
\hline $\begin{array}{l}\text { NQ NA } \\
\text { PESQUI } \\
\text { SA }\end{array}$ & $\begin{array}{c}\text { CLASSIFI } \\
\text { ÇÃO NA } \\
\text { SES }\end{array}$ & $\begin{array}{r}\text { LOTA } \\
\text { ÇAO }\end{array}$ & $\begin{array}{l}\text { REALI } \\
\mathrm{ZA} \text { TRI } \\
\mathrm{AGEM}\end{array}$ & $\begin{array}{l}\text { REALI } \\
\text { ZA CON } \\
\text { SULTA }\end{array}$ & $\left\{\begin{array}{l}\text { REALIZA } \\
\text { OUTRA A } \\
\text { T IVIDADE }\end{array}\right.$ & $\begin{array}{l}\text { SEM ATI } \\
\text { VIDADE } \\
\text { NO SETOR } \\
\text { DE SM }\end{array}$ & $\begin{array}{l}\text { LOTA } \\
\text { CAOO }\end{array}$ & $\begin{array}{l}\text { REALI } \\
\text { ZA TRI } \\
\text { AGEM }\end{array}$ & $\begin{array}{l}\text { REALI } \\
\mathrm{ZA} \\
\mathrm{AE}\end{array}$ & $\mid \begin{array}{l}\text { REALIZA } \\
\text { OUTRA A } \\
\text { TIVIDADE }\end{array}$ & $\begin{array}{l}\text { SEM ATI } \\
\text { VIDADE } \\
\text { NO SETOR } \\
\text { DE SM }\end{array}$ & $\begin{array}{l}\text { ISTA } \\
\text { ÇAO }\end{array}$ & $\begin{array}{l}\text { REALI } \\
\text { ZA TRI } \\
\text { AGEM }\end{array}$ & $\begin{array}{c}\text { REALI } \\
Z A \\
A E\end{array}$ & $\begin{array}{l}\text { REALIZA } \\
\text { OUTRA A } \\
\text { TIVIDADE }\end{array}$ & $\begin{array}{l}\text { SEMATI } \\
\text { VIDADE } \\
\text { NO SETOR } \\
\text { DE SM }\end{array}$ \\
\hline 1 & I & 1 & - & 1 & - & - & 1 & - & - & - & 1 & 1 & - & 1 & 1 & - \\
\hline 22 & Il & 1 & - & 1 & - & - & - & - & - & - & - & - & - & - & - & - \\
\hline 23 & I I & 2 & - & 2 & 1 & - & 1 & - & - & 1 & - & 1 & - & 1 & - & - \\
\hline 34 & I I I & 1 & - & 1 & - & - & - & - & - & - & - & 1 & - & 1 & 1 & - \\
\hline 35 & I I I & 1 & - & 1 & - & - & - & - & - & - & - & 1 & - & 1 & - & - \\
\hline 75 & V & 1 & - & 1 & 1 & & $\mathbf{x}$ & $x$ & $x$ & $x$ & $x$ & $x$ & $x$ & $x$ & $x$ & $x$ \\
\hline 81 & V & 1 & - & 1 & - & - & $\mathbf{x}$ & $x$ & $x$ & $x$ & $x$ & $x$ & $x$ & $x$ & $x$ & $x$ \\
\hline
\end{tabular}


QUADRO 16- Disponibilidade do I.N. responsável pela C.M. e A.E. realizadas nos CS do DRS-1. SP, segundo a classificação do CS e a numeração do mesmo na pesquisa. SP, 1979.

R. 1.2

\begin{tabular}{|c|c|c|c|c|c|c|c|c|c|c|c|c|c|c|c|c|}
\hline \multicolumn{2}{|c|}{ C.S. } & \multicolumn{5}{|c|}{$M E D I C O$} & \multicolumn{5}{|c|}{ E N F E R M E I R A } & \multicolumn{5}{|c|}{ O B S T E T R I Z } \\
\hline $\begin{array}{l}\text { NP NA } \\
\text { PESQUI } \\
\text { SA }\end{array}$ & $\begin{array}{c}\text { CLASSIFI } \\
\text { CAÇAO NA } \\
\text { SES }\end{array}$ & LOTA & $\begin{array}{l}\text { REALI } \\
\text { ZA TRI } \\
\text { AGEM }\end{array}$ & $\begin{array}{l}\text { REALI } \\
\text { ZA OON } \\
\text { SULTA }\end{array}$ & $\begin{array}{l}\text { REALIZA } \\
\text { OUTRA A- } \\
\text { T IVIDADE }\end{array}$ & $\begin{array}{l}\text { SEM ATI } \\
\text { VIDADE } \\
\text { NO SETOR } \\
\text { DE SM }\end{array}$ & $\begin{array}{l}\text { LOTA } \\
\text { ÇAO }\end{array}$ & $\begin{array}{l}\text { REALI } \\
\text { ZA TRI } \\
\text { AGEM }\end{array}$ & $\begin{array}{l}\text { REALI } \\
\mathrm{ZA} \\
\mathrm{AE}\end{array}$ & $\begin{array}{l}\text { REALIZA } \\
\text { OUTRA A } \\
\text { T IVIDADE }\end{array}$ & $\begin{array}{l}\text { SEM ATI } \\
\text { VIDADE } \\
\text { NO SETOR } \\
\text { DE SM }\end{array}$ & $\begin{array}{l}\text { LOTA } \\
\text { ÇĀO }\end{array}$ & $\begin{array}{l}\text { REALI } \\
\text { ZA TRI } \\
\text { AGEM } \\
\end{array}$ & $\begin{array}{c}\text { REALI } \\
\mathrm{ZA} \\
\mathrm{AE}\end{array}$ & $\begin{array}{l}\text { REALIZA } \\
\text { OUTRA A } \\
\text { IVIDADE }\end{array}$ & $\begin{array}{l}\text { SEM AT I } \\
\text { VIDADE } \\
\text { NO SETOR } \\
D E \quad S M \\
\end{array}$ \\
\hline 5 & I & 1 & - & 1 & - & - & 2 & - & - & 1 & 1 & 2 & - & 2 & - & - \\
\hline 8 & I & 1 & - & 1 & - & - & 1 & - & 1 & 1 & - & 1 & - & - & - & 1 \\
\hline 24 & I I & 1 & - & 1 & - & - & - & - & - & - & - & - & - & - & - & - \\
\hline 36 & I I I & 1 & - & 1 & - & - & - & - & - & - & - & - & - & - & - & - \\
\hline 40 & I I I & 1 & - & 1 & - & - & - & - & - & - & - & - & - & - & - & - \\
\hline 41 & [I] & 1 & - & 1 & - & - & 1 & - & - & - & 1 & - & - & - & - & - \\
\hline 48 & IV & 1 & - & 1 & - & 1 & $\mathbf{x}$ & $x$ & $x$ & $x$ & $x$ & $x$ & $x$ & $x$ & $x$ & $x$ \\
\hline 50 & IV & 1 & - & 1 & - & - & $\mathbf{x}$ & $x$ & $x$ & $x$ & $x$ & $x$ & $x$ & $x$ & $\mathbf{x}$ & $x$ \\
\hline 53 & IV & 1 & - & 1 & 1 & - & $\mathbf{x}$ & $x$ & $x$ & $x$ & $x$ & $\mathbf{x}$ & $\mathbf{x}$ & $\mathbf{x}$ & $x$ & $x$ \\
\hline 84 & V & 1 & - & 1 & - & - & $x$ & $x$ & $x$ & $\mathbf{x}$ & $x$ & $\mathbf{x}$ & $x$ & $x$ & $x$ & $x$ \\
\hline 85 & V & 1 & - & 1 & 1 & - & $\mathbf{x}$ & $x$ & $\mathbf{x}$ & $x$ & $x$ & $\mathbf{x}$ & $\mathbf{x}$ & $x$ & $x$ & $x$ \\
\hline 87 & V & 1 & - & 1 & 1 & - & $\mathbf{x}$ & $x$ & $\mathbf{x}$ & $x$ & $x$ & $x$ & $x$ & $x$ & $x$ & $x$ \\
\hline 102 & V & 1 & - & 1 & 1 & - & $\mathbf{x}$ & $\mathbf{x}$ & $\mathbf{x}$ & $x$ & $\mathbf{x}$ & $x$ & $x$ & $x$ & $x$ & $x$ \\
\hline 107 & V & 1 & - & 1 & - & - & $\mathbf{x}$ & $\mathbf{x}$ & $x$ & $\mathbf{x}$ & $\mathbf{x}$ & $\mathbf{x}$ & $x$ & $x$ & $x$ & $x$ \\
\hline 112 & V & 1 & - & 1 & 1 & - & $\mathbf{x}$ & $x$ & $\mathbf{x}$ & $x$ & $x$ & $x$ & $x$ & $x$ & $x$ & $x$ \\
\hline 119 & V & 1 & - & 1 & 1 & - & $\mathbf{x}$ & $\mathbf{x}$ & $x$ & $x$ & $x$ & $x$ & $\underline{x}$ & $x$ & $\underline{x}$ & $\mathbf{x}$ \\
\hline
\end{tabular}


QUADRO 17 -Disponibilidade do I.N. responsävel pela C.M. e A.E. realizadas nos CS do DRS-1, SP, segundo a classificação do CS e a numeração do mesmo na pesquisa. SP, 1979.

R.1.3

\begin{tabular}{|c|c|c|c|c|c|c|c|c|c|c|c|c|c|c|c|c|}
\hline \multicolumn{2}{|c|}{ C.s. } & \multicolumn{5}{|c|}{ ME D I C 0} & \multicolumn{5}{|c|}{ E N F $F$ E R M } & \multicolumn{5}{|c|}{ 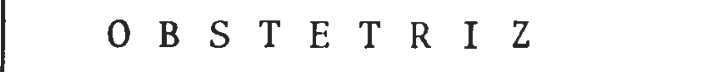 } \\
\hline $\begin{array}{ll}N^{9} & N A \\
\text { PESQUI- } \\
\text { SA }\end{array}$ & $\begin{array}{l}\text { CLASSIFI } \\
\text { CAO NA } \\
\text { SES }\end{array}$ & $\begin{array}{l}\text { LOTA } \\
\text { CAO }\end{array}$ & $\begin{array}{l}\text { REALI- } \\
\text { ZA TRIA } \\
\text { GEM }\end{array}$ & $\begin{array}{l}\text { REALI- } \\
\text { ZA CON } \\
\text { SULTA }\end{array}$ & $\begin{array}{l}\text { REALIZA } \\
\text { TUTRA A } \\
\text { TIDIDADE }\end{array}$ & $\begin{array}{l}\text { SEM ATI } \\
\text { VIDADE } \\
\text { No SETCR } \\
\text { SM }\end{array}$ & $\begin{array}{l}\text { LOTA } \\
\text { CAOO }\end{array}$ & $\begin{array}{l}\text { REALI } \\
\text { ZA TRI } \\
\text { GEM }\end{array}$ & $\left\{\begin{array}{l}\text { REALI - } \\
\mathrm{ZA} \\
\mathrm{AE}\end{array}\right.$ & $\begin{array}{l}\text { REAL IZA } \\
\text { OUTRA A } \\
\text { TIVIDADE }\end{array}$ & $\begin{array}{l}\text { SEM ATI } \\
\text { VIDAnE } \\
\text { NO SETOR } \\
\text { SM }\end{array}$ & $\begin{array}{l}\text { LOTA } \\
\text { SAO }\end{array}$ & $\mid \begin{array}{ll}\text { REALI - } \\
\text { ZA } & \text { TRI } \\
\text { GEM }\end{array}$ & $\left\{\begin{array}{l}\text { REALI } \\
Z \mathrm{~A} \\
\mathrm{AE}\end{array}\right.$ & $\begin{array}{l}\text { REALIZA } \\
\text { OUTRA A } \\
\text { TIVIDADE }\end{array}$ & $\begin{array}{l}\text { SEM ATI } \\
\text { VIDADE } \\
\text { NO SETOR } \\
\text { SM }\end{array}$ \\
\hline 12 & I & 1 & - & 1 & - & - & 1 & - & - & - & 1 & 1 & - & 1 & 1 & - \\
\hline 13 & I & 1 & - & 1 & 1 & - & - & - & - & - & - & 1 & - & 1 & 1 & - \\
\hline 28 & II & 1 & - & 1 & $\perp$ & - & 1 & - & - & - & 1 & 1 & - & 1 & 1 & - \\
\hline 43 & I I I & 1 & - & 1 & - & - & - & - & - & - & - & 1 & - & 1 & 1 & - \\
\hline 57 & IV & 1 & - & 1 & - & - & - & - & - & - & - & 1 & - & 1 & - & - \\
\hline 118 & $\mathrm{v}$ & 1 & - & 1 & - & - & $x$ & $x$ & $\mathbf{x}$ & $\mathbf{x}$ & $\mathbf{x}$ & $\mathrm{x}$ & $\mathbf{x}$ & $\mathrm{x}$ & $\mathbf{x}$ & \\
\hline 119 & v & 1 & - & 1 & 1 & 1 & $x$ & $x$ & $x$ & $x$ & $x$ & $x$ & $x$ & $x$ & $x$ & \\
\hline 120 & $\mathrm{~V}$ & 1 & - & 1 & 1 & - & $x$ & $x$ & $x$ & $x$ & $x$ & $x$ & $x$ & $x$ & $x$ & \\
\hline 132 & V & 2 & - & 2 & - & - & $\mathrm{x}$ & $x$ & $x$ & $x$ & $\mathbf{x}$ & $x$ & $x$ & $x$ & $x$ & \\
\hline & V & 1 & - & 1 & - & - & $x$ & $x$ & $x$ & $x$ & $x$ & $x$ & $x$ & $x$ & $x$ & \\
\hline
\end{tabular}


QUADRO 18 -Disponibilidade do I.N. responsāvel pela C.M. e A.E. realizadas nos CS do DRS-1, SP, segundo a classificação do CS e a numeração do mesmo na pesquisa. SP, 1979.

R. 1 . 4

\begin{tabular}{|c|c|c|c|c|c|c|c|c|c|c|c|c|c|c|c|c|}
\hline \multicolumn{2}{|c|}{ C.S } & \multicolumn{5}{|c|}{$\begin{array}{lllllll} & E & D & I & C & 0\end{array}$} & \multicolumn{5}{|c|}{ E N F E R M E I R A } & \multicolumn{5}{|c|}{$\begin{array}{lllllllll}O & \mathrm{~B} & \mathrm{~S} & \mathrm{~T} & \mathrm{E} & \mathrm{T} & \mathrm{R} & \mathrm{I} & \mathrm{Z}\end{array}$} \\
\hline$N^{2} \mathrm{NA}$ & CLASSIFI & LOTA & REALI & REALI & REALIZA & SEM ATI- & LOOTA & REALI & REALI & REALIZA & SEM ATI & LOTA & REALI- & REALI & REALIZA & SEM AT I \\
\hline PESQUI & ÇAO NA & ÇAO & ZA TRI & ZA CON & OUTRA $\underline{\text { A }}$ & $\begin{array}{l}\text { VIDADE NO } \\
\text { SETOR DE }\end{array}$ & ÇAO & ZA TRI & & OUTRA $\underline{A}$ & $\begin{array}{l}\text { VIDADE } \\
\text { NO SETOR }\end{array}$ & ÇĀO & ZA TRI & $\mathrm{ZA}$ & OUTRA A & NO SETOR \\
\hline SA & SES & & AGEM & SULTA & TIVIDADE & SM & & AGEM & $\mathrm{AE}$ & TIVIDADE & DE SM & & AGEM & & TIVIDADE & DE SM \\
\hline 17. & I & 1 & - & 1 & - & - & 1 & - & - & 1 & - & 3 & - & 2 & - & 1 \\
\hline 21 & I & 1 & - & 1 & 1 & - & 1 & - & - & 1 & - & 4 & - & 2 & - & 2 \\
\hline 29 & I I & 1 & - & 1 & 1 & - & 1 & - & - & 1 & - & - & - & - & - & - \\
\hline 30 & I I & 1 & - & 1 & & - & 1 & - & - & 1 & - & 1 & - & 1 & 1 & - \\
\hline 45 & I I I & 1 & - & 1 & 1 & - & - & - & - & - & - & - & - & - & - & - \\
\hline 46 & I I I & 1 & - & 1 & 1 & - & - & - & - & - & - & - & - & - & - & - \\
\hline 58 & IV & 1 & - & 1 & 1 & - & $x$ & $x$ & $\mathbf{x}$ & $x$ & $x$ & $\mathbf{x}$ & $\mathbf{x}$ & $\mathbf{x}$ & $x$ & $x$ \\
\hline 59 & IV & 1 & - & 1 & 1 & - & $\mathbf{x}$ & $x$ & $\mathbf{x}$ & $x$ & $x$ & $\mathbf{x}$ & $\mathbf{x}$ & $\mathbf{x}$ & $\mathbf{x}$ & $x$ \\
\hline 67 & IV & 1 & - & 1 & - & - & $x$ & $\mathbf{x}$ & $\mathbf{x}$ & $x$ & $\mathbf{x}$ & $x$ & $x$ & $x$ & $x$ & $x$ \\
\hline 69 & IV & 1 & - & 1 & 1 & - & $x$ & $\mathbf{x}$ & $\mathbf{x}$ & $x$ & $\mathbf{x}$ & $\mathbf{x}$ & $x$ & $x$ & $x$ & $x$ \\
\hline 70 & IV & 1 & - & 1 & - & - & $\mathbf{x}$ & $\mathbf{x}$ & $\mathbf{x}$ & $x$ & $x$ & $\mathbf{x}$ & $\mathbf{x}$ & $x$ & $\mathbf{x}$ & $x$ \\
\hline 72 & IV & 2 & - & 2 & 1 & - & $x$ & $x$ & $\mathbf{x}$ & $x$ & $\mathbf{x}$ & $\mathbf{X}$ & $\mathbf{x}$ & $x$ & $\mathbf{x}$ & $\mathbf{x}$ \\
\hline 142 & V & 1 & - & 1 & 1 & - & $x$ & $\mathbf{x}$ & $\mathbf{x}$ & $\mathbf{x}$ & $\mathbf{x}$ & $x$ & $\mathbf{x}$ & $x$ & $\mathbf{x}$ & $\mathbf{x}$ \\
\hline 148 & V & 1 & - & 1 & 1 & - & $x$ & $\mathbf{x}$ & $x$ & $\mathbf{x}$ & $x$ & $\mathbf{x}$ & $\mathbf{x}$ & $\mathbf{x}$ & $x$ & $\mathbf{x}$ \\
\hline 149 & V & 1 & - & 1 & - & - & $\mathbf{x}$ & $\mathbf{x}$ & $\mathbf{x}$ & $\mathbf{x}$ & $x$ & $x$ & $x$ & $\mathbf{x}$ & $\mathbf{x}$ & $\mathbf{x}$ \\
\hline 150 & V & 1 & - & 1 & 1 & - & $x$ & $\mathbf{x}$ & $\mathbf{x}$ & $\mathbf{x}$ & $\mathbf{x}$ & $\mathbf{x}$ & $\mathbf{x}$ & $\mathbf{x}$ & $x$ & $x$ \\
\hline 158 & V & 1 & - & 1 & - & - & $\mathbf{x}$ & $\mathbf{x}$ & $x$ & $\mathbf{x}$ & $\mathbf{x}$ & $\mathbf{x}$ & $\mathbf{x}$ & $\mathbf{x}$ & $x$ & $x$ \\
\hline 159 & V & 1 & - & 1 & - & - & $x$ & $\mathbf{x}$ & $\mathbf{x}$ & $x$ & $x$ & $\mathbf{x}$ & $\mathbf{x}$ & $x$ & $\mathbf{x}$ & $\mathbf{x}$ \\
\hline 163 & V & 1 & - & 1 & - & - & $x$ & $\mathbf{x}$ & $\mathbf{x}$ & $\mathbf{x}$ & $\mathbf{x}$ & $\mathbf{x}$ & $\mathbf{x}^{\prime}$ & $\mathbf{x}$ & $\mathbf{x}$ & $\mathbf{x}$ \\
\hline 186 & V & 1 & - & 1 & 1 & - & $x$ & $x$ & $\mathbf{x}$ & $x$ & $x$ & $\mathbf{x}$ & $x$ & $\mathbf{x}$ & $\mathbf{x}$ & $\mathbf{x}$ \\
\hline 187 & V & 1 & - & 1 & - & - & $x$ & $\mathbf{x}$ & $\mathbf{x}$ & $x$ & $x$ & $x$ & $\mathbf{x}$ & $\mathbf{x}$ & $x$ & $\mathbf{x}$ \\
\hline $\begin{array}{l}193 \\
194\end{array}$ & $V$ & $\frac{1}{1}$ & I & $\frac{1}{1}$ & - & $\overline{-}$ & $\begin{array}{l}x \\
x\end{array}$ & $\begin{array}{l}x \\
x\end{array}$ & $\begin{array}{l}x \\
x\end{array}$ & $\begin{array}{l}x \\
x\end{array}$ & $\mathbf{x}$ & $x$ & $\mathbf{x}$ & $x$ & $\begin{array}{l}x \\
x\end{array}$ & $x$ \\
\hline
\end{tabular}


dros $\mathrm{n}^{8} \mathrm{~s} 15$ a 18 temos:

- 59 médicos em exercício efetivo nos centros de saủde da amostra: 8 na R.1.1; 16 na R.1.2; 11 na R.1.3 e 24 na R.1.4.

A caracterização desta hora/instrumento serä tratạ da posteriormente.

- das 29* enfermeiras em exercício no DRS-1, 12 fo ram localizadas nas unidades sanitärias estudadas; assim distribuídas:

. 2 na R.1.1; 4 na R.1.2; 2 na R.1.3 e 4 na R.1.4, cada uma com 1.440 horas/trabalho disponiveis;

- há previsão para exercício da hora/enfermeira so mente nos centros de saủde I e II em virtude da escassez do instrumento, tendo sido identifica da a sua presença somente em 1 centro de saủde tipo III da amostra;

- Quanto às obstetrizes não foi possível conhecer o seu dimensionamento global; sua presença efetiva foi identificada com a seguinte distribuição: to ta1 21:

- 4 na R.1.1; 3 na R.1.2; 5 na R.1.3 e 9 na R.1. 4 .

Estes resultados foram utilizados para estruturação do Quadro de Computação - Anexo IV do qual foram extraídos os dados para o teste de associação dessa variável com o tempo de espera.

* Informação obtida da relação fornecida pelo Serviço de En fermagem do Nível Central da C.S.C. - S.E.S. - SP. 
3.5.1 Teste da relação com o instrumento nuclear

A Tabela 23 registra as gestantes segundo o tempo de espera da consulta e a presença do instrumento nuclear.Esses dados foram reelaborados, conforme a Tabe1a 24 para aplicação do teste da mediana.

o valor do $x^{2}$ calculado é 45,805 , superior, portanto, àque le tabulado $(7,815)$ para os graus de liberdade e nível de confiança de $95 \%$. Pode-se rejeitar, então, a hipótese nula.

Concluiu-se, portanto, que o tempo de espera está re lacionado com o instrumento nuclear, sendo maior naqueles cen tros de saúde que possuem enfermeira e obstetriz e bastante pe queno naqueles que possuem somente obstetriz.

TABELA 23-Gestantes segundo o tempo de espera da consulta e a presença do instrumento nuclear. SP,1979.

\begin{tabular}{c|c|c|c|c}
\hline \multirow{2}{*}{$\begin{array}{c}\text { TEMPO DE } \\
\text { ESPRA }\end{array}$} & \multicolumn{4}{|c}{ PRESENÇA } \\
\cline { 2 - 6 } & $\begin{array}{c}\text { ENFERMEIRA } \\
\text { E OBSTETRIZ }\end{array}$ & $\begin{array}{c}\text { SOMENTE } \\
\text { ENFERME IRA }\end{array}$ & $\begin{array}{c}\text { SOMENTE } \\
\text { OBSTETRIZ }\end{array}$ & $\begin{array}{l}\text { SEM ENFERMEI } \\
\text { RA OU OBSTET. }\end{array}$ \\
\hline 0 & 252 & 102 & 139 & 818 \\
$-1-10$ & 48 & 25 & 5 & 161 \\
$11-20$ & 17 & 2 & - & 19 \\
$21-40$ & 43 & 4 & - & 40 \\
$41-80$ & 6 & 2 & 2 & 16 \\
$81-120$ & 2 & - & 1 & 1.058 \\
\hline
\end{tabular}


TABELA 24 - Gestantes segundo a mediana do tempo de espera da consulta e a presen ça do instrumento nuclear (teste da mediana). SP, 1979.

\begin{tabular}{|c|c|c|c|c|c|}
\hline \multirow{2}{*}{$\begin{array}{l}\text { POS IÇÃO RELA } \\
\text { TIVAMENTE } \bar{A} \\
\text { MEDIANA } \\
\text { COMUM }\end{array}$} & \multicolumn{4}{|c|}{ PRESENÇA DO INSTRUMENTO NUCLEAR } & \multirow{2}{*}{ TOTAL } \\
\hline & $\begin{array}{l}\text { ENFERME IRA } \\
\text { O OBSTETR IZ }\end{array}$ & $\begin{array}{l}\text { SOMENTE } \\
\text { ENFERME I RA }\end{array}$ & $\begin{array}{l}\text { SOMENTE } \\
\text { OBSTETRIZ }\end{array}$ & $\begin{array}{l}\text { SEM ENFERMEI- } \\
\text { RA OU OBSTET. }\end{array}$ & \\
\hline Não excedem & $\begin{array}{r}232 \\
(266,15)\end{array}$ & $\begin{array}{c}102 \\
(103,25)\end{array}$ & $\begin{array}{c}139 \\
(112,43)\end{array}$ & $\begin{array}{c}818 \\
(809,17)\end{array}$ & 1.291 \\
\hline Exce dem & $\begin{array}{c}116 \\
(81,85)\end{array}$ & $\begin{array}{c}33 \\
(31,75)\end{array}$ & $\begin{array}{r}8 \\
(34,57)\end{array}$ & $\begin{array}{c}240 \\
(248,83)\end{array}$ & 397 \\
\hline TOTAL & 348 & 135 & 147 & 1.058 & 1.688 \\
\hline
\end{tabular}

Nota: os números entre parênteses sāo as frequências esperadas sob a hipōtese nu 1 a.

$x_{\text {calc. }}^{2}=45,805$ 
Poderíamos estranhar que a prova da associação des ta variável indique uma correlação do aumento do tempo de espera nas unidades sanitárias onde estão disponíveis os 3 instrumentos: o médico, pois ele é essencial para a presta ção da assistência, por isto não foi mencionado, a enferme ra e a obstetriz. Desde que os 3 sāo capacitados para o cum primento da função primordial da assistência de saúde à ges tante, sem nos determos no aspecto do gradiente envolvido nessa habilitação, seria lógico o resultado oposto: o tempo de espera deveria tender a diminuir onde os três instrunen tos se achassem presentes. Algumas suposições e algumas ce $\underline{r}$ tezas podem ser invocadas para explicar o fenômeno.Como cer teza estão aí os resultados do levantamento, alguns já apre sentados e discutidos: a enfermeira só é designada para as unidades de atendimento mais complexo, os centros de saúde tipo I e II, sendo que nos centros de saúde tipo III os car gos de enfermeira estão vagos por escassez do profissional ${ }^{*}$. Nos centros de saúde, de programação mais desenvolvida,pelo menos os do tipo $I, j a ̄$ houve uma associação positiva entre o aumento do tempo de espera e o tipo do centro de saúde. Es ta é uma da razões que explicaria a tendência do teste na presente variāvel. Os dados básicos são os mesmos, o que mu dou foram as circustâncias sob que são apresentados esses dados no estudo do relacionamento desta variável.

Além disto, foi verificado, analisado e discutido no estudo do relacionamento tempo de espera e cobertura,que as associações que interligam as flutuações destes dois fe nómenos podem provavelmente ser motivadas pela qualidade de diversos outros atibutos da consulta médica os quais estão igualmente presentes na estrutura subjacente desta variável; afinal, dela não foi excluída, apenas não foi mencionada, a hora/instrumento da consulta médica, responsável pela exis

* Informação estraída do cocumento já referido neste item, procedente do Serviço de Enfermagem - C.S.C. - S.E.S. $\mathrm{SP}$. 
tência da variável dependente que é um dos vértices desse triângulo que observamos.

Como suposição podemos levantar questões: se as en fermeiras e obstetrizes estivessem atuando plenamente ou se pudessem atuar plenamente na prestação da assistência de en fermagem, talvez a associação com a variável "disponibilida de do instrumento nuclear..." não tivesse sido positiva. Es ta suposição será discutida oportunamente.

3.6 Variāvel "Trimestre da gestação ao tempo da inscrição".

Como ficou dito no Capítulo VI as gestantes selecio nadas para constituirem a amostra nos centros de saúde, fo ram identificadas por meio das fichas arquivadas nesses cen tros. Dessas fichas retiramos os dados com que construímos as Tabelas de no 9 a 12 em que apresentamos uma amostra do vo lume de inscrições havidas no tempo do estudo, distribuída conforme o trimestre da gestação em que a inscrição se deu, segundo o centro de saủde focalizado e a Regional a ele re ferente.

Na R.1.1 ( Tabela 9 ) como podemos ver das 237 ins crições selecionadas a maior porção-109, concentrou-se no $2{ }^{\circ}$ trimestre $(45,99 \%)$, ficando $90(37,97 \%)$ no $1^{\circ}$ e 38 $(16,03 \%)$ no $3^{\circ}$.

Na R.1.2 ( Tabela 10 ) das 621 inscrições havidas foi a seguinte a distribuição:

- $221(35,59 \%)$ no $11^{\circ}$ trimestre

- $315(50,72 \%)$ no $2^{\circ}$ trimestre

- $85(13,69 \%)$ no $33^{\circ}$ trimestre.

Na R.1.3 as 201 inscrições ficaram assim distribuí das, Tabela 1]:

- $59(29,35 \%)$ no $1^{\circ}$ trimestre

- $113(56,22 \%)$ no $2{ }^{\circ}$ trimestre 
TABELA 9-Número de gestantes inscritas por idade de gestação, nos meses de janeiro a setembro de 1979 nas unidades sanitárias DRS-1, SP - incluídas na pes quisa, segundo a Regional e o tipo de CS, conforme amostra colhida no 1o cal. SP, 1979 .

R.1.1

\begin{tabular}{|c|c|c|c|c|c|c|}
\hline $\begin{array}{l}\text { TIPO } \\
\text { CS } \\
\text { CSA }\end{array}$ & $\begin{array}{l}N^{\circ} \quad \text { DO } \quad \text { CS } \\
\text { NA PESQUISA }\end{array}$ & DISTRITO SANITARIO & $\begin{array}{l}\text { INSCR . NO } \\
1^{8} \text { TRIMEST }\end{array}$ & $\begin{array}{ll}\text { INSCR. NO } \\
2^{\circ} & \text { TRIMEST. }\end{array}$ & $\begin{array}{l}\text { INSCR. NO } \\
3^{\circ} \\
\text { TRIMEST. }\end{array}$ & TOTAL \\
\hline I & 1 & Santa Cecília & 23 & 13 & 6 & 42 \\
\hline I I & 22 & Santa Cecília & 9 & 22 & 6 & 37 \\
\hline I I & 23 & Belenzinho & 17 & 27 & 7 & 51 \\
\hline I I I & 34 & Belenzinho & 11 & 14 & 7 & 32 \\
\hline I I I & 35 & Belenzinho & 17 & 25 & 2 & 44 \\
\hline $\mathrm{V}$ & 75 & Belenzinho & 6 & 10 & - & 16 \\
\hline V & 81 & Vila Mariana & 9 & 3 & 3 & 15 \\
\hline
\end{tabular}


TABEla 10 - Número de gestantes inscritas por idade da gestação nos meses de jane $\underline{i}$ ro a setembro de 1979 nas unidades sanitárias do DRS-1, SP incluídas na pesquisa, segundo a Regional e o Tipo de CS, conforme amostra colhida no local. SP, 1979 .

R. 1.2

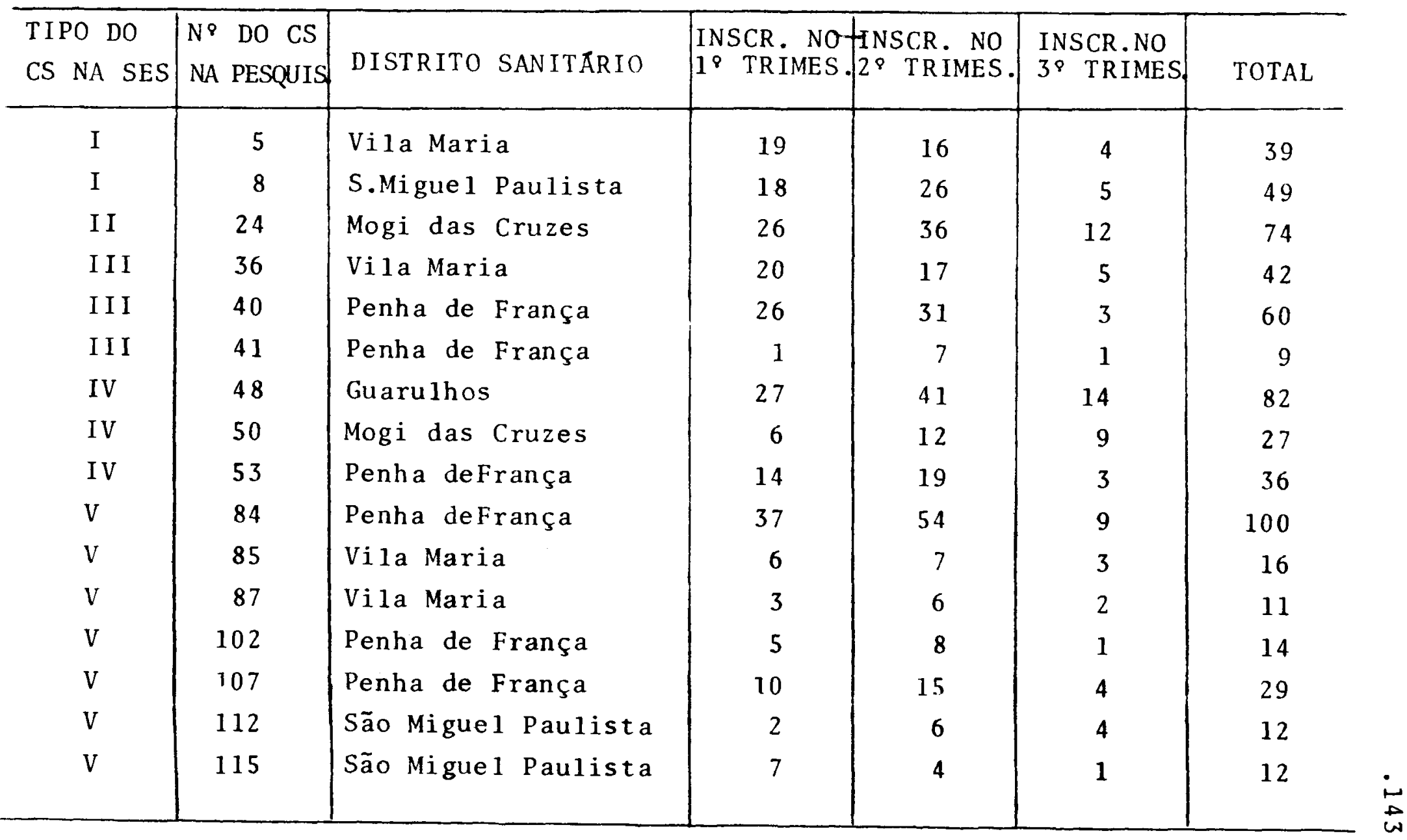


TABELA 11-Nümero de gestantes inscritas por idade da gestação nos meses de jane $\underline{\mathbf{i}}$ ro a setembro de 1979 nas unidades sanitárias do DRS-1,SP, incluídas na pesquisa, segundo a Regional e o tipo de CS, conforme amostra colhi da no local. SP, 1979 .

R. 1.3

\begin{tabular}{|c|c|c|c|c|c|c|}
\hline $\begin{array}{l}\text { TIPO DO } \\
\text { CS NA SES }\end{array}$ & $\begin{array}{lll}N^{8} & D O & C S \\
N A & P E S Q U I S\end{array}$ & DISTRITO SANITRRIO & $\begin{array}{l}\text { INSCR. NOI } \\
1^{\circ} \text { TRIMES } 2\end{array}$ & $\begin{array}{l}\text { SCR. NO } \\
\text { TRIMES. }\end{array}$ & $\begin{array}{l}\text { INSCR. NO } \\
3^{\circ} \text { TRIMES. }\end{array}$ & TOTAL \\
\hline I & 12 & S.Bernardo do Campo & 14 & 22 & 3 & 40 \\
\hline I & 13 & S. Caetano do Su 1 & 14 & 19 & 5 & 38 \\
\hline I I & 2.8 & S.Bernardo do Campo & 2 & 11 & 3 & 16 \\
\hline I I I & 43 & Jabaquara & 15 & 39 & 9 & 63 \\
\hline IV & 57 & Vila Prudente & 3 & 7 & 1 & 11 \\
\hline V & 118 & Santo André & 3 & 1 & 2 & 6 \\
\hline V & 119 & Santo André & 4 & 2 & 6 & 12 \\
\hline V & 120 & Santo André & 1 & 3 & 2 & 6 \\
\hline V & 1.32 & Vila Prudente & 3 & 3 & - & 6 \\
\hline V & 135 & Vila Prudente & - & 11 & 1 & 12 \\
\hline
\end{tabular}


TABELA 12-Nümero de gestantes inscritas por idade da gestação nos meses de jane ro a setembro de 1979 nas unidades sanitārias do DRS-1, SP incluídas na pesquisa, segundo a Regional e o tipo de CS, conforme amostra colhida no local. SP, 1979 .

R. 1.4

\begin{tabular}{|c|c|c|c|c|c|c|}
\hline $\begin{array}{lll}\text { TIPO } & \text { DO } \\
\text { CS NA } & \text { SES }\end{array}$ & $\begin{array}{ll}\text { NP } & \text { DO CS } \\
\text { NA } & \text { PESQU S }\end{array}$ & DISTRITO SANITARIO & $\begin{array}{l}\text { INSCR . NO } \\
1^{\circ} \text { TRIMES }\end{array}$ & $\begin{array}{ll}\text { INSCR. NO } \\
2^{\circ} & \text { TRIMES }\end{array}$ & $\begin{array}{l}\text { INSCR. NO } \\
3^{\circ} \text { TRIMES. }\end{array}$ & TOTAL \\
\hline $\begin{array}{l}\text { I } \\
\text { I I } \\
\text { I I } \\
\text { I I I } \\
\text { I I I } \\
\text { IV } \\
\text { IV } \\
\text { IV } \\
\text { IV } \\
\text { IV } \\
\text { IV } \\
\text { V } \\
\text { V } \\
\text { V } \\
\text { V } \\
\text { V } \\
\text { V } \\
\text { V } \\
\text { V } \\
\text { V } \\
\text { V } \\
\text { V }\end{array}$ & $\begin{array}{l}17 \\
21 \\
29 \\
30 \\
45 \\
46 \\
58 \\
59 \\
67 \\
69 \\
70 \\
72 \\
142 \\
148 \\
149 \\
150 \\
158 \\
159 \\
163 \\
186 \\
187 \\
193 \\
194\end{array}$ & $\begin{array}{l}\text { Butantã } \\
\text { Santo Amaro } \\
\text { Osasco } \\
\text { Butantã } \\
\text { Nossa Senhora do } 0 \\
\text { Tucuruvi } \\
\text { Osasco } \\
\text { Osasco } \\
\text { Lapa } \\
\text { Nosa Senhora do } 0 \\
\text { Tucuruvi } \\
\text { ltapecerica da Serra } \\
\text { Osasco } \\
\text { Butantã } \\
\text { Butantã } \\
\text { Butant ã } \\
\text { Lapa } \\
\text { Lapa } \\
\text { Lapa } \\
\text { Santo Amaro } \\
\text { Santo Amaro } \\
\text { Itapecerica da Serra } \\
\text { Itapecerica da Serra }\end{array}$ & $\begin{array}{r}7 \\
10 \\
22 \\
29 \\
17 \\
13 \\
13 \\
6 \\
4 \\
2 \\
7 \\
13 \\
25 \\
16 \\
4 \\
4 \\
5 \\
9 \\
2 \\
13 \\
11 \\
4 \\
-\end{array}$ & $\begin{array}{r}10 \\
22 \\
43 \\
21 \\
24 \\
21 \\
22 \\
16 \\
6 \\
7 \\
25 \\
36 \\
27 \\
26 \\
7 \\
7 \\
7 \\
7 \\
1 \\
16 \\
13 \\
6 \\
2\end{array}$ & $\begin{array}{r}3 \\
8 \\
11 \\
1 \\
5 \\
1 \\
7 \\
2 \\
2 \\
- \\
4 \\
12 \\
11 \\
11 \\
3 \\
2 \\
- \\
2 \\
3 \\
5 \\
12 \\
3 \\
1\end{array}$ & $\begin{array}{r}20 \\
40 \\
76 \\
51 \\
46 \\
35 \\
42 \\
24 \\
12 \\
9 \\
36 \\
61 \\
63 \\
53 \\
14 \\
13 \\
12 \\
18 \\
6 \\
34 \\
36 \\
13 \\
3\end{array}$ \\
\hline
\end{tabular}


$-29(9,64 \%)$ no 39 trimestre.

Na R.1.4 as 736 inscrições distribuíram-se da seguin te forma (Tabela 11):

$-236(32,07 \%)$ no $1^{8}$ trimestre

- $391(53,13 \%)$ no $2 \%$ trimestre

- $109(14,81 \%)$ no 39 trimestre

A tendência observada nas outras Regionais foi i dên tica a da R.1.1, com a maior concentração de inscrições cain do no $2^{\circ}$ trimestre, como, aliās, é a moda jā observada em nossos serviços, segundo relato de ciari Jr. C. et al ${ }^{19}$.

Os dados citados também prestaram-se para a elabora ção do Quadro 36 em que apresentamos a média da idade ges tacional ao tempo da inscrição em cada unidade sanitāria dis criminada por Regional.

O tempo de espera das gestantes amostradas foi pro cessado, utilizando-se também estes dados relativos à idade da gestação.

Achamos importante e interessante testar se esse tem po de espera flutuaria com as variaçōes da idade da gesta ção em que as gestantes se inscreveram.

Os resultados do teste, embora indicando outra pro blemática, estão dentro do contexto encontrado. 
3.6.l Teste da relação com a idade da gestação.

A distribuição das gestantes segundo o tempo de espe ra da consulta e a idade da gestação é aquela da Tabela 25 .

Foram reelaborados os elementos para aplicação do tes te da mediana, como se mostra na Tabela 26.

$0 x^{2}$ encontrado $\vec{e} 1,366$, que è menor que o tabulado $(5,991)$ para 2 graus de liberdade e nível de significância de $5 \%$. Não se pode, assim, rejeitar a hipótese nula.

A conclusão é que o tempo de espera da consulta não estã relacionado com a idade da gestação.

TABELA $2 \dot{5}$-Gestantes segundo o tempo de espera da consulta e a idade da gestação. SP, 1979.

\begin{tabular}{|c|c|c|c|c|c|c|c|}
\hline \multirow{2}{*}{\multicolumn{2}{|c|}{$\begin{array}{l}\text { TEMPO DE } \\
\text { ESPERA } \\
\text { (dias) }\end{array}$}} & \multicolumn{3}{|c|}{ IDADE } & \multicolumn{2}{|c|}{ GESTAÇAO } & \multirow[b]{2}{*}{ trimestre } \\
\hline & & $1^{\circ}$ & trimestre & $2 \circ$ & trimestre & $3^{\circ}$ & \\
\hline \multicolumn{2}{|l|}{0} & \multicolumn{3}{|c|}{454} & \multicolumn{2}{|l|}{650} & 187 \\
\hline 1 & -10 & \multicolumn{3}{|c|}{84} & \multicolumn{2}{|l|}{119} & 36 \\
\hline 11 & -20 & \multicolumn{3}{|c|}{17} & \multicolumn{2}{|l|}{21} & - \\
\hline 21 & -40 & \multicolumn{3}{|c|}{33} & \multicolumn{2}{|l|}{40} & 14 \\
\hline 41 & -80 & \multicolumn{3}{|c|}{12} & \multicolumn{2}{|l|}{13} & 1 \\
\hline 81 & -120 & \multicolumn{3}{|c|}{5} & \multicolumn{2}{|l|}{2} & 1 \\
\hline \multicolumn{2}{|c|}{ TOTAL } & \multicolumn{3}{|c|}{605} & \multicolumn{2}{|l|}{845} & 238 \\
\hline
\end{tabular}


TABELA 26 -Gestantes segundo a mediana do tempo de espera da consulta e a idade da gestação (teste da mediana).SP, 1979.

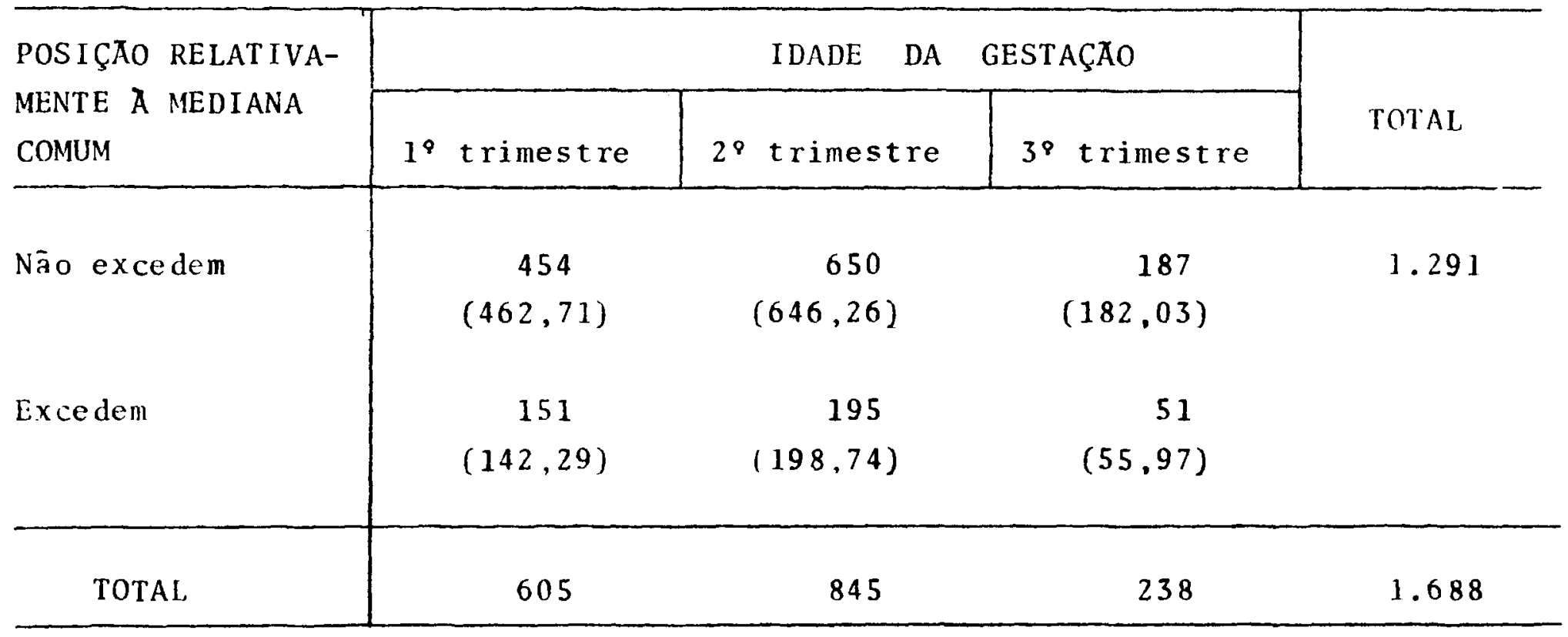

Nota: os nümeros entre parênteses são as frequências esperadas sob a hipótese nula.

$x_{\text {calc. }}^{2}=1,366$ 
A conclusão do teste de relação com o trimestre da gestação indica uma situação subliminar diferente da que se apresenta superficialmente: se olhamos por um lado o grande percentual de tempo de espera normal identificado contaríamos com uma justificativa para nos despreocuparmos como pro blema da espera que ao nivel em que se evindenciou não te ria significância. Entretanto, diante das diversas embrica ções, com características duvidosas, dos atributos da consul ta médica considerados indicadores de qualidade dos servi ços, vemos que o exame do comportamento da variável depen dente teve o mérito de deixar a descoberto um contexto cheio de aspectos questionáveis. As gestantes que não esperaram pela consulta foram, em termos de relatividade, uma parcela pequena, por sua vez não significativa do universo das gestantes esperadas e a quantidade de assistência que recebe ram apresentou deficit frente à aconselhävel. A quantidade de gestantes submetidas a espera para a consulta médica so freu esta espera indiscriminadamente, mesmo tendo se apre sentado para a consulta médica no $2^{\circ}$ ou no $3^{\circ}$ trimestre da gestação.

Os especialistas na assistência à saúde materna dão a maior ênfase à influência exercida pelos cuidados dispen sados à gestante no pré-natal obres resultados da gravidez. Há uma campanha acirrada para que se estudem os fatores que dificultam a atenção precoce e se adotem medidas de correção desses fatores. Donabedian, A. et a $1^{25}$ ao falarem dos $59 \%$ das gestantes que identificou como submetidas a cuidados prénatais inadequados, salienta a urgência de se intensificar a educação do püblico para o esclarecimento da necessidade dos cuidados precoces na gestação e da descoberta dos obstá culos à essa assistência na gravidez incipiente. Contudo,es te autor faz um reparo importante: os obstáculos estarão nas pessoas que não procuram o cuidado ou no tipo de assistên cia que 1 hes é oferecida? Tokuhata, G.K. et a ${ }^{65}$ no seu im portante relatório sobre a análise da relação cuidado prénatal e anormalidades obstétricas,dizemque quanto mais cedo a cliente começa o controle pré-natal, melhores os resulta 
dos da gestação, principalmente em relação à prematuridade com referência ao feto e em relação às complicações da gra videz (toxemias, infecções e hemorragias, entre outras), com referência à mãe.

Sernent, R.E. et al ${ }^{62}$ recomendanque os exames acura dos para seleção das gestantes portadoras de alto risco se jam feitos no início da gestaçāo, ou mesmo antes dela. E o que recomendantambém Ciari, Jr. C.et a1 14,15,16.

Korrey, J.F. et al $1^{21}$ dizem que o desconhecimento do início da gravidez juntamente com a primeira consulta médi ca tardia, são os responsảveis pela quadriplicação da taxa de mortalidade perinatal.

Para finalizar esta série de depoimentos sobre um problema que entre nós aparentemente não pode nem ainda ser prioritário, Monahan, H.B. et $a 1^{41}$ dão como indicador de boa qualidade da assistência pré-natal o início do controle até - princípio do $2^{\circ}$ trimestre, o $4^{\circ}$ mês da gestação Ciari, Jr. C. et a $1^{16,19}$ reduzem essa época para o $1^{\circ}$ trimestre.

3.7 Variáveis independentes complementares.

Dadas as limitaçōes deste estudo só foi possível a plicarmos os testes de comprovação de hipótese para as va riāveis analisadas e discutidas até aqui.

Quanto às restantes variáveis independentes que re lacionamos no Capítulov (Variáveis) nós as qualificamos de "complementares", como as denominamos neste sub-ítem;com os dados que sobre elas levantamos apresentamos os resultados em forma gráfica. o objetivo desejado foi proporcionarmos $\underline{u}$ ma visão figurada das associações que apresentam com o tem po de espera. Para isto construímos as Figuras $n^{\circ} 2$ e 3 que são apresentadas neste sub-item. 


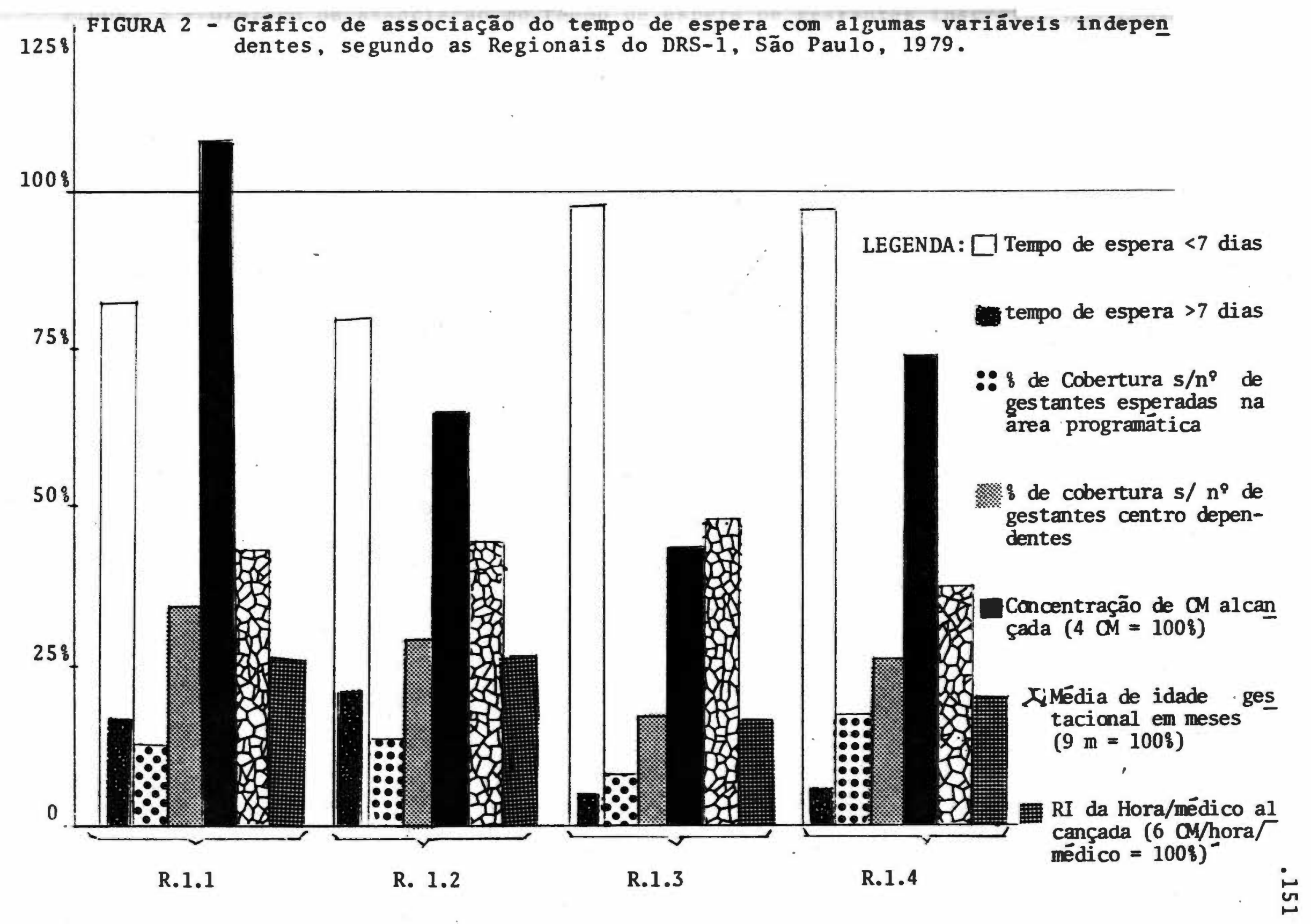




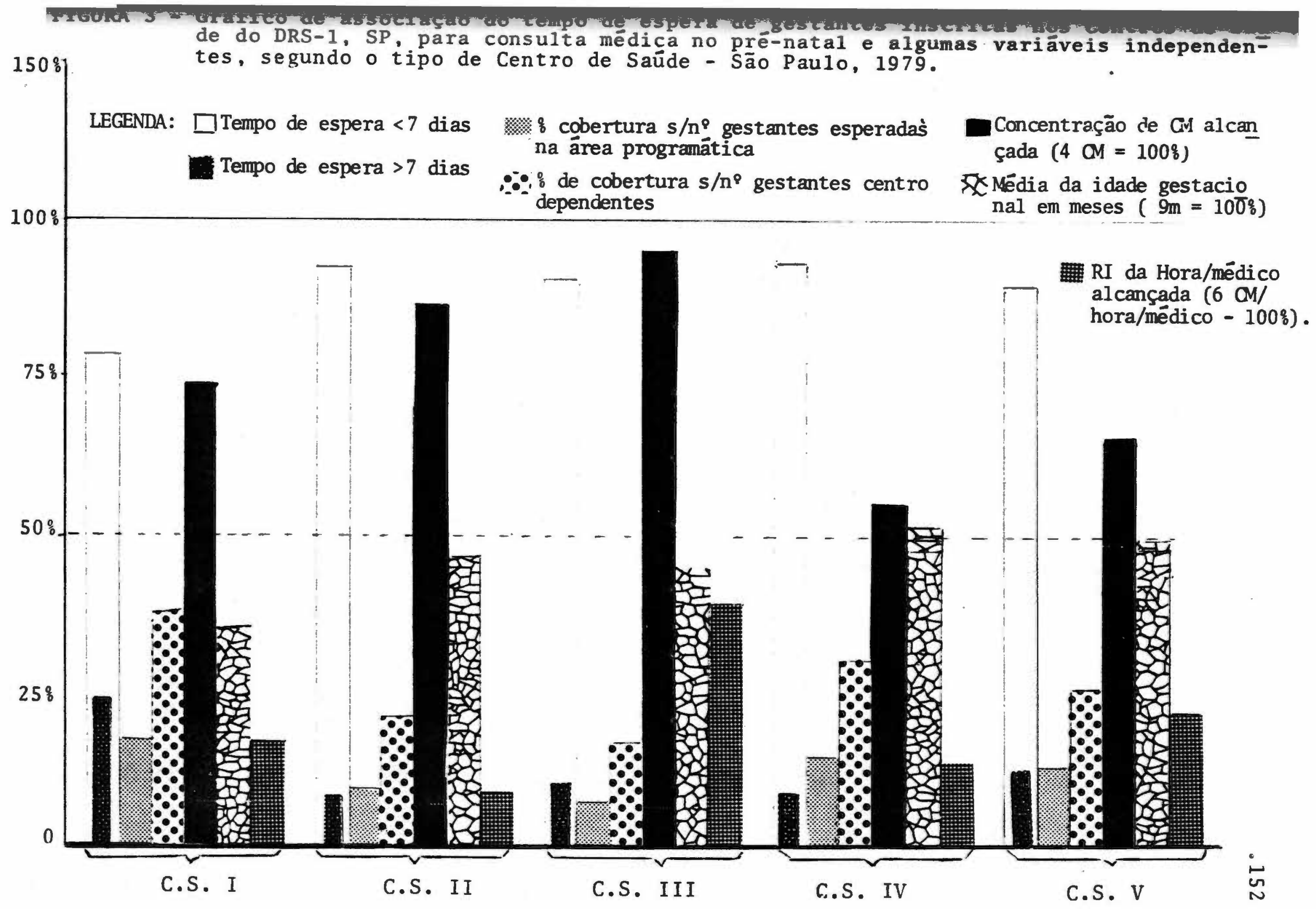


3.7.1 Modalidade do processo de atendimento das gestantes nos centros de saúde visando seu encaminhamento pa ra a primeira consulta médica no pré-natal.

Os dados referentes a esta variável foram colhidos diretamente nos centros de saúde por meio do levantamento de dados até então existentes mas não registrados. Estes de pois de processados, foram 1 ançados nas Tabelas de $n^{\circ} 13$ a 16.

Os elementos que integram a variävel são as formas de atendimento:

- agendamento:

- demanda reprimida ( 1 imitada);

- demanda aberta (ilimitada);

Os resultados nos mostram que nas 4 Regionais os mo dos adotados para a inscrição de gestantes foram:

- os agendamentos são preferidos em 30 centros de saúde ;

- a demanda limitada é usada em 19 unidades;

- a demanda aberta aparece como a moda em 7 unidades.

As considerações que se podem fazer em torno deste achado ligam-se especialmente à cobertura, à disponibilidade da hora/médico e ao grau de utlização deste instrumento.

Quanto à cobertura, pode-se associá-la quando baixa, à repressão da demanda exercida pelo agendamento e limitação de atendimentos, que é uma forma de agendamento não aparen te, em que a cliente é convidada a voltar em outra ocasião se a quantidade de atendimento dimensionada já tiver sido esgotada. Estas duas modalidades participam por certo na ex plicação do baixo tempo de espera identificado na maioria dos centros de saúde. Para reforçar esta suposição citamos 
TABELA 13 - Processo de inscrição das gestantes nos CS do DRS-1, $S P$, seguindo a classificação do CS e a numeração do mesmo na pesquisa. SP, 1979.

R.1.1

\begin{tabular}{|c|c|c|c|c|}
\hline \multicolumn{2}{|c|}{ CENTROS DE SADDE } & \multicolumn{3}{|c|}{ PROCESSO DE INSCRIÇAO } \\
\hline $\begin{array}{l}N^{\ominus} \text { NA } \\
\text { PESQUISA }\end{array}$ & $\begin{array}{l}\text { CLASS IFICA } \\
\text { ÇAO NA } \\
\text { SES }\end{array}$ & AGENDAMENTO & $\begin{array}{c}\text { DEMANDA } \\
\text { REPRIMIDA }\end{array}$ & $\begin{array}{r}\text { DEMANDA } \\
\text { ABERTA }\end{array}$ \\
\hline 1 & I & - & 1 & - \\
\hline 22 & I I & - & ' - & 1 \\
\hline 23 & I I & - & 1 & - \\
\hline 34 & I I I & 1 & - & - \\
\hline 35 & I. I I & - & - & 1 \\
\hline 75 & $\mathrm{~V}$ & - & - & 1 \\
\hline 81 & $\mathrm{v}$ & - & 1 & - \\
\hline TOTAL & & 1 & 3 & 3 \\
\hline
\end{tabular}


TABELA 14 - Processo de inscrição das gestantes nos CS do DRS-1, $S P$, seguindo a classificação do CS e a numeração do mesmo na pesquisa. SP, 1979.

R. 1.2

\begin{tabular}{|c|c|c|c|c|}
\hline \multicolumn{2}{|c|}{ CENTROS DE SAUDE } & \multicolumn{3}{|c|}{ PROCESSO DE INSCRI ÇAO } \\
\hline $\begin{array}{l}\text { NQ NA } \\
\text { PESQUISA }\end{array}$ & $\begin{array}{l}\text { ELASS IFICA- } \\
\text { EAO NA SES }\end{array}$ & AGENDAMENTO & $\begin{array}{c}\text { DEMANDA } \\
\text { REPR IMIDA }\end{array}$ & $\begin{array}{l}\text { DEMANDA } \\
\text { ABERTA } \\
\end{array}$ \\
\hline 5 & I & 1 & - & - \\
\hline 8 & I & 1 & - & - \\
\hline 24 & II & - & 1 & - \\
\hline 36 & I I I & 1 & - & - \\
\hline 40 & I I I & 1 & - & - \\
\hline 41 & I I I & - & 1 & - \\
\hline 48 & IV & 1 & - & - \\
\hline 50 & IV & - & - & 1 \\
\hline 53 & IV & - & - & 1 \\
\hline 84 & V & 1 & - & - \\
\hline 85 & V & 1 & - & - \\
\hline 87 & V & 1 & - & - \\
\hline 102 & $\mathrm{~V}$ & 1 & - & - \\
\hline 107 & V & 1 & - & - \\
\hline 112 & V & 1 & - & - \\
\hline 115 & $\mathrm{~V}$ & 1 & - & - \\
\hline TOTAL & & 12 & 2 & 2 \\
\hline
\end{tabular}


TABELA 15 -Processo de inscrição das gestantes nos CS do DRS-1 $S P$, seguindo a classificação do CS e a numeração do mesmo na pesquisa. SP, 1979.

$\mathrm{R} \cdot 1.3$

\begin{tabular}{|c|c|c|c|c|}
\hline CENTRC & $D E \quad S A O D E$ & PR & SSO DE INS & \\
\hline $\begin{array}{l}N^{P} \text { NA } \\
\text { PESQUISA }\end{array}$ & $\begin{array}{l}\text { CLASSIFICA } \\
\text { ÇAO NA SES }\end{array}$ & AGENDAMENTO & $\begin{array}{l}\text { DEMANDA } \\
\text { REPRIMIDA }\end{array}$ & $\begin{array}{l}\text { DEMANDA } \\
\text { ABERTA }\end{array}$ \\
\hline 12 & $\mathrm{I}$ & - & 1 & - \\
\hline 13 & I & - & 1 & - \\
\hline 28 & II & - & 1 & - \\
\hline 43 & I I I & 1 & - & - \\
\hline 57 & IV & - & 1 & - \\
\hline 118 & V & - & 1 & - \\
\hline 119 & V & - & 1 & - \\
\hline 120 & V & - & 1 & - \\
\hline 132 & V & - & 1 & - \\
\hline 135 & V & 1 & - & - \\
\hline \multicolumn{2}{|l|}{ TOTAL } & 2 & 8 & - \\
\hline
\end{tabular}


TABELA 16 -Processo de inscrição das gestantes nos CS do DRS-1 $S P$, seguindo a classificação do $C S$ e a numeração do mesmo na pesquisa. SP, 1979.

R.1.4

\begin{tabular}{|c|c|c|c|c|}
\hline CENTR & DE SAODE & PROCE & SSO DE INSC & \\
\hline$N^{P} \quad D A$ & CLASS I FI CA & & DEMANDA & DEMANDA \\
\hline PESQUISA & ÇAO NA SES & AGENDAMENTU & REPR IMIDA & ABERTA \\
\hline 17 & I & 1 & - & - \\
\hline 21 & I & - & - & 1 \\
\hline 29 & I I & 1 . & - & - \\
\hline 30 & I I & - & - & 1 \\
\hline 45 & I I I & 1 & - & - \\
\hline 46 & I I I & 1 & - & - \\
\hline 58 & IV & 1 & - & - \\
\hline 59 & IV & - & 1 & - \\
\hline 67 & IV & 1 & - & - \\
\hline 69 & IV & 1 & - & - \\
\hline 70 & IV & - & 1 & - \\
\hline 72 & IV & 1 & - & - \\
\hline 142 & V & 1 & - & - \\
\hline 148 & V & - & 1 & - \\
\hline 149 & V & 1 & - & - \\
\hline 150 & V & 1 & - & - \\
\hline 158 & V & 1 & - & - \\
\hline 159 & V & - & 1 & - \\
\hline 163 & V & 1 & - & - \\
\hline 186 & V & 1 & - & - \\
\hline 187 & V & - & 1 & - \\
\hline 193 & V & - & 1 & - \\
\hline 194 & V & 1 & - & - \\
\hline \multicolumn{2}{|l|}{ TOTAL } & 15 & 6 & 2 \\
\hline
\end{tabular}


ocorrências verificadas em alguns centros de saúde em que ob servamos o fenômeno da demanda reprimida. A propósito foi sú gerido no centro de saúde $n^{8} 8$ da R.l.2, em que foi verifi cada uma porcentagem significativa $(79,60 \%$ de gestantes atin gidas) de tempo de espera anormal, que a identificação do tempo de espera fosse feita previamente à inscrição e não so mente entre esta e a primeira consulta. Por contarmos com sé ria limitação de tempo pudemos apenas registrar a sugestãopa ra estudo em tempo oportuno.

Por sua vez é evidente que o mecanismo da repressão liga-se ao baixo grau de utilização do instrumento hora/médi co observado na maioria das unidades sanitárias estudadas. Se essa hora/instrumento fosse utilizada segundo sua disponibi lidade, ainda que o agendamento existisse teria somente o ca räter disciplinador da demanda e não o represssor.

5.7.2 Neste sub-item apresentaremos e discutiremos quatro de nossas variáveis independentes complementares:

- grau de alcance das metas normalizadas de concentração da consulta médica;

- rendimento da hora/médico verificada e

grau de utilização do instrumento nuclear;

- média da idade gestacional ao tempo da inscrição.

Os dados que caracterizam estas variāveis estão a presentados nos Quadros de $n^{i} \mathrm{~s} 19$ a 27 e ilustrados nas Figu ras 2 e 3 .

o objetivo de sua utilização é apresentarmos subsí dios para complementar a caracterização da nossa variável de pendente visando adicionarem-se elementos elucidativos nas con figurações da assistência prestada às gestantes nos centros de saủde da amostra.

O grau de alcance das metas normalizadas de concentração da consulta médica, foi conseguido a partir dos dados 
relativos a:

- volume de gestantes inscritas tirado dos Quadros de $\mathrm{n}^{\circ} \mathrm{S} 7$ a 10 ;

- volume de consultas médicas e de atendimento de en fermagem, disponíveis nos Quadros de 28 a 31.

Com este material fizemos o cálculo da produção con seguida e usando a fórmula:

$$
\mathrm{Cn}=\frac{\mathrm{N}^{\ominus} \text { consultas realizadas }}{N^{\ominus} \text { gestantes inscritas }}
$$

conseguimos a concentração alcançada de consultas médicas o ferecidas as gestantes nos centros de saúde. Este resultado foi lançado também nos Quadros de $n^{9} 19$ a 22 , de 23 a 27 . e 37. Também foi utilizado para construção das Figuras 2 e 3 .

A primeira vista a projeção nas Figuras 2 e 3 , da con centração realizada leva-nos a pensar que a concentração foi alta para todas as Regionais e todos os centros de saúde da amostra. Entretanto é um efeito ilusório pois deve-se conside rar que a grandeza $100 \%$ relativa à concentração equivale a 4 consultas, no mínimo, por gestante durante a gestação e que, toda quantidade menor que esta apresenta um indicador de defi ciência da atenção prestada às clientes.

Desta forma podemos ajustar o efeito visual e verif $\underline{i}$ car que somente na $R .1 .1$ a concentração foi de 4,34 conforme é comprovado pelo Quadro n̊ 19; aí se vê que, somente 2 unida des desta Regional não atingiram a concentração normalizada. Contudo, fica uma indagação suscitada pela projeção dos ou tros indicadores: teria sido conseguida uma concentração mé dica acima do mínimo desejāvel à custa de uma baixa cobertura por sub utilização do instrumento nuclear? é esta a suposição que se levanta, por exemplo, ao se comparar o grau de 0,03 de utilização do I.N. no centro de saúde $\mathrm{m}^{8} 23, \mathrm{com}^{0} \mathrm{grau}$ de co bertura de 0,66 e uma concentração de 4,25. Nesta Regional o 
QUADRO 28-Nümero de consultas médicas e de atendimento de en fermagem realizados nos meses de janeiro a setembro de 1979, nas unidades sanitárias do DRS-1 incluídas na pesquisa, segundo a Regional e o tipo de CS. SP, 1979 .

\begin{tabular}{|c|c|c|c|c|c|c|}
\hline & & & & & & R.1.1 \\
\hline Tि IPO DO & N DO CS & CONSUL? & IAS MEDICA & & ATEND.ENF & ERMAGEM \\
\hline & QUISA & ESPERADAS & REALIZAD. & CONCENTR & REAL IZAD. & CONCENTR \\
\hline I & 1 & 2.004 & 2.093 & 4,86 & 2.260 & 4,82 \\
\hline I I & 22 & 1.960 & 126 & 3,31 & - & - \\
\hline I I & 23 & 1.772 & 255 & 4,55 & 346 & 0.77 \\
\hline I I I & 34 & 484 & 593 & 3,50 & 551 & 3.67 \\
\hline I I I & 35 & 1.456 & 345 & 4,25 & 345 & 3,96 \\
\hline v & 75 & 288 & 181 & 4,85 & 267 & 4,85 \\
\hline $\mathrm{v}$ & 81 & 780 & 678 & 5,05 & 238 & 0,83 \\
\hline
\end{tabular}

FONTES: SEADE - SEPLAN - SP

Seção de Planejamento. Divisão de Estudos e Progra mas DRS-1 - C.E.S. - S.E.S.- SP 
QUADRO 29-Número de consultas mëdicas e de atendimento de en fermagem realizados nos meses de janeiro a setembro de 1979, nas unidades sanitärias do DRS-1 incluidas na pesquisa, segundo a Regional e o tipo de CS. SP. 1979 .

R.1.2

\begin{tabular}{|c|c|c|c|c|c|c|}
\hline \multirow{2}{*}{$\begin{array}{l}\text { TI PO DO } \\
\text { CS NA } \\
\text { SES } \\
\end{array}$} & \multirow{2}{*}{$\begin{array}{lll}\text { NP } & \text { DO } & \text { CS } \\
\text { NA } & \text { PES } \\
\text { QU ISA } & \end{array}$} & \multicolumn{3}{|c|}{ CONSULTAS MEDICAS } & \multicolumn{2}{|c|}{ ATEND.ENFERMAGEM } \\
\hline & & ESPERADAS & REALIZ. & CONCENTR. & REALIZ . & CONCENTR \\
\hline I & 5 & 2.364 & 672 & 1,56 & 1.618 & 3,76 \\
\hline I & 8 & 3.580 & 1.621 & 2,22 & 1.448 & 1,98 \\
\hline I I & 24 & 1.500 & 472 & 1,39 & 75 & 0,22 \\
\hline I I I & 36 & ]. 420 & 1.070 & 6,52 & 58 & 0,35 \\
\hline I I I & 40 & 1.212 & 238 & 1,87 & 174 & 1,32 \\
\hline I I I & 41 & 1.908 & 1.855 & 4,69 & 1.865 & 4,72 \\
\hline IV & 48 & 5.400 & 562 & 3,21 & 428 & 2,44 \\
\hline IV & 50 & 228 & 13 & 0,11 & 99 & 0,90 \\
\hline IV & 53 & 808 & 213 & 2,95 & 145 & 2,01 \\
\hline V & 84 & 476 & 616 & 3,58 & 590 & 3,43 \\
\hline v & 85 & 2.668 & 46 & 2.87 & 50 & 3,12 \\
\hline V & 87 & 476 & 28 & 1,75 & 8 & 0,50 \\
\hline V & 102 & 404 & 147 & 2,77 & 29 & 0,54 \\
\hline V & 107 & 636 & 364 & 3.71 & 665 & 3,72 \\
\hline $\mathrm{V}$ & 112 & 1.808 & 15 & 0,38 & 17 & 0,43 \\
\hline V & 115 & 300 & 172 & 2.26 & - & - \\
\hline
\end{tabular}

FCNTES: SEADE - SEPLAN

Seção de Planejamento - Divisão de EStudos e Frogramas DRS-1 - C.E.S. - S.E.S. - SP. 
QUADRO 30-Número de consultas médicas e de atendimento de enfermagem realizados nos meses de janeiro a setembro de 1979, nas unidades sanitárias do DRS-1 incluídas na pesquisa, segundo a Regional o o tipo de CS. SP, 1979 .

\begin{tabular}{|c|c|c|c|c|c|c|}
\hline \multirow{2}{*}{$\begin{array}{l}\text { TIPO DO } \\
\text { CS NA } \\
\text { SES }\end{array}$} & \multirow{2}{*}{$\begin{array}{lll}N^{\circ} & \text { DO } & \text { CS } \\
\text { NA } & \text { PES } \\
\text { QU I ISA } & \end{array}$} & \multicolumn{3}{|c|}{ CONSULTAS MEDICAS } & \multicolumn{2}{|c|}{ ATEND. ENFERMAGE!! } \\
\hline & & ESPERADAS & REALIZ . & CONCENTR & REALIZAD & CONCENTR. \\
\hline I & 12 & 344 & 91 & 1,93 & 40 & 0,85 \\
\hline I & 13 & 7.022 & 422 & 2,77 & 176 & 1,15 \\
\hline II & 28 & 948 & 192 & 1,93 & 234 & 2,36 \\
\hline I I I & 43 & 5.904 & 1,193 & 3,62 & - & - \\
\hline IV & 57 & 2.540 & 86 & 0,60 & 231 & 1,62 \\
\hline V & 118 & 1.216 & 59 & 1,40 & 79 & 1,88 \\
\hline V & 119 & 240 & 110 & 3,54 & 82 & 2,64 \\
\hline V & 120 & 432 & 255 & 2,04 & 109 & 0,87 \\
\hline V & 132 & 636 & 28 & 1,40 & 47 & 3,03 \\
\hline V & 135 & 1.272 & 9 & 0,25 & 14 & 0,40 \\
\hline
\end{tabular}

FONTES: SEADE - SEPLAN - SP

Seção de Planejamento - Divisão de Estudos e Progra mas DRS-1 - C.E.S. - S.E.S. - SP 
QUADRO 31-Número de consultas médicas e de atendimento de en fermagem realizados nos meses de janeiro a setembro de 1979, nas unidades sanitärias do DRS-1 incluidas na pesquisa, segundo a Regional e o tipo de CS. SP, 1979 .

R. 1.4

\begin{tabular}{|c|c|c|c|c|c|c|}
\hline \multirow{2}{*}{$\begin{array}{l}\text { TIPO DO } \\
\text { CS NA } \\
\text { SES }\end{array}$} & \multirow{2}{*}{$\begin{array}{lll}\text { NP } & \text { DO } & \text { CS } \\
\text { NA } & \text { PES } \\
\text { QUISA } & \end{array}$} & \multicolumn{3}{|c|}{ CONSULTAS MEDICAS } & \multicolumn{2}{|c|}{ ATEND.ENFERMAGEM } \\
\hline & & ESPERADAS & REALIZ. & CONCENTR & REALIZ. & CONCENTR \\
\hline I. & 17 & 584 & 660 & 6.53 & 184 & 1,82 \\
\hline I & 21 & 9.128 & 727 & 1,54 & 561 & 1,19 \\
\hline II & 29 & 968 & 695 & 2,88 & - & - \\
\hline I I & 30 & 2.348 & 421 & 1,55 & 338 & 1,24 \\
\hline I I I & 45 & 2.136 & 748 & 5,08 & 815 & 5,54 \\
\hline I I I & 46 & 1.420 & 688 & 6,74 & - & - \\
\hline IV & 58 & 1.664 & 279 & 1,84 & 146 & 0,96 \\
\hline IV & 59 & 708 & 193 & 0.42 & - & $=$ \\
\hline IV & 67 & 560 & 64 & 5,81 & 82 & 7,45 \\
\hline IV & 69 & 2.632 & 488 & 5,03 & 91 & 0,93 \\
\hline IV & 70 & 476 & 76 & 0.57 & 87 & 0,65 \\
\hline IV & 72 & 1.344 & 246 & 1,82 & 86 & 0,63 \\
\hline V & 142 & 1.760 & 321 & 4,72 & 22 & 0,32 \\
\hline V & 148 & 588 & 177 & 3,76 & 16 & 0,34 \\
\hline V & 149 & 588 & 83 & 0,85 & 44 & 0,45 \\
\hline V & 150 & 588 & 149 & 3,17 & 320 & 6.80 \\
\hline V & 158 & 532 & 60 & 1,81 & 46 & 0,97 \\
\hline V & 159 & 360 & 163 & 3,19 & 295 & 5,78 \\
\hline$-V$ & 163 & 1.120 & 45 & 0,60 & 318 & 4,24 \\
\hline V & 186 & 1.828 & 57 & 0,80 & 48 & 0,67 \\
\hline V & 187 & 1.828 & 60 & 1,02 & - & - \\
\hline V & 193 & 480 & 662 & 3.26 & 594 & 2,92 \\
\hline V & 194 & 900 & 386 & 3,03 & 105 & 0,82 \\
\hline
\end{tabular}

FONTES: SEADE - SEPLAN - SP

Seção de Planejamento - Divisão de Estudos e Progra mas DRS-1 - C.E.S. -S.E.S. - SP 
maior grau de utilização do I.N. foi 0,78 para uma das unida des, as demais sö chegaram at $\vec{e} 0,28$.

Nas outras Regionais a concentração média global va riou de 1,69 na R.1.3 a 2,87 na R.1.4, resultado que podemos classificar, de acordo com os parâmetros discutidos pelos es pecialistas, como uma produção insuficiente para se proteger a saūde da gestante. Em reforço desta consideração apresenta mos o Quadro $n^{\circ} 37$ em que se pode verificar o grau de alcance da concentração realizada frente à concentração programada:so mente 5 dos centros de saúde estudados apresentaram una razão ideal nessa comparação: os centros de saúde $n^{\circ} \mathrm{s} 1$ e 34 (R.1.1), $64($ R.1.2), 17 e 193 (R.1.4).

Este fato cerca-se ainda de uma característica agra vante: no desenvolvimento do nosso levantamento foi possível verificar uma quantidade bastante significativa de fichas es pecializadas dentro dos prontuários em que se registraram poucas consultas,muitas vezes uma apenas, ao ponto de ser ne cessārio excluir o indivíduo da amostra devidoà caréncia de dá dos. Este fato, repetido vezes sem conta, juntamente com a $\underline{\mathbf{e}}$ xiguidade de informaçōes registradas sobre ocorrências mörbidas, leva à suposição de que a continuidade do cuidado deixa a desejar, tornando-se um problema que deve ser colocado em pauta para investigação sistemätica e não casual como a que fizemos neste particular.

Quanto ao rendimento instrumental da hora/médico e ao grau de utilização deste instrumento, adotamos para obtê-lo a förmula:

$$
\text { R.I. }=\frac{N^{8} \text { C.M. 2o ano }}{\text { total hora mëdicas }}
$$

Para chegarmos a esta fase utilizamos os dados obtí dos com o cälculo das horas/médico disponíveis, das horas tra balhadas, e do número de consultas médicas realizadas. Estes dados estão disponíveis nos Quadros de $n^{\circ} \mathrm{s} 32$ a 35 e dele tam bëm faz parte o rendimento instrumental obtido. 
QUADRO 37 - Grau de alcance das metas programadas para a consulta médica das gestantes nos centros de saúde da amostra, segundo as Regionais do DRS-1, SP, 1979.

\begin{tabular}{|c|c|c|c|c|c|c|c|}
\hline \multicolumn{2}{|c|}{ R.1.1 } & \multicolumn{2}{|c|}{ R. 1.2} & \multicolumn{2}{|c|}{ R. 1.3} & \multicolumn{2}{|c|}{ R. 1.4} \\
\hline$N^{\circ} \quad$ CS & $\begin{array}{l}\text { Grau de a1 } \\
\text { cance da cn }\end{array}$ & $\mathrm{N}^{\circ} \mathrm{CS}$ & $\begin{array}{l}\text { Grau de al } \\
\text { cance da } \overline{\bar{n}}\end{array}$ & $\mathrm{~N}^{\circ} \mathrm{CS}$ & $\begin{array}{l}\text { Grau de al } \\
\text { cance daca }\end{array}$ & $\mathrm{N}^{\circ} \mathrm{CS}$ & $\begin{array}{l}\text { rau de al } \\
\text { ance da } \bar{c}\end{array}$ \\
\hline 1 & 1,04 & 5 & 0,28 & 12 & 0,26 & 17 & 1,13 \\
\hline 22 & 0,06 & 8 & 0,45 & 13 & 0,06 & 21 & 0,08 \\
\hline 23 & 0,14 & 24 & 0,31 & 28 & 0,20 & 29 & 0,72 \\
\hline 34 & 1,23 & 36 & 0,75 & 43 & 0,20 & 30 & 0,18 \\
\hline 35 & 0,24 & 40 & 0,20 & 57 & 0,03 & 45 & 0,34 \\
\hline 75 & 0,63 & 41 & 0,97 & 118 & 0,05 & 46 & 0,48 \\
\hline 81 & 0,87 & 48 & 0,10 & 119 & 0,46 & 58 & 0,17 \\
\hline & & 50 & 0,06 & 120 & 0,59 & 59 & 0,27 \\
\hline & & 53 & 0,26 & 132 & 0,04 & 67 & 0,11 \\
\hline & & 84 & 0,29 & 135 & 0,01 & 69 & 0,19 \\
\hline & & 85 & 0,02 & & & 70 & 0,16 \\
\hline & & 187 & 0,06 & & & 72 & 0,18 \\
\hline & & 102 & 0,36 & & & 142 & 0,18 \\
\hline & & 107 & 0,57 & & & 148 & 0,30 \\
\hline & & 112 & 0,01 & & & 149. & 0,14 \\
\hline & & 115 & 0,57 & & & 150 & 0,25 \\
\hline & & & & & & 158 & 0,11 \\
\hline & & & & & & 159 & 0,45 \\
\hline & & & & & & 163 & 0,04 \\
\hline & & & & & & 186 & 0,03 \\
\hline & & & & & & 187 & 0,03 \\
\hline & & & & & & 193 & 1,38 \\
\hline & & & & & & 194 & 0,43 \\
\hline
\end{tabular}


QUADRO 32 -Dados básicos para câlculo do R.I. da hora/médico, segundo o tipo do CS no DRS-1, SP e número do mesmo na pesquisa. SP, 1979 .

R.1.1

\begin{tabular}{|c|c|c|c|c|c|}
\hline CENTROS & DE SAODE & \multirow{2}{*}{$\begin{array}{l}\text { N: CONSUL- } \\
\text { TAS MEDI } \\
\text { CAS ESP. }\end{array}$} & \multirow{2}{*}{$\mid \begin{array}{ll}N^{\circ} & \text { CONSUL } \\
\text { TAS } & \text { MEDI- } \\
\text { CAS } & \text { REALIZ }\end{array}$} & \multirow{2}{*}{$\begin{array}{l}\text { HORAVMEDICO } \\
\text { DISPONIVEL }\end{array}$} & \multirow{2}{*}{$\begin{array}{l}\text { RENDIMENTO } \\
\text { INSTRUMENTAI } \\
\text { HORA/MEDICO }\end{array}$} \\
\hline $\begin{array}{l}\text { CLASSIFICACAAO } \\
\text { NA PESQUISA }\end{array}$ & $\begin{array}{l}\text { Nं NA PESQUI } \\
\text { SA }\end{array}$ & & & & \\
\hline$I$ & 1 & 1.920 & 2.093 & 1.440 & 1,45 \\
\hline II & 22 & 1.960 & 126 & 720 & 0,17 \\
\hline II & 23 & 456 & 255 & 1.440 & 0,17 \\
\hline III & 34 & 5.412 & 595 & 360 & 1,65 \\
\hline III & 35 & 956 & 345 & 360 & 0,95 \\
\hline V & 75 & 1.124 & 181 & 144 & 1,25 \\
\hline V & 81 & 1.592 & 678 & 144 & 4,70 \\
\hline
\end{tabular}


QUADRO 33-Dados básicos para cảlculo do R.I. da hora/médico, segundo o tipo do $\mathrm{CS}$ no $\mathrm{DRS}-1$, SP e nümero do mesmo na pesquisa. SP, 1979 .

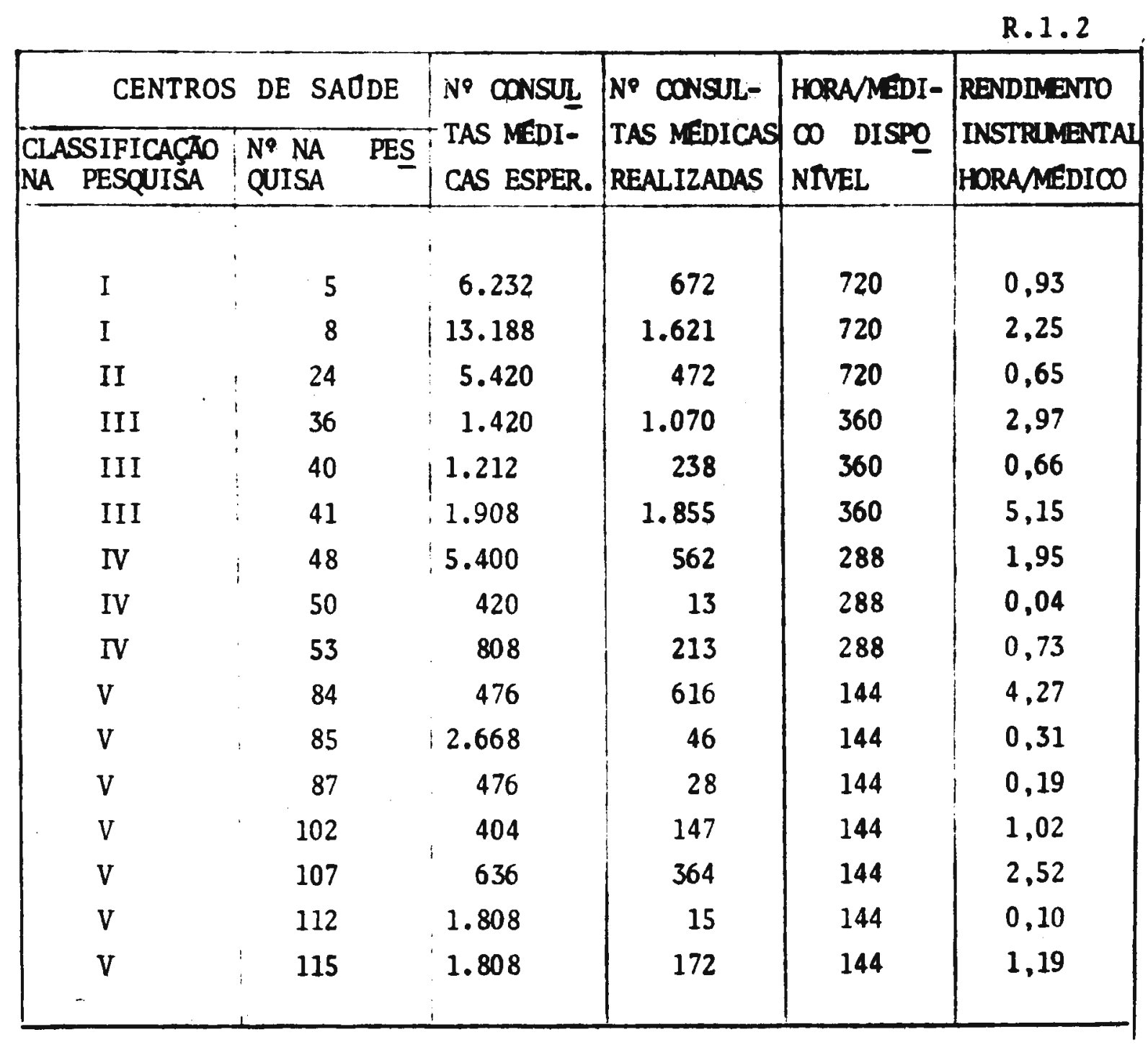


QUADRO 34-Dados básicos para cálculo do R.I. da hora/médico, segundo o tipo do CS no DRS-1, SP e número do mesmo na pesquisa. SP, 1979 .

R.1. 3

\begin{tabular}{|c|c|c|c|c|c|}
\hline \multicolumn{2}{|c|}{ CENTROS DE SAODE } & \multirow{2}{*}{$\begin{array}{l}N^{\circ} \text { CONSUL } \\
\text { TAS MEDI- } \\
\text { CAS ESP- }\end{array}$} & \multirow{2}{*}{$\begin{array}{l}\text { N CONSJL } \\
\text { TAS MEDI- } \\
\text { CAS REALIZ. }\end{array}$} & \multirow{2}{*}{$\begin{array}{l}\text { HORAMEDI } \\
\text { CO DISPO- } \\
\text { NIVEL }\end{array}$} & \multirow{2}{*}{$\begin{array}{l}\text { RENDIMENTO } \\
\text { INSTRUMENTAL } \\
\text { HORA/MEDICO }\end{array}$} \\
\hline $\begin{array}{l}\text { CLASSIFICACAO } \\
\text { NA PESQUISA }\end{array}$ & $\begin{array}{l}N^{\circ} \text { NA } \\
\text { PESQUISA }\end{array}$ & & & & \\
\hline I & 12 & 16.700 & 91 & 720 & 0,12 \\
\hline I & 13 & 5.480 & 422 & 720 & 0,58 \\
\hline II & 28 & 8.852 & 192 & 720 & 0,26 \\
\hline III & 43 & 5.904 & 1.193 & 360 & 3,31 \\
\hline IV & 57 & 2.540 & 86 & 288 & 0,29 \\
\hline v & 118 & 1.216 & 59 & 144 & 0,40 \\
\hline $\mathrm{V}$ & 119 & 240 & 110 & 144 & 0,76 \\
\hline V & 120 & 780 & 255 & 144 & 1,77 \\
\hline V & 132 & 636 & 28 & 288 & 0.09 \\
\hline V & 135 & 1.260 & 9 & 144 & 0,06 \\
\hline
\end{tabular}


QUADRO 35-Dados básicos para cálculo do R.I. da hora/médico, segundo o tipo do CS no DRS-1, SP e número do mesmo na pesquisa. SP, 1979 ,

$\mathrm{R} .1 .4$

\begin{tabular}{|c|c|c|c|c|c|}
\hline $\begin{array}{l}\frac{\text { CENTROS }}{\text { CLASSIFICACSAOAO }} \\
\text { NA PESQUISA }\end{array}$ & $\begin{array}{l}\text { DE SAODE } \\
\begin{array}{l}\mathrm{N}^{\circ} \mathrm{NA} \\
\text { PESQUISA }\end{array}\end{array}$ & $\begin{array}{l}\text { N9 CONSUL- } \\
\text { TAS MEDICAS } \\
\text { ESPERADAS }\end{array}$ & $\begin{array}{l}\text { N' CONSUL- } \\
\text { TAS MEDICAS } \\
\text { REALIZADAS }\end{array}$ & 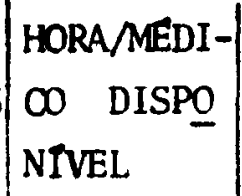 & $\begin{array}{l}\text { RENDIMENTO } \\
\text { INSTRUMENTAL } \\
\text { HORAMEDICO }\end{array}$ \\
\hline I & 17 & 584 & 660 & 720 & 0,91 \\
\hline I & 21 & 9.128 & 727 & 720 & 1,00 \\
\hline I I & 29 & 6.208 & 695 & 720 & 0,96 \\
\hline I I & 30 & 2.348 & 421 & 720 & 0,58 \\
\hline I I I & 45 & 2.136 & 748 & 360 & 2,07 \\
\hline I I I & 46 & 1.420 & 688 & 360 & 1,91 \\
\hline IV & 58 & 3.120 & 279 & 288 & 0,96 \\
\hline IV & 59 & 2.028 & 193 & 288 & 0,67 \\
\hline IV & 67 & 1.120 & 45 & 288 & 0,15 \\
\hline IV & 69 & 2.632 & 488 & 288 & 1,69 \\
\hline IV & 70 & 476 & 76 & 288 & 0,26 \\
\hline IV & 72 & 4.656 & 246 & 576 & 0,42 \\
\hline V & 142 & 1.760 & 321 & 144 & 2,22 \\
\hline V & 148 & 588 & 177 & 144 & 1,22 \\
\hline V & 149 & 588 & 83 & 144 & 0,57 \\
\hline $\mathrm{V}$ & 150 & 588 & 149 & 144 & 1,03 \\
\hline V & 158 & 532 & 60 & 144 & 0,41 \\
\hline V & 159 & 560 & 163 & 144 & 1,13 \\
\hline V & 163 & 560 & 64 & 144 & 0,44 \\
\hline V & 186 & 1.828 & 57 & 144 & 0,39 \\
\hline V & 187 & 1.828 & 60 & 144 & 0,41 \\
\hline V & 193 & 736 & 662 & 144 & 4,59 \\
\hline V & 194 & 2.000 & 386 & 144 & 2,68 \\
\hline
\end{tabular}


Consideramos estes quadros como um recurso para estru turação dos Quadros comparativos de $n^{\circ} s 19$ a 27 e das Figuras 2 e 3 .

Tanto o R.I. da hora/médico como o grau de utilização deste instrumento foram baixos em todas as Regionais:

$$
\begin{aligned}
& \text { R. } 1.1 \text { com } 1,48 \text { de R.I. e } 0,25 \text { de G.U. } \\
& \text { R.1.2 com } 1,56 \text { de R.I. e } 0,26 \text { de G.U. } \\
& \text { R.1.3 com } 0,76 \text { de R.I. e } 0,12 \text { de G.U. } \\
& \text { R.1.4 com } 1,11 \text { de R.I. e } 0,18 \text { de G.U. }
\end{aligned}
$$

$E$ interessante notar que a R.1.2 onde se verificou o maior tempo de espera é a que apresenta o maior R.I. e o maior G.U.. Estes resultados evidenciam a sub utilização do instrumento nuclear horä/médico. O ponto nodal parece estar situado nas causas desta sub utilização; se verificarmos a cobertura vemos que foi globalmente baixa e seríamos levados a supor a existência de um grande tempo ocioso, porém a experiência não comprovada e a literatura referente a este problema conforme Adami', Ciari et a1 16,19 , Giron ${ }^{29}$ e Schor ${ }^{60}$ falam do proble ma da pequena disponibilidade real da hora/médico devidoà cur ta permanência do instrumento nuclear nos centros de saúde. Não cabe discutir neste trabalho, as causas da sub utilização verificada; a referência $\vec{e}$ dada apenas como dado informativo para estudo dos fatores que estariam caracterizando essa cons tante sub utilização. Além da sub utilização da hora/instru mento, outra constatação se delineia: hā indícios de que té nha havido super estimativa da hora médica dimensionada: é o fato que se percebe pelo exame da ocorrência da cobertura quan do se apresenta com um alto grau de alcance concomitantemente com um al to graude concentração realizada e um pequeno grau de utilização do I.N. (V. Quadros 19 a 27).

A média da idade gestacional é focalizada aqui como um indicador que qualifica a atençāo prestada à gestante.

A propósito dela já apresentamos uma anālise e discus são, quando tratamos dos resultados do teste de relacionamen 
to do tempo de espera e trimestre da gestação.

Fizemos o cálculo separado das médias de idade gesta ciona ${ }^{\star}$ por se tratar de dado que se presta à manipulação ao se comparar a qualidade dos atributos da atividade consulta/ médica. Os resultados que obtivemos foram usados neste senti do conforme apresentados no Quadro $n^{9} 36$ mostrado neste $i$ tem. Também a partir dele construímos os Quadros de $n^{\circ} \mathrm{s} 19$ a 27 e as Figuras 2 e 3-

De acordo com a farta literatura em que esta variável é estudada, a média da idade gestacional situada no $1^{\circ}$ trimes tre é um dos indicadores de boa qualidade da assistência à ges tante, sendo o ideal para o qual devem tender todos os serviços, usando para isto dos recursos administrativos e educa cionais disponiveis.

Os autores salientam que não é suficiente existirem as facilidades institucionais, ẻ necessärio que sejam aceitas e utilizadas pela população alvo; isto depende, como se sabe e muito bem salienta candeias ${ }^{12}$, do conhecimento adequado dos problemas que podem interferir bloqueando essa utilização, a fim de se planejar e implantar um processo educativo que in flua, melhorando-o, no comportamento negativo das gestantes com relação à assistência pré-natal.

Nesta ordem de idéias, somente 2 centros de saúde dos estudados, o $n^{8} 30$ e o 115 estariam em condiçōes aceitáveis quanto à procura dos serviços prē-natais em idade ótima, pois a média de idade gestacional neles verificada foi de 2 meses e 26 dias e 2 meses e 13 dias respectivamente.

Nas demais unidades, segundo as Regionais as médias globais verificadas foram:

* Aplicamos para esse cálculo a fórmula apresentada por Ciari et a 19 . 
QUADRO 36-Média da idade gestacional das gestantes inscritas nos Centros de Saúde do DRS-1-SP, no período de janeiro a setembro de 1979, segundo a Regional, o tipo de Centro de Saúde e a numeração deste na pesquisa.

\begin{tabular}{|c|c|c|c|c|c|c|c|c|c|c|c|}
\hline \multicolumn{3}{|c|}{ R. 1.1} & \multicolumn{3}{|c|}{$\mathrm{R} .1 .2$} & \multicolumn{3}{|c|}{ R. 1.3} & \multicolumn{3}{|c|}{ R. 1.4} \\
\hline \multicolumn{2}{|c|}{ CENTRO DE SAODE } & \multirow{2}{*}{$\begin{array}{l}\text { MEDIA DE } \\
\text { IDADE GES } \\
\text { TACIONAL }\end{array}$} & \multicolumn{2}{|c|}{ CENTRO DE SAUIDE } & \multirow{2}{*}{$\begin{array}{l}\text { MEDIA DE } \\
\text { IDADE GES } \\
\text { TACIONAL }\end{array}$} & \multicolumn{2}{|c|}{ CENTRO DE SAODE } & \multirow{2}{*}{$\begin{array}{l}\text { MEDIA DE } \\
\text { IDADE GES } \\
\text { TACIONAL }\end{array}$} & \multicolumn{2}{|c|}{ CENTRO DE SADDE } & \multirow{2}{*}{$\begin{array}{l}\text { MEDIA DE } \\
\text { IDADE GES } \\
\text { TACIONAL }\end{array}$} \\
\hline $\begin{array}{l}N^{9} \text { NA } \\
\text { PESQUISA }\end{array}$ & $\begin{array}{l}\text { CLASSIFI } \\
\text { CAO-SES }\end{array}$ & & $\begin{array}{l}N^{\top} \text { NA } \\
\text { PESQUISA } \\
\end{array}$ & $\begin{array}{l}\text { CLASSIFI } \\
\text { CAO-SES }\end{array}$ & & $\begin{array}{l}\begin{array}{l}N^{\circ} \mathrm{NA} \\
\text { PESQUISA }\end{array} \\
\end{array}$ & $\begin{array}{l}\text { CLASSIFI } \\
\text { CAOO-SES }\end{array}$ & & $\begin{array}{l}N^{\circ} \text { NA } \\
\text { PESQUISA }\end{array}$ & $\begin{array}{l}\text { CLASSIFI } \\
\text { CAO-SES }\end{array}$ & \\
\hline $\begin{array}{l}\text { I } \\
\text { I I } \\
\text { I I } \\
\text { I I I } \\
\text { I I I } \\
V \\
\text { V }\end{array}$ & $\begin{array}{l}1 \\
22 \\
23 \\
34 \\
35 \\
75 \\
81\end{array}$ & $\begin{array}{rrr}3 \mathrm{~m} & 11 & \mathrm{~d} \\
4 \mathrm{~m} & 6 & \mathrm{~d} \\
4 \mathrm{~m} & 5 & \mathrm{~d} \\
4 \mathrm{~m} & 13 & \mathrm{~d} \\
3 \mathrm{~m} & 22 & \mathrm{~d} \\
3 \mathrm{~m} & 9 & \mathrm{~d} \\
3 \mathrm{~m} & 28 & \mathrm{~d}\end{array}$ & $\begin{array}{r}5 \\
8 \\
24 \\
36 \\
40 \\
41 \\
48 \\
50 \\
53 \\
84 \\
85 \\
87 \\
102 \\
107 \\
112 \\
115\end{array}$ & $\begin{array}{l}\text { I } \\
\text { I } \\
\text { I I } \\
\text { I I I } \\
\text { I I I } \\
\text { I I I } \\
\text { I V } \\
\text { IV } \\
\text { I V } \\
\text { V } \\
\text { V } \\
\text { V } \\
\text { V } \\
\text { V } \\
\text { V } \\
\text { V }\end{array}$ & $\begin{array}{lrl}3 \mathrm{~m} & 23 & \mathrm{~d} \\
3 \mathrm{~m} & 24 & \mathrm{~d} \\
4 \mathrm{~m} & 8 & \mathrm{~d} \\
3 \mathrm{~m} & 7 & \mathrm{~d} \\
3 \mathrm{~m} & 11 & \mathrm{~d} \\
4 \mathrm{~m} & 9 & \mathrm{~d} \\
4 \mathrm{~m} & 7 & \mathrm{~d} \\
5 \mathrm{~m} & 9 & \mathrm{~d} \\
3 \mathrm{~m} & 25 & \mathrm{~d} \\
3 \mathrm{~m} & 21 & \mathrm{~d} \\
4 \mathrm{~m} & 9 & \mathrm{~d} \\
4 \mathrm{~m} & 13 & \mathrm{~d} \\
4 \mathrm{~m} & 6 & \mathrm{~d} \\
4 \mathrm{~m} & 5 & \mathrm{~d} \\
4 \mathrm{~m} & 22 & \mathrm{~d} \\
2 \mathrm{~m} & 13 & \mathrm{~d}\end{array}$ & $\begin{array}{r}12 \\
13 \\
28 \\
43 \\
57 \\
118 \\
119 \\
120 \\
132 \\
135\end{array}$ & $\begin{array}{l}\text { I } \\
\text { I } \\
\text { I I } \\
\text { I I I } \\
\text { IV } \\
V \\
V \\
V \\
V \\
\text { V }\end{array}$ & $\begin{array}{rrr}4 \mathrm{~m} & 6 & \mathrm{~d} \\
3 \mathrm{~m} & 29 & \mathrm{~d} \\
4 \mathrm{~m} & 23 & \mathrm{~d} \\
4 \mathrm{~m} & 9 & \mathrm{~d} \\
4 \mathrm{~m} & 2 & \mathrm{~d} \\
4 \mathrm{~m} & 2 & \mathrm{~d} \\
3 \mathrm{~m} & 23 & \mathrm{~d} \\
5 \mathrm{~m} & 3 & \mathrm{~d} \\
3 \mathrm{~m} & 29 & \mathrm{~d} \\
4 \mathrm{~m} & 23 & \mathrm{~d}\end{array}$ & $\begin{array}{l}17 \\
21 \\
29 \\
30 \\
45 \\
46 \\
58 \\
59 \\
67 \\
69 \\
70 \\
72 \\
142 \\
148 \\
149 \\
150 \\
158 \\
159 \\
163 \\
186 \\
187 \\
193 \\
194\end{array}$ & $\begin{array}{l}\text { I } \\
\text { I } \\
\text { I I } \\
\text { I I } \\
\text { I I I } \\
\text { I I I } \\
\text { IV } \\
\text { IV } \\
\text { IV } \\
\text { IV } \\
\text { IV } \\
\text { IV } \\
\text { V } \\
\text { V } \\
\text { V } \\
\text { V } \\
\text { V } \\
\text { V } \\
\text { V } \\
\text { V } \\
\text { V } \\
\text { V } \\
\text { V } \\
\end{array}$ & $\begin{array}{rrr}3 \mathrm{~m} & 15 & \mathrm{~d} \\
4 \mathrm{~m} & 11 & \mathrm{~d} \\
3 \mathrm{~m} & 28 & \mathrm{~d} \\
2 \mathrm{~m} & 26 & \mathrm{~d} \\
3 \mathrm{~m} & 25 & \mathrm{~d} \\
3 \mathrm{~m} & 19 & \mathrm{~d} \\
4 \mathrm{~m} & 9 & \mathrm{~d} \\
4 \mathrm{~m} & 8 & \mathrm{~d} \\
3 \mathrm{~m} & 7 & \mathrm{~d} \\
3 \mathrm{~m} & 26 & \mathrm{~d} \\
4 \mathrm{~m} & 19 & \mathrm{~d} \\
4 \mathrm{~m} & 8 & \mathrm{~d} \\
3 \mathrm{~m} & 25 & \mathrm{~d} \\
4 \mathrm{~m} & 12 & \mathrm{~d} \\
4 \mathrm{~m} & 12 & \mathrm{~d} \\
4 \mathrm{~m} & 12 & \mathrm{~d} \\
3 \mathrm{~m} & 9 & \mathrm{~d} \\
3 \mathrm{~m} & 25 & \mathrm{~d} \\
5 \mathrm{~m} & 12 & \mathrm{~d} \\
3 \mathrm{~m} & 23 & \mathrm{~d} \\
4 \mathrm{~m} & 17 & \mathrm{~d} \\
4 \mathrm{~m} & 15 & \mathrm{~d} \\
4 \mathrm{~m} & 21 & \mathrm{~d} \\
\end{array}$ \\
\hline & $3 \mathrm{~m} 26 \mathrm{~d}$ & $\mathrm{~d}$ & & $3 \mathrm{~m} 29 \mathrm{~d}$ & & & $9 \mathrm{~d}$ & $d$ & & $4 \mathrm{~m}$ & $\mathrm{~d}$ \\
\hline
\end{tabular}




$$
\begin{aligned}
& \text { R.1.1 - } 3 \text { meses e } 26 \text { dias; } \\
& \text { R.1.2 }-3 \text { meses e } 29 \text { dias; } \\
& \text { R.1.3 }-4 \text { meses e } 9 \text { dias; } \\
& \text { R.1.4 - } 4 \text { meses e } 2 \text { dias }
\end{aligned}
$$

Em 2 centros de saúde o $n^{\circ} 50$ na $R .1 .2$ e o $n^{\circ} 163$ na R.1.4 as mêdias foram: no $1^{\circ}: 5$ meses e 9 dias e no $2^{\circ}: 5$ me ses e 12 dias.

No centro de saủde $n^{\circ} 50$, a título de ilustração, sạ lientamos que a cobertura alcançada foi de $101,90 \%$ com um grau de alcance de 2,26 (sendo 1 a razão desejāvel), a concentra ção real foi de 2,95 , o R.I. 0,04 e o grau de utilização ins trumenta1 foi de 0,006 .

Se correlacionarmos todos estes resultado temos um quadro que fala por si quanto às adequações dos atributos da atividade consulta médica,essencial no cuidado prë-natal.

3.7.3 Variāvel independente complementar "atuação do instrumen to nuclear responsāvel pela consulta médica e pelo aten dimento de enfermagem".

Deste item excluímos o instrumento nuclear da consul ta médica por jā ter sido retro focalizado.

Informações sobre a quantidade dos instrumentos hora/ enfermeira e hora/obstetriz jả foram proporcionadas no item 3.5 ao relatarmos os resultados do estudo da variável "dis ponibilidade do instrumento nuclear...".

Aqui os aspectos que são do nosso interesse focalizar são as atividades que estes dois instrumentos realizam ou deveriam realizar dentro do setor de saūde materna.

Assim sendo, a partir do levantamento de dados não re gistrados configuramos a seguinte situação (apresentada nos Quadros $\mathrm{n}^{\circ} \mathrm{s} 15$ a 18 ) : 
- As 12 enfermeiras cuja presença foi identificada distribuem-se nas 4 Regionais a saber:

. 2 na R.1.1

. 4 na R. 1.2

. 2 na R. 1.3

. 4 na R. 1.4

As atividades* que estas 12 enfermeiras realizam têm a seguinte estrutura:

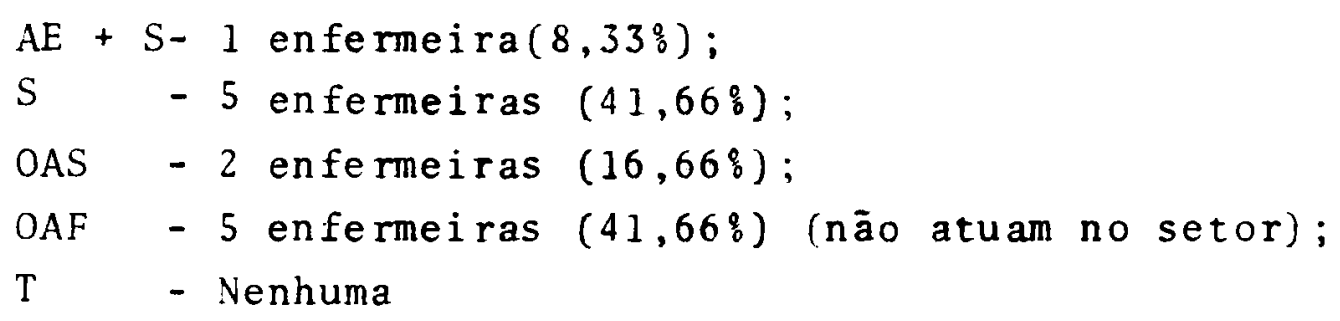

As 21 obstetrizes presentes nas Regionais desempenham as seguintes atividades:

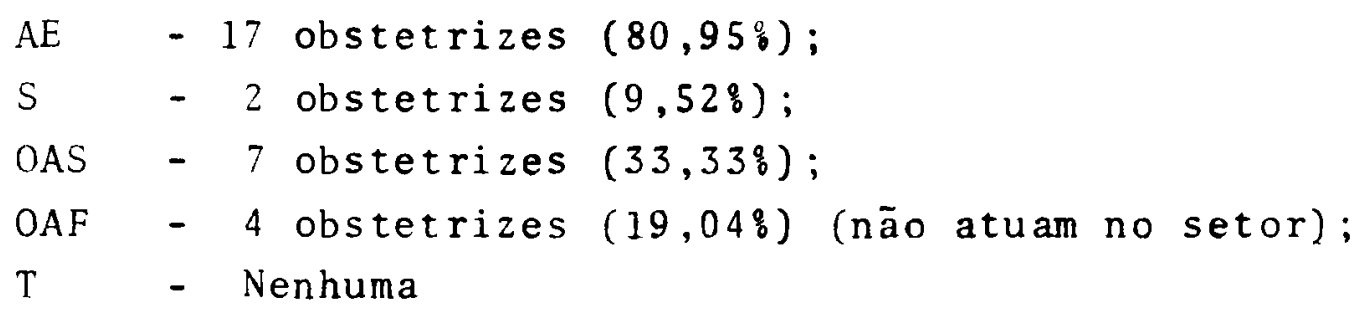

Algumas destas atividades são desempenhadas simulta neamente, quer pelas enfermeiras, quer pelas obstetrizes, daí a porcentagem global ultrapassar $100 \%$. Interessou-nos apresen tar os percentuais tendo em vista a evidencia da atividade "OAF" que consideramos injustificáve 1 racionalmente, tanto quan to o não conhecimento do problema em profundidade, nos permite exarar um parecer. Para emitir esta opinião, nós nos basea mos no conhecimento não empírico da situação e na experiência de autores que estudaram o assunto, pois sabemos que a sub $\underline{u}$ tilização destes 2 instrumentos no setor de saúde materna é um fato. As razões são múltiplas, algumas citadas em outros

* $\mathrm{AF}=$ atendimento de enfermagem; $S=$ supervisão; $O A S=$ ou tras atividades no setor; $O A F=$ outras atividades fora do setor; $T=$ triagem. 
trabalhos como em Adami ${ }^{1}$ as quais podemos transpor para este nosso, dada a sua propriedade: o não reconhecimento das dispo nibilidades profissionais destes 2 instrumentos, principalmen te pela classe médica.

Os problemas operacionais e funcionais dos centros de saúde, condicionando os desvios evidentes de funçōes, são ou tras razões existentes, como é o caso de enfermeiras e obste trizes designadas para o desempenho de atividades restritas às salas de curativos e injeções ou para funções burocräticas.

Cabe também lembrar ocorrências ligadas a necessidades advindas do nosso subdesenvolvimento: : os problemas de morbidades evitáveis por meio da vacinaçāo ainda são prioritá rios pela nossa precariedade em educação sanitāria e cam panhas que se impoẽm para o seu controle absorvem uma parte razoável das horas/trabalho disponíveis das enfermeiras e às vezes das obtetrizes.

Também me recendo comprovação empírica existe o fato do despreparo das enfermeiras para atividades especificas em saúde materna. A observação não testada mostra que este pro fissional muitas vezes é ausente em relação ao setor porque não possui o conhecimento necessário que lhe daria a seguran ça do desempenho, portanto, o ajustamento na função.

Este despreparo também existe em relação ao processo elementar da prestação de assistência de enfermagem e ao de sempenho da função administrativa, como relatou Adami ${ }^{1}$ em trá balho recente.

Podemos, então conjecturar se a não atuação ou a peque na atuação das enfermeiras estaria contribuindo,e quanto,para a vigência doquadro que se delineou ao exame dos resultados do levantamento realizado para embasar este trabalho.Quanto pode ria contribuir para melhorar a situação, a plena e adequada utili 2 açāo dos 2 instrumentos nucleares em apreço?

Os autores consultados são unânimes em enfatizar a neces sidade da participação da enfermeira e obstetriz não só como força de trabalhodireto, mas também como agente multiplicador e regula dor na assistência à gestante. 
Fala-se da responsabilidade da enfermeira em assumir a independência do seu desempenho, no preparo do qual a Nação sofre um ônus que necessita ser justificado, e não o será pe la sub utilização - Dantas ${ }^{23}$ diz que à enfermagem cabe defí nir sua prōpria estratégia de ação e para isto é urgente ava liar a atuação da enfermagem, especificamente nos setores da Assistência à Maternidade e a Infância, com o fito do determi nar as diretrizes de preparo e trabalhos futuros.

Barros, S. \& Pinto ${ }^{10}$ ressaltam que "a educaçāo dos profissionais deve estar voltada para uma crítica sobre a prá tica proffissional numa atitude coerente e inovadora".

Nascimento $0^{45}$ ao focalizar a contribuição do enferme $\underline{i}$ ro obstetra na prevenção do alto risco, fala da necessidadeda atuação do enfermeiro obstetra (ou não, desde que habilitado a isto) alēm da prestação da assistência direta, também nas e tapas de diagnóstico da situação e no planejamento consequente-

A este propósito Cieto ${ }^{20}$ enfatiza as necessidades de se fazerem pesquisas em enfermagem e de se prepararem as en fermeiras para isto, pois, só com base em inquéritos sistemátí $\cos$ se conseguira um atendimento adequado das necessidades re ais. Essas considerações reforçam o nosso parecer quanto à ne cessidade de se procurar conhecer"de visu" a situação do grú po gestantes e estudar qual seria a participação racional e ideal da enfermagem no tratamento da problemática existente. Gentile de Mello ${ }^{28}$ dá ênfase à importância da participação da enfermeira no planejamento da assistência à saúde, salientando o alto custo do profissional para que seja desviado para refas delegáveis e a capacidade comprovada de atuações da en fermagem jā registrada nesta área do trabalho em saúde.

Adams $^{2}$ orientando sobre a utilização da estatística em saúde pelas enfermeiras, salienta a necessidade de ser as sumida pelas enfermeiras e obstetrizes a responsabilidade que Thes compete na elevação do nível de saúde das mães e filhos. Para isto ressaltamos seu parecer quanto à importância da $\underline{i}$ 
dentificação das necessidades da população alvo.

Neste mesmo sentido, como reforço, citamos calnan ${ }^{11}$ que fala em especial do perigo da prätica por intuição; Lewis 39, quando diz que a prática do processo de enfermagem pode dar à enfermeira a segurança de que necessita para fazer face às necessidades dos pacientes que assiste, salientando as fa zes deste processo e entre elas a do diagnóstico da situação; Duarte $^{27}$, expõe exemplos de diagnöstico da atuação da enfermeira em saúde materna e justifica plenamente a contribuição deste profissional na atenção direta à gestante sadia.

Shalesinger 59 no seu trabalho sobre a influência de necessiciades interrelacionadas, informa sobre os resultados e recomendações quanto à identificação das necessidades, não so mente das clientes, mas tambēm da instituição e dos profissio nais; pondera sobre o papel dos diversos membros da equipe em saúde materna e relaciona os resultados sobre as necessidades identificadas: entre elas destacamos a da identificação e a preciação do papel executado pelos diversos membros. Sobre as consideraçōes de Kraegel 34 nös nos apoiamos tambëm para sali entar a necessidade de basear a assistência nas necessidades dos pacientes. Este autor comenta que o problema da insufici ência das enfermeiras está igualmente no seu mau aproveitamen to e na falta de estudos que demonstrem os benefícios de sua melhor utilização. Ele ressalta que, quando as necessidades das pacientes não são o foco da assistência, outras necessida desfazem um sifão dos recursos e energias em detrimento das assistidas.

Reeder ${ }^{56}$, com muita propriedade discorre sobre esses possiveis beneficios a que nos referimos acima, dizendo que a investigação tem provado que, quando as enfermeiras ampliam seu papel e são membros atuantes da equipe, hả uma notável di minuição das faltas das gestantes às consultas pré-natais e redução da mortalidade infantil. Fala também da necessidade de se orientar a enfermeira sobre suas funções na saúde mater na para que seja de utilidade efetiva, principalmente no con 
trole da gestante sadia.

Por fim, Horta ${ }^{32}$ reforça todos esses pareceres com sua conhecida ênfase, sobre a necessidade de se aplicar o pro cesso de enfermagem na assistência dos pacientes e sobre a necessidade condicionante e consequente de se preparar a en fermeira (e a obstetriz) para este desempenho.

Contudo, para que possa ser mudado o estado atual das coisas, em que, para ilustrar, lembremos-nos do exposto há pou co: de 12 enfermeiras existentes em 11 unidades sanitārias, 5 não têm a menor atuação no setor de saúde materna e de 21 ob $\underline{s}$ tetrizes, cuja atribuição específica seria o desempenho do cargo neste setor, 4 não atuam absolutamente aí, será necessā rio um estudo mais amplo e mais profundo que este e necessariamente especifico. Um dos passos condicionantes dessa poss bilidade parece-nos já foi dado: é o movimento no sentido de se definirem padrōes de assistência de enfermagem para que se possa fazer uma avaliação sistemātica e vālida da situação e se planejarem medidas de ajuste que se evidenciem necessárias. Assim é que o Informe Final ${ }^{49}$ do Grupo de Trabalho do línis rio da Saūde, na exposição que faz dos resultados das ativida des desse grupo, relata como um dos padrões para avaliação do desempenho da enfermagem, a identificação de grupos de alto risco e a asseguração de atenção primāria a este grupo. Outro padrão citado, entre vārios, é que a enfermagem aplique inqué ritos para essa avaliação, e que tome decisões baseadas nesse inquérito.

Esperemos que a sistemática para a utilização desses padrões seja implantada e que, então, as enfermeiras e ob $\underline{s}$ tetrizes, em saủde materna, sejam capacitadas, em consequência, para uma participação efetiva e tão necessāria no setor.

Quais os fatores que poderiam condicionar as associa ções do tempo de espera com as variäveis independentes estudadas?

Como não constou dos nossos objetivos a identificação 
destes fatores, podemos pelo raciocínio lógico, com o amparo de estudos relacionados e diante dos resultados obtidos na a valiação de metas, levantar a seguinte hipótese para futura comprovação:

- a variação do tempo de espera maior que o intervalo aceitảvel seria condicionada pelos seguintes even tos ou por alguns deles:

- a cobertura alcançada acima da meta proposta, pro vocou um desajustamento da razão OA: OP* .

Este desajustamento poderia,em consequência, condi cionar a ocorrência de eventos negativos como o aumento do tempo de espera se os instrumentos não estivessem sendo reajustados;

- sub utilização da hora/instrumento/mẻdico/enfermeira e obstetriz; este fator de associação foi comprovado por estudos comentados em Adami ${ }^{2}$, Ciari et a1 16,19 , Giron ${ }^{29}$, Schor ${ }^{60}$ e pelos re sultados do nosso levantamento, apresentados nos Quadros de n's 19 a 27 ;

- desequilíbrio decorrente da sub utilização acima citada, frente à demanda real que se desconhece, dada a repressão da mesma, como apresentado,nas $\mathrm{T} \underline{a}$ belas de 12 a 15 ;

- possível desconhecimento da problemätica subjacen te devido à provável dificuldade de se aplicarem técnicas de avaliação tanto quantitativas como qualitativas, entre outros motivos, pela precarie dade dos registros existentes.

* Segundo Ramos 55 , a avaliação da eficācia de um programa po de ser medida pela comparação do objetivo alcançado(OA) com o objetivo programado(OP). 
VIII- CONCLUSŌES 
De acordo com os objetivos propostos para este traba tho apresentamos, a seguir as conclusōes do estudo realizado.

1. O "tempo de espera" foi identificado como o que se escoa desde a data da inscrição das gestantes nos centros de saúde para o controle pré-natal a té a data da primeira consulta médica.

2. O "tempo de espera" foi caracterizado em aceitā vel, quando dentro do parāmetro de normalidade o intervalo de 0 a 7 dias - e não aceitävel, quan do ultrapasa este parāmetro.

3. O "tempo de espera" apresentou-se com uma grande deza muito maior dentro do parâmetro de normalida de em todas as unidades da amostra nas Regionais do DRS-1, SP, numa proporçāo de $7: 1$ em relaçāo ao tempo de espera não aceitável.

4. As associações do "tempo de espera", estatisticamente significativas, foram comprovadas em rela cionamento com:

- a localização geográfica das unidades sanitá rias da amostra;

- os tipos de centro de saúde selecionados;

- a presença dos instrumentos nucleares da consul ta médica e do atendimento de enfermagem nas u nidades do estudo;

- o percentual da meta de cobertura alcançado.

5. Não houve associação entre tempo de espera e ida de da gestação ao tempo da inscriçāo.

6. Foram encontrados indícios de associação entre o grau de utilização do instrumento hora/mèdico e - alcance das metas de cobertura e concentração. 
7. Foram encontrados indícios de associação entre a disponibilidade dos instrumentos hora/enfermeira e hora/obstetriz com as variações do "tempo de es pera" e o grau de eficácia da cobertura.

8. Foi evidenciada a sub utilização dos instrumentos hora/médico, hora/enfermeira e hora/obstetriz.

9. Diante dos resultados que evidenciam pequeno grau de eficácia das metas e a sub utilização dos instrumentos nucleares das consultas médicas e do a tendimento de enfermagem, concluímos que a alta porcentagem de "tempo de espera" aceitável. isola damente, não deve ser considerada como um indício de boa qualidade da assistência de saúde prestada às gestantes incluídas no estudo. 
I X - RECOMENDAÇ̄ESS 
Cons ide rando:

- que a demanda reprimida identificada no atendimento das gestantes, nos centros de saúde da rede do DRS1, SP, pode ter influído na apresentação do tempo de espera encontrado;

- que o baixo grau da eficácia das metas assisten ciais propostas e o pequeno grau de utilização dos instrumentos nucleares da consulta mëdica e do aten dimento de enfermagem podem ter participado no con dicionamento dessa apresentação;

- que esses fatores podem estar influindo na aceita ção dos serviços pelas gestantes;

Recomendamos que sejam promovidos estudos no sentido de:

1. identificar-se a porção real de gestantes que de $\underline{i}$ $x a m$ de receber assistência de saúde na ärea geo gräfica da Grande São Paulo;

2. possibilitar-se o conhecimento, junto das pró prias gestantes da verdadeira configuração do tem po de espera para a inscrição no pré-natal dos Serviços de Saúde da Grande São Paulo;

3. utilizar-se plena e adequadamente os instrumentos hora/enfermeira e hora/obstetriz na assistência de saúde prestada às gestantes nas unidades sanitá rias do DRS-1, SP. 


\section{$X$ - REFERÊNCIAS BIBLIOGRÁFICAS}


1. ADAMI, N.P. Funções da enfermeira nos centros de saüde da Secretaria de Estado da Saúde de São Paulo. São Paulo, Faculdade de Saúde Pública da USP, 1978.

2. ADAMS, C.J. Empleo de las estadisticas de Salud en la Ví gilancia y la evaluacion de programas de maternidad. In SEMINARIO SOBRE ASPECTOS DE ENFERMERIA-OBSTETRICIA EN - SALU maternoinfantil y planificacion de la FAMILIA, Washington. D.C., Organizacion Panamericana de la Sa lud, 1974. (OPAS - Pub1. cient., 291).

3. AGUIRRE, C. A. ed. Atencion a la madre $y$ al niñomenor de 5 años con enfasis en la atencion primaria. Cali, Co lombia, Editorial Nur, 1978.

4. ALMEIDA, P.A.M. de et al. Identificação e avaliação dos fatores clínicos da gestação de alto risco. Rev. Saúde püb1., S. Paulo, 9: 417-25, 1975.

5. ALPER, M.H. \& ROAF, E.R. Anesthetic management of the high-risk pregnancy. Clin. Obstet.Gynec., 16: 347-60, 1973 .

6. ANDERSON, U.M. et al. High-risk groups: definition and identification. New Eng1. J. Med., 273: 308-13, 1965.

7. ANDRADE, O.B. de Sistemática operacional de enfermagem de saūde pública: contribuição à programação de saúde. São Pau10, 1976. (mimeografado).

8. AUBRY, R.H. \& NESBITT Jr., R.E.L. High-risk obstetrics. I. Perinatal outcome in relation to a broadened approach Amer. J. Obstet. Gynec., 105: 241-7, 1969.

9. AUBRY, R.H. E PENNINGTON,J.C. Identification and evaluat ion of high-risk pregnancy - The Perinatal Concept - Clin. Obstet. Gynec. 16: 3-27, 1973. 
10. BARROS, S. \& PINTO, S. Programa materno infantil e o sis tema nacional de saúde. In: REUNIÃO DE ENFERMAGEM MA TERNO INFANTIL DA BAHIA, 1a., Salvador, 1978. Anais. Salvador, Associação Brasileira de Enfermagem/Escola de Enfermagem da UFBA, 1978. p. 8-14.

11. CALNAN, M.F. \& HANRON, J. B. Nursing Assessment dialogue with meaning. Superv. Nurse, 2 (7): 18-9, 21, 1971.

12. CANDEIAS, N.M.F. Educação em saūde na prevenção do risco gravídico pré-natal e risco interconcepcional. São Paulo, 1979. (Tese de Doutoramento - Faculdade de Saú de Pública da USP).

13. CASTELAZO-AYALA, L. Embargo y feto de alto riesgo. I Con cepto actual de embarazo de alto riesgo. Gac. med.México, 107: 51-5, 1974 .

14. CIARI Jr., C. \& ALMEIDA, P.A.M. de Anālise do coeficien te de mortalidade materna no município de Osasco, São Paulo, Brasil. Rev.Saúde públ., S.Paulo, 6: 237-44, 1972 .

15. CIARI Jr., C. \& ALMEIDA, P.A.M. de Elementos de avalia ção do "risco gravídico". Rev. Saúde púb1., São Pau $10, \underline{6}: 57-78,1972$.

16. CIARI Jr., C. E SIQUEIRA, A.A.F. de Problemas de saüde materno-infantil no Brasil. In: PARETA, J.M.N. Saúde da Comunidade: Temas de Medicina Preventiva e Social. São Paulo, Ed. Mc Graw-Hill do Brasil.

17. CIARI Jr., C. et al "Acreditação" de serviços de pré-na tal. Rev. Saúde púb1., S. Paulo, ㅇ: 187-202, 1974.

18. CIARI, Jr., C. et al. Avaliação qualitativa dos serviços de pré-natal: auditoria de fichas clínicas. Rev. Saūde püb1.., S. Paulo, ㅇ: 203-12, 1974 . 
19. CIARI Jr., C. et al. Avaliação quantitativa de serviços de pré-natal. Rev. Saúde púb1., S.Paulo, 6: 361-70, 1972 .

20. CIETTO, L. Pesquisa e desenvolvimento da enfermagem:consi deraçōes sobre sua importāncia na ărea materno-infantil. Enf. Novas Dimens., 2: 93-7, 1976.

21. CORREY, J. F. et al. What is meant by "at risk" pregnancy? Australian Family Physician, 6: 205-12, 1977.

22. Coslovsky, S. Conceituação clínica de risco. Femina, $\underline{3}$ : $719-22,1975$.

23. DANTAS, C.D.C. A realidade materno infantil no contexto global da saúde. In: REUNIAO DE ENFERMAGEM MATERNO IN FANTIL DA BAHIA, 1a., Salvador, 1978. Anais. Salvador, Associação Brasileira de Enfermagem/Escola de Enferma gem da UFBA, 1979. p. 1-7.

24. DIRETRIZES para saüde. (transcrito do Jornal de Brasilia, 8 abr. 1979).

25. DONABEDIAN, A. \& ROSENFELD, L.S. Some factors influencing prenatal care. New Eng1. J. Med., 265: 1-6, 1961.

26. DUARTE, N.M.N. \& MUXFELDT, L.C. O papel da enfermeira na assistência à gestante sadia. Rev. bras. Enf., 28: 704,1975 .

27. FISHER, Sir Ronald A. \& YATES, F. Tabelas estatisticaspa ra pesquisa em biologia, medicina e agricultura. São Paulo, Ed. USP/ed. Polígono, 1971.

28. GENTILE DE MELLO, C. A participação da enfermagem no pla nejamento de saúde. Rev. paul. Hosp., 19 (8): 4-61971. 
29. GIRON, S.G. et a1. A importância do diagnōstico em nível local para o planejamento de serviços de saúde materna. Rev. Saüde pübl., S. Paulo, 8: 43-9, 1974.

30. GOMES, H.C. de C. et a1. Comunicação sobre estudos de morbidade. Rio de Janeiro, Instituto de Planejamento da Saúde da Fundação SESP, 1970. (apresentado ao $18^{\circ}$ Con gresso Brasileiro de Higiene, 1970 - mimeografado).

31. HOBEL, C.J. et a1. Prenatal and intrapartum high-risk Screennig. I. Prediction of the high-risk neonate. Amer. J. Obstet. Gynec., 117: 1-9, 1973.

32. HORTA, W. de A. Conceito de Enfermagem. Rev.Esc. Enf. USP, $\underline{2}$ (2): 1-5, 1968 .

33. KLEIN, M. D. G KARTEN, I. Maternal deaths: a health and socioeconomic challenge. Amer. J. Obstet. Gynec., 110: $298-303,1971$.

34. KRAEGEL, J. M. et al. A system of patient care based on patient needs. Nurs. Outlook, 20: 257-64, 1972.

35. LAURENTI, R. \& SIQUEIRA A.A.F. O problema de mortalidade neo-natal em São Paulo, Brasil. Rev. Saūde püb1. S.Pau $10, \underline{6}: 45-55,1972$.

36. LAURENTI, R. et al. Mortalidade perinatal em São Paulo, Brasil. Rev. Saúde púb1. S.Paulo, 9 : 115-24, 1975 .

37. LEITE, L. ¿ SOUZA, M.de L. de Controle da gestação de alto risco. São Paulo, Faculdade de Saúde. Pública dausp, 1978. (apresentado à Disciplina Assistência de Enferma gem de Saúde Pública em Saúde Materna e da Criança - mi meografado). 
38. LESSER, A. J. Progress in maternal and child health. Chi1d. Today, 1: 7-12, 1972.

39. LEWIS, L. This I believe... about the nursing process Key to care. Nurs Outlook, 16 (5): 26-9, 1968.

40. MINISTERIO DE SALUD PUBLICA. Reso1ucion nume ro 001187 de 1962 (agosto 6): por la cual se adopta el manual de normas generales y programa sobre Proteción Materno-Infanti1. Bogota , 1962. (mimeografado).

41. MONAHAN, H.B. \& SPENCER, E.C. Deterrents to prenatal care. Children. 9: $114-9,1962$.

42. MONETTI, V. \& CARVAIHO, P.R. de Mortalidade materna e na infância no Estado de São Paulo (aspectos demográficos, sōcio-culturais e médico-sanitários). 2a. ed. São Pau 1o, Instituto de Saủde. Divisão de Saủde Materna e da Criança, 1976. (Pub1., 29. Sërie D, n 11).

43. MONETTI, V. et al. Diretrizes gerais para a politica estadual de promoção, prevenção e recuperação de Saüde materno-infantil; relatório. São Paulo, Instituto da Saúde - Divisão de Saúde Materna e da Criança, 1973. (P b1., 19. Série D, nº 6).

44. MORTALIDAD y morbidade perinatales. Cron. OMS, 25: 280-7, 1971 .

45. NASCIMENTO, N.M. de F. Contribuição do enfermeiro obste tra na prevenção da G.A.R. In: REUNIAO DE ENFERMAGEM MATERNO-INFANTIL DA BAHIA, 1a., Salvador, 1978. Anais. Salvador, Associação Brasileira de Enfermagem/Escola de Enfermagem da UFBA, 1978. p. 39-44.

46. NESBITT Jr., R.E.L. \& AUBRY, R.H. High-risk obstetrics. I V Value of semiobjective grading system in identifynig 
the vulnerable group. Amer. J. Obstet. Gynec., 103: $972-85,1969$.

47. NICK, E. ¿ KELLNER, S.R. de O. Fundamentos de estatística para as ciências de comportamento. Rio de Janeiro, Ed. Renes, 1971.

48: ORGANIZAÇION PANAMERICANA DE LA SALUD. Plan decena1 de salud para las Americas; Informe final. Washington, D.C., 1972. (Documento oficia1, 118).

49. PADROES mínimos de assistência de enfermagem à comunidade; Informe final. Brasília, Ministério da Saüde/Orga nização Panamericana da Saúde, 1977.

50. PEREIRA, E.M. Curso de Metodologia e Projetos de Pesquisa. São Paulo, 1979 (mimeografado).

51. PERKIN, G.M. Assessment of reproductive risk in nonpregnant women: a guide to establishing priorities for contraceptive care. Amer. J. Obstet. Gynec., 101:70917,1968 .

52. PETERS, W. ¿ SUMMERS, G.W. Anālise estatística e processo decisório. Rio de Janeiro, Fundação Getülio Vargas, 1973.

53. PINOTTI, J.A. et a1. O que é gravidez de alto risco? Femina, 2: $329-35,1974$.

54. PORTARIA SS-CG $n^{8} 8$, de 6-6-72. In: SECRETARIA DE ESTADO DA SAUDE: Coordenadoria de Saúde da Comunidade. Portarias do coordenador: período de junho de 1971 a março de 1973. coletânea. São Pau1o, 1973. 
55. RAMOS, R. O Problema da Avaliação em Saúde Püblica. Rey. Saüde püb 1. S.Paulo, $8505-1 \%, 1974$.

56. REEDER, S.R. et a 1. Enfermería matemo-infantil.

Washington, D.D. Organizacion Panaericana de la Salud, $19^{-8}$.

57. REUNION ŁSPECIAL DE MINISTROS DE SALUD DE LAS AMERICAS, da., Washington, D.C., 1977. Informe final y documento de referencia. Washington, D.C., Organización Pana mericana de la Salud, 1978. COPAS - Documento oficial, $55)$.

58. SCHLESINGER, E.R. \& NESBITT Jr., R.E.L. Publica health viewpoint: scope and perspective. Clin. Obstet.Gynec., 4: $317-25,1961$.

59. SCHLESINGER, R.H. et a 1. Out-patient care: the influence of interrelated needs. Amer. J. publ. H1th, 52: 184452,1962 .

60. SCHOR, R. et al. Diagnóstico da situação de assistência pré-natal de uma divisão regional de saúde do Estado de São Paulo, Brasil. Rev. Saūde pübl., São Paulo, $\underline{9}$ : $351-62,1975$.

61. SECRETARIA DE ESTADO DA SADDE. Coordenadoria de Saūde da Comunidade. Normas e instruçōes. São Paulo, s.d.

62. SERMENT, R. et al. Organisation d'une consultation de grossesses à risques e' levés. Rev. franç. Gynēc.,67: $639-42,1972$.

63. SIEGEL, S. Estatística não-paramétrica para as ciências do comportamento. São Paulo, McGraw-Hil1 do Brasil, 1975 . 
64. SOUZA, M. de L. de Estudo de algumas características de mulheres da zona urbana de Florianópolis que já tive ram uma ou mais gestações c do Centro de Saúde, sua re 1 ação com assistência prê-nata1. São Paulo. (Dissertação de Mestrado - Faculdade de Saūde Püblica da USP).

65. TOKUHATA, G.K. et al. Prenatal care and obstetric abnormalities: experiences of 185.000 Pennsylvani births. J. chron. Dis., 26: 163-85, 1973.

66. WALLACE, H.M. Factors associated with Perinatal mortaly and Morbidity. Clin. Obstet. Gynec., 13: 13-43, 1970 .

67. WORLD HEALTH ORGANIZATION. Expert Committee on Maternal and Child Health. Geneva, 1975. New trends and approaches in the delivery of maternal and child care in health services: sixth report. Geneva, 1976.(Techn. Rep. Ser., 600).

68. YUNES, J. Diagnōstico da situação de saúde püblica no mu nicípio de São Paulo em 1968. Rev. Hosn. clin. Fac. Med. S. Pau1o, 25: 83-9, 1970 .

69. YUNES, J. Programa Nacional de saüde materno-infantil. In: CONFERENCIA NACIONAL DE SAUDE, 5a., Brasilia, 1975. Anais. Brasília, Ministērio da Saüde, 1975. p. 43-134. 
ANEXOS 


\section{QUADRO}

Nümero de gestantes inscritas no DRS-1, SP, por mês do ano de 197 e por trimestre da ges tação, segundo os tipos e denominaçōes dos centros de saūde.

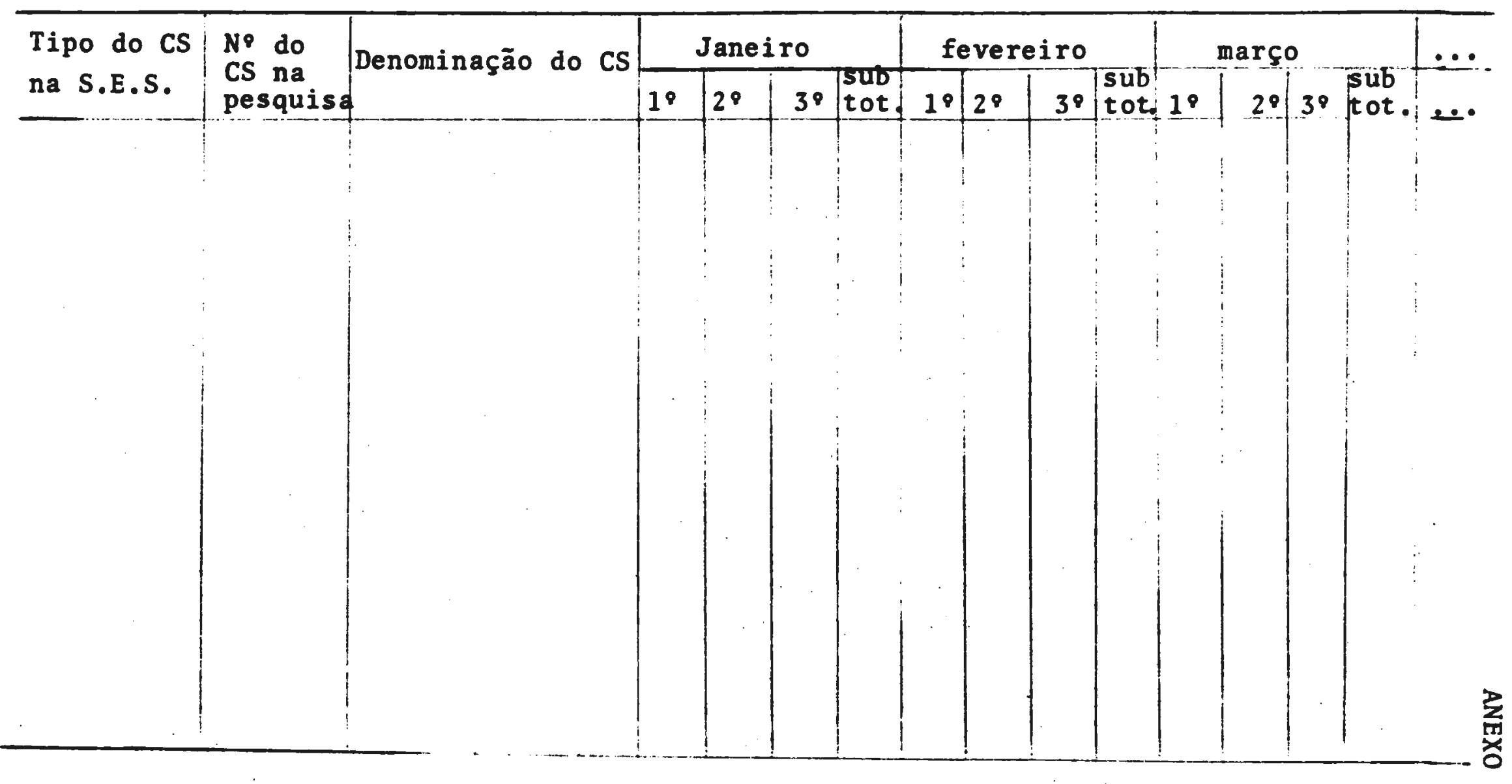


C.S.

R. 1-

ANEXO II

\begin{tabular}{|c|c|c|c|c|c|c|c|c|c|}
\hline \multirow{2}{*}{$\begin{array}{l}\text { DISCRIMINAÇAO } \\
\text { DE } \\
\text { DADOS }\end{array}$} & \multirow{2}{*}{$\begin{array}{l}\text { Medico } \\
\text { consul- } \\
\text { tante no } \\
\text { setor } \\
\text { de S.M. }\end{array}$} & \multicolumn{2}{|c|}{ Enfermeirs } & \multicolumn{4}{|c|}{ Obstetriz } & \multicolumn{2}{|c|}{ Meta diäria } \\
\hline & & 1 & 2 & 1 & 2 & 3 & 4 & $\begin{array}{l}\text { Limita } \\
\text { da con } \\
\text { forme } \\
\text { o agend }\end{array}$ & $\begin{array}{l}\text { Limita } \\
\text { da con } \\
\text { forme } \\
\text { a deman }\end{array}$ \\
\hline a- Lotaçāo efetiva & & & & & & & & $\ldots \ldots$ & $\cdots$ \\
\hline $\begin{array}{l}\text { b- Realização de } \\
\text { atividades de: } \\
\text { 1. Triagem de } \\
\text { gestantes }\end{array}$ & & & & & & & & $\begin{array}{l}\ldots \ldots \\
\ldots \ldots \\
\ldots \ldots \\
\ldots \ldots \\
\ldots \ldots \\
\ldots \ldots\end{array}$ & $\begin{array}{l}\cdots \\
\cdots \\
\cdots \\
\cdots\end{array}$ \\
\hline $\begin{array}{l}\text { 2. Consulta de } \\
\text { gestantes }\end{array}$ & & & & & & & & & \\
\hline $\begin{array}{l}\text { 3. Atendimento } \\
\text { de enfermagen } \\
\text { a gestantes }\end{array}$ & & & & & & & & & \\
\hline $\begin{array}{l}\text { 4. Supervisāo do } \\
\text { setor de S.M. }\end{array}$ & & & & & & & & & \\
\hline $\begin{array}{l}\text { 5. Outras ativi } \\
\text { dades no Se } \\
\text { tor de S.M. }\end{array}$ & & & & & & & & $\begin{array}{l}\cdots \cdots \\
\cdots \cdots \\
\cdots \cdots \\
\cdots \cdots \\
\cdots \cdots\end{array}$ & \\
\hline $\begin{array}{l}\text { 6. Outras ativi } \\
\text { dados fora do } \\
\text { setor de S.M. }\end{array}$ & & & & & & & & $\begin{array}{l}\cdots \cdots \\
\cdots \cdots \\
\cdots \cdots \\
\cdots \cdots \\
\cdots \cdots\end{array}$ & \\
\hline
\end{tabular}


C.S.

R. 1 -

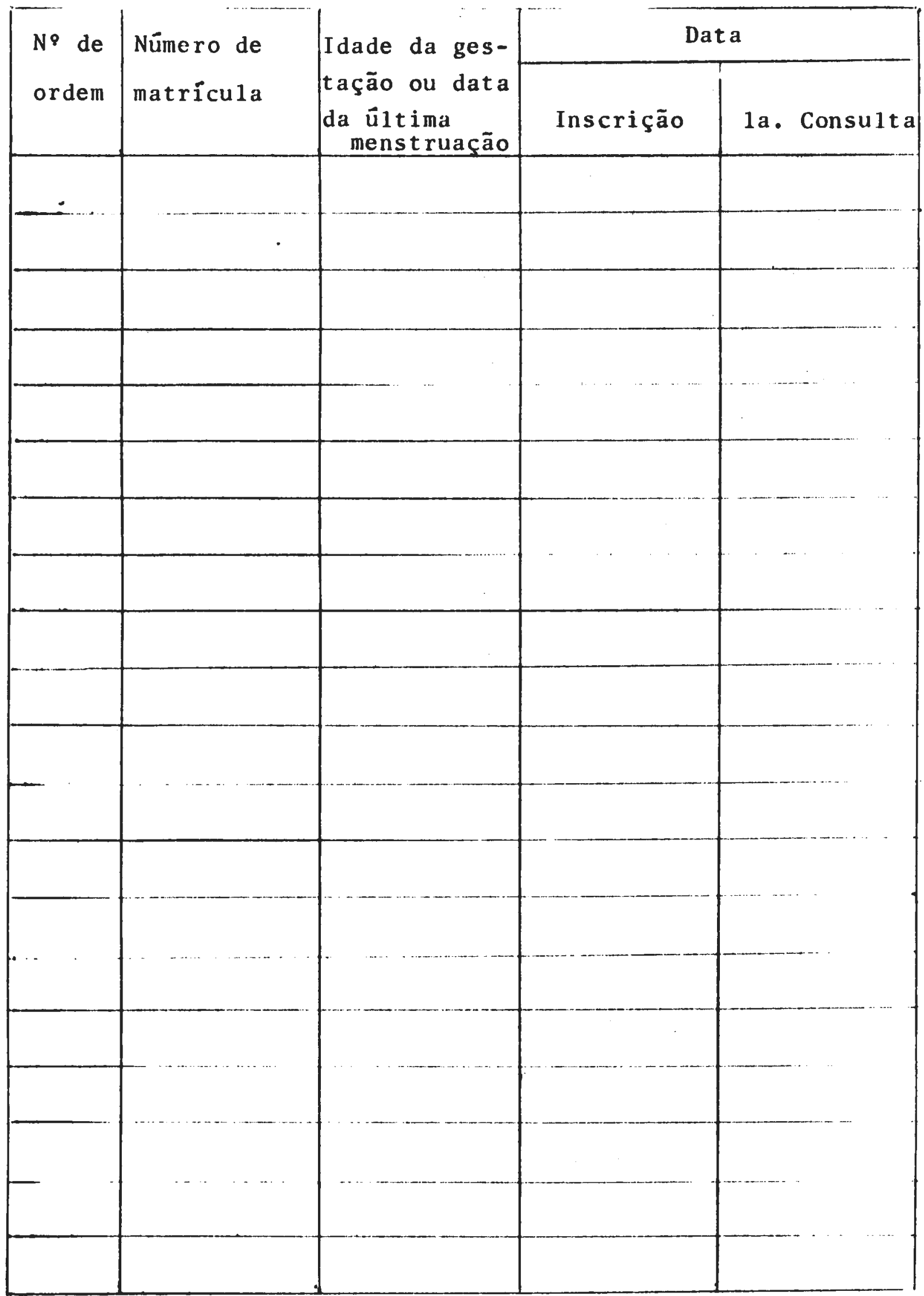




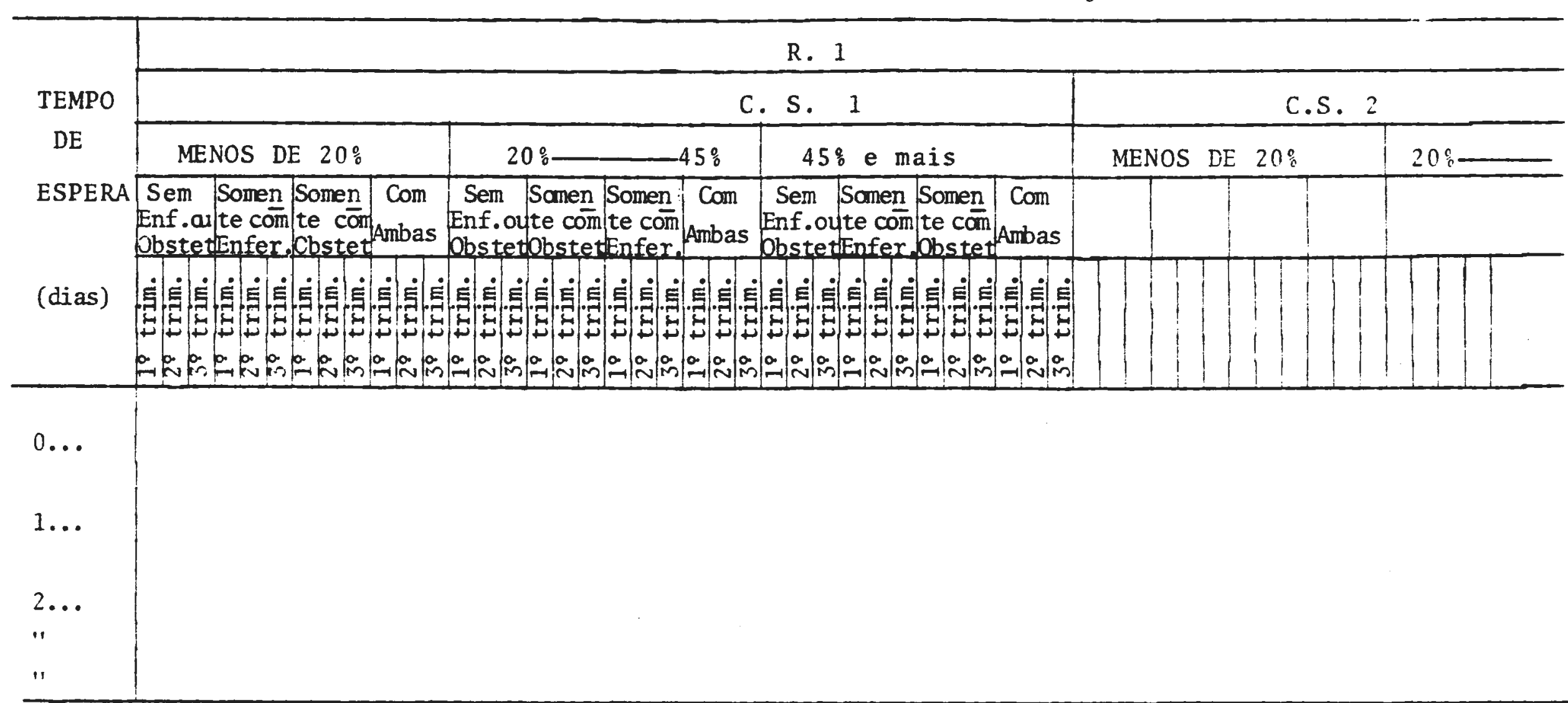


INSTRUÇOES PARA O LEVANTAMENTO DE DADOS

1. Definição dos termos usados nas fichas de levantamento

\section{$1.1 \quad$ Ficha $n^{\circ} 1$}

No cabeçalho das colunas:

- Discriminação de dados $=\vec{e}$ a apresentação das informaçõés que devem ser colhidas.

- Saúde Materna é o conjunto de atividades executadas num Centro de Saúde com a finalidade de controlar o estado de saúde das gestantes.

- Médico consultante no setor de S.M. = é o mëdico que a tende as gestantes, quer seja um clínico geral ou um es pecialista no setor.

- Enfermeira - $\vec{e}$ o profissional que fez o curso universitảrio de enfermagem e, na Secretaria de Saúde - S:P., é lotada como enfermeira que exerce a função de chefia do serviço de enfermagem no centro de saủde, podendo realizar qualquer atividade de enfermagem.

- Obstetriz - é a profissional que fez o curso de obstetrí cia e, na Secretaria de Saủde é lotada como obstetriz; xerce comumente a função de prestação de assistência de enfermagem a gestantes, podendo realizar as atividades que caracterizam esta função, tais como:

- consulta de enfermagem, ou atendimento de enfermagem como é denominada na Secretaria de Saúde:

- administração de tratamentos prescritos pelo médico;

- aplicação de vacinas;

- realização de curativos, etc.

- Meta diária - é a quantidade diária da atividade que de ve ser realizada.

Nesta ficha só interessa o levantamento das metas refe rentes a consultas e atendimentos de enfermagem. 


\section{Limitada conforme agendamento}

Significa o caso em que no C.S. hã fixação do $n^{8}$ de ges tantes que podem ser atendidas no dia para inscrição e para consultas.

\section{Limitada conforme a demanda}

Significa que as gestantes que procuram o C.S. para con trole são todas atendidas sem precisarem de agendamento prévio.

- Lotação efetiva

Significa a existência real do médico consultante, da en fermeira e da obstetriz.

- Triagem

E o conjunto de atividades realizadas com o fim de selecionar as gestantes que procuram diariamente o C.S. para inscrição e encaminhä-las para o agendamento da consulta ou para a própria consulta.

- Consulta de gestantes

E o conjunto de atividades realizadas por profissional competente podendo constar de: exame físico geral da ges tante, exame obstétrico e prescriçāo das açōes que forem julgadas necessārias. Na Secretaria da Saúde - SP, esta atividade refere-se somente ao médico.

- Atendimento de enfermagem a gestantes

E o conjunto de ações que o profissional enfermeira e obstetriz executam com o fim de controlar o estado de saủde da gestante podendo constar de: exame obstëtrico e orientação das gestantes sobre os cuidados que devem observar.

Na Secretaria da Saúde esta atividade é equivalente à consulta de enfermagem.

- Supervisão

E o conjunto de atividades realizadas pela enfermeira e/ ou obstetriz com a finalidade de verificar as condiçōes 
em que o serviço estā sendo feito e daí as orientações necessārias para manter o serviço dentro das instruções existentes.

- Outras atividades no setor de saủde materna Referem-se a quaisquer outras atividades que o mëdico,en fermeira ou obstetriz disserem que executam na ärea de saúde materna e que não correspondem às definições aqui citadas de consulta, atendimento de enfermagem e supervi são.

- Nenhuma atividade no setor de saúde materna

E a expressão a ser considerada quando o médico,enfermei ra e obstetriz informarem que não executam nenhuma ativi dade permanente com as gestantes.

\subsection{Ficha $\mathrm{n}^{\circ} 2$}

- No de ordem

E o número ordenado das gestantes que forem sorteadas pa ra o levantamento.

- $N^{9}$ de matrícula

E o número que recebem as fichas das gestantes quando a mesma vai ao centro de saüde pela primeira vez para con trole da gestação atual.

Encontra-se na ficha índice, na ficha de controle e no prontuārio da gestante.

- Idade da gestação

E o mês da gestação em que se encontrava a cliente na da ta da inscrição.

Se este dado não existir, anotar a data da ültima mens truação.

- Data da última menstruação

E a data colocada no prontuärio da gestante pelo profís sional - médico, enfermeira ou obstetriz. que o preen 
cheu, referente ao inicio da gestação.

- Data da inscrição

Inscrição é a data em que a gestante compareceu pela prí meira vez ao Centro de Saúde para controle da gestação a tual. Está registrada nas diversas fichas da cliente.

- Data da primeira consulta

Refere-se à primeira consulta feita pelo médico ou o pri meiro atendimento de enfermagem feito pela obstetriz às gestantes.

2. Orientação para o preechimento das fichas de levantamento.

\section{$2.1 \quad$ Ficha $\mathrm{n}^{8} 1$}

Item a - "Lotação efetiva"

Esta informação deve ser pedida ao médico diretor do Cen tro de Saúde ou ao encarregado administrativo.

Registrar as respostas da seguinte maneira:

- Nas colunas correspondentes a mêdicos consultantes, enfer meira e obstetriz, escrever:

- um "S" quando a informação recebida confirmar a existência do profissional.

- um "N" quando a informação negar a existência.

- escrever um traço horizontal na

Observação: A partir do item b cada profissinal - médico,en fermeira e obstetriz - quando existir no C.S., deve ser entrevistado individualmente e respon der os quesitos seguintes.

Registrar as respostas da seguinte maneira:

- com referência aos itens $1,2,4$ e 5: Triagem, Consulta de Gestantes, Supervisāo do Se tor de Saúde Materna e Outras atividades;

- Nas colunas correspondentes a mëdico consul- 
tante, enfermeira e obstetriz, escrever:

- um "S" quando a resposta for Sim;

- um "N" quando a resposta for Não;

- com referência aos itens $n^{\circ} s 2$ e 3 , consul ta de gestantes, e atendimento de enfermagem a gestantes, na coluna "Meta diäria":

- nas duas sub colunas, escrever:

- um S ou um $N$ se a resposta for sim ou não

- com referência ao item n: 3 , nas colunas cor respondentes à enfermeira e obstetriz, escre ver:

- um $S$ quando a resposta for sim

- um $N$ quando a resposta for não

- com referência ao item n' 6, nas colunas cor respondentes a mëdico, enfermeira e obste triz, escrever:

- um $S$ quando a resposta confirmar que o pro fissional não executa nenhuma atividade

- um traço horizontal "_-_", quando algum ou vários dos itens de 1 a 5 tiverem sido pre enchidos com SIM.

3. Tëcnica do levantamento

- Apresentar-se ao Médico Chefe perguntar o nome do M.C.ou ao encarregado administrativo ou a outra pessoa que este ja substituindo o M.C.; entregar-lhe a carta de apresen tação.

- Explicar resumidamente o que vai ser feito, mostrando as fichas de levantamento.

- Entrevistar o encarregado administrativo, ou mesmo o $M$. C. (Mëdico Chefe) para preencher o item " $a$ " da licha $n$ ? 
1 .

- Pedir permissăo para retirar do fichário as fichas que fo rem necessärias para o levantamento.

- Procurar o fichärio central, localizar as fichas de con trole das gestantes e contar quantas fichas existem na gaveta(mesmo que sejam muitas).

- Retirar as fichas de controle das gestantes para a amos tra da seguinte forma:

- Se não houver perinissäo para se retirar todas as fichas para o levantamento dos dados, fazer o levantamento de cada ficha sorteada e recolocá-la no devido lugar que deve ter sido marcado ao se retirä-la.

- Se for permitido retirar todas as fichas sorteadas, fa zer o seguinte:

- Dividir o número de fichas contadas na gaveta pelo número de gestantes que devem fazer parte da amostra do centro de saúde em que se estiver.

- O resultado desta divisão serā o número de fichas que deve ser contado em cada intervalo.

- Retirar, então, a primeira ficha do fichário de con trole.

- Deixar esta ficha ao lado (cuidadosamente para não misturā-1a com outros papéis, nem perdê-1a).

- Contar, a seguir, tantas fichas quanto for o número considerado como intervalo.

- Retirar a ūltima ficha contada e colocá-la jlinto da primeira escolhida.

- Contar novamente o mesmo nümero de fichas correspondente ao intervalo, retirando a última ficha contada.

- Colocar esta ficha junto das duas outras retiradas.

- Repetir a contagem do intervalo e a retirada da $\vec{u} 1 t \underline{j}$ ma ficha contada até completar o nümero de fichas ne cessárias para completar o tamanho da amostra. 
- Se se chegar ao fim do fichärio e não se tiver ain da conseguido todas as fichas necessárias, contar as fichas que tiverem sobrado, voltar ao princípio do fichário, completar a contagem do intervalo e re tirar a ültima ficha contada, continuando o mesmo processo de antes até completar o nümero de fichas da amostra.

- Depois de retiradas todas as fichas necessārias, olhar os números dos prontuários correspondentes a cada fi cha de controle e retirá-los do fichário geral. Fazer o levantamento dos dados conforme as instruçōes. 
Orfeio Rl-C ne $194 / 79$

Geral ne $487 / 79$

Säo Paulo, 04 de junbo de 1.979.

Senhor Diretor.

Pr ateogäo we termed do Ofleio ESP 62/79, de prouldade de Saide Priblica da U.S.P., vinos apreantar a V.Sa., a Paformixa URIA DE LOURDES RODRICUES, R.G. 4.325.329, Aurdliar de Innino ' do Depertanento de Prfition de Savide Públion, a qual estark acompanhada de pes quisadore (vide lista a anexo), devidanente identifioados a que por esta Diretoria coth autorisada desemrolver pesquisa junto ao Centro de Savide, com vilatas a tema:

$n$ Conhecimento do teapo médio existente dende o primeiro ' aparecimento das gentante para inscrigäo nos Centros de Sáride at ' i primeira coneulta médioa ".

Cabe esclareoer, que a peequiea

se deservolverá en duas otapas:

1) Levantanento prévio;

2) a coleta definitiva de dados referentea so tea supra ci tedo; näo haver interferbnoia na rotim don sarvigos, sen quaisquer responsabilidade o sen ones para o Batedo.

Atenciosenente,

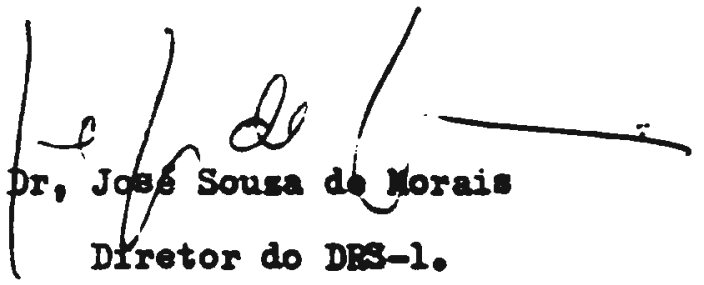

Sos Diretore

Centros de Sarde da Regiäo Metropolitana

de Säo Paule.

JSI/mpn.

1. e. . 